DEPARTAMENTO DE NEUROCIÊNCIAS E CIÊNCIAS DO COMPORTAMENTO, FACULDADE DE MEDICINA DE RIBEIRÃO PRETO, UNIVERSIDADE DE SÃO PAULO

DANIEL BARBOSA DE ALMEIDA PRADO

Efeitos de doses repetidas do nitroprussiato de sódio ou do canabidiol no período de maturação cerebral em um modelo animal de esquizofrenia 
DANIEL BARBOSA DE ALMEIDA PRADO

Efeitos de doses repetidas do nitroprussiato de sódio ou do canabidiol no período de maturação cerebral em um modelo animal de esquizofrenia

Tese de Doutorado apresentada ao Programa de Pós-graduação em Neurologia da Faculdade de Medicina de Ribeirão Preto da Universidade de São Paulo para a obtenção do título de Doutor em Ciências Médicas na área de concentração de Neurologia.

Orientador: Prof. Dr. Jaime Eduardo Cecílio Hallak 
Autorizo a reprodução e divulgação total ou parcial deste trabalho, por qualquer meio convencional ou eletrônico, para fins de estudo e pesquisa, desde que citada a fonte.

Almeida Prado, Daniel

Efeitos de doses repetidas do nitroprussiato de sódio ou do canabidiol no período de maturação cerebral em um modelo animal de esquizofrenia, 2020.

158f.: il.

Tese de Doutorado, apresentada à Faculdade de Medicina de Ribeirão Preto da Universidade de São Paulo. Área de concentração: Neurologia.

Orientador: Prof. Dr. Jaime Eduardo Cecílio Hallak

1. Esquizofrenia. 2. Nitroprussiato de Sódio. 3. Canabidiol. 4. Cetamina. 5. Neurodesenvolvimento. 6. Maturação Cerebral. 7. Modelo Animal de Esquizofrenia. 


\section{Efeitos de doses repetidas do nitroprussiato de sódio ou do canabidiol no período de maturação cerebral em um modelo animal de esquizofrenia}

Tese de Doutorado apresentada ao Programa de Pós-graduação em Neurologia da Faculdade de Medicina de Ribeirão Preto da Universidade de São Paulo para a obtenção do título de Doutor em Ciências Médicas na área de concentração de Neurologia.

Aprovado em:

Banca Examinadora

Prof. Dr. Jaime Eduardo Cecílio Hallak

Examinador: Prof. Dr.

Examinador: Prof. Dr.

Examinador: Prof. Dr.

Examinador: Prof. Dr. 
Dedico minha tese de doutorado, talvez um dos meus maiores feitos acadêmicos em vida, integralmente, a minha amada esposa Camila, e a meus queridos filhos Augusto e Gustavo. Muito obrigado pela compreensão de tantas e tantas noites distantes, entendendo o significado de um bem maior. 


\section{AGRADECIMENTOS}

\section{O presente trabalho foi realizado com apoio da Coordenação de Aperfeiçoamento de Pessoal de Nível Superior - Brasil (CAPES) - Código de Financiamento 001.}

Sou eternamente grato ao Prof. Dr. Jaime Eduardo Cecílio Hallak, meu querido orientador, exemplo de pessoa ética, honesta e humana. Gratidão, a meu ver não se resume a palavras ou frases, mas sim as experiências emocionais que vivemos em momentos importantes da nossa existência, e em todos esses, a presença dele quando não física, mas emocional, esteve sempre presente.

Sinto-me muito honrado e feliz, por ter sido inicialmente acolhido em nossa Universidade pelo amável Prof. Dr. Antônio Waldo Zuardi e, por esse motivo, o agradeço profundamente. Mesmo que atualmente distante fisicamente dele, sintome muito próximo emocionalmente, lembrando diariamente com apreço de toda a ternura e carinho que recebi dele no início de minha trajetória acadêmica.

Jamais esqueceria a amizade verdadeira e sincera do Prof. Dr. José Alexandre de Souza Crippa, profissional íntegro, dedicado e, literalmente, um exemplo a ser seguido. Essas características únicas me fazem sentir grande gratidão e enorme apreço a sua pessoa e a seus ensinamentos.

Em especial, agradeço ao Prof. Dr. João Paulo Machado de Souza, amigo querido que sempre agiu com a presteza e a cumplicidade que apenas amizades fraternas e verdadeiras possuem.

A Dra. Ludmyla Kandratavicius, meu mais sincero agradecimento, seu sorriso e carinho, características marcantes da sua personalidade são cativantes, e denotam o maior exemplo do que é ter boa vontade e senso de trabalho em equipe.

Por fim, agradeço a Isabella Caroline da Silva Dias por toda sua presteza e afinco durante fases importantes de todo o desenvolvimento deste projeto. 
O sábio não é o homem que fornece as verdadeiras respostas, é o que formula as verdadeiras perguntas.

Claude Lévi-Strauss 
ALMEIDA PRADO, D. Efeitos de doses repetidas do nitroprussiato de sódio ou do canabidiol no período de maturação cerebral em um modelo animal de esquizofrenia. 158f. Tese (Doutorado) - Faculdade de Medicina de Ribeirão Preto, Universidade de São Paulo, Ribeirão Preto, 2020.

\section{RESUMO}

Introdução: a esquizofrenia é um transtorno mental crônico e agressivo que afeta aproximadamente $1 \%$ da população mundial. Trata-se de uma síndrome clínica com diversas dimensões psicopatológicas, disruptivas, as quais desequilibram várias características clínicas naturais do ser humano, e que não possui cura. Esse distúrbio também pode ser compreendido como um transtorno neurodesenvolvimental, o que implica dizer que esse estaria associado a determinadas fases do desenvolvimento do cérebro humano. Evidências atuais provenientes de estudos sobre o tratamento do quadro, de trabalhos post mortem, de investigações de neuroimagem e de modelos animais experimentais, demonstram que essas alterações estariam relacionadas à interação de diversos mecanismos fisiopatológicos como, por exemplo, a desregulação dopaminérgica, o distúrbio glutamatérgico e o desequilíbrio do sistema dos receptores endocanabinoides. É sabido também que determinadas drogas, ainda sob investigação, poderiam interagir com esses sistemas através de mecanismos ainda desconhecidos, porém com propriedades terapêuticas e até mesmo, possivelmente, profiláticas. Trata-se do canabidiol (CBD), do nitroprussiato de sódio (NPS) e da associação de ambas. Objetivos: o principal objetivo do presente estudo foi o de testar os efeitos de doses repetidas de NPS e de CBD, isoladamente e em associação, durante o processo de maturação cerebral de ratos Wistar, observando especificamente a possibilidade de eventual ausência do aparecimento de um quadro schizophrenia like, previamente induzido através da administração de cetamina (CET). Secundariamente, o modelo animal de psicose com CET utilizado neste projeto foi avaliado quanto a sua eficácia e viabilidade e, por fim, eventuais influências de gênero na análise dos resultados encontrados foram sistematicamente discutidas. Métodos: foram utilizados cento e vinte e oito ratos Wistar machos e fêmeas, divididos em dezesseis grupos específicos, aleatoriamente randomizados e com doze dias de idade na época do início do protocolo experimental. Esses animais foram previamente tratados com CBD, NPS e com a associação entre ambas as drogas durante vinte e um dias consecutivos ao longo de seu amadurecimento cerebral. Após dez dias de intervalo, os roedores foram expostos por cinco dias consecutivos ao modelo animal de esquizofrenia induzido por CET e, então, os testes comportamentais de campo aberto, preferência por sacarose e reconhecimento de objetos foram realizados. Resultados: tanto NPS quanto CBD, bem como a associação entre ambas as substâncias puderam, após o término do estudo, ser consideradas substâncias aparentemente efetivas na prevenção de sintomas característicos da esquizofrenia. Esses dados foram constatados por meio dos resultados apresentados após a tarefa comportamental de campo aberto, na qual a maior parte dos grupos do estudo teve a capacidade de atenuar sintomas psicóticos positivos produzidos, através da diminuição das distâncias totais percorridas pelos animais do grupo que foram, previamente ao teste, estimuladas por CET. Os desfechos descritos também podem ser comprovados pelos resultados dos testes de reconhecimento de objetos, pois as mesmas drogas pareceram ser 
extremamente efetivas em prevenir sintomas psicóticos da dimensão cognitiva da esquizofrenia, sendo responsáveis por aumentar o tempo de exploração de um objeto novo em detrimento a um já conhecido, posteriormente aos efeitos de piora cognitiva induzida pela CET no teste. Conclusão: os dados apresentados neste trabalho proporcionam, pela primeira vez na literatura, indícios claros de efetividade e segurança quanto ao uso preventivo de NPS, CBD e da associação de ambas as substâncias, quanto ao desenvolvimento da esquizofrenia.

Palavras-chave: Esquizofrenia. Nitroprussiato de sódio. Canabidiol. Cetamina. Neurodesenvolvimento. Maturação cerebral. Modelo animal de esquizofrenia. 
ALMEIDA PRADO, D. Effects of repeated doses of sodium nitroprusside or cannabidiol on the brain maturation period in an animal model of schizophrenia. 158f. Tese (Doutorado) - Faculdade de Medicina de Ribeirão Preto, Universidade de São Paulo, Ribeirão Preto, 2020.

\section{ABSTRACT}

Introduction: schizophrenia is a chronic and aggressive mental disorder that affects approximately $1 \%$ of the world's population. It is a clinical syndrome with several disruptive psychopathological dimensions, which may unbalance many natural clinical characteristics of the human being, and has no cure. This illness may also be understood as a neurodevelopmental disorder, and can be noted it is associated with certain phases of human brain development. Current evidence originated from studies on treatment of this condition, post mortem work, neuroimaging investigations and experimental animal models demonstrate that these changes are related to the interaction of several pathophysiological mechanisms, such as: dopamine dysregulation; glutamate disbalance and imbalance of the endocannabinoid receptor system. It is also known that certain drugs, currently under investigation, could interact with these systems through mechanisms still unknown, however, consisting of therapeutic and possibly prophylactic properties. These drugs are cannabidiol (CBD), sodium nitroprusside (SNP) and an association of both. Objectives: the main objective of the present study was to test the effects of repeated doses of SNP and $\mathrm{CBD}$, used alone and in association between them, during the brain maturation process of Wistar rats, specifically observing the possible absence of a clinical condition of schizophrenia, in which has been previously induced by ketamine (KET) administration. Secondly, the animal model of schizophrenia induced by KET administration used in this project was evaluated according to its efficacy and viability, and after all, any gender influences in the analysis of the results were systematically discussed. Methods: one hundred and twenty eight male and female Wistar rats were chosen for this experiment and they were divided into sixteen specific groups, arbitrarily randomized and twelve days old at the time of beginning of the experimental protocol. These animals were previously treated with CBD, SNP and also with the association between both drugs for twenty-one consecutive days throughout their brain maturation. After the interval of ten days, the animals were exposed for five consecutive days to the animal model of KET-induced schizophrenia and then open field test for behavior, as well as sucrose preference and object recognition tests were performed. Results: both SNP and CBD, as well as the association between both drugs could, after the end of the study, be considered apparently effective in the prevention of characteristic symptoms of schizophrenia. These data were verified through the results presented after the open field test for behavior, in which most of the study groups had the ability to reduce the positive psychotic symptoms produced by diminishing the total distances traveled by the rats from the group that were stimulated by KET, before performing the test. The outcomes presented in this study may also be proved by the results of the object recognition tests, seeing that the same drugs seemed to be extremely effective in preventing psychotic symptoms of the cognitive dimension of schizophrenia and these drugs were responsible for increasing the new object exploration time to the detriment of another object already known after the negative effects of KET-induced cognitive impairment on the test. Conclusion: for the first time, the data presented in 
this paper provide indicated clearly the effectiveness and safety on the preventive use of SNP, CBD and the association of both drugs concerning the development of schizophrenia.

Keywords: Schizophrenia. Sodium nitroprusside. Cannabidiol. Ketamine. Neurodevelopment. Brain maturation. Animal model of schizophrenia. 


\section{LISTA DE FIGURAS}

Figura 1 - Os reguladores já conhecidos e alvos potenciais para medicamentos das sinapses de receptores NMDA incluiriam o sitio de coagonistas de glicina na subunidade NR1, serina racemase, D-aminoácido oxidase, o ativador de D-aminoácido oxidase e o sítio da recaptação de D-serina. Aspartato e glutamato seriam agonistas; glicina e D-serina seriam coagonistas de receptores NMDA. O bloqueio de magnésio seria liberado pela despolarização. PCP seria um bloqueador de canal. D-serina seria sintetizada pela serina racemase da L-serina. D-serina estaria localizada em neurônios e células da glia, seria captado através da GlyT-1 e metabolizado para Serina pelo sítio de recaptação da D-serina. D-serina seria metabolizada pela $\mathrm{D}$-aminoácido oxidase dentro da hidroxipiruvato. A degradação seria inibida pelo benzoato. $O$ ambiente do ativador de $D$ aminoácido oxidase como ativador ou inibidor ainda seria incerto. Glicina seria captada pela Glyt-1 e metabolizada em L-serina pelo sistema de clivagem de glicina. Sarcosina inibiria a captação de glicina através da

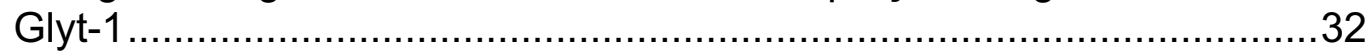

Figura 2 - Representação gráfica da fotografia e da estrutura molecular do nitroprussiato de sódio. a) fotografia molecular do nitroprussiato de sódio, em que os átomos estão representados pelas esferas através de códigos convencionais por cores, em que: carbono (cinza), oxigênio (vermelho), nitrogênio (azul claro), sódio (azul escuro) e ferro (laranja) (imagem ilustrativa obtida em https://pixels.com/featured/3-sodiumnitroprusside-drug-molecule-molekuul.html. b) estrutura molecular do nitroprussiato de sódio extraído da bula do medicamento Nitropress ${ }^{\circledR}$ (Sodium Nitroprusside Injection), do laboratório Valeant Pharmaceuticals

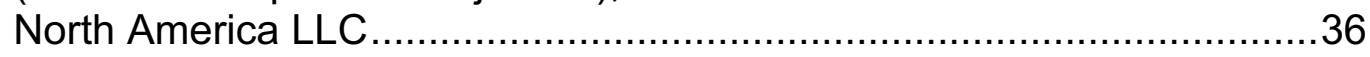

Figura 3 - $O$ modelo neurodesenvolvimental da esquizofrenia. a) $O$ desenvolvimento cortical normal envolveria proliferação, migração, arborização (formação de circuitos) e mielinização, sendo os dois primeiros processos ocorrendo predominantemente durante o período pré-natal e os outros dois contínuos ao longo das duas décadas iniciais da vida. Os efeitos associados da poda da arborização neuronal e da deposição de mielina explicariam a redução progressiva do volume de substância cinzenta observada em estudos longitudinais de neuroimagem. Além dessas reduções globais observadas, alterações locais seriam muito mais complexas. Dados de cérebros humanos e não humanos indicariam aumento de sinapses inibitórias e diminuição de sinapses excitatórias ocorrendo no córtex pré-frontal de adolescentes e de adultos jovens, durante o período dos pródromos e início de psicose. b) A trajetória do desenvolvimento da esquizofrenia em crianças poderia incluir uma formação reduzida de vias inibitórias e poda excessiva de vias excitatórias, levando a um balanço excitatório-inibitório anormal no córtex pré-frontal. Mielinização reduzida também alteraria a conectividade. Embora dados atuais apoiem cada um desses possíveis mecanismos neurodesenvolvimentais para a esquizofrenia, nenhum foi provado como causador da síndrome. Detecção de alterações 
neurodesenvolvimentais prodrômicas poderiam permitir intervenções precoces com potencial prevenção de psicose

Figura 4 - Esquema didático dos diferentes grupos experimentais do estudo. Solução Salina (SAL); Glicose a $5 \%$ (GLI); Cetamina (CET); Nitroprussiato de Sódio (NPS); Canabidiol (CBD) …............................50

Figura 5 - Desenho experimental da sequência de eventos de todas as etapas da pesquisa. Dias do nascimento (N); Intraperitoneal (IP); Glicose a $5 \%$ (GLI); Nitroprussiato de Sódio (NPS); Canabidiol (CBD); Solução Salina (SAL); Cetamina (CET) .50

Figura 6 - a) Arena convencional utilizada na realização do teste de "Campo Aberto", para a avaliação da atividade locomotora. b) Exemplo de quantificação da atividade locomotora de um rato que recebeu injeção de cetamina $(30 \mathrm{mg} / \mathrm{kg})$ através do programa "Open Source 6.1" (Insight ${ }^{\circ}$, Ribeirão Preto, Brasil). c) Exemplificação da proporção de tempo gasto nas bordas e no centro da arena, baseado no perfil de trajetória de cada animal estimado pelo programa "Image J®"...

Figura 7 - Exemplo de jaula habitualmente utilizada na realização do teste de "Preferência por Sacarose", para a avaliação de anedonia nos animais do estudo. a) Exemplo de um recipiente utilizado no teste, especificamente adaptado para a ingestão das soluções de água deionizada e açucarada. b) Jaula característica, já montada, com os recipientes prontos para o recebimento dos animais. .55

Figura 8 - a) Desenho do esquema didático para o protocolo do teste de "Reconhecimento de Objetos". (Imagem ilustrativa obtida do acervo digital do Departamento de Neurociências e Ciências do Comportamento da FMRP da USP). b) Imagem ilustrativa de um aparato contendo um objeto em forma de tubo (cor roxa), outro em forma de bola (cor vermelha) e um terceiro em forma de cone (cor verde), utilizado para a realização do teste de "Reconhecimento de Objetos".

Figura 9 - Representação gráfica da ANOVA $\left(F_{[3,31]}=6,191 ; p<0,002\right)$, e do teste post hoc de Newman-Keuls $(p<0,05)$, realizado entre os grupos de ratos machos após o teste comportamental de campo aberto: atividade locomotora - distância total percorrida. As barras coloridas foram reconstruídas pelas médias e erro padrão dos resultados, e representam os respectivos grupos do estudo, em que: GLI-SAL (cinza); GLI-CET (azul); NPS-SAL (vinho); NPS-CET (verde). Glicose a 5\% (GLI); Solução Salina (SAL); Nitroprussiato de Sódio (NPS); Cetamina (CET) (Resultado Estatisticamente Significativo).

Figura 10 - Representação gráfica da ANOVA $\left(F_{[3,32]}=21,41 ; p<0,000\right)$, e do teste post hoc de Newman-Keuls $(p<0,05)$, realizado entre os grupos de ratos fêmeas após o teste comportamental de campo aberto: atividade locomotora - distância total percorrida. As barras coloridas foram reconstruídas pelas médias e erro padrão dos resultados, e representam os respectivos grupos do estudo, em que: GLI-SAL (cinza); GLI-CET (azul); NPS-SAL (vinho); NPS-CET (verde). Glicose a 5\% (GLI); Solução Salina (SAL); Nitroprussiato de Sódio (NPS); Cetamina (CET). (Resultado Estatisticamente Significativo). 
Figura 11 - Representação gráfica da ANOVA $\left(F_{[3,36]}=6,314 ; p<0,001\right)$, e do teste post hoc de Newman-Keuls $(p<0,05)$, realizado entre os grupos de ratos machos após o teste comportamental de campo aberto: atividade locomotora - distância total percorrida. As barras coloridas foram reconstruídas pelas médias e erro padrão dos resultados, e representam os respectivos grupos do estudo, em que: GLI-SAL (cinza); GLI-CET (azul); CBD-SAL (vinho); CBD-CET (verde). Glicose a 5\% (GLI); Solução Salina (SAL); Canabidiol (CBD); Cetamina (CET). * (Resultado Estatisticamente Significativo).

Figura 12 - Representação gráfica da ANOVA $\left(F_{[3,37]}=24,04 ; p<0,000\right)$, e do teste post hoc de Newman-Keuls $(p<0,05)$, realizado entre os grupos de ratos fêmeas após o teste comportamental de campo aberto: atividade locomotora - distância total percorrida. As barras coloridas foram reconstruídas pelas médias e erro padrão dos resultados, e representam os respectivos grupos do estudo, em que: GLI-SAL (cinza); GLI-CET (azul); CBD-SAL (vinho); CBD-CET (verde). Glicose a 5\% (GLI); Solução Salina (SAL); Canabidiol (CBD); Cetamina (CET). * (Resultado Estatisticamente Significativo).

Figura 13 - Representação gráfica da ANOVA $\left(F_{[3,32]}=9,451 ; p<0,000\right)$, e do teste post hoc de Newman-Keuls ( $p<0,05$ ), realizado entre os grupos de ratos machos, após o teste comportamental de campo aberto: atividade locomotora - distância total percorrida. As barras coloridas foram reconstruídas pelas médias e erro padrão dos resultados, e representam os respectivos grupos do estudo, em que: GLI-SAL (cinza); GLI-CET (azul); NPS/CBD-SAL (vinho); NPS/CBD-CET (verde). Glicose a 5\% (GLI); Solução Salina (SAL); Nitroprussiato de Sódio (NPS); Canabidiol (CBD); Cetamina (CET). * (Resultado Estatisticamente Significativo)...65

Figura 14 - Representação gráfica da ANOVA $\left(F_{[3,30]}=19,02 ; p<0,000\right)$, e do teste post hoc de Newman-Keuls $(p<0,05)$, realizado entre os grupos de ratos fêmeas, após o teste comportamental de campo aberto: atividade locomotora - distância total percorrida. As barras coloridas foram reconstruídas pelas médias e erro padrão dos resultados, e representam os respectivos grupos do estudo, em que: GLI-SAL (cinza); GLI-CET (azul); NPS/CBD-SAL (vinho); NPS/CBD-CET (verde). Glicose a 5\% (GLI); Solução Salina (SAL); Nitroprussiato de Sódio (NPS); Canabidiol (CBD); Cetamina (CET). * (Resultado Estatisticamente Significativo)...66

Figura 15 - Representação gráfica da ANOVA $\left(F_{[3,31]}=2,824 ; p<0,054\right)$, e do teste post hoc de Newman-Keuls $(p<0,05)$, realizado entre os grupos de ratos machos após o teste comportamental de campo aberto: atividade locomotora - proporção de tempo no centro da arena. As barras coloridas foram reconstruídas pelas médias e erro padrão dos resultados, e representam os respectivos grupos do estudo, em que: GLI-SAL (cinza); GLI-CET (azul); NPS-SAL (vinho); NPS-CET (verde). Glicose a 5\% (GLI); Solução Salina (SAL); Nitroprussiato de Sódio (NPS); Cetamina (CET)

Figura 16 - Representação gráfica da ANOVA $\left(F_{[3,32]}=1,856 ; p<0,157\right)$, e do teste post hoc de Newman-Keuls $(p<0,05)$, realizado entre os grupos de ratos fêmeas após o teste comportamental de campo aberto: atividade 
locomotora - proporção de tempo no centro da arena. As barras coloridas foram reconstruídas pelas médias e erro padrão dos resultados, e representam os respectivos grupos do estudo, em que: GLI-SAL (cinza); GLI-CET (azul); NPS-SAL (vinho); NPS-CET (verde). Glicose a 5\% (GLI); Solução Salina (SAL); Nitroprussiato de Sódio (NPS); Cetamina (CET) 68

Figura 17 - Representação gráfica da ANOVA $\left(F_{[3,36]}=5,211 ; p<0,004\right)$, e do teste post hoc de Newman-Keuls $(p<0,05)$, realizado entre os grupos de ratos machos, após o teste comportamental de campo aberto: atividade locomotora - proporção de tempo no centro da arena. As barras coloridas foram reconstruídas pelas médias e erro padrão dos resultados, e representam os respectivos grupos do estudo, em que: GLI-SAL (cinza); GLI-CET (azul); CBD-SAL (vinho); CBD-CET (verde). Glicose a 5\% (GLI); Solução Salina (SAL); Canabidiol (CBD); Cetamina (CET). * (Resultado Estatisticamente Significativo). 69

Figura 18 - Representação gráfica da ANOVA $\left(F_{[3,37]}=2,714 ; p<0,058\right)$, e do teste post hoc de Newman-Keuls $(p<0,05)$, realizado entre os grupos de ratos fêmeas, após o teste comportamental de campo aberto: atividade locomotora - proporção de tempo no centro da arena. As barras coloridas foram reconstruídas pelas médias e erro padrão dos resultados, e representam os respectivos grupos do estudo, em que: GLI-SAL (cinza); GLI-CET (azul); CBD-SAL (vinho); CBD-CET (verde). Glicose a 5\% (GLI); Solução Salina (SAL); Canabidiol (CBD); Cetamina (CET). * (Resultado Estatisticamente Significativo).

Figura 19 - Representação gráfica da ANOVA ( $\left.F_{[3,32]}=1,540 ; p<0,223\right)$, e do teste post hoc de Newman-Keuls $(p<0,05)$, realizado entre os grupos de ratos machos após o teste comportamental de campo aberto: atividade locomotora - proporção de tempo no centro da arena. As barras coloridas foram reconstruídas pelas médias e erro padrão dos resultados, e representam os respectivos grupos do estudo, em que: GLI-SAL (cinza); GLI-CET (azul); NPS/CBD-SAL (vinho); NPS/CBD-CET (verde). Glicose a 5\% (GLI); Solução Salina (SAL); Nitroprussiato de Sódio (NPS); Canabidiol (CBD); Cetamina (CET) 71

Figura 20 - Representação gráfica da ANOVA $\left(F_{[3,30]}=0,295 ; p<0,828\right)$, e do teste post hoc de Newman-Keuls $(p<0,05)$, realizado entre os grupos de ratos machos após o teste comportamental de campo aberto: atividade locomotora - proporção de tempo no centro da arena. As barras coloridas foram reconstruídas pelas médias e erro padrão dos resultados, e representam os respectivos grupos do estudo, em que: GLI-SAL (cinza); GLI-CET (azul); NPS/CBD-SAL (vinho); NPS/CBD-CET (verde). Glicose a 5\% (GLI); Solução Salina (SAL); Nitroprussiato de Sódio (NPS); Canabidiol (CBD); Cetamina (CET) 72

Figura 21 - Representação gráfica da ANOVA $\left(F_{[3,31]}=6,530 ; p<0,001\right)$, e do teste post hoc de Newman-Keuls $(p<0,05$ ), realizado entre os grupos de ratos machos após o teste comportamental de preferência por sacarose. As barras coloridas foram reconstruídas pelas médias e erro padrão dos resultados, e representam os respectivos grupos do estudo, em que: GLI-SAL (cinza); GLI-CET (azul); NPS-SAL (vinho); NPS-CET (verde). 
Glicose a 5\% (GLI); Solução Salina (SAL); Nitroprussiato de Sódio (NPS); Cetamina (CET). * (Resultado Estatisticamente Significativo) ....73

Figura 22 - Representação gráfica da ANOVA $\left(F_{[3,32]}=8,597 ; p<0,000\right)$, e do teste post hoc de Newman-Keuls $(p<0,05)$, realizado entre os grupos de ratos fêmeas após o teste comportamental de preferência por sacarose. As barras coloridas foram reconstruídas pelas médias e erro padrão dos resultados, e representam os respectivos grupos do estudo, em que: GLI-SAL (cinza); GLI-CET (azul); NPS-SAL (vinho); NPS-CET (verde). Glicose a 5\% (GLI); Solução Salina (SAL); Nitroprussiato de Sódio (NPS); Cetamina (CET). * (Resultado Estatisticamente Significativo) ....74

Figura 23 - Representação gráfica da ANOVA $\left(F_{[3,36]}=2,773 ; p<0,055\right)$, e do teste post hoc de Newman-Keuls $(p<0,05)$, realizado entre os grupos de ratos machos após o teste comportamental de preferência por sacarose. As barras coloridas foram reconstruídas pelas médias e erro padrão dos resultados, e representam os respectivos grupos do estudo, em que: GLI-SAL (cinza); GLI-CET (azul); CBD-SAL (vinho); CBD-CET (verde). Glicose a 5\% (GLI); Solução Salina (SAL); Canabidiol (CBD); Cetamina (CET). .75

Figura 24 - Representação gráfica da ANOVA $\left(F_{[3,37]}=7,317 ; p<0,000\right)$, e do teste post hoc de Newman-Keuls $(p<0,05)$, realizado entre os grupos de ratos fêmeas após o teste comportamental de preferência por sacarose. As barras coloridas foram reconstruídas pelas médias e erro padrão dos resultados, e representam os respectivos grupos do estudo, em que: GLI-SAL (cinza); GLI-CET (azul); CBD-SAL (vinho); CBD-CET (verde). Glicose a 5\% (GLI); Solução Salina (SAL); Canabidiol (CBD); Cetamina (CET). * (Resultado Estatisticamente Significativo) .

Figura 25 - Representação gráfica da ANOVA $\left(F_{[3,32]}=4,077 ; p<0,014\right)$, e do teste post hoc de Newman-Keuls $(p<0,05)$, realizado entre os grupos de ratos machos após o teste comportamental de preferência por sacarose. As barras coloridas foram reconstruídas pelas médias e erro padrão dos resultados, e representam os respectivos grupos do estudo, em que: GLI-SAL (cinza); GLI-CET (azul); NPS/CBD-SAL (vinho); NPS/CBD-CET (verde). Glicose a 5\% (GLI); Solução Salina (SAL); Nitroprussiato de Sódio (NPS); Canabidiol (CBD); Cetamina (CET). * (Resultado Estatisticamente Significativo) …....................................................77

Figura 26 - Representação gráfica da ANOVA $\left(F_{[3,30]}=4,371 ; p<0,011\right)$, e do teste post hoc de Newman-Keuls $(p<0,05)$ realizado entre os grupos de ratos fêmeas, após o teste comportamental de preferência por sacarose. As barras coloridas foram reconstruídas pelas médias e erro padrão dos resultados, e representam os respectivos grupos do estudo, em que: GLI-SAL (cinza); GLI-CET (azul); NPS/CBD-SAL (vinho); NPS/CBD-CET (verde). Glicose a 5\% (GLI); Solução Salina (SAL); Nitroprussiato de Sódio (NPS); Canabidiol (CBD); Cetamina (CET). * (Resultado Estatisticamente Significativo) .78

Figura 27 - Representação gráfica da ANOVA no teste de $30 \min \left(F_{[3,30]}=7,655 ; p\right.$ $=0,000)$, no teste de $24 \mathrm{~h}(\mathrm{~F}[3,30]=0,270 ; p=0,845)$, e do teste post hoc de Newman-Keuls $(p<0,05)$, realizado entre os grupos de ratos machos após o teste de reconhecimento de objetos. As barras coloridas 
foram reconstruídas pelas médias e erro padrão dos resultados, e representam os respectivos grupos do estudo, em que: GLI-SAL (cinza); GLI-CET (azul); NPS-SAL (vinho); NPS-CET (verde). Glicose a $5 \%$ (GLI); Solução Salina (SAL); Nitroprussiato de Sódio (NPS); Cetamina (CET). * (Resultado Estatisticamente Significativo)... 79

Figura 28 - Representação gráfica da ANOVA no teste de 30 min $\left(F_{[3,32]}=3,739 ; p\right.$ $=0,020)$, no teste de $24 \mathrm{~h}(\mathrm{~F}[3,32]=7,371 ; p=0,000)$, e do teste post hoc de Newman-Keuls $(p<0,05)$, realizado entre os grupos de ratos fêmeas após o teste de reconhecimento de objetos. As barras coloridas foram reconstruídas pelas médias e erro padrão dos resultados, e representam os respectivos grupos do estudo, em que: GLI-SAL (cinza); GLI-CET (azul); NPS-SAL (vinho); NPS-CET (verde). Glicose a 5\% (GLI); Solução Salina (SAL); Nitroprussiato de Sódio (NPS); Cetamina (CET). * (Resultado Estatisticamente Significativo). .80

Figura 29 - Representação gráfica da ANOVA no teste de $30 \min \left(F_{[3,36]}=9,992 ; p\right.$ $<0,000)$, no teste de 24 h $(F[3,36]=0,720 ; p=0,546)$, e do teste post hoc de Newman-Keuls $(p<0,05)$, realizado entre os grupos de ratos machos após o teste de reconhecimento de objetos. As barras coloridas foram reconstruídas pelas médias e erro padrão dos resultados, e representam os respectivos grupos do estudo, em que: GLI-SAL (cinza); GLI-CET (azul); CBD-SAL (vinho); NPS-CET (verde). Glicose a 5\% (GLI); Solução Salina (SAL); Canabidiol (CBD); Cetamina (CET). (Resultado Estatisticamente Significativo) 81

Figura 30 - Representação gráfica da ANOVA no teste de $30 \min \left(F_{[3,36]}=3,461 ; p\right.$ $=0,026)$, no teste de $24 \mathrm{~h}(\mathrm{~F}[3,36]=8,419 ; \mathrm{p}=0,000)$ e do teste post hoc de Newman-Keuls $(p<0,05)$, realizado entre os grupos de ratos fêmeas após o teste de reconhecimento de objetos. As barras coloridas foram reconstruídas pelas médias e erro padrão dos resultados, e representam os respectivos grupos do estudo, em que: GLI-SAL (cinza); GLI-CET (azul); CBD-SAL (vinho); NPS-CET (verde). Glicose a 5\% (GLI); Solução Salina (SAL); Canabidiol (CBD); Cetamina (CET). (Resultado Estatisticamente Significativo).

Figura 31 - Representação gráfica da ANOVA no teste de $30 \min \left(F_{[3,32]}=5,961 ; p\right.$ $=0,002)$, no teste de $24 \mathrm{~h}(\mathrm{~F}[3,32]=0,718 ; p=0,548)$, e do teste post hoc de Newman-Keuls $(p<0,05)$, realizado entre os grupos de ratos machos após o teste de reconhecimento de objetos. As barras coloridas foram reconstruídas pelas médias e erro padrão dos resultados, e representam os respectivos grupos do estudo, em que: GLI-SAL (cinza); GLI-CET (azul); NPS/CBD-SAL (vinho); NPS/CBD-CET (verde). Glicose a 5\% (GLI); Solução Salina (SAL); Nitroprussiato de Sódio (NPS); Canabidiol (CBD); Cetamina (CET). * (Resultado Estatisticamente Significativo) .83

Figura 32 - Representação gráfica da ANOVA no teste de $30 \min \left(F_{[3,30]}=6,230 ; p\right.$ $=0,002)$, no teste de $24 \mathrm{~h}(\mathrm{~F}[3,30]=13,280 ; p<0,000)$, e do teste post hoc de Newman-Keuls $(p<0,05)$, realizado entre os grupos de ratos fêmeas após o teste de reconhecimento de objetos. As barras coloridas foram reconstruídas pelas médias e erro padrão dos resultados, e representam os respectivos grupos do estudo, em que: GLI-SAL (cinza); 
GLI-CET (azul); NPS/CBD-SAL (vinho); NPS/CBD-CET (verde). Glicose a 5\% (GLI); Solução Salina (SAL); Nitroprussiato de Sódio (NPS); Canabidiol (CBD); Cetamina (CET). * (Resultado Estatisticamente Significativo) 


\section{LISTA DE ABREVIATURA E SIGLAS}

EUA

Estados Unidos da América

SNC

Sistema nervoso central

OMS

Organização Mundial de Saúde

PET

Tomografia por emissão de pósitrons (positron emission tomography)

SPECT

Tomografia por emissão de fóton único (single photon emission computed tomography)

D2

Dopamina 2

PCP

Fenciclidina (phencyclidine)

CET

Cetamina

NMDA

$\mathrm{N}$-metil-D-aspartato

AMPA

Ácido a-amino-3-hidroxi-5-metilisoxazol-4-propiônico

GlyT-1

DSM-IV

Transportador de glicina 1 (glycine transporter-1)

Manual Diagnóstico e Estatístico das Doenças Mentais - $4^{a}$ edição (Diagnostic and Statistical Manual of Mental Disorders 4th Edition)

SANS

Escala de Avaliação de Sintomas Negativos (Scale for the Assessment of Negative Symptoms)

NMDA-ON-GMPc N-metil-D-aspartato-Óxido-Nítrico-Monofosfato-cíclico-de-

Guanosina

(N-methyl-D-aspartate-Nitric-Oxide-cyclic-

Guanosine-Monophosphate)

ON

Óxido nítrico

GMPc

Monofosfato cíclico de guanosina (cyclic-GuanosineMonophosphate)

NOS Óxido Nítrico Sintetase

AMPc Monofosfato cíclico de adenosina (cyclic-AdenosineMonophosphate)

PANSS Escala de avaliação das síndromes positiva e negativa para esquizofrenia

RNA Ácido ribonucleico (ribonucleic acid)

NPS Nitroprussiato de sódio

SER Sistema dos receptores endocanabinóides 


$\begin{array}{ll}\text { CBD } & \text { Canabidiol } \\ \text { CB1 } & \text { Canabinóide do tipo 1 } \\ \text { CB2 } & \text { Canabinóide do tipo 2 } \\ \text { THC } & \Delta \text {-tetrahidrocanabinol } \\ \text { 2-AG } & \text { 2-araquidonoilglicerol } \\ \text { AHAG } & \text { Amido hidrolase de ácidos graxos } \\ \text { GABA } & \text { Ácido gama-aminobutírico } \\ \text { TRPV } & \text { Transitório potencial do tipo valinóide } \\ \text { QI } & \text { Quociente intelectual } \\ \text { UHR } & \text { Ultra alto risco (ultra high risk) } \\ \text { SHR } & \text { Ratos hipertensivos espontaneamente } \\ & \text { hypertensive rats) } \\ \text { BPRS } & \text { Escala breve de avaliação psiquiátrica (brief psychiatric rating } \\ & \text { scale) } \\ \text { DSM-V } & \text { Manual Diagnóstico e Estatístico das Doenças Mentais - 5 } \\ & \text { edição (Diagnostic and Statistical Manual of Mental Disorders - } \\ & \text { 5th Edition) } \\ \text { MATRICS } & \text { Measurement and Treatment Research to Improve Cognition in } \\ \text { NIMH } & \text { Schizophrenia } \\ & \text { National Institute of Mental Health }\end{array}$




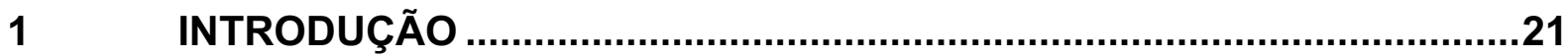

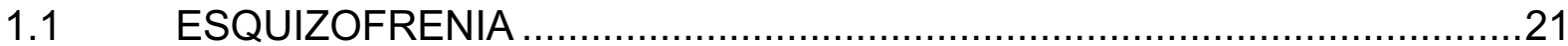

1.1.1 Aspectos clínico-fenomenológicos .....................................................21

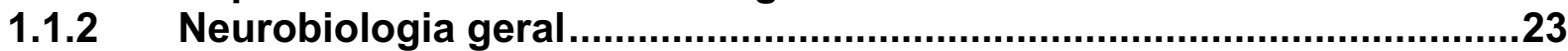

1.1.3 Fisiopatologia do modelo dopaminérgico ..............................................24

1.1.4 Fisiopatologia do modelo glutamatérgico ........................................27

1.1.5 O sistema N-metil-D-aspartato-Óxido-Nítrico-Monofosfato-cíclico-de-

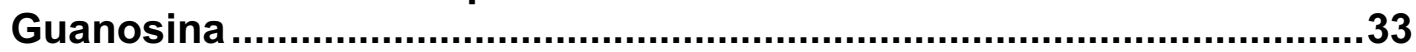

1.1.6 Nitroprussiato de sódio …............................................................35

1.1.7 Fisiopatologia do modelo endocanabinoide …....................................38

1.1.8 Canabidiol .........................................................................................

1.1.9 A hipótese neurodesenvolvimental na esquizofrenia.........................43

2 OBJETIVOS

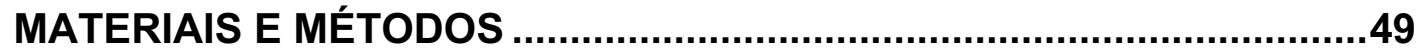

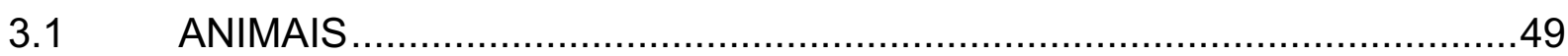

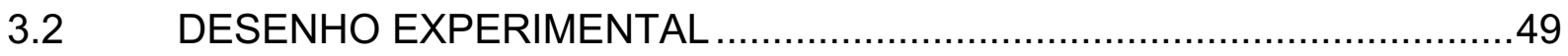

3.3 PROTOCOLO DAS ETAPAS DO DESENHO EXPERIMENTAL

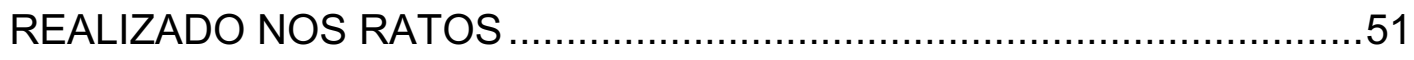

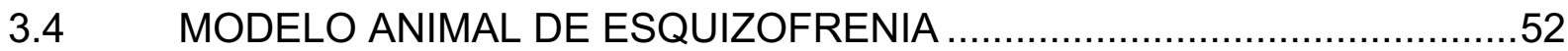

3.5 PROTOCOLOS DE TESTES COMPORTAMENTAIS REALIZADOS .........53

3.5.1 Teste de campo aberto: atividade locomotora e proporção de tempo no centro da arena .........................................................................53

3.5.2 Teste de preferência por sacarose …...........................................54

3.5.3 Teste de reconhecimento de objetos ............................................56

3.6 PROCESSAMENTO DO TECIDO CEREBRAL …................................57

3.7 ANÁLISE ESTATÍSTICA DOS RESULTADOS ..................................58

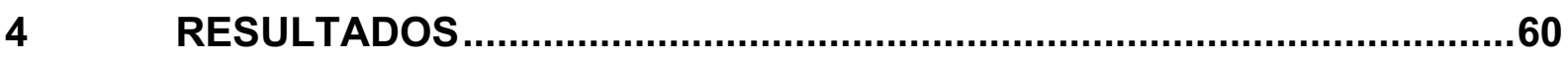

4.1 EXPERIMENTO DO TESTE DE CAMPO ABERTO: ATIVIDADE

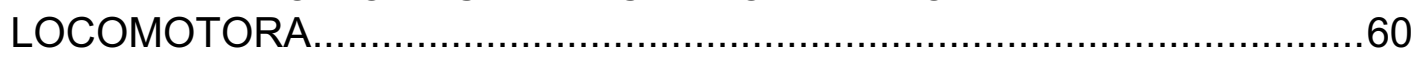

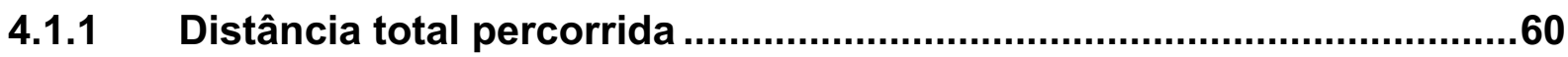

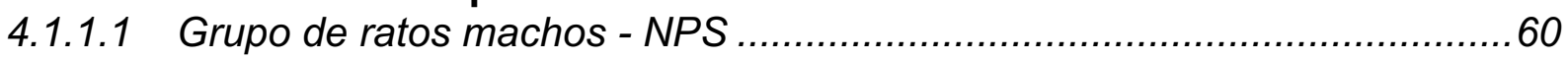

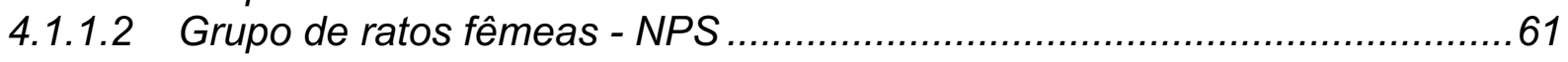

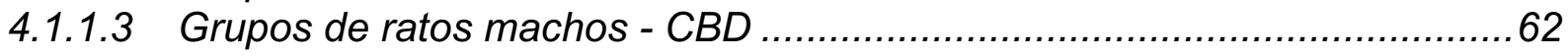

4.1.1.4 Grupos de ratos fêmeas - CBD ......................................................63

4.1.1.5 Grupos de ratos machos - NPS/CBD ...........................................6

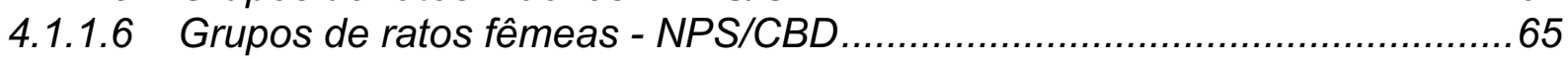

4.1.2 Proporção de tempo no centro da arena ............................................66

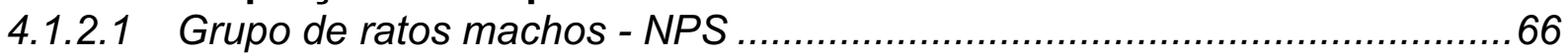

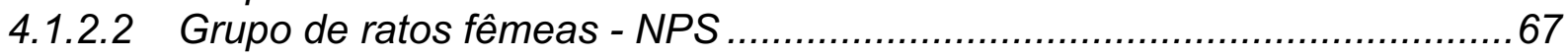

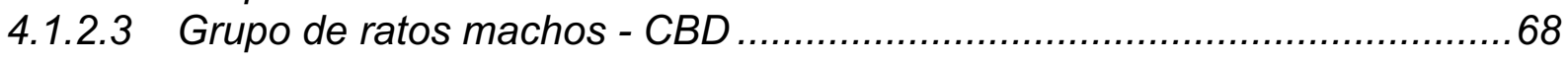

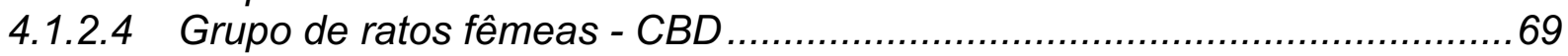

4.1.2.5 Grupo de ratos machos - NPS/CBD ................................................ 70 
4.1.2.6 Grupo de ratos fêmeas - NPS/CBD..................................................71

4.2 EXPERIMENTO DO TESTE DE PREFERÊNCIA POR SACAROSE .........72

4.2.1 Grupo de ratos machos - NPS .........................................................72

4.2.2 Grupo de ratos fêmeas - NPS .............................................................

4.2.3 Grupo de ratos machos - CBD ............................................................74

4.2.4 Grupo de ratos fêmeas - CBD .............................................................75

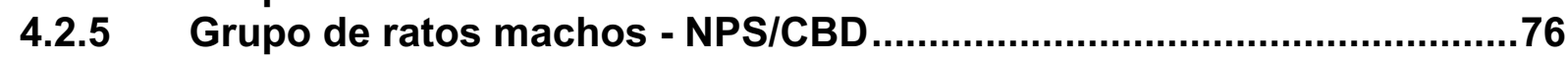

4.2.6 Grupo de ratos fêmeas - NPS/CBD .................................................77

4.3 RESULTADOS DO TESTE DE RECONHECIMENTO DE OBJETOS ........78

4.3.1 Grupos de ratos machos - NPS ..............................................................

4.3.2 Grupos de ratos fêmeas - NPS .........................................................

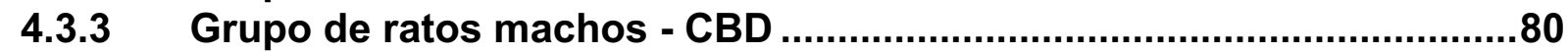

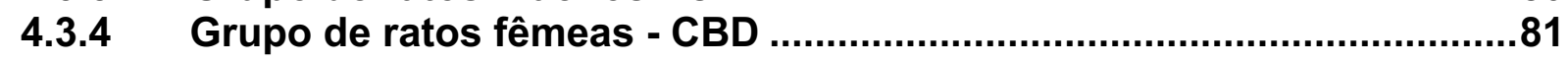

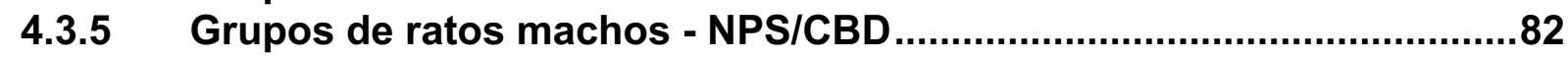

4.3.6 Grupos de ratos fêmeas NPS/CBD ......................................................... 83

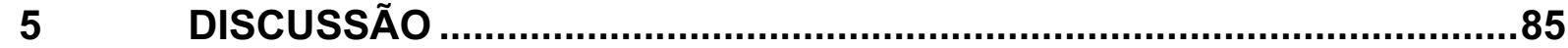

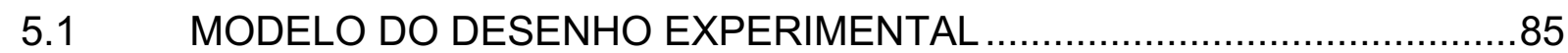

5.2 CAMPO ABERTO

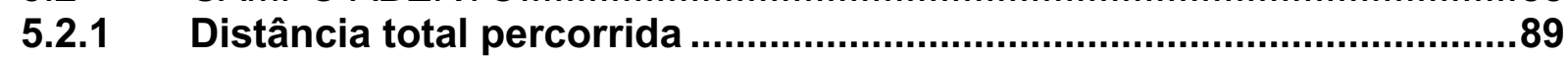

5.2.2 Proporção de tempo gasto no centro da arena ....................................103

5.3 PREFERÊNCIA POR SACAROSE ..............................................107

5.4 RECONHECIMENTO DE OBJETOS ……......................................115

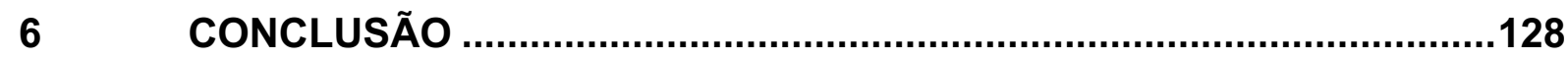

REFERÊNCIAS

ANEXO A - FOLHA DE APROVAÇÃO DO COMITÊ DE ÉTICA ..........................158 


\section{INTRODUÇÃO}

\subsection{ESQUIZOFRENIA}

\subsubsection{Aspectos clínico-fenomenológicos}

A esquizofrenia é um transtorno mental crônico e extremamente agressivo que afeta aproximadamente $1 \%$ da população mundial adulta (SHAO et al., 2019). Trata-se de uma síndrome clínica com diversas dimensões psicopatológicas, disruptivas, as quais desequilibram várias características clínicas naturais do ser humano, e que não possui cura (VAN OS; KAPUR, 2009).

Infelizmente, apesar de as estratégias farmacológicas atuais empregadas no tratamento deste transtorno evidenciar alguns resultados positivos, melhores em sintomas positivos e piores em sintomas negativos, cognitivos, afetivos e desorganizados, ainda estão longe de serem considerados tratamentos verdadeiramente eficazes (MARDER et al., 2019). Por esse motivo, esses medicamentos, os quais são denominados como antipsicóticos, vêm sendo extremamente criticados pela opinião pública, por pacientes e até mesmo por médicos renomados, os quais são céticos em afirmar que, na verdade, essas substâncias possuiriam muito mais efeitos colaterais e baixa eficácia do que resultados (LEUCHT et al., 2017).

Esse distúrbio também pode ser compreendido como um transtorno neurodesenvolvimental, o que implica dizer que esse estaria associado a determinadas fases do desenvolvimento do cérebro humano. Esse conceito foi introduzido na literatura científica mundial por Weinberger, em 1986, o qual explica que atualmente vários estudos genéticos, epigenéticos e de neuroimagem, evidenciam que o neurodesenvolvimento do período pré-natal seria um período crítico para a expressão do risco do início do transtorno (WEINBERGER, 2017). Esses estudos de expressão genética seriam consistentes em evidenciar que os genes implicados à esquizofrenia mostrariam expressão relativamente maior durante o período fetal, do que durante o período pós-natal (BLOOMFIELD et al., 2016).

Epidemiologicamente se trataria de um transtorno com alto risco hereditário para o seu desenvolvimento, o qual estaria principalmente evidenciado por estudos epidemiológicos realizados em gêmeos monozigóticos e dizigóticos (HILKER et al., 
2018). Corroborando Hilker et al. (2018), vale ressaltar que dos últimos cinco estudos mais recentes realizados em gêmeos até o ano de 2017, a taxa de concordância para gêmeos monozigóticos seria de 41 a $65 \%$ e de 0 a $28 \%$ para gêmeos dizigóticos (CARDNO; GOTTESMAN, 2000). Entretanto, há de se considerar que esses estudos possuiriam diversos vieses metodológicos porque esses definem ter ou não ter o diagnóstico de esquizofrenia no momento da realização da pesquisa e, por conseguinte, uma grande parcela de sujeitos ainda estaria sob alto risco de desenvolver o transtorno por um grande período de tempo, mesmo após o término do estudo (HILKER et al., 2018).

Atualmente, existem várias abordagens que tentam classificar a esquizofrenia no intuito de melhor compreendê-la, e uma das mais aceitas seria a abordagem dimensional, introduzida na literatura por Crow (1980), o qual postulou nessa época os tão célebres sintomas positivos e negativos do transtorno. Essa hipótese foi aperfeiçoada por Liddle (1987), que adicionou a esse constructo o conceito da desorganização, e que finalmente foi sistematizada por Lindenmayer em 1994, o qual definiu um novo modelo dimensional mais amplo chamado, na língua nativa do autor, de "A new five factor model of schizophrenia", que adicionava aos conceitos prévios, a dimensão cognitiva e a afetiva do transtorno (LINDENMAYER; BERNSTEIN-HYMAN; GROCHOWSKI, 1994).

Economicamente, em termos de gastos em saúde pública mundial, um estudo realizado por $\mathrm{Wu}$ e colaboradores no ano de 2005 descreveu que a esquizofrenia gerou, aproximadamente, custos ao redor de 62,7 bilhões de dólares, em 2002, nos Estados Unidos da América (EUA), e desses 22,7 bilhões através de custos diretos, 7,6 bilhões em custos diretos não médicos e 32,4 bilhões em custos indiretos, sendo que o maior componente dos custos indiretos gerados seria a perda de produtividade no trabalho (WU et al., 2005). Desse modo, se pode inferir que esse transtorno mental geraria altíssimo grau de incapacidade funcional, pois contaria com aproximadamente $1,1 \%$ de todas as causas de incapacidade funcional ajustada pelos anos de vida e $2,8 \%$ de todos os anos vividos com incapacidade (DALTIO; MARI; FERRAZ, 2011).

No Brasil, poucos são os estudos que se propuseram a explorar o tema, desses, cabe citar o de Leitão e colegas, os quais através de um trabalho retrospectivo realizado em 2006, concluíram após estudar o impacto dos custos médico-hospitalares diretos nos serviços de saúde pública no Estado de São Paulo, 
que os gastos diretos da esquizofrenia no país foram da ordem aproximada de 191 milhões de dólares em 1998, responsáveis por 2,2\% de todos os gastos em saúde pública do país (LEITÃO et al., 2006).

\subsubsection{Neurobiologia geral}

De acordo com pesquisas recentes, é fato que inerente ao mecanismo fisiopatológico deste transtorno, ao passo em que o paciente portador de esquizofrenia desenvolve um quadro de psicose franca, os mecanismos neurobiológicos envolvidos com a gênese do quadro já estariam ativos há muitos anos (KAHN; SOMMER, 2015).

Vários achados neurobiológicos corroboram essa afirmação como, por exemplo, a informação de que ao tempo do diagnóstico inicial, pacientes portadores de esquizofrenia possuiriam volume intracraniano médio diminuído, quando comparado com controles saudáveis. Esses resultados, amplamente extraídos através de uma extensa metanálise realizada por Haijma e colaboradores, em 2013, revelam uma possível diferença consistente na diminuição do volume intracraniano de pacientes portadores de esquizofrenia de início recente e crônica e de pacientes virgens de medicamentos (HAIJMA et al., 2013).

Estudos realizados em fases prodrômicas da esquizofrenia também vêm fornecendo subsídios para que se compreenda a esquizofrenia como um transtorno que se inicia em fases mais precoces do desenvolvimento humano. Entende-se por fase prodrômica da esquizofrenia aquela em que o indivíduo antes de apresentar o transtorno, especificamente, apresentaria danos cognitivos leves, alterações de humor, de ansiedade, de sintomas psicóticos sutis, além de declínio social e ocupacional (FUSAR-POLI et al., 2012). Nesse sentido, uma recente revisão sistemática realizada em pacientes em fase prodrômica sugere que os volumes das áreas temporal e frontal desses sujeitos estariam diminuídos, porém nem tanto como quando no início do quadro psicótico franco (WOOD et al., 2013). Outro estudo, porém, realizado com ênfase na substância branca da região frontal, evidenciou uma possível redução progressiva na integridade das fibras brancas dessa região, especificamente, naqueles pacientes que mais tarde desenvolveriam o transtorno propriamente dito (KARLSGODT et al., 2009). 
No intuito de tentar entender as causas das alterações cerebrais existentes, em todas as etapas da esquizofrenia, se torna necessário compreender esse transtorno dentro de um contexto multifatorial. Contexto esse cujas evidências atuais provêm de estudos sobre o tratamento do quadro, de trabalhos post mortem, de investigações de neuroimagem, bem como de modelos animais experimentais. Mais importante ainda seria compreender a integração dessas evidências de maneira inter-relacionada e sistematizada. Assim, esses resultados demonstram que essas alterações estariam relacionadas à interação de diversos mecanismos fisiopatológicos, como por exemplo, a desregulação dopaminérgica, o distúrbio glutamatérgico, o aumento de processos cerebrais inflamatórios, entre outras (KAHN; SOMMER, 2015).

Complementando o conhecimento descrito acima sobre esses circuitos cerebrais anômalos, que estariam relacionados à esquizofrenia, Hallak e colaboradores realizaram um estudo sobre os efeitos do canabidiol em um modelo animal de esquizofrenia e introduziram na literatura o conceito de que, provavelmente, o sistema cerebral dos canabinoides também estaria interrelacionado com ambos os sistemas dopaminérgico e glutamatérgico (HALLAK et al., 2011).

\subsubsection{Fisiopatologia do modelo dopaminérgico}

O primeiro modelo neurobiológico proposto para a etiopatogenia da esquizofrenia foi o modelo dopaminérgico, no qual teoricamente os sintomas do transtorno seriam provenientes de uma hiperatividade desse neurotransmissor em determinas áreas cerebrais. Denominada, posteriormente, de "A hipótese dopaminérgica na esquizofrenia" se acredita que essa tenha sido arquitetada através da contribuição do conhecimento de vários pesquisadores, os quais possuíam diversas linhas diferentes de trabalho, porém que se relacionavam entre si em um mesmo objetivo, descobrir os sistemas neuronais dopaminérgicos que estariam por trás do transtorno (HOWES et al., 2012).

Essa hipótese, inicialmente introduzida na literatura por Carlsson e colegas, em 1957 (CARLSSON; LINDQVIST; MAGNUSSON, 1957), e que foi, genialmente, sistematizada por Snyder em 1973, através da publicação de um artigo, cujo título na língua nativa do autor foi denominado de "Amphetamine psychosis: A "model" 
schizophrenia mediated by catecholamines" (SNYDER, 1973), acabou se tornando na época o modelo neurobiológico mais bem estudado e validado cientificamente, sendo aceito como crucial na compreensão da gênese da doença1. Essa teoria proporcionou uma explicação simples, porém consistente a respeito das causas do transtorno, como pôde ser observado através de inúmeras evidências científicas provenientes de trabalhos de diversos autores, como por exemplo, por meio dos estudos de Kety (1965), o qual também acreditava que a psicose por anfetaminas poderia ser encarada como um modelo biológico para a esquizofrenia.

Outras contribuições históricas e não menos importantes vieram de Carlsson e Lindqvist (1963), que sugeriram que as fenotiazinas agiriam bloqueando os receptores de dopamina. Não obstante, também as ideias do próprio Snyder (1972) já sugeriam que a psicose por anfetaminas deveria ser mediada pela dopamina e seus receptores específicos.

Como descrito acima, todos esses achados e tantos outros mais levaram Snyder, em 1973, a postular determinada hipótese na qual a esquizofrenia seria mediada pelo aumento da atividade dopaminérgica e de seus respectivos receptores em regiões cerebrais específicas. Entretanto, esse modelo neurobiológico não era suficiente para responder, com clareza, todas as perguntas sobre a fisiopatologia real do transtorno, levando a conclusão final de que a hipótese da dopamina na esquizofrenia seria muito mais uma teoria viável para a explicação da gênese do transtorno, do que um modelo neurobiológico estrito propriamente útil (SNYDER, 1973).

Mais recentemente, corroborando as ideias de Carlsson e Snyder, um extenso artigo de revisão realizado por Lieberman e colegas, em 1987, evidenciou vários estudos que demonstravam que a administração de anfetamina e de outras substâncias psicoativas, como: a cocaína e a efedrina, que pareciam aumentar as concentrações extracelulares de dopamina, induzindo sintomas psicóticos semelhantes aos observados na esquizofrenia (LIEBERMAN; KANE; ALVIR, 1987). Esses agentes faziam parte de um grupo de substâncias classificadas como psicoestimulantes e que, por definição, seriam drogas que estimulariam o sistema

\footnotetext{
${ }^{1}$ Apesar do termo doença, por muito tempo, não ter sido aceito para a definição de uma entidade psiquiátrica, pois segundo a Organização Mundial de Saúde (OMS), o termo doença só deveria ser utilizado para patologias que pudessem ser mensuradas e diagnosticadas através de exames complementares, o autor se reserva ao direito de, em algumas situações, utilizar o termo doença, pois inúmeras são as evidências científicas atuais que demonstram que a esquizofrenia seria uma síndrome clínica de etiologia orgânica, mas que infelizmente ainda não possui um marcador biológico adequado que a defina como tal.
} 
nervoso central (SNC) e simpático, através de efeitos agonistas da neurotransmissão catecolaminérgica (MOORE, 1977). Essas substâncias agiriam, predominantemente, por meio da liberação de aminas biogênicas nos sítios de armazenamento de terminais nervosos pré-sinápticos, além de bloquearem a sua recaptação (FERRIS; TANG; MAXWELL, 1972). A administração aguda dessas drogas produziria vários sintomas característicos que eram encontrados na esquizofrenia, tais como: agitação psicomotora, euforia, insônia, anorexia entre outras alterações da sensopercepção e comportamento (GROVES; REBEC, 1976).

Voltando para década de 1970, pesquisadores também tentavam entender o motivo pelo qual alguns pacientes apresentavam excelente resposta aos medicamentos antipsicóticos, enquanto que outros respondiam inadequadamente ou até mesmo não demonstravam nenhum resultado para a ação desses agentes (ANDREWS, 2003). Desse modo, ao passo em que os estudos sobre dopamina e esquizofrenia foram se desenvolvendo, outra importante linha de pesquisa desenvolvida sobre a validade do modelo dopaminérgico na esquizofrenia tentava demonstrar resultados mais claros sobre a eficácia clínica dos antipsicóticos (HOWES; MCCUTCHEON; STONE, 2015).

$\mathrm{Na}$ linha desses resultados, diversas pesquisas descreveram que, possivelmente, o potencial de ação terapêutico desses agentes estaria diretamente relacionado com a sua afinidade pelos receptores de dopamina, que estariam aumentados e localizados mais especificamente no estriado (OWEN et al., 1978). Por conseguinte, descobriu-se que a eficácia clínica do tratamento da esquizofrenia estaria relacionada com anormalidades específicas na densidade de receptores de dopamina nessa região, mas não na densidade de moléculas transportadoras de dopamina (MACKAY et al., 1982; PEARCE et al., 1990).

Apesar de todos esses estudos descritos acima, com toda essa gama de evidências a respeito da associação de dopamina e de esquizofrenia, os quais contribuíram de maneira exponencial para o conhecimento acerca dos mecanismos neuronais envolvidos com a gênese do transtorno, há de se ressaltar uma série de limitações na interpretação dessas informações (HOWES; MCCUTCHEON; STONE, 2015). Portanto, segundo Howes, Mccutcheon e Stone (2015), bem como outros pesquisadores da época, percebeu-se que substâncias, como as anfetaminas e a reserpina, também interagiriam com outras monoaminas cerebrais e não somente com a dopamina, além também do fato de que não havia uma informação clara a 
respeito do locus das anormalidades dopaminérgicas encontradas no cérebro in vivo (DAVIS et al., 1991).

Desde aquela época então, o conhecimento sobre as várias regiões anatômicas cerebrais, que estariam relacionadas com a esquizofrenia, era proveniente em sua maioria de estudos realizados em cérebros post mortem. Mesmo assim, atualmente, exames mais modernos de neuroimagem (TRZESNIAK et al., 2011) realizados, por exemplo, através de tomografia por emissão de pósitrons (PET) e tomografia por emissão de photon único (SPECT) entre outros vêm corroborando aqueles resultados prévios descritos acima, evidenciados por análises post mortem (KIM; HOWES; KAPUR, 2013).

Entre essas diversas anormalidades anatômicas cerebrais já relacionadas com a fisiopatologia da esquizofrenia, chama a atenção aquelas que estariam relacionadas ao antagonismo de receptores de dopamina 2 (D2), alvo de ação da maior parte dos antipsicóticos desenvolvidos naquela época. É o caso, por exemplo, dos terminais dos neurônios dopaminérgicos localizados no estriado de pacientes portadores desse transtorno (KAPUR et al., 1996). Outra área anatômica que estaria intimamente relacionada com a doença e que também hoje em dia pesquisas vêm demonstrando relação clara com o transtorno seria o tálamo mediodorsal. Essa estrutura se conecta, fortemente, com o córtex pré-frontal, e através de estudos de neuroimagem funcional parece possuir ativação nitidamente diminuída em pacientes portadores de esquizofrenia durante tarefas cognitivas (SIGURDSSON, 2016).

Com todas essas evidências descritas acima, em síntese, pode-se afirmar que a hipótese dopaminérgica na esquizofrenia não elucida o mecanismo preciso da fisiopatologia do transtorno e, desse modo, pesquisadores tentam desde aquela época a duras penas encontrar novos modelos neurobiológicos, que expliquem de maneira mais convincente a gênese da doença.

\subsubsection{Fisiopatologia do modelo glutamatérgico}

Na década de 1960, concomitantemente ao início das pesquisas sobre a neurotransmissão dopaminérgica na esquizofrenia, pesquisadores começaram a estudar o papel de outro neurotransmissor, o glutamato, na gênese do transtorno (YANG; TSAI, 2017). A ideia de se estudar a neurotransmissão glutamatérgica na esquizofrenia se inicia, então, pela observação de médicos especialistas a usuários 
de fenciclidina (PCP), também conhecida como a droga de abuso angel dust, e de cetamina (CET), pois esses indivíduos desenvolviam um quadro esquizofrenia-like bem característico ao encontrado na própria doença (OLNEY et al., 1999). Essa síndrome cursava além apenas dos sintomas positivos e negativos que a psicose por anfetaminas provocava, com os mesmos sinais e sintomas que afetam todas as dimensões psicopatológicas do transtorno, ou seja, as dimensões: positiva, negativa, desorganizada, cognitiva e afetiva (MORRIS; COCHRAN; PRATT, 2005). Após anos de estudo, descobriu-se que isso ocorria porque substâncias como a PCP e a própria CET antagonizavam receptores N-metil-D-aspartato (NMDA), produzindo psicose (FROHLICH; VAN HORN, 2014).

O primeiro relato do uso de antagonistas glutamatérgicos como um modelo farmacológico para a esquizofrenia ocorreu em 1962 e foi realizado por Luby e pesquisadores. Esses autores escreveram, nessa época, um artigo original no qual testaram a viabilidade de vários modelos experimentais de psicose, como por exemplo, a privação de sono, o isolamento sensorial e o do uso de drogas psicotomiméticas e introduziram, desse modo, o conceito de que drogas como a PCP poderiam induzir a uma gama de sinais e de sintomas que provocariam um quadro clínico de sintomatologia muito parecida com o da esquizofrenia (LUBY et al., 1962). A substância utilizada foi o Sernyl®e, [1-(1-phenylcyclohexyl)] monohidrocloro de piperidina, um agente pré-anestésico e tranquilizante que foi patenteado em 1952 pelo laboratório Parke-Davis $®$ (MION, 2017).

Durante vários anos, após esses primeiros relatos de Luby e colegas, era sabido que tais agentes antagonistas glutamatérgicos causavam um quadro esquizofrenia-like nos indivíduos que eram usuários dessas substâncias, porém ninguém sabia ao certo o modo ou mais precisamente os mecanismos cerebrais responsáveis por esse fenômeno. Até que no ano de 1995, Olney e Farber publicaram o primeiro artigo científico explicando tecnicamente sobre a então denominada "Hipótese glutamatérgica na esquizofrenia", através da observação de que agentes antagonistas de receptores NMDA poderiam provocar déficits característicos dessa doença em humanos (OLNEY; FARBER, 1995). Esses dois pesquisadores descreveram que uma possível disfunção de receptores glutamatérgicos poderia explicar a fisiopatologia do transtorno, corroborando achados prévios de Kim e colaborares na década de 1980, os quais introduziram os 
conceitos iniciais a respeito do modelo glutamatérgico na esquizofrenia (KIM et al., 1980).

Dando maior ênfase e atenção a esses novos conceitos em relação à esquizofrenia, Deakin e Simpson, em 1997, sistematizaram esses resultados citados acima, descrevendo que determinados receptores glutamatérgicos ionotrópicos, que são essenciais para a plasticidade neuronal, estariam relacionados com a hipoatividade de receptores do tipo NMDA e, assim, poderiam estar envolvidos com a gênese da doença (DEAKIN; SIMPSON, 1997).

Alguns agentes antagonistas glutamatérgicos distintos, como por exemplo, a PCP, a CET com seus isômeros S (+) ou R (-) vêm sendo utilizados como possíveis modelos farmacológicos viáveis para a indução de quadros esquizofrenia-like em humanos e em animais durante todos esses anos. Atualmente, após um extenso artigo de revisão realizado em 2014 por Frohlich e Van Horn, essas opções farmacológicas distintas foram corroboradas por esses autores como modelos farmacológicos viáveis, que ainda se estenderam em definir que a CET seria o modelo farmacológico mais adequado e seguro de indução a um quadro esquizofrenia-like, através do antagonismo dos receptores NMDA (FROHLICH; VAN HORN, 2014).

A respeito do mecanismo da neurotransmissão na hipótese glutamatérgica da esquizofrenia, é importante mencionar que o glutamato parece ser o aminoácido mais abundante encontrado no cérebro de mamíferos (LODGE, 2009). Esse neurotransmissor possuiria dois tipos de receptores, os metabotrópicos e os ionotrópicos, os quais de acordo com estudos recentes seriam possíveis de afirmar que as maiores evidências do envolvimento desses receptores glutamatérgicos na esquizofrenia ocorreriam pelos receptores ionotrópicos, que poderiam ser subdivididos em NMDA, e não-NMDA, ou seja, ácido a-amino-3-hidroxi-5metilisoxazol-4-propiônico (AMPA) e kainato (KALIA; KALIA; SALTER, 2008). Tanto os receptores NMDA, como os não-NMDA fariam parte da neurotransmissão glutamatérgica, entretanto os receptores NMDA estariam mais bem associados à fisiopatologia da esquizofrenia, de acordo com vários estudos prévios que tentaram evidenciar que o bloqueio desses, através da PCP, provocaria esquizofrenia (LIN; LANE; TSAI, 2012).

Mais especificamente então, os estudos atuais sobre a hipótese da neurotransmissão glutamatérgica na esquizofrenia demonstram que os receptores 
NMDA devem ser regulados ou até mesmo controlados por estruturas classificadas como agonistas, coagonistas, além de uma série de moléculas como as poliaminas, o zinco, o magnésio, a própria PCP e, também, a CET (BLISS; COLLINGRIDGE, 1993). Esses receptores NMDA também seriam constituídos por subunidades denominadas NR1, NR2 ou NR3 e juntos comporiam canais de receptores heterométricos, ou seja, de diferentes tamanhos e com características farmacológicas distintas (LAURIE; SEEBURG, 1994). Essas estruturas possuiriam características únicas, que além de se ligarem ao glutamato e até mesmo ao aspartato, também se conectariam a determinados sítios coagonistas separados, específicos para ligantes endógenos como a D-serina, glicina e D-alanina. A conexão com esses sítios coagonistas separados poderia aumentar a frequência da abertura desses supostos canais iônicos, que seriam ativados por agonistas de receptores NMDA, facilitando a transmissão excitatória no cérebro (JOHNSON; ASCHER, 1987). Na verdade, a ativação desses ligantes como a D-serina, glicina e D-alanina, junto com o glutamato, seria necessária para a abertura de outros canais iônicos de receptores NMDA, porém dessa vez outro tipo de canal conhecido como ionóforo, ou seja, que seria solúvel em lipídeos (CHESSELL et al., 1991).

Desses ligantes descritos acima, a D-alanina seria o ligante menos importante na neurotransmissão excitatória do neocórtex e, por esse motivo, a maior parte dos estudos atuais se concentra em estudar a ligação da D-serina e da glicina nos sítios de receptores NMDA de D-serina e de glicina (LIN; LANE; TSAI, 2012). Dentro desse contexto, essas substâncias seriam imprescindíveis para a neurotransmissão glutamatérgica, uma vez que essas aumentariam a eficácia da comunicação entre os neurônios glutamatérgicos, pois ao recrutarem receptores ionóforos aumentariam a duração e a frequência da abertura dos canais iônicos, promovendo turnover de receptores NMDA (FADDA et al., 1988; NONG et al., 2003). É sabido também que a conexão de D-serina nos receptores NMDA, principalmente, da subunidade NR1, se ligaria mais fortemente aos receptores NMDA do que a glicina e, por conseguinte, outro dado importante seria que as sinapses de D-serina e de glicina nos receptores NMDA da subunidade NR1, não estariam totalmente saturados em regiões como o córtex pré-frontal, hipocampo e tálamo, sugerindo que agonistas de D-serina e glicina seriam capazes de melhorar a neurotransmissão de receptores NMDA (LABRIE; RODER, 2010). 
A partir do conhecimento mais profundo dos receptores NMDA ionotrópicos, como explicado anteriormente, diversos centros de pesquisa tentaram realizar vários tipos diferentes de tratamentos, visando sempre resultados efetivos e consistentes nos sintomas da esquizofrenia, através do agonismo desses receptores ionotrópicos. Em 2013, Papanastasiou e seus colegas, através de um artigo de revisão, referiram que a maioria dos fármacos em desenvolvimento, nessa linha de pesquisa, agiria como agonistas nos sítios de glicina B ou visariam aumentar as concentrações sinápticas de glicina através da inibição do transportador de glicina 1 (GlyT1) (PAPANASTASIOU; STONE; SHERGILL, 2013). Esses fármacos em questão seriam a D-alanina, a D-serina, a glicina (agonistas de glicina), a D-cicloserina (agonista parcial de glicina), a $\mathrm{N}$-acetilcisteína (precursor da glutationa e modulador de receptores NMDA) e a sarcosina (inibidor endógeno de GlyT-1).

A figura abaixo (ver figura 1) reproduz uma espécie de representação gráfica mais detalhada do circuito das sinapses dos receptores NMDA (LIN; LANE; TSAI, 2012). 
Figura 1 - Os reguladores já conhecidos e alvos potenciais para medicamentos das sinapses de receptores NMDA incluiriam o sitio de coagonistas de glicina na subunidade NR1, serina racemase,

D-aminoácido oxidase, o ativador de D-aminoácido oxidase e o sítio da recaptação de D-serina. Aspartato e glutamato seriam agonistas; glicina e D-serina seriam coagonistas de receptores NMDA. O bloqueio de magnésio seria liberado pela despolarização. PCP seria um bloqueador de canal. Dserina seria sintetizada pela serina racemase da L-serina. D-serina estaria localizada em neurônios e células da glia, seria captado através da GlyT-1 e metabolizado para Serina pelo sítio de recaptação da D-serina. D-serina seria metabolizada pela D-aminoácido oxidase dentro da hidroxipiruvato. A degradação seria inibida pelo benzoato. O ambiente do ativador de D-aminoácido oxidase como ativador ou inibidor ainda seria incerto. Glicina seria captada pela Glyt-1 e metabolizada em L-serina pelo sistema de clivagem de glicina. Sarcosina inibiria a captação de glicina através da Glyt-1

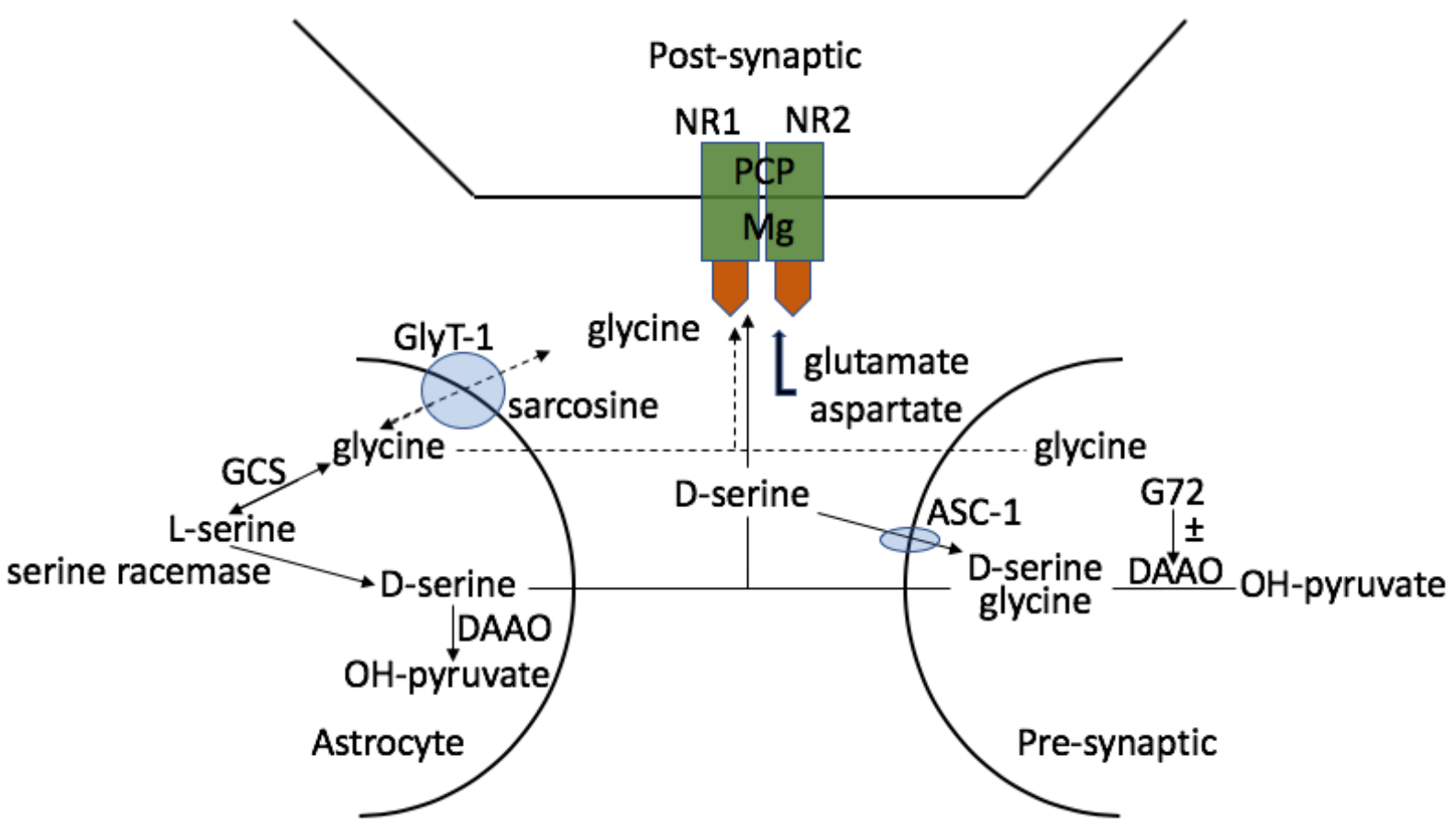

Fonte: Adaptado de Lin, Lane e Tsai (2012).

Vários estudos realizados nos sítios de glicina, embora com amostras pequenas, mostraram alguns indícios de resultados no tratamento de sintomas positivos, negativos e cognitivos da esquizofrenia (JAVITT et al., 1999; JAVITT et al., 2001; JAVITT, 2008). Apesar do pequeno tamanho desses testes, seus resultados aparentemente encorajadores estimularam o interesse das empresas farmacêuticas em desenvolver drogas visando ativação dos receptores de glicina. Entretanto, após vários ensaios clínicos desenvolvidos se percebeu que essas drogas não seriam realmente efetivas para o tratamento da esquizofrenia, como demonstra, por exemplo, Buchanan e colaboradores, os quais escreveram um artigo concluindo que as drogas citadas acima e até mesmo outras com mecanismos de ação similares não evidenciaram nenhum resultado consistente na melhora de sintomas da esquizofrenia (BUCHANAN et al., 2007). 
O estudo de Buchanan et al. (2007) foi um dos mais bem elaborados sobre o tema até o momento, e consistiu de um ensaio clínico randomizado, duplo-cego, realizado nos EUA e em Israel, com as drogas glicina, D-cicloserina e placebo para o tratamento de sintomas negativos e cognitivos da esquizofrenia. Foram selecionados 157 participantes, que preencheram os critérios do "Manual Diagnóstico e Estatístico das Doenças Mentais - $4^{a}$ edição" (DSM-IV) para esquizofrenia e, especificamente, para os sintomas negativos da doença, de moderados a graves (AMERICAN PSYCHIATRIC ASSOCIATION, 2000). Através da "Escala de Avaliação de Sintomas Negativos" (SANS), uma escala para acesso aos sintomas negativos da esquizofrenia e, também, através de uma bateria de testes cognitivos, os grupos acima descritos foram comparados, não sendo encontrada nenhuma diferença estatística entre esses. Esses resultados então sugeriram que nem glicina e nem Dcicloserina seriam agentes terapêuticos efetivos para o tratamento da esquizofrenia (BUCHANAN et al., 2007).

Dessa maneira, estudar outras medicações, com diferentes mecanismos de ação, que pudessem produzir alterações benéficas no sistema glutamatérgico de pacientes portadores de esquizofrenia se tornou o foco de pesquisadores que se aprofundaram nessa linha de pesquisa. E, por conseguinte, outra abordagem de medicamentos, ou melhor ainda, uma outra teoria que visava resolver o problema do antagonismo glutamatérgico na esquizofrenia e, cujo mecanismo de ação não teria como objetivo principal os sítios de glicina, seria a do sistema conhecido como Nmetil-D-aspartato-Óxido-Nítrico-Monofosfato-cíclico-de-Guanosina

(NMDA-ONGMPc).

\subsubsection{0 sistema N-metil-D-aspartato-Óxido-Nítrico-Monofosfato-cíclico-de- Guanosina}

Por meio de evidências recentes de várias outras anormalidades no circuito glutamatérgico, Miüller e Schwarz (2007) descreveram que as alterações de neurotransmissão glutamatérgica encontradas nessa doença poderiam estar relacionadas ao sistema descrito acima, ou seja, ao circuito NMDA-ON-GMPc. Na mesma linha de evidências, diversos outros estudos corroboraram Miüller e Schwarz (2007), referindo que na esquizofrenia haveria uma diminuição considerável de metabólitos de óxido nítrico (ON) e de monofosfato cíclico de guanosina (GMPc) 
(RAMIREZ et al., 2004). Entre esses estudos é conhecido o trabalho, por exemplo, em 2004, de Nakano e colaboradores, que descreveram uma provável associação entre sintomas negativos da esquizofrenia e diminuição de níveis plasmáticos de metabolitos de ON (NAKANO et al., 2010). Outro artigo prévio, que corroborou os mesmos achados descritos pela equipe de Nakano, foi escrito por Gattaz e colegas em 1983, no qual esses autores já descreviam provável diminuição de GMPc em pacientes portadores de esquizofrenia (GATTAZ et al., 1983).

Portanto, no intuito de se compreender mais adequadamente o sistema NMDA-ON-GMPc descrito anteriormente se torna necessário conhecer o sistema do ON no cérebro de humanos. O ON é um gás gerado pela conversão da L-arginina em L-citrulina pela enzima ON sintetase (ONS) (BREDT; SNYDER, 1992). Existiriam, basicamente, três formas de ONS, a ONS neuronal, a induzível e a endotelial (BERNSTEIN et al., 2005). No cérebro humano, então, o ON seria responsável pela ligação e consequente ativação do receptor guanilato ciclase solúvel, que aumentaria a síntese do segundo mensageiro, ou seja, do GMPc, que por sua vez ativaria as quinases dependentes de GMPc em células alvo (RUSSWURM; KOESLING, 2004; HOBBS; IGNARRO, 1996). O ON também se conectaria aos receptores NMDA através da ONS neuronal, aumentando a produção de ON endógeno ao redor das sinapses NMDA, ativando seus receptores e, consequentemente, aumentando a atividade da neurotransmissão mediada por glutamato (BRENMAN; BREDT, 1997).

Explicando mais detalhadamente ainda o que ocorre nesse sistema se pode afirmar que a ativação glutamatérgica de receptores NMDA permitiria influxo de cálcio para dentro da célula, que por sua vez se ligaria a calmodulina, que é uma proteína que possui alta afinidade com as moléculas de cálcio, produzindo monofosfato cíclico de adenosina (AMPc) e GMPc, estimulando a ONS neuronal a produzir mais ON (MAYER; HEMMENS, 1997). Por sua vez, esse novo ON gerado estimularia a enzima guanilato ciclase solúvel, aumentando mais uma vez as concentrações de GMPc, o qual possuiria o papel de poder modular a atividade de proteínas quinases, a translação de ácido ribonucleico (RNA) mensageiro e a síntese de produtos derivados dos genes (BERNSTEIN et al., 2005; AKYOL et al., 2004). Todo esse mecanismo, então, melhoraria a reposta glutamatérgica do cérebro humano (OLIVEIRA et al., 2015). 
Desse modo seria coerente inferir que drogas que pudessem agir na resposta glutamatérgica, através do circuito NMDA-ON-GMPc, poderia melhorar sintomas da esquizofrenia. Entretanto, pesquisas recentes realizadas por meio de agonistas de receptores NMDA via ON para o tratamento da esquizofrenia vêm demonstrando resultados inconsistentes, possivelmente, devido ao rápido desenvolvimento de tolerância desses compostos, secundariamente a um processo de dessensibilização de receptores NMDA (TUOMINEN; TIIHONEN; WAHLBECK, 2005).

No intuito de tentar resolver esse problema de dessensibilização de receptores NMDA, Bujas-Bobanovic e sua equipe encontraram evidências científicas importantes em que acreditam terem conseguido evitar esse problema de dessensibilização e tolerância (BUJAS-BOBANOVIC et al., 2000). Esses investigadores, através de um artigo publicado no ano de 2000, demonstraram que com a infusão de nitroprussiato de sódio (NPS), um potente doador de ON, eles conseguiram, aparentemente, abolir o comportamento psychosis like e a expressão cerebral do proto-oncogene c-fos em ratos, que foram induzidos com PCP. Infelizmente, o mecanismo exato pelo qual o NPS produziria seus efeitos em animais tratados com a PCP ainda não está claro, mesmo já se conhecendo que além da produção de ON no cérebro e aumento da produção de GMPc, o NPS parece modular as atividades dos receptores NMDA (HOYT et al., 1992; MANZONI et al., 1992).

\subsubsection{Nitroprussiato de sódio}

Dessa maneira, seria interessante conhecer de maneira mais ampla o que realmente seria a molécula NPS e, consequentemente, quais seriam os seus efeitos no cérebro humano. O NPS, como já descrito, seria um importante doador de ON, o qual foi descoberto ao final de 1800 (LOCKWOOD et al., 2010) e passou a uso clínico a partir de 1929 para o tratamento da hipertensão arterial severa e, também, para indução de hipotensão em cirurgias para redução da perda sanguínea intraoperatória (JOHNSON, 1929). Atualmente, é comercializado através de administração endovenosa, e possui uso restrito em função do acúmulo de ferrocianida após múltiplas dosagens (MARIK; VARON et al., 2007). Possui molécula ativa igual ao do desenho abaixo (ver figura 2), a qual é composta de uma molécula 
de ferro ferroso e de cinco moléculas de cianeto, além de um grupo nitrosil (MULLICA; TIPPIN; SAPPENFIELD, 1991).

Figura 2 - Representação gráfica da fotografia e da estrutura molecular do nitroprussiato de sódio. a) fotografia molecular do nitroprussiato de sódio, em que os átomos estão representados pelas esferas através de códigos convencionais por cores, em que: carbono (cinza), oxigênio (vermelho), nitrogênio (azul claro), sódio (azul escuro) e ferro (laranja) (imagem ilustrativa obtida em https://pixels.com/featured/3-sodium-nitroprusside-drug-molecule-molekuul.html). b) estrutura molecular do nitroprussiato de sódio extraído da bula do medicamento Nitropress $®$ (Sodium Nitroprusside Injection), do laboratório Bausch Health Americas, Inc.
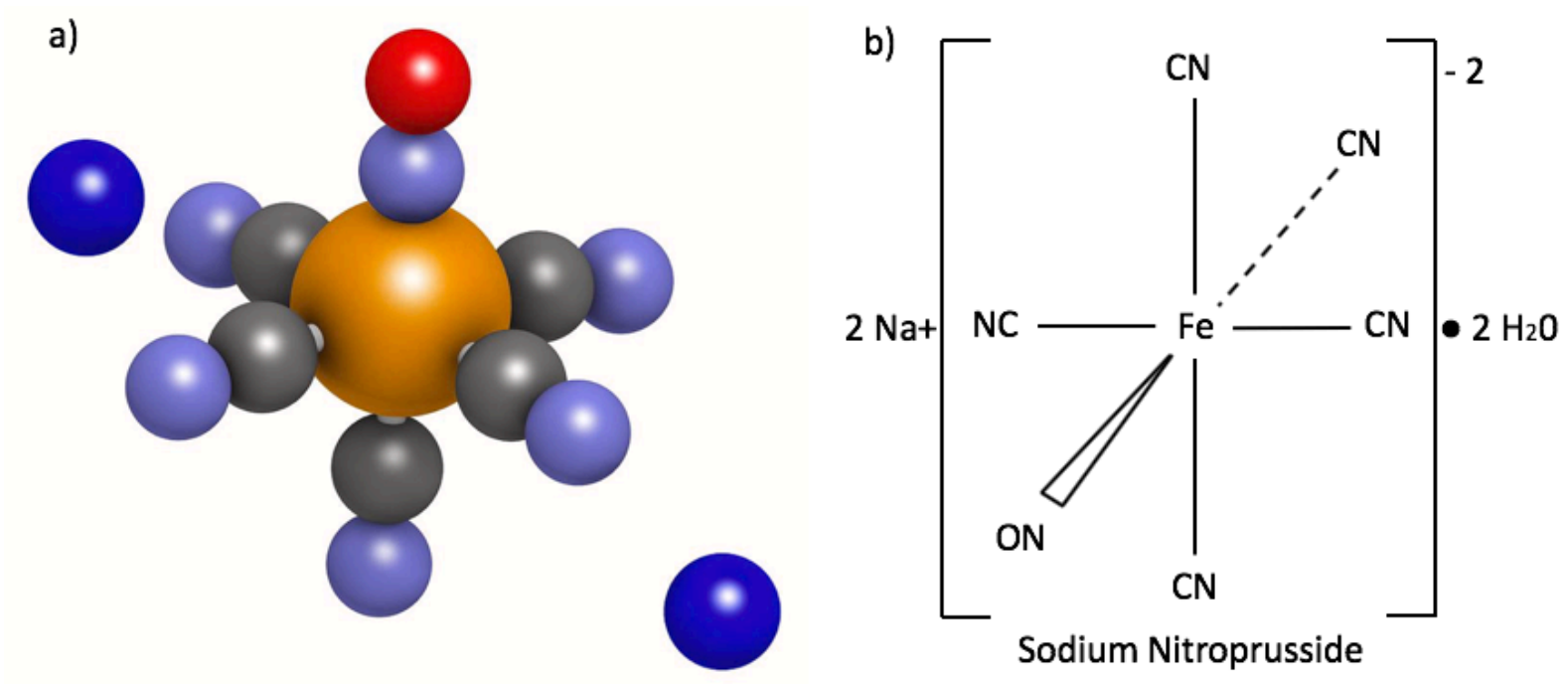

Fonte: Adaptado de Dailymed (2016).

No corpo humano, o NPS interagiria com a oxihemoglobina no sangue, produzindo metahemoglobina enquanto liberaria cianeto e ON. Depois disso, gerando toda a cascata de eventos descrita acima, em que resumidamente o ON ativaria a guanilato ciclase solúvel, a qual aumentaria a produção de GMPc, modulando a ação de proteínas quinases (LOCKWOOD et al., 2010). Em posse do conhecimento mencionado nos últimos parágrafos se pode afirmar que as observações pré-clínicas descritas levaram ao desenvolvimento de uma hipótese de pesquisa na qual o NPS poderia melhorar sintomas de pacientes portadores de esquizofrenia.

Baseado nessas pesquisas prévias, o grupo de pesquisa da FMRP da USP, responsável pela referida tese de doutorado em questão, e chefiado pelo Professor Jaime Hallak, publicou um artigo científico original, no "American Journal of Psychiatry", no ano de 2013, no qual se testou, de maneira inédita, a efetividade do NPS quanto ao tratamento de sintomas de pacientes portadores de esquizofrenia (HALLAK et al., 2013). Os resultados foram surpreendentes, porque se pode observar uma aparente melhora rápida dos sintomas da doença, após apenas uma 
infusão da substância. Mais interessante foi a descoberta de que mesmo após uma única administração endovenosa rápida de quatro horas de NPS, essa parece ter sido suficiente para que os efeitos de melhora clínica permanecessem por até quatro semanas. Desse modo, após o término do estudo, talvez, a principal questão a ser respondida foi: como o NPS, que possui meia vida de eliminação tão pequena, poderia ter produzido um efeito tão duradouro no tratamento dos sintomas do transtorno? Ainda não se pode responder a essa pergunta com clareza e, portanto, novos estudos deverão tentar respondê-la com mais propriedade. Entretanto, o aparente efeito terapêutico tão duradouro encontrado no estudo proporcionou aos pesquisadores, envolvidos com esse trabalho, formular uma nova hipótese de pesquisa na qual o NPS poderia possuir propriedades terapêuticas preventivas em referência aos sintomas da esquizofrenia, uma vez que apenas uma única dosagem da substância parece ter proporcionado resultados estendidos de aproximadamente trinta dias.

Corroborando a hipótese descrita acima, Oliveira et al. (2015) elaboraram um estudo em que se avaliou o uso do NPS administrado em tempos distintos (12h, 1 dia, 2 dias e 1 semana) em um modelo animal de esquizofrenia usando a CET como indutor de um quadro schizophrenia like. Os resultados surpreendentes tiveram como conclusão que a administração de NPS até uma semana antes da CET, aparentemente, parece ter prevenido o aparecimento dos sintomas da doença em ratos.

Desse modo, os resultados provenientes da equipe de Hallak et al. (2013), associados aos do estudo de Oliveira et al. (2015), forneceram evidências científicas de que o NPS poderia provocar efeitos preventivos e duradouros em sintomas psicóticos nos organismos tratados previamente com essas substâncias. Assim, nasce a ideia de se estudar a possibilidade de prevenir os sintomas da esquizofrenia através do uso prévio do NPS, sendo esse um dos principais objetivos da tese de doutorado em questão.

Ainda, segundo Hallak et al. (2011), provavelmente, deva existir algum tipo de interação específica de um outro sistema de neurotransmissão com o sistema glutamatérgico descrito acima, e se trata do sistema dos receptores endocanabinoides (SRE). Esse autor, juntamente com seus colegas, descreve que estudar os efeitos do canabidiol (CBD), um canabinoide presente na planta Cannabis sativa, através de modelos animais de psicose com CET, poderia melhorar 
o conhecimento científico sobre a inter-relação entre os sistemas glutamatérgico e endocanabinoide, além de guiar estudos posteriores sobre a possível farmacoterapia do CBD para o tratamento da esquizofrenia (HALLAK et al., 2011).

\subsubsection{Fisiopatologia do modelo endocanabinoide}

O SRE no cérebro humano parece consistir de um mecanismo neuromodulatório complexo que possuiria um papel importante no desenvolvimento maturacional do SNC, na plasticidade sináptica e na resposta neurológica aos insultos endógenos e ambientais (JIANG et al., 2010; GAO et al., 2010). O SRE seria composto, basicamente, de receptores canabinoides, de canabinoides endógenos (endocanabinoides), e de enzimas responsáveis pela síntese e degradação dos endocanabinoides (LU; MACKIE, 2016).

Atualmente, acredita-se que os dois principais tipos de receptores canabinoides no organismo humano seriam o receptor canabinoide do tipo 1 (CB1) e o receptor canabinoide do tipo 2 (CB2) (HOWLETT et al., 2002). Os receptores CB1 seriam as estruturas mais abundantes no organismo humano e estariam localizados, principalmente, no SNC e periférico, mais especificamente, em regiões cerebrais como hipocampo, córtex, gânglios da base, cerebelo e medula espinhal. Já os receptores $\mathrm{CB} 2$ seriam encontrados também no sistema nervoso periférico, além do sistema imunológico (ZUARDI et al., 2012). Outros tipos de receptores canabinoides, que também estariam intimamente relacionados a esse sistema, seriam o receptor transitório potencial e o receptor ativado por proliferadores de peroxissomas (O'SULLIVAN, 2007).

Nesse sistema, acoplado aos receptores canabinoides, de maneira geral, existiriam estruturas conhecidas como endocanabinoides, que seriam lipídeos endógenos, os quais possuiriam a capacidade de interagir com o comportamento de maneira parecida aos efeitos produzidos pelo componente psicoativo da Cannabis sativa, conhecido como $\Delta$ 9-tetrahidrocanabinol (THC) (LU; MACKIE, 2016). A primeira descrição na literatura a respeito dos endocanabinoides presentes no cérebro humano, que também são conhecidos como ligantes endógenos de receptores canabinoides, versou sobre a descoberta da anandamida (araquidonoil etanolamida) e da 2-AG (2-araquidonoilglicerol), ambas realizadas na década de 1990 (DEVANE; AXELROD, 1994; MECHOULAM et al., 1995). Gonsiorek e 
colaboradores testaram a eficácia específica dos endocanabinoides 2-AG e evidenciaram que esse tipo de ligante endógeno aparentemente seria um agonista altamente eficaz de CB1 e de CB2 (GONSIOREK et al., 2000). Em contrapartida, a anandamida, outro tipo de lipídeo endógeno vinculado aos receptores canabinoides e já descrito acima, também foi amplamente testado por outro grupo de pesquisa que encontrou resultados em que havia sido possível inferir que esse parece ser um agonista completo de receptores CB1 e parcial de CB2 (LUK et al., 2004). Desse modo, em circuitos neuronais em que os níveis funcionais de receptores canabinoides são deficitários, bem como em sistemas em que esses receptores não apresentam potência necessária para estimular, de maneira adequada, trajetos neuronais, a anandamida poderia antagonizar os efeitos dos agonistas mais eficazes já conhecidos na literatura (MACKIE; DEVANE; HILLE, 1993).

Em suma, o SRE então seria formado de receptores canabinoides, e associados a esses receptores, os endocanabinoides propriamente ditos, além de determinadas enzimas que atuariam em sua biossíntese, como por exemplo, a lipase diacilglicerol, bem como outras que atuariam em sua degradação e, dessa vez, por esse mecanismo se teria a lipase monoacilglicerol e a amido hidrolase de ácidos graxos (AHAG) (GUPTA et al., 2014).

A ideia de se estudar o SRE na esquizofrenia surgiu por meio da observação de usuários de Cannabis que, eventualmente, em algum momento de suas vidas desenvolviam um quadro de psicose franca (SMIT; BOLIER; CUIJPERS, 2004). Observações descritas de acordo com o alto número de usuários dessa substância, levando a Cannabis a poder ser considerada como a droga ilícita mais utilizada na sociedade, sendo que a maioria de seus usuários a experimentou pela primeira vez ainda na adolescência (ZUARDI, 2006). É sabido também que existe altíssima associação entre uso dessa substância e o desenvolvimento de esquizofrenia, principalmente, quando utilizada durante a adolescência e a vida de adulto jovem, entretanto, apenas indivíduos que seriam vulneráveis geneticamente a essa substância é que desenvolveriam a doença (DONOGHUE et al., 2014). Teoricamente, os adolescentes estariam mais suscetíveis à ação de longo termo da Cannabis, porque nesse período os seus cérebros ainda estariam em uma fase de neurodesenvolvimento e, portanto, mais vulneráveis a esses insultos ambientais (MURRAY et al., 2017). 
Complementando as informações descritas acima, atualmente, é sabido que o consumo de Cannabis poderia induzir sintomas psicóticos em indivíduos normais e também poderia facilitar a predisposição ao desenvolvimento de esquizofrenia em pessoas vulneráveis geneticamente (ZUARDI et al., 2012).

O THC, que seria o principal constituinte da Cannabis, aparentemente deve ser o maior responsável pelos efeitos psicotomiméticos dessa planta e foi isolado, inicialmente, por Gaoni e Mechoulam na década de 1960 (GAONI; MECHOULAM, 1964). Estudos realizados com administração aguda de THC parecem evidenciar que esse canabinoide exógeno exerceria sua ação cerebral atuando como um potente agonista de receptores $\mathrm{CB} 1$, se ligando e, consequentemente, hiperestimulando esses receptores (D'SOUZA et al., 2012). O THC, então, exerceria certo tipo de influência ainda a ser investigada corretamente a respeito da liberação de neurotransmissores já sabidamente envolvidos com a patofisiologia da esquizofrenia, como a dopamina e o glutamato (MOUSLECH; VALLA, 2009; MATYAS et al., 2006). Vários estudos longitudinais realizados nas últimas décadas dão suporte a esse modelo fisiopatológico para a esquizofrenia, ou seja, o modelo dos receptores endocanabinoides (ZUARDI et al., 2011). Essa hipótese de pesquisa ganhou força após várias comprovações científicas provenientes de estudos de neuroimagem (WONG et al., 2010) e post mortem (DEAN et al., 2001), em que foi possível acreditar que uma aparente hiperatividade do SRE estaria relacionada ao desenvolvimento da esquizofrenia.

Dando seguimento à hipótese do SRE na esquizofrenia, é importante mencionar que outros canabinoides, porém dessa vez os endógenos também estariam relacionados ao desenvolvimento da doença. É o caso, por exemplo, da Anandamida, a qual estaria aumentada na esquizofrenia, o que pode ser comprovado por meio de vários estudos, os quais demonstraram que no líquor e no plasma, esse endocanabinoide estaria aumentado nos quadros agudos do transtorno, em pacientes que nunca usaram antipsicóticos e em pacientes em primeiro episódio, quando comparado com controles saudáveis (GIUFFRIDA et al., 2004). Entretanto, em indivíduos em estágios prodrômicos, níveis aumentados de anandamida estariam associados ao menor risco de conversão para a esquizofrenia, sugerindo que o aumento de anandamida deveria ser apenas compensatório, diante do contexto descrito (KOETHE et al., 2009). 
Atualmente, os níveis séricos de anandamida vêm sendo reconhecidos como parte de um grupo de novos tratamentos potenciais para a esquizofrenia. $O$ antagonismo de receptores CB1, os quais diminuiriam os níveis de anandamida, demonstram indícios de excelentes resultados na diminuição dos níveis de ansiedade, porém com respostas inconsistentes como agente antipsicótico (GUPTA et al., 2014). Assim, alternativamente, estudos sobre novas drogas, cujo foco de ação seria a potencialização dos níveis endógenos de anandamida, estariam evidenciando resultados excelentes, principalmente, em sintomas psicóticos em fases iniciais da esquizofrenia e, também, em modelos animais da doença (TZAVARA et al., 2006; ROSER; VOLLENWEIDER; KAWOHL, 2010). A anandamida, por si só, possui baixa biodisponibilidade, porém existem drogas, como - CBD e outras mais, que reduziriam sua desativação via inibição da AHAG, bloqueando sua recaptação dentro do neurônio (FOWLER, 2006). Por exemplo, em um estudo de 42 pacientes em fase aguda da esquizofrenia, o CBD mostrou eficácia comparada a amisulpirida para sintomas positivos e negativos da doença, porém com melhor tolerabilidade. De qualquer maneira, a melhora desses sintomas estaria correlacionada ao aumento da anandamida, sugerindo que o CBD poderia mediar seu efeito via inibição de AHAG (LEWEKE et al., 2012).

\subsubsection{Canabidiol}

O CBD seria o maior constituinte não psicotomimético da planta Cannabis sativa e seus eventuais efeitos terapêuticos estão sendo estudados pelos seus benefícios farmacológicos já bem estabelecidos em função da ausência, já devidamente esclarecida, dos efeitos psicotomiméticos do THC (ZUARDI et al., 1982). O CBD produziria um perfil dose-dependente complexo de efeitos farmacológicos como consequência aos vários mecanismos de ação como, por exemplo, o antagonismo não competitivo de receptores CB1, o agonismo inverso de receptores $\mathrm{CB} 2$, o bloqueio da captação da anandamida e a inibição da hidrólise enzimática do mesmo endocanabinoide (PERTWEE, 2008).

Desse modo, então, uma vez que o CBD, entre outras ações, além de bloquear a captação, inibiria a hidrólise enzimática de anandamida, seria interessante entender qual seria o resultado bioquímico dessas ações no SNC. Para responder a essa questão se deve lembrar, como já descrito acima, que a 
anandamida seria um ligante endógeno dos receptores CB1 e CB2, sintetizada sob demanda e liberada nas sinapses em que ativaria receptores CB1 com muito mais afinidade do que ativaria receptores CB2, indiretamente diminuindo a liberação de alguns neurotransmissores como glutamato, dopamina e ácido gama-aminobutírico (GABA). A anandamida também seria um importante agonista do receptor transitório potencial do tipo valinoide (TRPV), facilitando assim ainda mais, a liberação do neurotransmissor glutamato em determinadas regiões cerebrais (ALMEIDA et al., 2014).

Estudos recentes também vêm evidenciando que o CBD seria um agonista da atividade de receptores serotoninérgicos 5-HT1A e diminuiria a captação de adenosina $[3 \mathrm{H}]$ e estimularia os receptores TPV. Evidências científicas, em trabalhos animais, descrevem que o CBD provocaria seus efeitos por meio de uma curva dose-resposta ainda a ser desvendada, que estaria relacionada a determinadas dosagens específicas com consequentes respostas, as quais incluiriam efeitos ansiolíticos, antieméticos, neuroprotetores, anti-inflamatórios e sedativos (HALLAK et al., 2011). Já em humanos, esses mesmos estudos, como já foi mencionado, referem que o THC produziria vários sinais e sintomas que estariam associados com a esquizofrenia (D'SOUZA et al., 2004), enquanto que o CBD apresentaria apenas alguns efeitos comportamentais e de sedação em altas dosagens (ZUARDI; GUIMARÃES; MOREIRA, 1993). Entretanto, diversos trabalhos atuais vêm demonstrando o CBD como uma possiblidade inovadora para o tratamento da esquizofrenia. Zuardi e colaboradores referem que encontraram evidências preliminares nas quais o CBD pareceu ter potencializado a ação antipsicótica de drogas já bem estabelecidas para o tratamento da esquizofrenia (ZUARDI et al., 2006). Esse mesmo grupo de pesquisa, através de uma extensa revisão bibliográfica realizada em 2012, é unânime em afirmar que seus resultados demonstram que através de estudos pré-clínicos e clínicos, claramente, seria possível afirmar que o CBD pareceu ser capaz de melhorar sintomas psicóticos em dosagens que não comprometeriam o funcionamento motor dos pacientes, embora o mecanismo exato pelo qual o CBD exerceria esses efeitos ainda é incerto (ZUARDI et al., 2012).

Dentro desse contexto, no intuito de melhor elucidar esse tema se deve voltar ao conceito da esquizofrenia como um transtorno do neurodesenvolvimento, como mencionado no texto acima, e mais importante ainda, de que maneira os sistemas dopaminérgico, glutamatérgico e endocanabinoide se inter-relacionariam e, 
eventualmente, influenciariam o neurodesenvolvimento dos pacientes portadores de esquizofrenia.

\subsubsection{A hipótese neurodesenvolvimental na esquizofrenia}

A esquizofrenia, atualmente, deve ser encarada como um transtorno neurodesenvolvimental, ou seja, uma doença que afetaria o cérebro dos humanos durante os processos do desenvolvimento maturacional do encéfalo. Como definem Mueser e McGurk (2004), um transtorno cujo resultado clínico seria, provavelmente, proveniente da interação entre fatores genéticos e ambientais.

Dentro de um panorama histórico, desde a década de 1980, vários pesquisadores contribuíram para a denominação desse termo neurodesenvolvimental. Vale ressaltar que os primeiros e mais importantes, por conseguirem sistematizar os constructos que ajudaram a definir esse conceito, foram Feinberg (1982), Weinberger (1987) e Murray et al. (1991). Sendo Weinberger o primeiro autor a propor, formalmente, a tão conhecida atualmente "Hipótese neurodesenvolvimental para a esquizofrenia". Na linha desse raciocínio, principalmente nessa época, em que essa hipótese foi criada, essa possuía muito mais um caráter teórico do que uma formulação cientificamente comprovada através de marcadores biológicos. Ao longo da história dessa hipótese, outros estudiosos do tema, não menos importantes para o estudo desse conceito, que também acreditavam nessa doença como um transtorno neuroevolutivo e que corroboraram os pesquisadores citados acima, foram Lewis e Levitt (2002), Pilowsky, Kerwin e Murray (1993) e Waddington (1993).

Proporcionando embasamento científico a essa teoria, Cardno e seus colegas encontraram evidências que sugeriram que entre parentes em primeiro grau de paciente portadores de esquizofrenia, a chance de uma pessoa desenvolver a doença seria da ordem de $10 \%$, enquanto que entre gêmeos monozigóticos o risco passaria para 44\% (CARDNO et al., 1999). Entretanto, esses autores complementam interpretando os dados de seus resultados, inferindo que se a esquizofrenia fosse uma doença estritamente genética, gêmeos monozigóticos teriam concordância para o desenvolvimento do transtorno próximo a $100 \%$. Seguindo as mesmas ideias desses estudos, Andreasen refere que baseado nesses conceitos poderia se inferir que a esquizofrenia deveria ser encarada como uma 
doença multifatorial, a qual envolveria diversos genes e, muito provavelmente, genes diferentes em indivíduos distintos, além de parecer possuir grandes influências do meio ambiente (ANDREASEN, 1999).

De maneira teórica, vale ressaltar que é sabido que a psicose franca se iniciaria tipicamente ao final da adolescência ou no começo da vida adulta, por volta de 18 a 25 anos, época na qual algumas estruturas cerebrais, como por exemplo, o córtex pré-frontal ainda estariam em pleno desenvolvimento (INSEL, 2010). Apesar da psicose franca se iniciar nessa idade, vários estudos atuais vêm demonstrando que alterações cerebrais e genéticas em pacientes portadores de esquizofrenia apresentariam manifestações muito mais precoces (MURRAY et al., 2017).

Desse modo, segundo esses pesquisadores e alguns outros, a alteração mais crítica ocorreria durante os estágios finais do desenvolvimento cerebral, quando o cérebro realizaria uma revisão de suas conexões sinápticas e apresentaria seu crescimento final por volta dos 20 anos (MURRAY et al., 1991). Essas teorias ficaram conhecidas por mielinização, poda sináptica e o estabelecimento de conexões corticocorticais (WEINBERGER, 1987; FEINBERG, 1982; RANDALL, 1983). Diversos outros artigos corroboraram essas informações como, por exemplo, outro estudo de Andreasen, o qual refere que a substância ectópica, a qual seria formada por um agrupamento de neurônios, que não chegariam ao seu destino adequado durante o processo de migração neuronal para o córtex, seria mais frequente em pacientes portadores de esquizofrenia do que em pessoas saudáveis (ANDREASEN et al., 1999). Outro estudo seria o realizado por Crow, no qual ele postula que uma anomalia do desenvolvimento neuronal seria a assimetria cerebral, e que esta poderia ser uma aresta do desenvolvimento neocortical e que o alargamento ventricular tipicamente encontrado em pacientes com esquizofrenia seria secundária a essa, produzindo a doença (CROW,1997).

No que diz respeito aos descritos gatilhos ambientais, é importante compreender que esses pródromos, ou seja, esses precursores citados acima seriam sutis e não específicos, porém consistentes em demonstrar que a psicose não se iniciaria em um cérebro saudável, mas sim em um cérebro que já possuiria algum grau de comprometimento (WOODBERRY; GIULIANOL SEIDMAN, 2008). Essa afirmação se torna evidente, por exemplo, através de uma grande coorte realizada na Dinamarca com um follow-up de 45 anos, a qual evidenciou que adultos portadores de esquizofrenia possuiriam história positiva para atraso nos processos 
de maturação neuronal, previamente ao desenvolvimento de psicose franca (SORENSEN et al., 2010). Os dados provenientes desse estudo também são importantes por corroborar outros trabalhos prévios, que evidenciaram que o quociente intelectual (QI) de crianças, as quais mais tarde desenvolveriam a doença, estaria reduzido quando comparado com controles saudáveis (REICHENBERG et al., 2010). Esses fatores ambientais mencionados acima, também estariam relacionados aos eventos pré e perinatais, como por exemplo, má nutrição materna, infecções no segundo trimestre de gestação, distócias perinatais e exposição a citosinas, as quais consequentemente também aumentariam o risco do desenvolvimento de esquizofrenia (BROWN; DERKITS, 2010).

Assim, o modelo que se aplicaria mais adequadamente ao neurodesenvolvimental seria aquele no qual haveria algum tipo de insulto precoce pré, peri e/ou pós-natal, um longo período latente ao longo da maturação cerebral, até o início da psicose franca no final da adolescência ou começo da vida adulta. Corroborando essa teoria, segundo Insel, uma possibilidade seria que algum tipo de insulto neuronal precoce no período inicial da vida, o qual não se manifestaria até um período mais tardio do neurodesenvolvimento, começasse a provocar alterações de funcionamento bioquímico na neurotransmissão dos circuitos envolvidos com a doença (INSEL, 2010). Logicamente, em um ambiente no qual alterações biológicas compensatórias nesse processo de maturação neuronal ocorrem em organismos saudáveis e que seriam responsáveis por evitar a doença, não fossem suficientes para poder compensar essas lesões precoces iniciadas em períodos mais iniciais do desenvolvimento do cérebro.

Todo esse mecanismo, sistematizado por Insel (2010), foi previamente descrito na literatura, por Thompson e Levitt, os quais denominaram esse processo de "alostase do desenvolvimento" (THOMPSON; LEVITT, 2010). Corroborando a ideia central dessa teoria, outra possibilidade seria que algum tipo de lesão no processo de neurodesenvolvimento influenciaria determinado tipo de circuito ou processo cerebral. Por exemplo, o ajuste fino de sinapses inibitórias e excitatórias no córtex pré-frontal, as quais só dariam efeitos sutis nessa fase passassem a provocar alterações biológicas específicas quando uma espécie de balanço ou regulação mais precisa fosse necessário existir e que em função da doença não existisse. Por conseguinte, esse mecanismo no final da adolescência seria responsável por desencadear a doença propriamente dita (AYHAN et al., 2011). A figura abaixo (ver 
figura 3) ilustra a hipótese atual do modelo neurodesenvolvimental e as eventuais alterações cerebrais, que ocorreriam durante esse processo.

Figura 3 - O modelo neurodesenvolvimental da esquizofrenia. a) $O$ desenvolvimento cortical normal envolveria proliferação, migração, arborização (formação de circuitos) e mielinização, sendo os dois primeiros processos ocorrendo predominantemente durante o período pré-natal e os outros dois contínuos ao longo das duas décadas iniciais da vida. Os efeitos associados da poda da arborização neuronal e da deposição de mielina explicariam a redução progressiva do volume de substância cinzenta observada em estudos longitudinais de neuroimagem. Além dessas reduções globais observadas, alterações locais seriam muito mais complexas. Dados de cérebros humanos e não humanos indicariam aumento de sinapses inibitórias e diminuição de sinapses excitatórias ocorrendo no córtex pré-frontal de adolescentes e de adultos jovens, durante o período dos pródromos e início de psicose. b) A trajetória do desenvolvimento da esquizofrenia em crianças poderia incluir uma formação reduzida de vias inibitórias e poda excessiva de vias excitatórias, levando a um balanço excitatório-inibitório anormal no córtex pré-frontal. Mielinização reduzida também alteraria a conectividade. Embora dados atuais apoiem cada um desses possíveis mecanismos neurodesenvolvimentais para a esquizofrenia, nenhum foi provado como causador da síndrome. Detecção de alterações neurodesenvolvimentais prodrômicas poderiam permitir intervenções precoces com potencial prevenção de psicose

a)

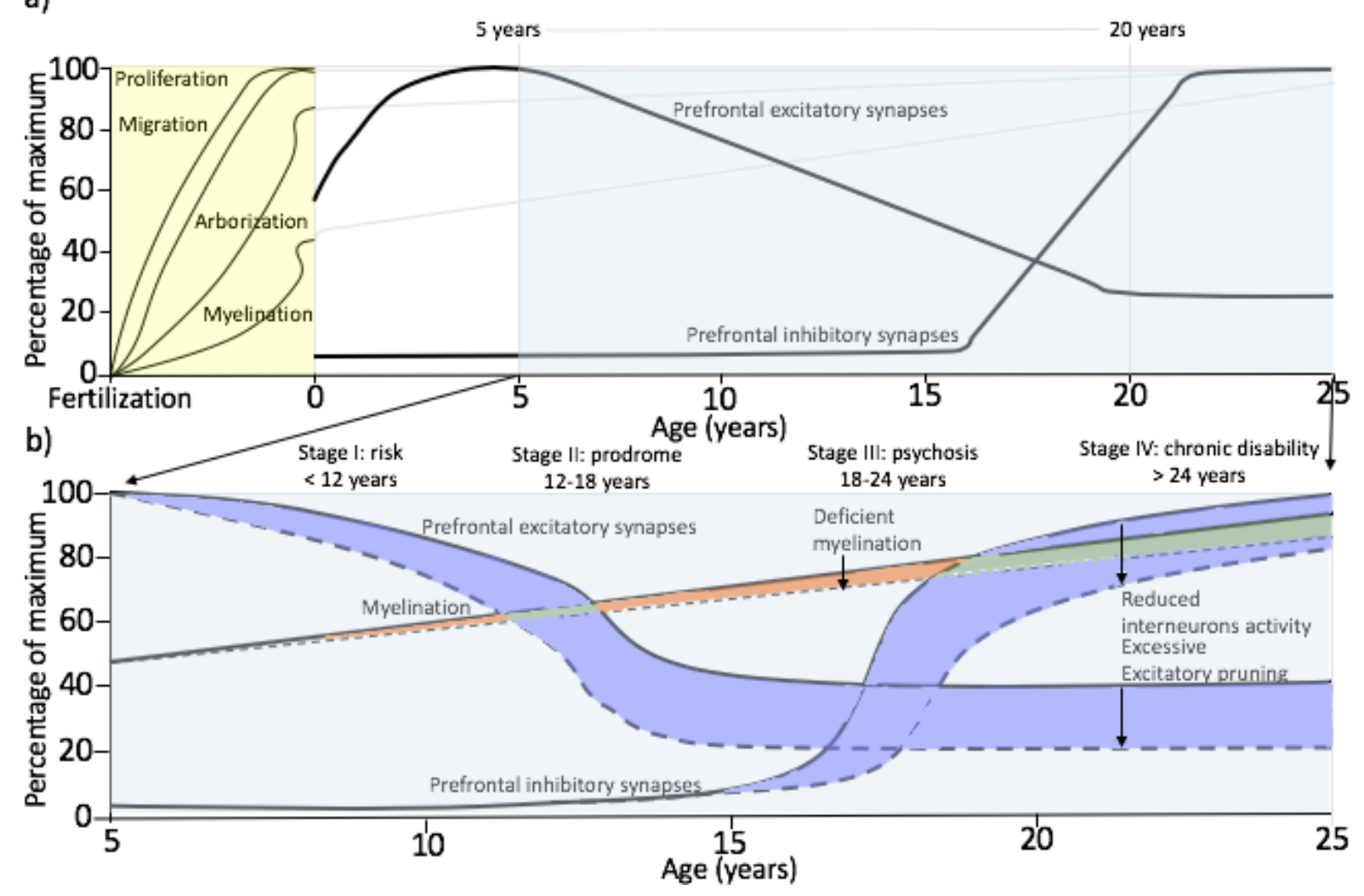

Fonte: Adaptado de Insel (2010).

De acordo com esses conceitos, os quais evidenciariam a esquizofrenia como uma doença que possuiria origem no processo do neurodesenvolvimento humano, seria muito interessante descobrir quais seriam os eventuais efeitos que determinadas substâncias poderiam exercer durante esses processos do desenvolvimento humano. Pontualmente, então, substâncias já evidentemente 
comprovadas pelo menos como possuidores de indícios de resultados no tratamento da esquizofrenia como, por exemplo, as que teriam a capacidade de interagir com os receptores NMDA nesse processo, eventualmente, poderiam trazer mais conhecimento acerca do desenvolvimento maturacional do cérebro humano. Não obstante, a ideia do grupo de trabalho da referida tese de doutorado em questão seria a de realizar um estudo através de um modelo animal de esquizofrenia, na qual o NPS, o qual já foi descrito como sendo um potente doador de ON, fosse utilizado durante o processo inicial da maturação cerebral de ratos, como uma espécie de tentativa de técnica imunizatória, a qual teria o objetivo de evitar o aparecimento da doença através da indução da mesma pelo uso da CET.

Dando mais embasamento científico ao referido estudo, é importante mencionar que, segundo pesquisas recentes, outra maneira de poder entender, de forma mais complexa, o sistema dos receptores NMDA, o qual também já possuiria mecanismo de neurotransmissão inter-relacionado ao sistema dopaminérgico descrito na literatura, seria estudar o papel dos receptores endocanabinoides no cérebro através do uso do CBD (HALLAK et al., 2011). Portanto, no mesmo modelo animal de esquizofrenia induzido por CET e descrito acima, outro ponto chave da ideia do departamento científico do mesmo grupo, também seria o da associação do uso do CBD isoladamente, e em associação ao NPS nesse mesmo estudo. 


\section{OBJETIVOS}

O objetivo principal do presente estudo foi o de testar os efeitos de doses repetidas de NPS e de CBD isoladamente e em associação, durante o processo de maturação cerebral de ratos, observando especificamente a possibilidade de eventual ausência do aparecimento de um quadro esquizofrenia like, previamente induzido através da administração de CET.

Secundariamente, o modelo animal de psicose com CET utilizado nesse projeto foi avaliado quanto a sua eficácia e viabilidade, e por fim, eventuais influências de gênero na análise dos resultados encontrados foram sistematicamente discutidas. 


\section{MATERIAIS E MÉTODOS}

\subsection{ANIMAIS}

Para a realização do estudo foram utilizados 128 ratos Wistar machos e fêmeas, divididos em 16 grupos específicos, descritos abaixo, com 12 dias de idade na época do início do protocolo experimental, pesando em média de $30 \mathrm{~g}$ nesse mesmo período e acompanhados de suas respectivas mães em função do fato de serem muito jovens. Optou-se por esse número de animais, pois de acordo com o procedimento experimental de Keilhoff e colaboradores, oito animais tratados com CET e oito animais tratados com salina fisiológica seriam suficientes para observação inequívoca de diferenças comportamentais e neuropatológicas entre os grupos do estudo (KEILHOFF et al., 2004).

Todos os animais do estudo foram provenientes do Biotério Central da Faculdade de Medicina de Ribeirão Preto (FMRP) da Universidade de São Paulo (USP). Considerando previamente a taxa de mortalidade dos ratos, após a injeção das drogas, se estimou uma necessidade adicional de $30 \%$ dos animais previstos, sendo então solicitado esse número sobressalente de animais ao Biotério Central.

Estes animais foram mantidos em caixas de polipropileno $(40 \times 33 \times 18 \mathrm{~cm})$ contendo raspas de madeira (maravalha) sobre o assoalho. Durante todo o período dos experimentos, os animais ficaram alojados em biotério com temperatura controlada em $25 \pm 2^{\circ} \mathrm{C}$ e, foram submetidos ao ciclo de 12 horas de claro e 12 horas de escuro com luzes acesas às $7 \mathrm{~h}$. Os ratos tiveram livre acesso à comida e água.

Todos os procedimentos foram realizados de acordo com as normas previstas pelo Conselho Nacional de Controle em Experimentação Animal (CONCEA), além de serem submetidos à avaliação prévia pela Comissão de Ética no Uso de Animais (CEUA) da FMRP da USP (CEUA 62/2016, Anexo A).

\subsection{DESENHO EXPERIMENTAL}

Para a realização do desenho experimental do estudo, os animais do trabalho foram subdivididos, por finalidade didática, em grupos experimentais segundo a figura abaixo (ver figura 4 ). 
Figura 4 - Esquema didático dos diferentes grupos experimentais do estudo. Solução Salina (SAL); Glicose a 5\% (GLI); Cetamina (CET); Nitroprussiato de Sódio (NPS); Canabidiol (CBD)

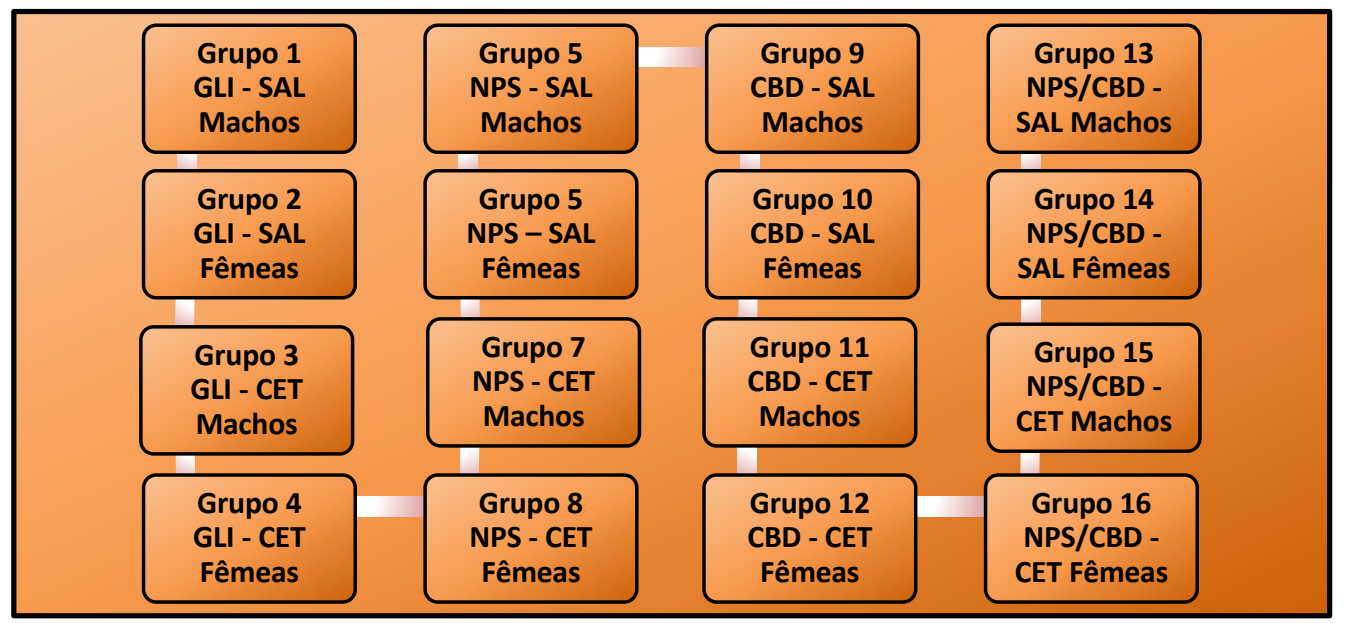

Fonte: Elaborado pelo autor.

A sequência de eventos ao longo do tempo que resume, de maneira sistemática, o protocolo do desenho experimental do estudo pode ser visualizado em detalhes, de acordo com a figura abaixo (ver figura 5).

Figura 5 - Desenho experimental da sequência de eventos de todas as etapas da pesquisa. Dias do nascimento (N); Intraperitoneal (IP); Glicose a 5\% (GLI); Nitroprussiato de Sódio (NPS); Canabidiol (CBD); Solução Salina (SAL); Cetamina (CET)

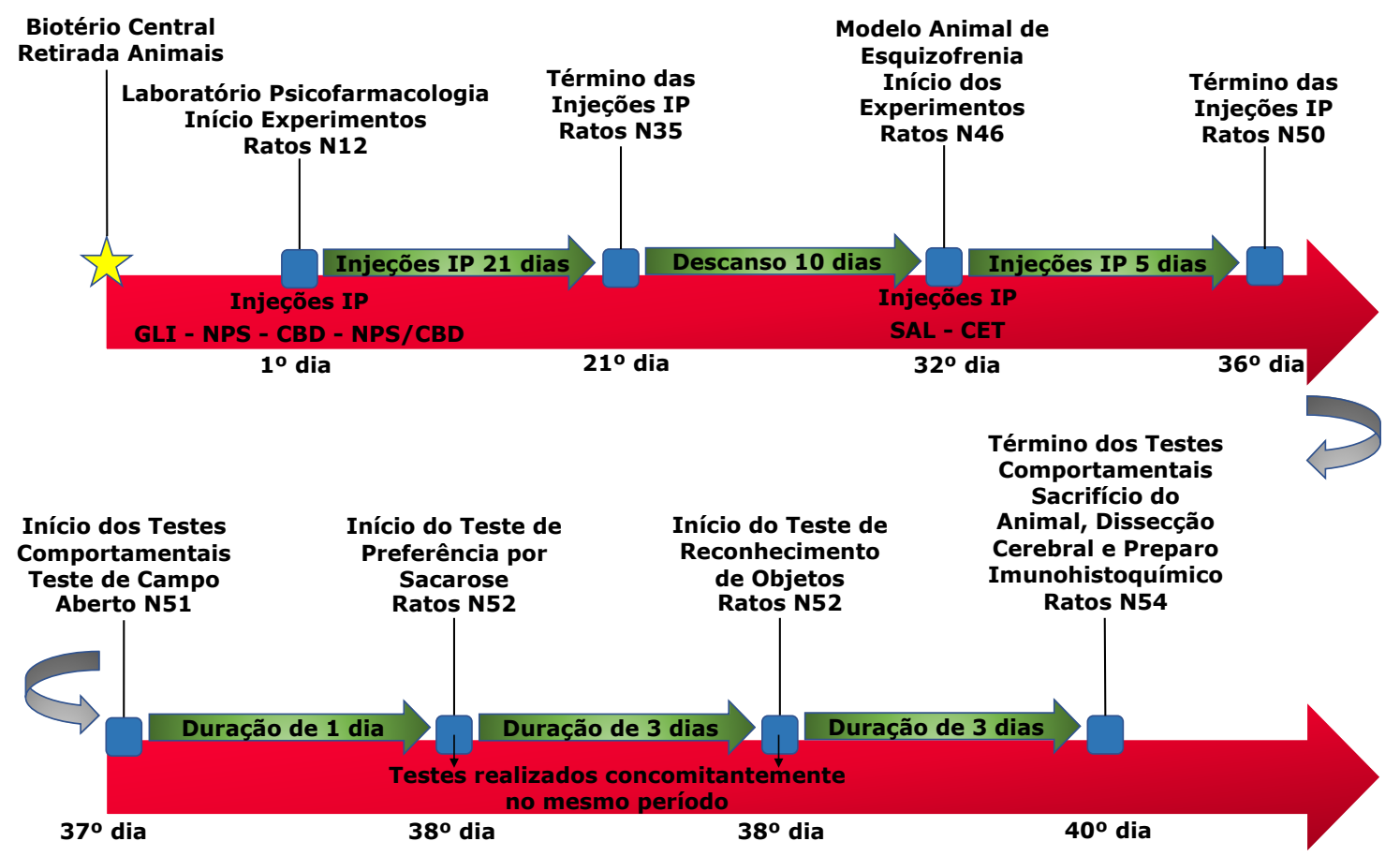

Fonte: Elaborado pelo autor. 


\subsection{PROTOCOLO DAS ETAPAS DO DESENHO EXPERIMENTAL REALIZADO NOS RATOS}

Nos dias predefinidos em que os experimentos com os animais do estudo foram realizados, o protocolo que segue descrito à frente foi minuciosamente cumprido por todos os pesquisadores envolvidos com a pesquisa. O protocolo consistiu em uma sequência de eventos em que todos os ratos dos diversos grupos do estudo foram removidos de suas jaulas, pesados e separados, individualmente, em uma caixa acrílica $(45 \times 35 \times 30 \mathrm{~cm})$. Os animais foram mantidos nessa área por uma hora para que pudessem ter tempo de se adaptarem ao novo local. Durante o ciclo de fotoperíodo com luz (entre $7 \mathrm{~h}$ e $14 \mathrm{~h}$ ), os ratos receberam as injeções intraperitoneais das diversas substâncias envolvidas com o estudo, ou seja, CBD, NPS, CBD + NPS ou glicose a 5\% (GLI). Imediatamente após a injeção, cada animal foi colocado no centro de um campo aberto e, então, foi observado por trinta minutos. Depois disso, o aparato foi limpo com solução de etanol a $5 \%$ e os ratos alocados randomicamente de volta em suas jaulas.

De acordo com o protocolo descrito acima, os animais do grupo, que foram submetidos ao NPS, receberam uma injeção intraperitoneal (IP) de NPS (Nitropruss $\AA$; Cristalia), sob a apresentação de pó liofilizado que foi diluído em solução glicosada (soro glicosado a $5 \%$ ) na dosagem de $2.5 \mathrm{mg} / \mathrm{kg}$ de peso corporal. Por se tratar de um estudo inédito, essa dosagem utilizada de NPS foi baseada em um estudo prévio de Bujas-Bobanovic et al. (2000). As administrações de NPS foram realizadas, diariamente, por 21 dias consecutivos, coincidentemente ao período de maturação cerebral de ratos, seguindo o desenho experimental criado de acordo com a experiência do grupo de pesquisa do autor do projeto.

Dando seguimento às sessões experimentais, os animais do grupo CBD receberam injeções IP de CBD em pó, com aproximadamente 99,9\% de pureza (BSPG-Pharm, Sandwich, Reino Unido), diluído em $2 \%$ de polisorbato 80 (Tween $®$ 80; Sigma-Aldrich, Darmstadt, Alemanha) e $98 \%$ de solução salina (cloreto de sódio a $0,9 \%$ ) na dosagem de $1 \mathrm{mg} / \mathrm{kg}$ de peso corporal. Essa dosagem foi baseada em um estudo prévio realizado por Levin et al. (2014). Seguindo o mesmo protocolo utilizado para o grupo NPS, as administrações de CBD também foram realizadas por 21 dias consecutivos. 
O grupo de animais, que recebeu o CBD associado ao NPS, seguiu estritamente o mesmo protocolo utilizado para o grupo CBD e para o grupo NPS, isoladamente. Os ratos do grupo controle receberam apenas injeção IP de solução glicosada a $5 \%$, também por 21 dias consecutivos.

\subsection{MODELO ANIMAL DE ESQUIZOFRENIA}

A CET, como já explicado anteriormente nesta tese de doutorado, seria um derivado do PCP que agiria como uma substância antagonista não competitiva de receptores NMDA, a qual seria capaz, em doses subanestésicas, de induzir sintomas positivos, negativos, e déficits cognitivos similares aos encontrados na esquizofrenia (FROHLICH; VAN HORN, 2014). Os efeitos psicotomiméticos da CET seriam transitórios, reversíveis e influenciados pelo tempo, dose e condições de administração (KEILHOFF et al., 2004). Farmacologicamente, a CET possuiria o desenho molecular do 2-(o-clorofenil)-2-(metilamino)-cicloexanona, e seria classificada como uma arilcicloalquilamina derivada da PCP com peso molecular de 238 daltons e pKa (operação matemática que permite calcular a acidez de uma solução) de 7,5 (OLIVEIRA et al., 2004). É comercialmente utilizada como uma mistura racêmica de dois isômeros opticamente ativos (enantiômeros), o $S(+)$ e o $R$ (-) associada aos conservantes cloreto de benzetônio e ao clorbutanol (KOHRS; DURIEUX, 1998). Trabalhos sobre modelos animais evidenciaram que a $S(+)$ CET possui aproximadamente quatro vezes mais afinidade para receptores NMDA do que a $\mathrm{R}(-) \mathrm{CET}$, e por esse motivo foi droga escolhida para os testes com os animais (PFENNINGER et al., 2002).

Dessa maneira, após 31 dias do início das injeções IP das substâncias (CBD, NPS, CBD + NPS e GLI) utilizadas no estudo e descritas acima, ou seja, quando os ratos atingiram 46 dias de idade, o protocolo de indução do modelo animal de esquizofrenia descrito no parágrafo acima foi realizado. Assim, todos os ratos dos diversos grupos do estudo foram, mais uma vez, removidos de suas jaulas, pesados e novamente separados, individualmente, em uma caixa acrílica (45 x 35 x $30 \mathrm{~cm}$ ). Eles também ficaram nessa área por uma hora para poderem ter tempo de se adaptarem aquele novo local. Durante o ciclo de fotoperíodo com luz (entre $7 \mathrm{~h}$ e $14 \mathrm{~h}$ ), os ratos receberam as injeções de CET. Imediatamente após as injeções, cada animal foi colocado no centro de um campo aberto e, então, foi observado por 30 
minutos. Depois disso, o aparato foi limpo com solução de etanol a $5 \%$ e os ratos alocados randomicamente.

Foram injetadas nos animais, doses diárias de $30 \mathrm{mg} / \mathrm{kg}$ de peso corporal de cloridrato de CET (Ketamin®; Cristalia) dissolvidos em $100 \mathrm{ml}$ de veículo estéril, por via IP durante cinco dias consecutivos. Essa dosagem foi baseada em um estudo prévio realizado por Nunes et al. (2012). Os animais do grupo controle receberam também por via IP, solução salina (cloreto de sódio 0,9\%) na dosagem de $10 \mathrm{ml} / \mathrm{kg}$ de peso corporal também no respectivo tempo de cinco dias consecutivos.

\subsection{PROTOCOLOS DE TESTES COMPORTAMENTAIS REALIZADOS}

\subsubsection{Teste de campo aberto: atividade locomotora e proporção de tempo no centro da arena}

O aparato utilizado no estudo para a realização do teste de "Campo Aberto" consistiu em uma arena quadrada $(46 \times 46 \mathrm{~cm}$ ), com piso branco e delimitada por paredes transparentes provenientes da empresa Insight $($ (Insight $\AA$, Ribeirão Preto, Brasil) (Ver figura 6). Esse equipamento possui sensores de movimento infravermelhos, que registram a locomoção, que pode ser compreendida pela distância e velocidade média, além de atividades não ambulatórias, ou seja, levantamento, que consiste em movimentos ascendentes ou com as patas dianteiras em contato com a parede ou independente. Os valores obtidos como resultados do teste foram calculados em blocos de quatro minutos ou no tempo total de registro de vinte minutos através do software da mesma empresa, denominado de "Open Source 6.01" (Insight $₫$, Ribeirão Preto, Brasil). A velocidade também foi medida e produziu resultados semelhantes (dados não mostrados) como aqueles encontrados para a distância. Ao término de cada teste, a arena foi devidamente limpa com água após cada animal ser submetido ao experimento. Determinadas mudanças nos padrões de locomoção em campo aberto, como hiperatividade (aumento da atividade locomotora vertical e horizontal) são comumente interpretadas como comportamentos psicóticos (SCHIORRING, 1979).

Por outro lado, medidas de comportamento de ansiedade incluem a proporção relativa de trajetória usada para explorar os quadrantes do centro, em relação àqueles localizados adjacentes às paredes da arena (BATH et al., 2012; 
SESTAKOVA et al., 2013). A arena de campo aberto foi dividida por linhas pretas em 64 quadrados de $5,75 \times 5,75 \mathrm{~cm}$. Os 16 quadrados centrais foram definidos como zona central e os 48 quadrados laterais como zona de borda. A proporção de tempo gasto nas bordas e centro do campo aberto foi estimada pelo programa "Image J®", baseado no perfil de trajetória de cada animal. Os sintomas de ansiedade têm sido há muito tempo definidos como uma característica central da esquizofrenia desde sua caracterização (TANDON; NASRALLAH; KESHAVAN, 2009). Os ratos foram colocados, inicialmente, no centro da arena e testados apenas uma vez na tarefa de campo aberto.

Figura 6 - a) Arena convencional utilizada na realização do teste de "Campo Aberto", para a avaliação da atividade locomotora. b) Exemplo de quantificação da atividade locomotora de um rato que recebeu injeção de cetamina $(30 \mathrm{mg} / \mathrm{kg}$ ) através do programa "Open Source 6.1" (Insight $₫$, Ribeirão Preto, Brasil). c) Exemplificação da proporção de tempo gasto nas bordas e no centro da arena, baseado no perfil de trajetória de cada animal estimado pelo programa "Image J®"

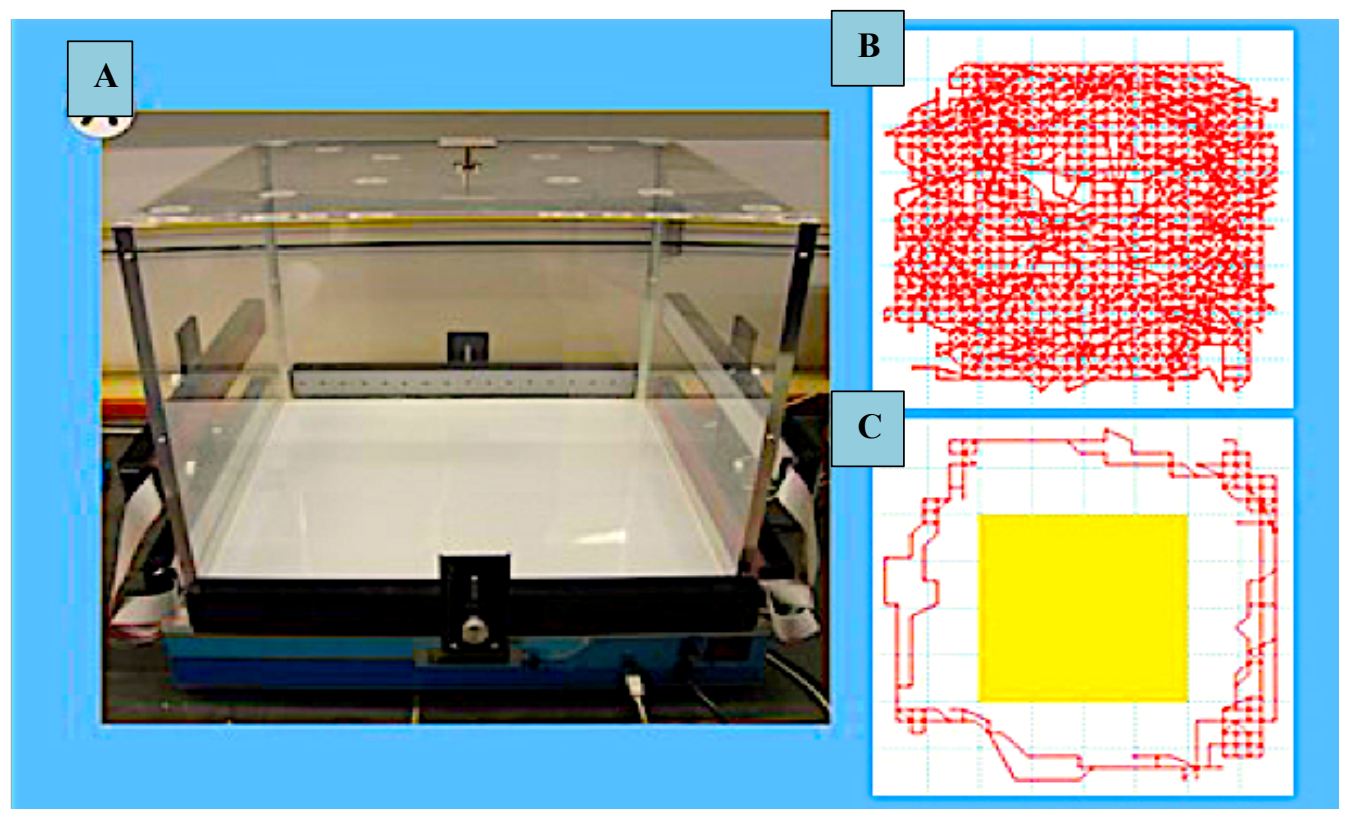

Fonte: Acervo digital do Departamento de Neurociências e Ciências do Comportamento da FMRP da USP.

\subsubsection{Teste de preferência por sacarose}

O teste de preferência por sacarose foi realizado por todos os animais dos grupos do estudo, seguindo estritamente o protocolo descrito a seguir: inicialmente, cada animal foi colocado em uma jaula específica (Ver figura 7) por 72 horas, com livre acesso a comida e com duas garrafas de água idênticas, que foram randomicamente inseridas na jaula e substituídas a cada 24 horas. Uma garrafa 
conteve $250 \mathrm{ml}$ de água deionizada e a outra $250 \mathrm{ml}$ também de água deionizada, porém a $1 \%$ de sucrose (Synth®, Diadema, Brasil).

O volume final de cada garrafa foi medido ao término das 24 horas, durante três dias consecutivos. A ingestão total dos fluidos ingeridos nas 72 horas foi analisada entre os diferentes grupos do estudo, por meio do teste de Kruskal-Wallis. Assim, a preferência por sucrose foi calculada através da proporção da ingestão de sucrose em comparação ao total de fluido ingerido e seus valores convertidos em porcentagem. Importante mencionar que um dos principais objetivos da realização do teste foi o de observar o quanto os animais se desinteressam pela solução açucarada, de certa forma, o quanto eles se tornaram anedônicos. É sabido que a Anedonia seria um importante sintoma depressivo, que poderia ser reconhecido em ratos que perderam a preferência por líquidos adocicados em comparação a água deionizada comum (MAZARATI et al., 2007). Na esquizofrenia, a anedonia é reconhecida como um importante sintoma que faria parte da dimensão afetiva do transtorno (TANDON; NASRALLAH; KESHAVAN, 2009).

Figura 7 - Exemplo de jaula habitualmente utilizada na realização do teste de "Preferência por Sacarose", para a avaliação de anedonia nos animais do estudo. a) Exemplo de um recipiente utilizado no teste, especificamente adaptado para a ingestão das soluções de água deionizada e açucarada. b) Jaula característica, já montada, com os recipientes prontos para o recebimento dos animais

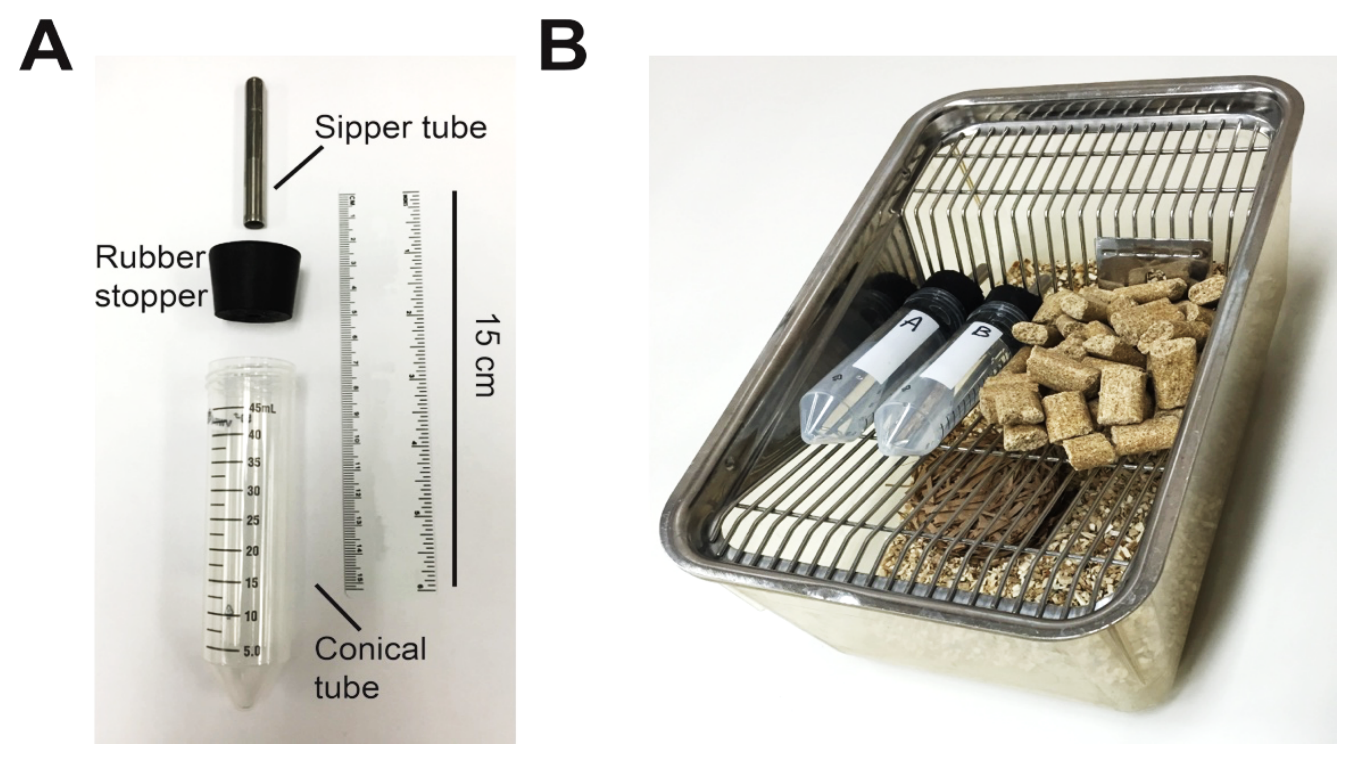

Fonte: Adaptado de Eagle et al. (2015). 


\subsubsection{Teste de reconhecimento de objetos}

O teste de "Reconhecimento de Objetos" permite que o animal gaste o maior tempo necessário explorando um objeto novo do que um objeto familiar e neste estudo foi realizado de acordo com os procedimentos descritos por Wiescholleck e Manahan-Vaughan (2012). Esse comportamento típico do animal permite a análise da memória declarativa de roedores (ENNAUCER; DELACOUR, 1988). No dia seguinte, após o término do teste de "Campo Aberto", os animais foram habituados durante 20 minutos a uma caixa de madeira com $46 \mathrm{~cm}$ de diâmetro e $24 \mathrm{~cm}$ de largura para a livre exploração do aparato utilizado no teste, na ausência de objetos. Após 24 horas da habituação, os animais foram colocados novamente na mesma caixa, com dois objetos idênticos: $A$ e $A$ (cubos mágicos) para a livre exploração deles por cinco minutos. Os objetos ficaram fixados nos cantos direito e esquerdo com fitas adesivas e sempre limpos com álcool $30^{\circ}$ após a realização de cada teste.

Para o comportamento exploratório foi definido: cheirar ou tocar os objetos com o focinho e com as patas anteriores. Desse modo, o paradigma experimental consistiu em uma fase de aquisição, ou seja, treino, e teste propriamente dito, separados por um intervalo de trinta minutos. Nesse caso, após o intervalo de descanso, o animal foi recolocado na caixa com o objeto familiar A e um objeto novo $\mathrm{B}$ (tubo) com o tempo de cinco minutos para a nova exploração do ambiente. No dia seguinte, após mais 24 horas do último teste, o animal foi recolocado mais uma vez na caixa com o mesmo objeto familiar A e outro objeto distinto $C$ (cone) com o mesmo tempo de cinco minutos para explorar novamente o ambiente. O tempo gasto explorando cada objeto (familiar ou novo) foi registrado em vídeo e quantificado manualmente. $O$ índice de reconhecimento foi calculado como porcentagem do tempo de exploração do objeto novo em relação ao tempo total de exploração para ambos os objetos. Esse índice foi utilizado para a comparação entre os grupos experimentais do estudo.

A tarefa de reconhecimento de um objeto novo seria sensível (prejudicada) aos distúrbios provocados por antagonistas de receptores NMDA, no caso a CET, apresentando altos valores preditivos já validados cientificamente, além de ser útil para a avaliação da disfunção cognitiva em modelos de esquizofrenia (NEIL et al., 2010). 
Figura 8 - a) Desenho do esquema didático para o protocolo do teste de "Reconhecimento de Objetos". (Imagem ilustrativa obtida do acervo digital do Departamento de Neurociências e Ciências do Comportamento da FMRP da USP). b) Imagem ilustrativa de um aparato contendo um objeto em forma de tubo (cor roxa), outro em forma de bola (cor vermelha) e um terceiro em forma de cone (cor verde), utilizado para a realização do teste de "Reconhecimento de Objetos"

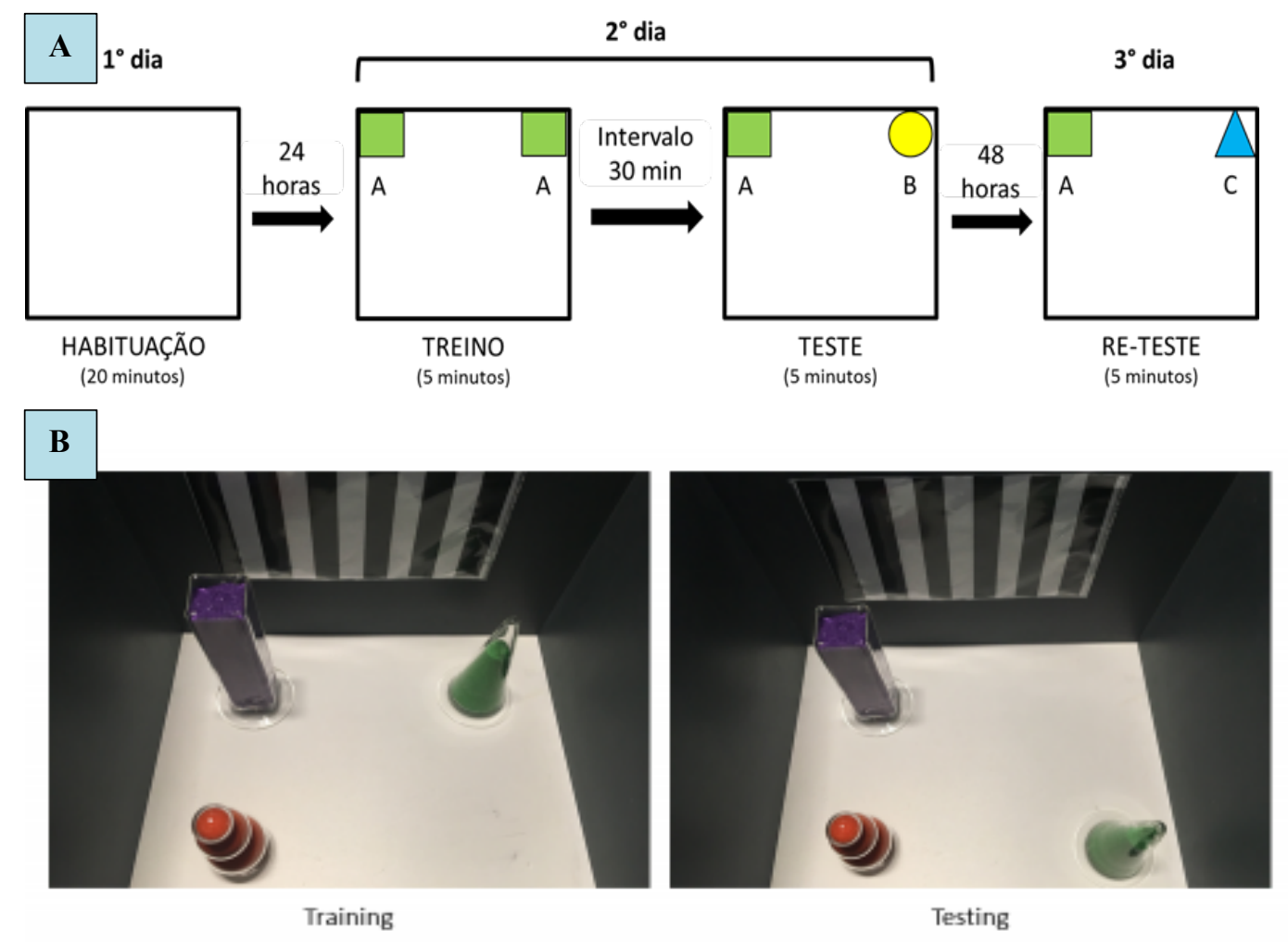

Fonte: Adaptado de NCBC (2019).

\subsection{PROCESSAMENTO DO TECIDO CEREBRAL}

No quarto dia, após os testes comportamentais, os animais foram profundamente anestesiados com tiopental sódico (30 mg/kg IP). A perfusão foi realizada via intracardíaca. Com o auxílio de uma agulha foi puncionado o ventrículo esquerdo do animal, em seguida, foi realizada uma incisão no átrio direito que permitiu a saída dos líquidos. Após a incisão no átrio direito foi infundida uma solução salina tamponada $0,9 \%$ no volume de $100 \mathrm{ml}$. A seguir uma solução de sulfeto de sódio $0,1 \%$ (150 a $200 \mathrm{ml}$ ) em salina tamponada foi infundida, seguida por paraformaldeído tamponado 4\% (150 a $200 \mathrm{ml})$. Após a perfusão, o cérebro foi removido da caixa óssea, com o auxílio de uma goiva, e colocado em solução de paraformaldeído tamponado a $4 \%$ por 4 horas. A seguir, os cérebros foram desidratados. A desidratação visa extração de água e sua substituição por um solvente orgânico adequado e, posterior inclusão em parafina. 
O tecido foi sucessivamente colocado em uma série de soluções com concentrações crescentes de álcool, iniciando com álcool $70 \%$ até álcool absoluto. Após esse passo, o tecido foi diafanizado em xilol e incluído em parafina. Os blocos em parafina foram cortados de forma seriada em fatias de $8 \mu \mathrm{m}$ de espessura, sendo as fatias montadas em lâminas gelatinizadas. Após a secagem, as lâminas foram escorridas em estufa a $60^{\circ} \mathrm{C}$ por duas horas e armazenadas para posterior realização da Imunohistoquímica de nNOS. Este protocolo já foi padronizado pelo "Laboratório de Investigação em Epilepsia" - HC-FMRP/USP.

\subsection{ANÁLISE ESTATÍSTICA DOS RESULTADOS}

O desenho estatístico utilizado nesta tese de doutorado foi constituído por variáveis contínuas paramétricas, assim, se tornou necessário uma avaliação específica a respeito da normalidade da amostra em questão. Portanto, para a avaliação dessas variáveis contínuas foram utilizados os testes de KolgomorovSmirnov e de Shapiro-Wilk, com o intuito de se testar a normalidade das amostras do estudo. Desse modo, variáveis contínuas normalmente distribuídas foram analisadas no estudo, através da realização de análises de variância (ANOVA) de uma via. Complementarmente, em alguns poucos testes isolados, variáveis nãoparamétricas foram avaliadas através do teste de Kruskal-Wallis.

Dando sequência para a descrição dos métodos estatísticos utilizados, posteriormente a realização dessas ANOVAs, o teste de Brown-Forsythe foi conduzido, tendo como propósito avaliar se as amostras das ANOVAs realizadas possuíam variâncias iguais, fato que proporcionou a validade do teste $F$, o qual também foi realizado.

Assim, com o teste de Brown-Forsythe devidamente confirmado se partiu para a realização do teste de Bartlett, o qual teve a mesma finalidade de avaliação da homocedasticidade da amostra descrita acima, ou seja, da homogeneidade de variâncias.

Após o término das ANOVAs, as quais identificaram se existia ou não diferenças entre os grupos, foram realizados os testes post hoc, por meio do método de múltiplas comparações, que por sua vez se denomina de teste de NewmanKeuls, que teve o objetivo de apontar as reais diferenças encontradas entre os níveis. 
Em todos os testes foi fixado em 0,05 ou $5 \%$ (alfa $<0,05$ ), o nível para rejeição da hipótese de nulidade. Para a realização desses testes foi utilizado o programa "GraphPad Prism® 8 versão 8.1.2" (GraphPad® Software, San Diego, EUA). 


\section{RESULTADOS}

\subsection{EXPERIMENTO DO TESTE DE CAMPO ABERTO: ATIVIDADE LOCOMOTORA}

\subsubsection{Distância total percorrida}

\subsubsection{Grupo de ratos machos - NPS}

Os resultados da ANOVA de uma via realizada no grupo descrito acima evidenciaram que houve diferenças estatisticamente significativas para 0 fator tratamento $(F[3,31]=6,191 ; p<0,002)$ (ver figura 9$)$. O teste post hoc de NewmanKeuls $(p<0,05)$ demonstrou que os animais do grupo GLI-CET apresentaram maiores distâncias totais percorridas do que o grupo GLI-SAL e do que o grupo NPS-SAL, mas não quando comparado com o grupo NPS-CET. As demais comparações entre os grupos não apresentaram outras diferenças significativas. 
Figura 9 - Representação gráfica da ANOVA $(F[3,31]=6,191 ; p<0,002)$, e do teste post hoc de Newman-Keuls $(p<0,05)$, realizado entre os grupos de ratos machos após o teste comportamental

de campo aberto: atividade locomotora - distância total percorrida. As barras coloridas foram reconstruídas pelas médias e erro padrão dos resultados, e representam os respectivos grupos do estudo, em que: GLI-SAL (cinza); GLI-CET (azul); NPS-SAL (vinho); NPS-CET (verde). Glicose a 5\%

(GLI); Solução Salina (SAL); Nitroprussiato de Sódio (NPS); Cetamina (CET) * (Resultado Estatisticamente Significativo).

\section{Distância Total Percorrida}

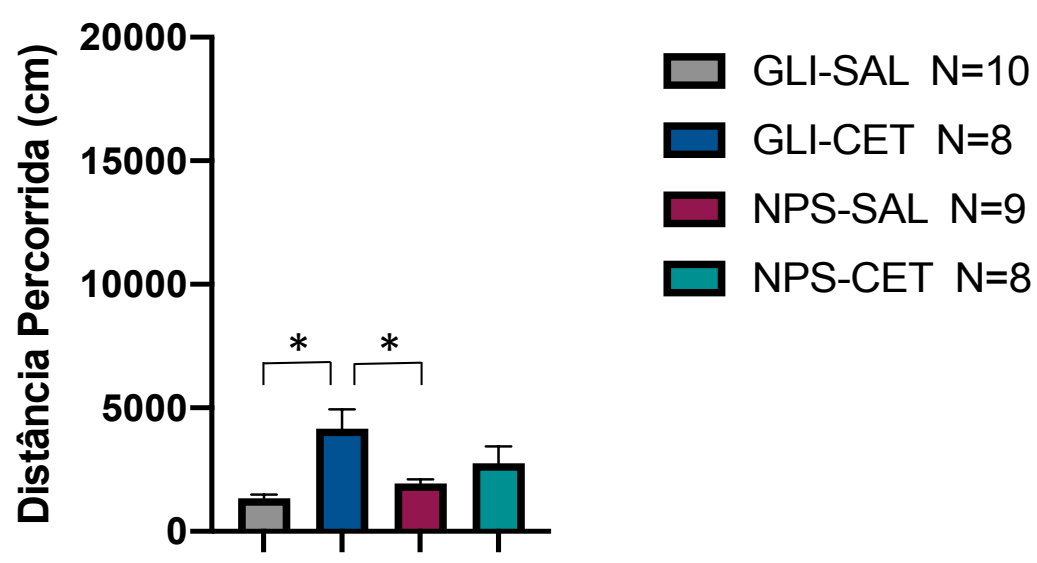

Grupos

Fonte: Elaborado pelo autor.

\subsubsection{Grupo de ratos fêmeas - NPS}

Os resultados da ANOVA de uma via realizada no grupo descrito acima evidenciaram que houve diferenças estatisticamente significativas para 0 fator tratamento $\left(F_{[3,32]}=21,410 ; p<0,001\right)$ (ver figura 10$)$. $O$ teste post hoc de NewmanKeuls $(p<0,05)$ demonstrou que os animais do grupo GLI-CET apresentaram maiores distâncias totais percorridas do que o grupo GLI-SAL, do que grupo NPSSAL e, também, do que o grupo NPS-CET. As demais comparações entre os grupos não apresentaram outras diferenças significativas. 
Figura 10 - Representação gráfica da ANOVA $(F[3,32]=21,410 ; p<0,001)$, e do teste post hoc de Newman-Keuls $(p<0,05)$, realizado entre os grupos de ratos fêmeas após o teste comportamental de campo aberto: atividade locomotora - distância total percorrida. As barras coloridas foram reconstruídas pelas médias e erro padrão dos resultados, e representam os respectivos grupos do estudo, em que: GLI-SAL (cinza); GLI-CET (azul); NPS-SAL (vinho); NPS-CET (verde). Glicose a 5\%

(GLI); Solução Salina (SAL); Nitroprussiato de Sódio (NPS); Cetamina (CET). * (Resultado Estatisticamente Significativo).

\section{Distância Total Percorrida}

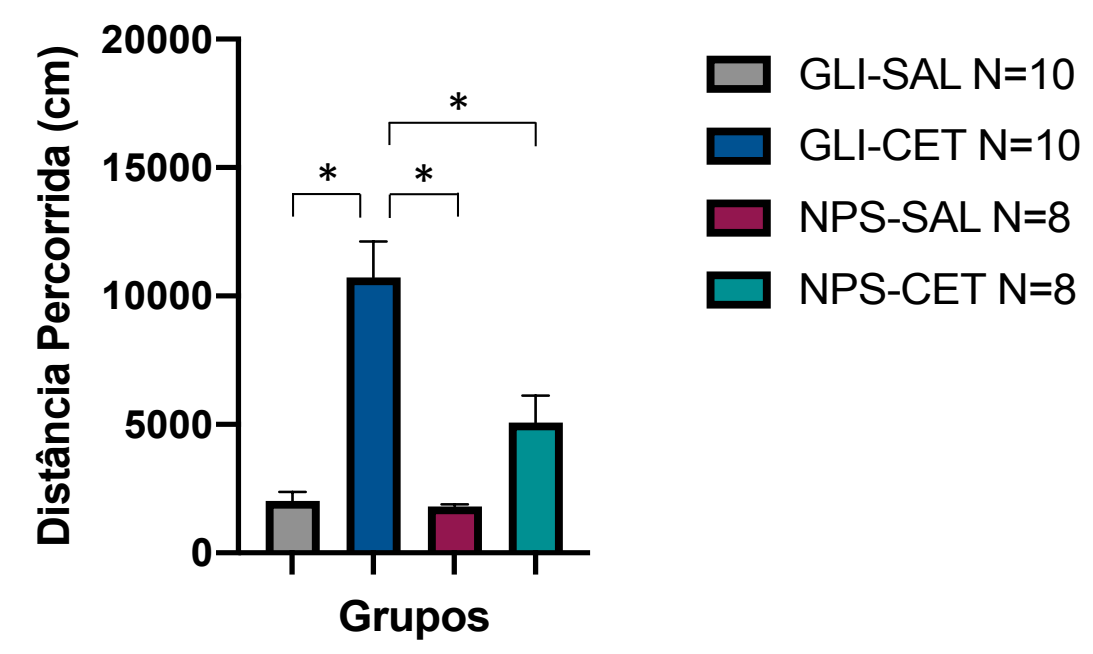

Fonte: Elaborado pelo autor.

\subsubsection{Grupos de ratos machos - CBD}

Os resultados da ANOVA de uma via realizada no grupo descrito acima evidenciaram que houve diferenças estatisticamente significativas para $\circ$ fator tratamento $(F[3,36]=6,314 ; p<0,001)$ (ver figura 11). $O$ teste post hoc de NewmanKeuls $(p<0,05)$ demonstrou que os animais do grupo GLI-CET apresentaram maiores distâncias totais percorridas do que o grupo GLI-SAL e do que o grupo CBD-SAL, mas não quando comparado com o grupo CBD-CET.

Estes resultados evidenciaram também que os animais do grupo CBD-CET apresentaram maiores distâncias totais percorridas do que o grupo GLI-SAL e do que o grupo CBD-SAL. As demais comparações entre os grupos não apresentaram outras diferenças significativas. 
Figura 11 - Representação gráfica da ANOVA $(F[3,36]=6,314 ; p<0,001)$, e do teste post hoc de Newman-Keuls $(p<0,05)$, realizado entre os grupos de ratos machos após o teste comportamental

de campo aberto: atividade locomotora - distância total percorrida. As barras coloridas foram reconstruídas pelas médias e erro padrão dos resultados, e representam os respectivos grupos do estudo, em que: GLI-SAL (cinza); GLI-CET (azul); CBD-SAL (vinho); CBD-CET (verde). Glicose a 5\%

(GLI); Solução Salina (SAL); Canabidiol (CBD); Cetamina (CET). * (Resultado Estatisticamente Significativo).

\section{Distância Total Percorrida}

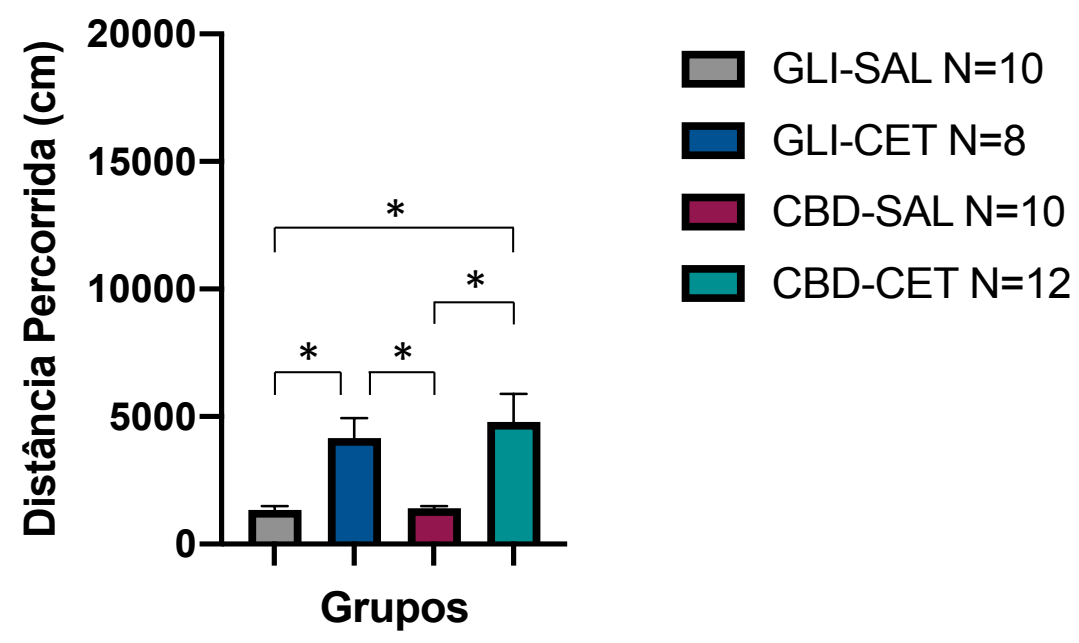

Fonte: Elaborado pelo autor.

\subsubsection{Grupos de ratos fêmeas - CBD}

Os resultados da ANOVA de uma via realizada no grupo descrito acima evidenciaram que houve diferenças estatisticamente significativas para $\circ$ fator tratamento $\left(F_{[3,37]}=24,040 ; p<0,001\right)$ (ver figura 12). $O$ teste post hoc de NewmanKeuls $(p<0,05)$ demonstrou que os animais do grupo GLI-CET apresentaram maiores distâncias totais percorridas do que o grupo GLI-SAL, do que o grupo CBDSAL e, também, do que o grupo CBD-CET. Estes resultados evidenciaram também que os animais do grupo CBD-CET apresentaram maiores distâncias totais percorridas do que o grupo GLI-SAL e do que o grupo CBD-SAL. As demais comparações entre os grupos não apresentaram outras diferenças significativas. 
Figura 12 - Representação gráfica da ANOVA $(F[3,37]=24,040 ; p<0,001)$, e do teste post hoc de Newman-Keuls $(p<0,05)$, realizado entre os grupos de ratos fêmeas após o teste comportamental de campo aberto: atividade locomotora - distância total percorrida. As barras coloridas foram reconstruídas pelas médias e erro padrão dos resultados, e representam os respectivos grupos do estudo, em que: GLI-SAL (cinza); GLI-CET (azul); CBD-SAL (vinho); CBD-CET (verde). Glicose a 5\%

(GLI); Solução Salina (SAL); Canabidiol (CBD); Cetamina (CET). * (Resultado Estatisticamente Significativo).

\section{Distância Total Percorrida}

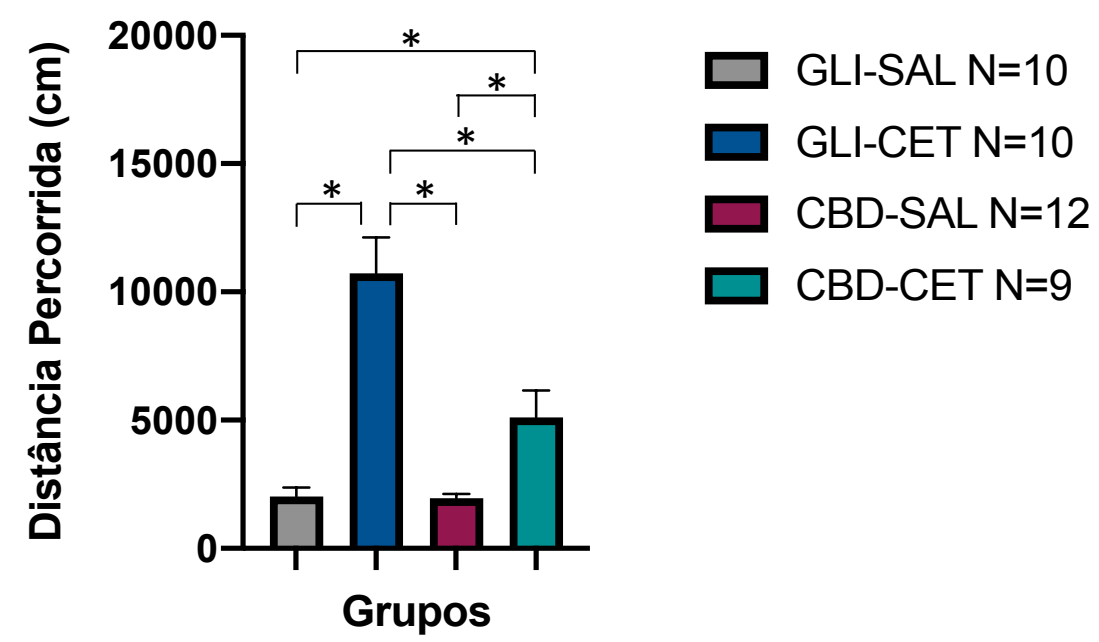

Fonte: Elaborado pelo autor.

\subsubsection{Grupos de ratos machos - NPS/CBD}

Os resultados da ANOVA de uma via realizada no grupo descrito acima evidenciaram que houve diferenças estatisticamente significativas para 0 fator tratamento $\left(F_{[3,32]}=9,451 ; p<0,001\right)$ (ver figura 13). O teste post hoc de NewmanKeuls $(p<0,05)$ demonstrou que os animais do grupo GLI-CET apresentaram maiores distâncias totais percorridas do que o grupo GLI-SAL, do que grupo NPS/CBD-SAL e, também, do que o grupo NPS/CBD-CET. Estes resultados evidenciaram também que os animais do grupo NPS/CBD-CET apresentaram maiores distâncias totais percorridas do que o grupo GLI-SAL. As demais comparações entre os grupos não apresentaram outras diferenças significativas. 
Figura 13 - Representação gráfica da ANOVA $(F[3,32]=9,451 ; p<0,001)$, e do teste post hoc de Newman-Keuls $(p<0,05)$, realizado entre os grupos de ratos machos, após o teste comportamental de campo aberto: atividade locomotora - distância total percorrida. As barras coloridas foram reconstruídas pelas médias e erro padrão dos resultados, e representam os respectivos grupos do estudo, em que: GLI-SAL (cinza); GLI-CET (azul); NPS/CBD-SAL (vinho); NPS/CBD-CET (verde).

Glicose a 5\% (GLI); Solução Salina (SAL); Nitroprussiato de Sódio (NPS); Canabidiol (CBD); Cetamina (CET). * (Resultado Estatisticamente Significativo)

\section{Distância Total Percorrida}

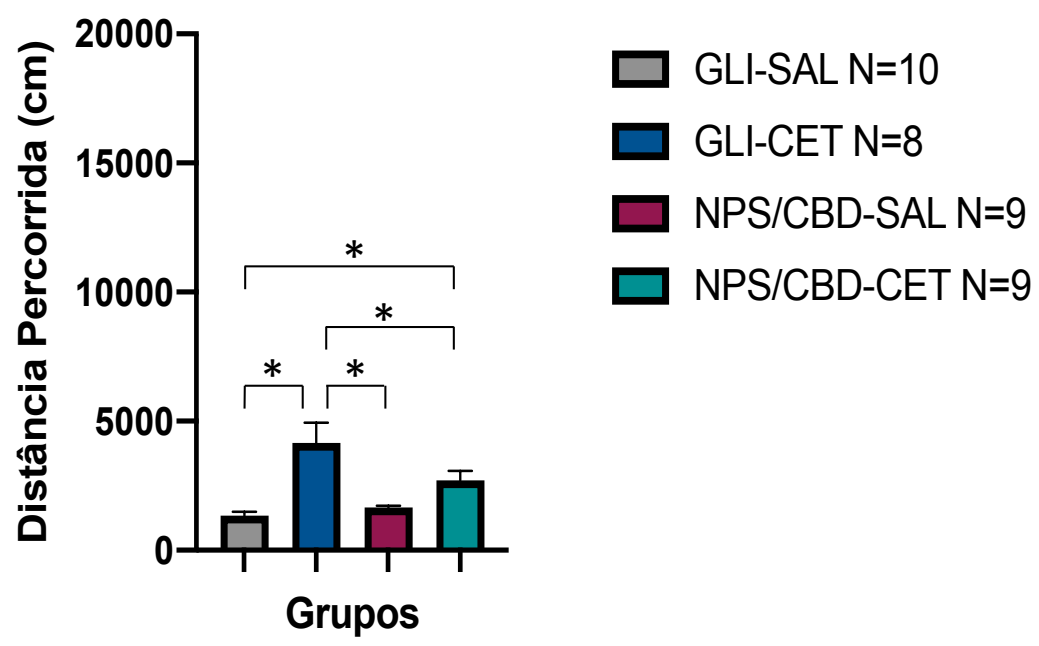

Fonte: Elaborado pelo autor.

\subsubsection{Grupos de ratos fêmeas - NPS/CBD}

Os resultados da ANOVA de uma via realizada no grupo descrito acima evidenciaram que houve diferenças estatisticamente significativas para 0 fator tratamento $\left(F_{[3,30]}=19,020 ; p<0,001\right)$ (ver figura 14). $O$ teste post hoc de NewmanKeuls $(p<0,05)$ demonstrou que os animais do grupo GLI-CET apresentaram maiores distâncias totais percorridas do que o grupo GLI-SAL, do que grupo NPS/CBD-SAL e, também, do que o grupo NPS/CBD-CET. O estudo evidenciou também que os animais do grupo NPS/CBD-CET apresentaram maiores distâncias totais percorridas do que o grupo GLI-SAL e do que o grupo NPS/CBD-SAL. As demais comparações entre os grupos não apresentaram outras diferenças significativas. 
Figura 14 - Representação gráfica da ANOVA $(F[3,30]=19,020 ; p<0,001)$, e do teste post hoc de Newman-Keuls $(p<0,05)$, realizado entre os grupos de ratos fêmeas, após o teste comportamental de campo aberto: atividade locomotora - distância total percorrida. As barras coloridas foram reconstruídas pelas médias e erro padrão dos resultados, e representam os respectivos grupos do estudo, em que: GLI-SAL (cinza); GLI-CET (azul); NPS/CBD-SAL (vinho); NPS/CBD-CET (verde).

Glicose a 5\% (GLI); Solução Salina (SAL); Nitroprussiato de Sódio (NPS); Canabidiol (CBD);

Cetamina (CET). * (Resultado Estatisticamente Significativo)

\section{Distância Total Percorrida}

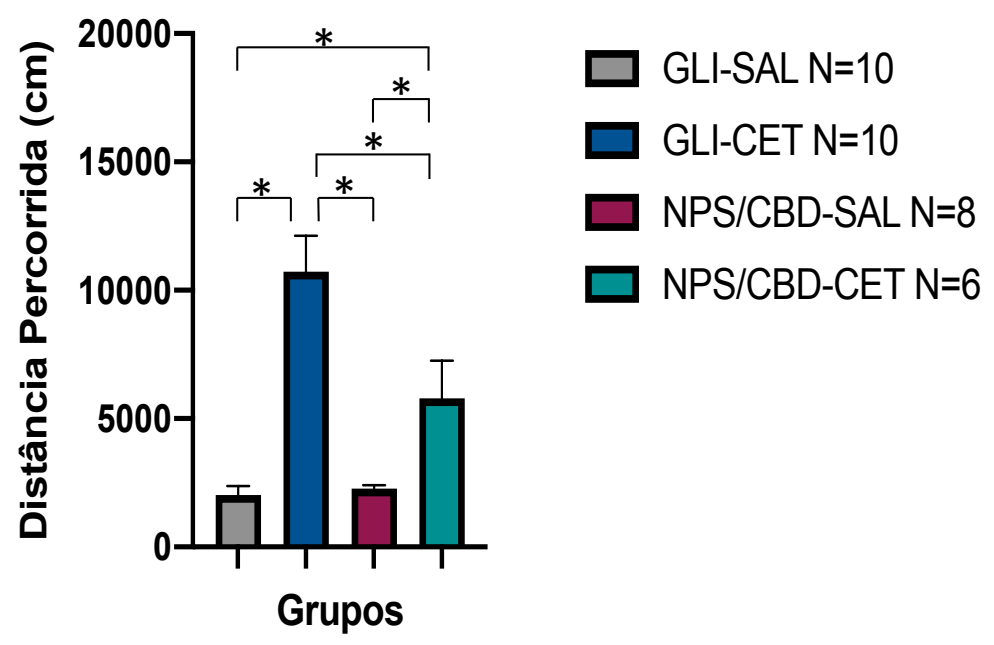

Fonte: Elaborado pelo autor.

\subsubsection{Proporção de tempo no centro da arena}

\subsubsection{Grupo de ratos machos - NPS}

Os resultados da ANOVA de uma via realizada no grupo descrito acima evidenciaram que houve diferenças estatisticamente significativas para $\circ$ fator tratamento $\left(F_{[3,31]}=2,824 ; p<0,054\right)$ (ver figura 15). Entretanto, o teste post hoc de Newman-Keuls $(p<0,05)$ demonstrou que essas diferenças estatísticas encontradas não eram, verdadeiramente, significativas. As demais comparações entre os grupos não apresentaram outras diferenças significativas. 
Figura 15 - Representação gráfica da ANOVA $(F[3,31]=2,824 ; p<0,054)$, e do teste post hoc de Newman-Keuls $(p<0,05)$, realizado entre os grupos de ratos machos após o teste comportamental de campo aberto: atividade locomotora - proporção de tempo no centro da arena. As barras coloridas foram reconstruídas pelas médias e erro padrão dos resultados, e representam os respectivos grupos do estudo, em que: GLI-SAL (cinza); GLI-CET (azul); NPS-SAL (vinho); NPS-CET (verde). Glicose a $5 \%$ (GLI); Solução Salina (SAL); Nitroprussiato de Sódio (NPS); Cetamina (CET)

\section{Proporção de Tempo no Centro da Arena}

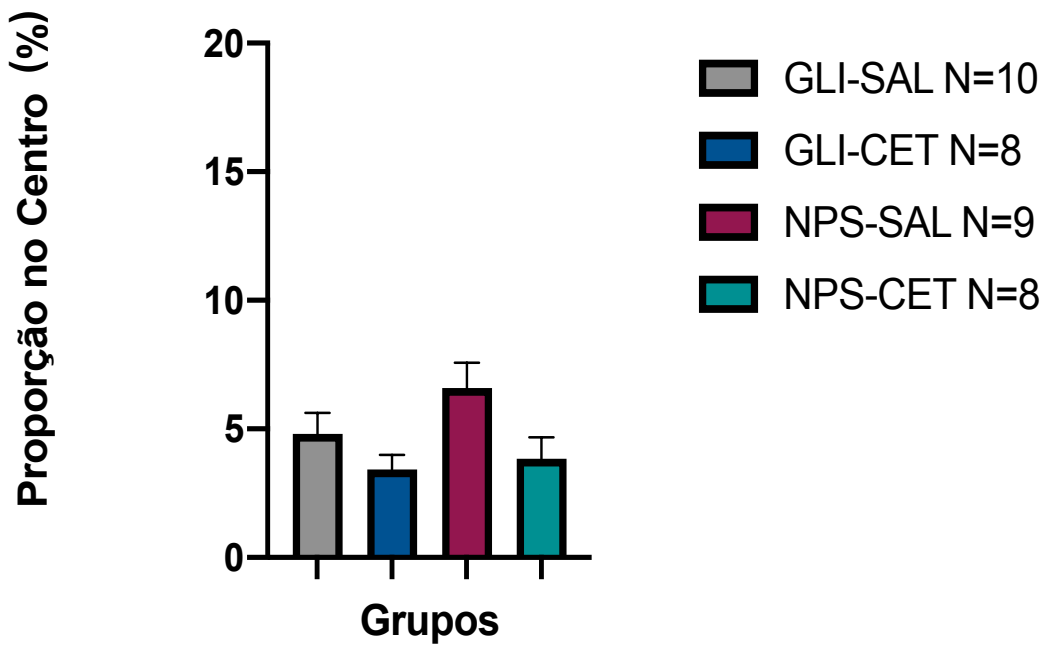

Fonte: Elaborado pelo autor.

\subsubsection{Grupo de ratos fêmeas - NPS}

Os resultados da ANOVA de uma via realizada no grupo descrito acima evidenciaram que houve diferenças estatisticamente significativas para 0 fator tratamento $\left(F_{[3,32]}=1,856 ; p<0,157\right)$ (ver figura 16). Entretanto, o teste post hoc de Newman-Keuls $(p<0,05)$ demonstrou que essas diferenças estatísticas encontradas não eram, verdadeiramente, significativas. As demais comparações entre os grupos não apresentaram outras diferenças significativas. 
Figura 16 - Representação gráfica da ANOVA $(F[3,32]=1,856 ; p<0,157)$, e do teste post hoc de Newman-Keuls $(p<0,05)$, realizado entre os grupos de ratos fêmeas após o teste comportamental de campo aberto: atividade locomotora - proporção de tempo no centro da arena. As barras coloridas foram reconstruídas pelas médias e erro padrão dos resultados, e representam os respectivos grupos do estudo, em que: GLI-SAL (cinza); GLI-CET (azul); NPS-SAL (vinho); NPS-CET (verde). Glicose a $5 \%$ (GLI); Solução Salina (SAL); Nitroprussiato de Sódio (NPS); Cetamina (CET)

\section{Proporção de Tempo no Centro da Arena}

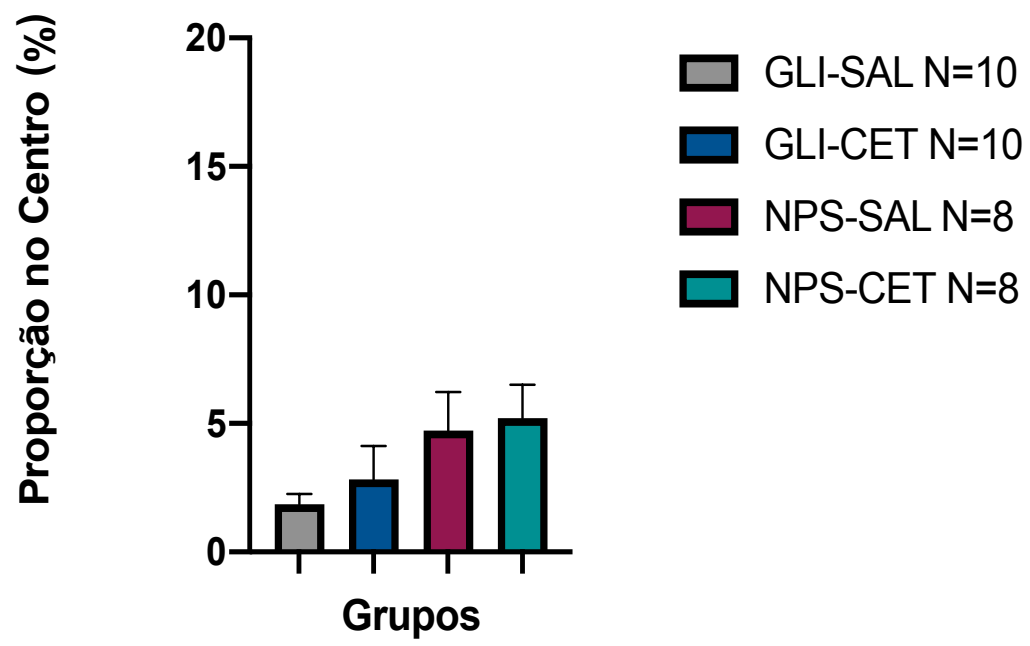

Fonte: Elaborado pelo autor.

\subsubsection{Grupo de ratos machos - CBD}

Os resultados da ANOVA de uma via realizada no grupo descrito acima evidenciaram que houve diferenças estatisticamente significativas para $\circ$ fator tratamento $(F[3,36]=5,211 ; p<0,004)$ (ver figura 17). O teste post hoc de NewmanKeuls $(p<0,05)$ demonstrou que os animais do grupo CBD-SAL apresentaram maiores proporções de tempo gasto no centro da arena do que o grupo GLI-SAL, do que grupo GLI-CET e, também, do que o grupo CBD-CET. As demais comparações entre os grupos não apresentaram outras diferenças significativas. 
Figura 17 - Representação gráfica da ANOVA $(F[3,36]=5,211 ; p<0,004)$, e do teste post hoc de Newman-Keuls $(p<0,05)$, realizado entre os grupos de ratos machos, após o teste comportamental de campo aberto: atividade locomotora - proporção de tempo no centro da arena. As barras coloridas foram reconstruídas pelas médias e erro padrão dos resultados, e representam os respectivos grupos do estudo, em que: GLI-SAL (cinza); GLI-CET (azul); CBD-SAL (vinho); CBD-CET (verde). Glicose a $5 \%$ (GLI); Solução Salina (SAL); Canabidiol (CBD); Cetamina (CET). * (Resultado Estatisticamente Significativo)

\section{Proporção de Tempo no Centro da Arena}

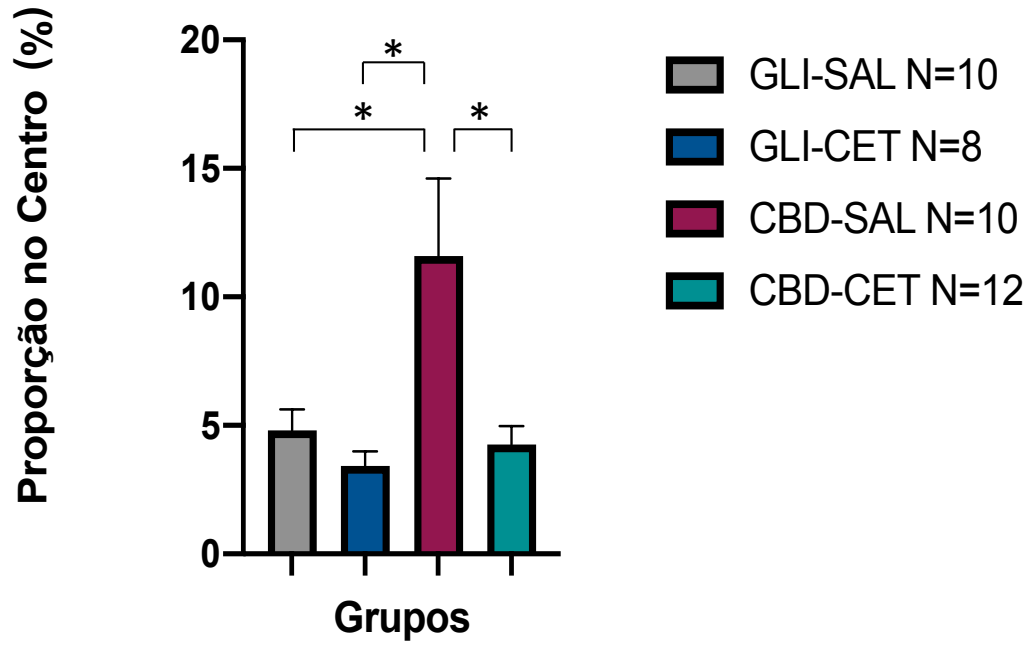

Fonte: Elaborado pelo autor.

\subsubsection{Grupo de ratos fêmeas - CBD}

Os resultados da ANOVA de uma via realizada no grupo descrito acima evidenciaram que houve diferenças estatisticamente significativas para 0 fator tratamento $(F[3,37]=2,714 ; p<0,058)$ (ver figura 18$)$. O teste post hoc de NewmanKeuls $(p<0,05)$ demonstrou que os animais do grupo CBD-SAL apresentaram maiores proporções de tempo gasto no centro da arena do que o grupo GLI-SAL. As demais comparações entre os grupos não apresentaram outras diferenças significativas. 
Figura 18 - Representação gráfica da ANOVA $(F[3,37]=2,714 ; p<0,058)$, e do teste post hoc de Newman-Keuls $(p<0,05)$, realizado entre os grupos de ratos fêmeas, após o teste comportamental de campo aberto: atividade locomotora - proporção de tempo no centro da arena. As barras coloridas foram reconstruídas pelas médias e erro padrão dos resultados, e representam os respectivos grupos do estudo, em que: GLI-SAL (cinza); GLI-CET (azul); CBD-SAL (vinho); CBD-CET (verde). Glicose a $5 \%$ (GLI); Solução Salina (SAL); Canabidiol (CBD); Cetamina (CET). * (Resultado Estatisticamente Significativo)

\section{Proporção de Tempo no Centro da Arena}

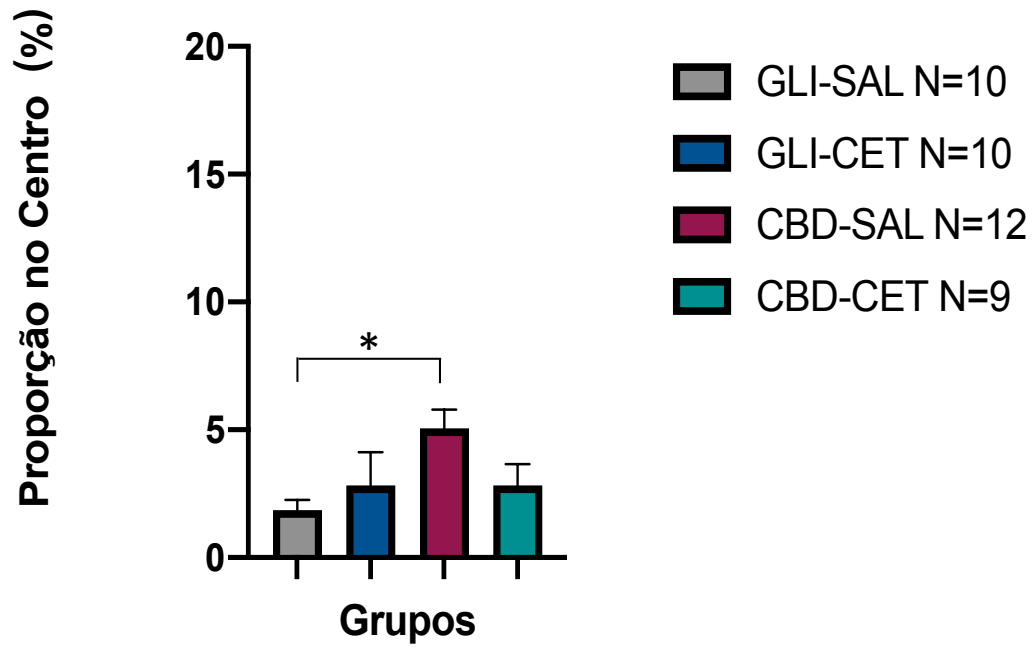

Fonte: Elaborado pelo autor.

\subsubsection{Grupo de ratos machos - NPS/CBD}

Os resultados da ANOVA de uma via realizada no grupo descrito acima evidenciaram que houve diferenças estatisticamente significativas para 0 fator tratamento $\left(F_{[3,32]}=1,540 ; p<0,223\right)$ (ver figura 19). Entretanto, o teste post hoc de Newman-Keuls $(p<0,05)$ demonstrou que essas diferenças estatísticas encontradas não eram, verdadeiramente, significativas. As demais comparações entre os grupos não apresentaram outras diferenças significativas. 
Figura 19 - Representação gráfica da ANOVA $(F[3,32]=1,540 ; p<0,223)$, e do teste post hoc de Newman-Keuls $(p<0,05)$, realizado entre os grupos de ratos machos após o teste comportamental de campo aberto: atividade locomotora - proporção de tempo no centro da arena. As barras coloridas foram reconstruídas pelas médias e erro padrão dos resultados, e representam os respectivos grupos do estudo, em que: GLI-SAL (cinza); GLI-CET (azul); NPS/CBD-SAL (vinho); NPS/CBD-CET (verde).

Glicose a 5\% (GLI); Solução Salina (SAL); Nitroprussiato de Sódio (NPS); Canabidiol (CBD);

Cetamina (CET)

\section{Proporção de Tempo no Centro da Arena}

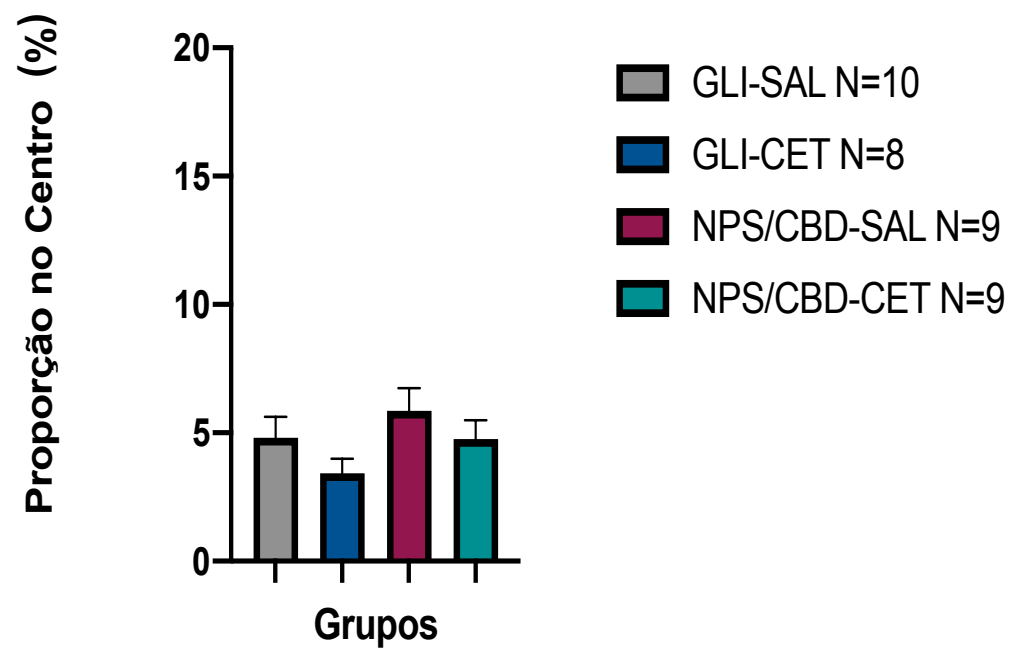

Fonte: Elaborado pelo autor.

\subsubsection{Grupo de ratos fêmeas - NPS/CBD}

Os resultados da ANOVA de uma via realizada no grupo descrito acima evidenciaram que houve diferenças estatisticamente significativas para 0 fator tratamento $\left(F_{[3,30]}=0,295 ; p<0,828\right)$ (ver figura 20$)$. Entretanto, o teste post hoc de Newman-Keuls $(p<0,05)$ demonstrou que essas diferenças estatísticas encontradas não eram, verdadeiramente, significativas. As demais comparações entre os grupos não apresentaram outras diferenças significativas. 
Figura 20 - Representação gráfica da ANOVA $(F[3,30]=0,295 ; p<0,828)$, e do teste post hoc de Newman-Keuls $(p<0,05)$, realizado entre os grupos de ratos machos após o teste comportamental de campo aberto: atividade locomotora - proporção de tempo no centro da arena. As barras coloridas foram reconstruídas pelas médias e erro padrão dos resultados, e representam os respectivos grupos do estudo, em que: GLI-SAL (cinza); GLI-CET (azul); NPS/CBD-SAL (vinho); NPS/CBD-CET (verde).

Glicose a 5\% (GLI); Solução Salina (SAL); Nitroprussiato de Sódio (NPS); Canabidiol (CBD);

Cetamina (CET)

\section{Proporção de Tempo no Centro da Arena}

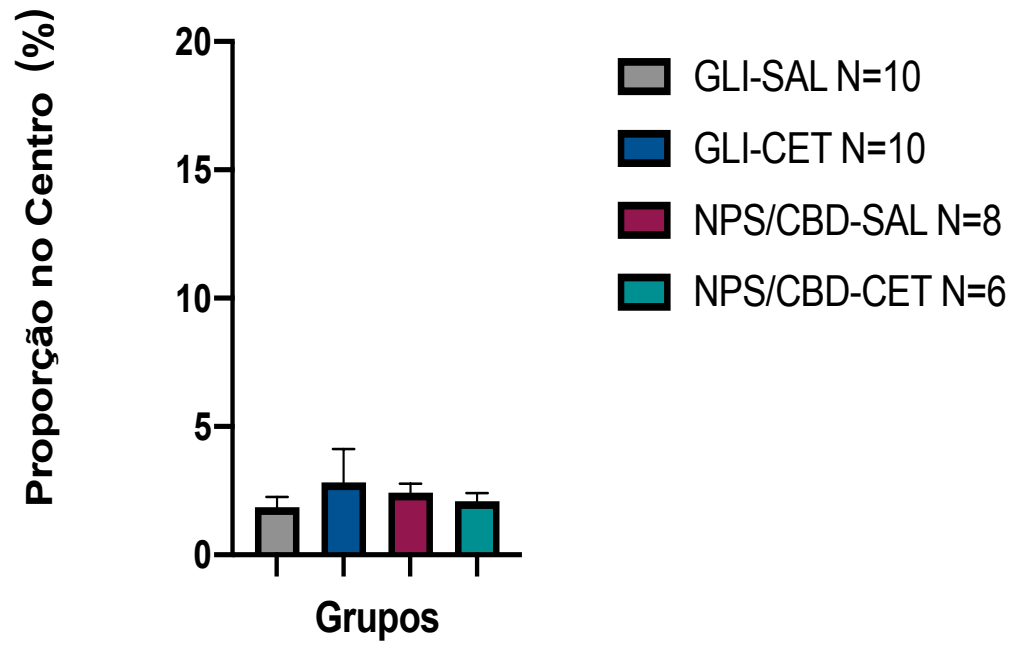

Fonte: Elaborado pelo autor.

\subsection{EXPERIMENTO DO TESTE DE PREFERÊNCIA POR SACAROSE}

\subsubsection{Grupo de ratos machos - NPS}

Os resultados da ANOVA de uma via realizada no grupo descrito acima evidenciaram que houve diferenças estatisticamente significativas para $\circ$ fator tratamento $(F[3,31]=6,530 ; p<0,001)$ (ver figura 21). $O$ teste post hoc de NewmanKeuls $(p<0,05)$ demonstrou que os animais do grupo GLI-SAL apresentaram maiores ingestões de sacarose do que o grupo GLI-CET, do que o grupo NPS-SAL e, também, do que o grupo NPS-CET. As demais comparações entre os grupos não apresentaram outras diferenças significativas. 
Figura 21 - Representação gráfica da ANOVA $(F[3,31]=6,530 ; p<0,001)$, e do teste post hoc de Newman-Keuls $(p<0,05)$, realizado entre os grupos de ratos machos após o teste comportamental de preferência por sacarose. As barras coloridas foram reconstruídas pelas médias e erro padrão dos resultados, e representam os respectivos grupos do estudo, em que: GLI-SAL (cinza); GLI-CET (azul); NPS-SAL (vinho); NPS-CET (verde). Glicose a 5\% (GLI); Solução Salina (SAL); Nitroprussiato de Sódio (NPS); Cetamina (CET). * (Resultado Estatisticamente Significativo)

\section{Teste de Preferência por Sacarose}

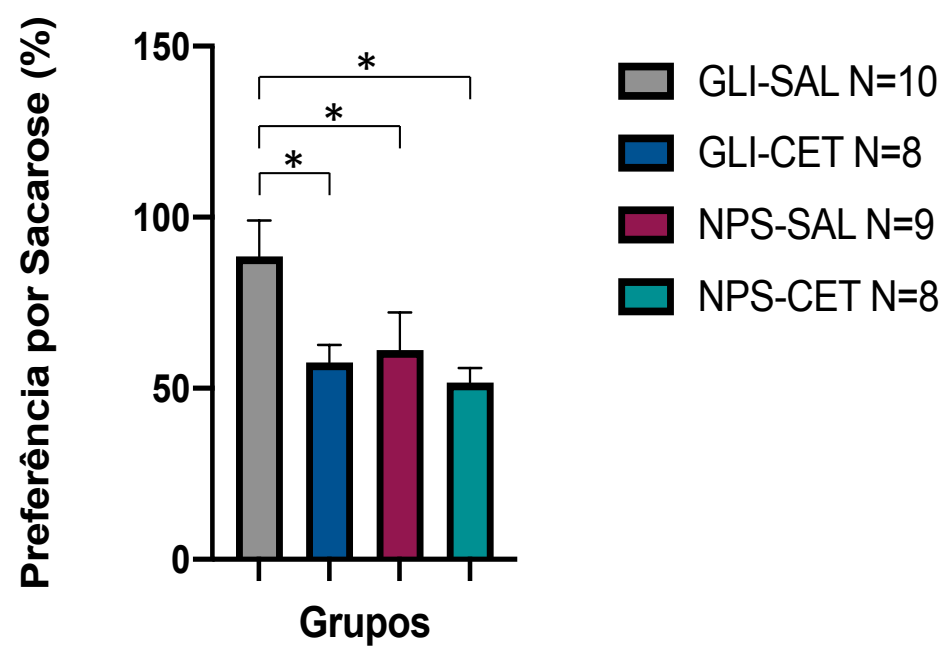

Fonte: Elaborado pelo autor.

\subsubsection{Grupo de ratos fêmeas - NPS}

Os resultados da ANOVA de uma via realizada no grupo descrito acima evidenciaram que houve diferenças estatisticamente significativas para $\circ$ fator tratamento $\left(F_{[3,32]}=8,597 ; p<0,001\right)$ (ver figura 22). $O$ teste post hoc de NewmanKeuls $(p<0,05)$ demonstrou que os animais do grupo GLI-SAL apresentaram maiores ingestões de sacarose do que o grupo NPS-SAL e do que o grupo NPSCET. Os resultados evidenciaram também que os animais do grupo GLI-CET apresentaram maiores ingestões de sacarose do que o grupo NPS-SAL e do que o grupo NPS-CET. As demais comparações entre os grupos não apresentaram outras diferenças significativas. 
Figura 22 - Representação gráfica da ANOVA $(F[3,32]=8,597 ; p<0,001)$, e do teste post hoc de Newman-Keuls $(p<0,05)$, realizado entre os grupos de ratos fêmeas após o teste comportamental de preferência por sacarose. As barras coloridas foram reconstruídas pelas médias e erro padrão dos resultados, e representam os respectivos grupos do estudo, em que: GLI-SAL (cinza); GLI-CET (azul); NPS-SAL (vinho); NPS-CET (verde). Glicose a 5\% (GLI); Solução Salina (SAL); Nitroprussiato de Sódio (NPS); Cetamina (CET). * (Resultado Estatisticamente Significativo)

\section{Teste de Preferência por Sacarose}

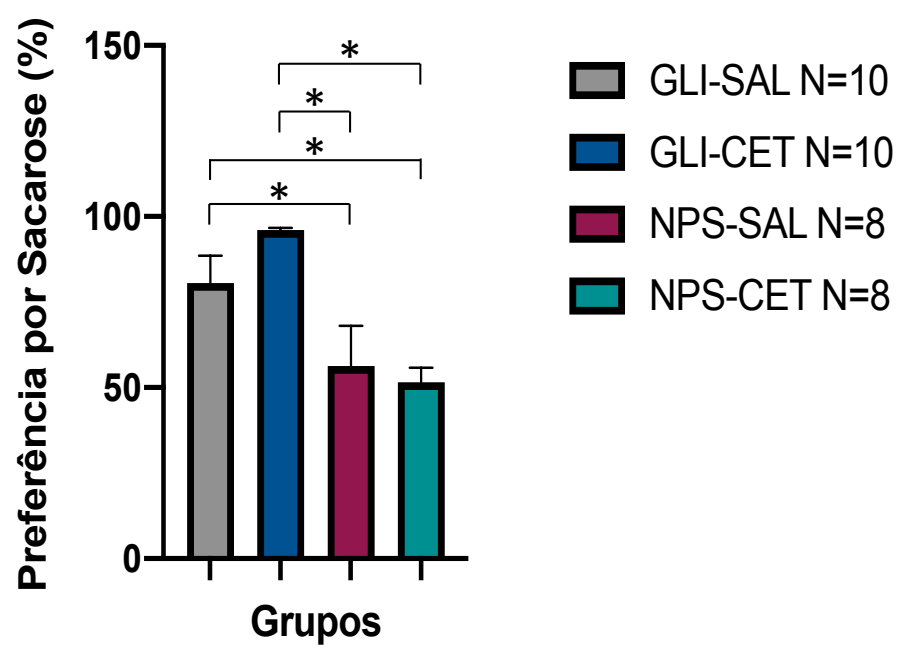

Fonte: Elaborado pelo autor.

\subsubsection{Grupo de ratos machos - CBD}

Os resultados da ANOVA de uma via realizada no grupo descrito acima evidenciaram que houve diferenças estatisticamente significativas para 0 fator tratamento $\left(F_{[3,36]}=2,773 ; p<0,055\right)$ (ver figura 23). Entretanto, o teste post hoc de Newman-Keuls $(p<0,05)$ demonstrou que essas diferenças estatísticas encontradas não eram, verdadeiramente, significativas. As demais comparações entre os grupos não apresentaram outras diferenças significativas. 
Figura 23 - Representação gráfica da ANOVA $(F[3,36]=2,773 ; p<0,055)$, e do teste post hoc de Newman-Keuls $(p<0,05)$, realizado entre os grupos de ratos machos após o teste comportamental de preferência por sacarose. As barras coloridas foram reconstruídas pelas médias e erro padrão dos resultados, e representam os respectivos grupos do estudo, em que: GLI-SAL (cinza); GLI-CET (azul); CBD-SAL (vinho); CBD-CET (verde). Glicose a 5\% (GLI); Solução Salina (SAL); Canabidiol (CBD); Cetamina (CET)

\section{Teste de Preferência por Sacarose}

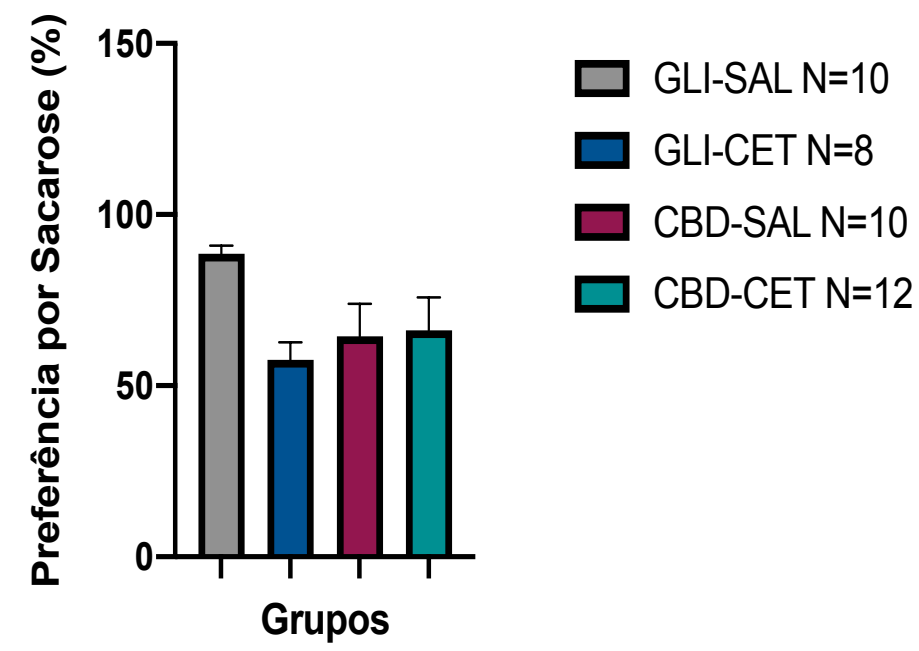

Fonte: Elaborado pelo autor.

\subsubsection{Grupo de ratos fêmeas - CBD}

Os resultados da ANOVA de uma via realizada no grupo descrito acima evidenciaram que houve diferenças estatisticamente significativas para o fator tratamento $(F[3,37]=7,317 ; p<0,001)$ (ver figura 24). O teste post hoc de NewmanKeuls $(p<0,05)$ demonstrou que os animais do grupo GLI-SAL apresentaram maiores ingestões de sacarose do que o grupo CBD-CET. Os resultados evidenciaram também que animais do grupo GLI-CET apresentaram maiores ingestões de sacarose do que o grupo CBD-SAL e do que o grupo CBD-CET. As demais comparações entre os grupos não apresentaram outras diferenças significativas. 
Figura 24 - Representação gráfica da ANOVA $(F[3,37]=7,317 ; p<0,001)$, e do teste post hoc de Newman-Keuls $(p<0,05)$, realizado entre os grupos de ratos fêmeas após o teste comportamental de preferência por sacarose. As barras coloridas foram reconstruídas pelas médias e erro padrão dos resultados, e representam os respectivos grupos do estudo, em que: GLI-SAL (cinza); GLI-CET (azul); CBD-SAL (vinho); CBD-CET (verde). Glicose a 5\% (GLI); Solução Salina (SAL); Canabidiol (CBD); Cetamina (CET). * (Resultado Estatisticamente Significativo)

\section{Teste de Preferência por Sacarose}

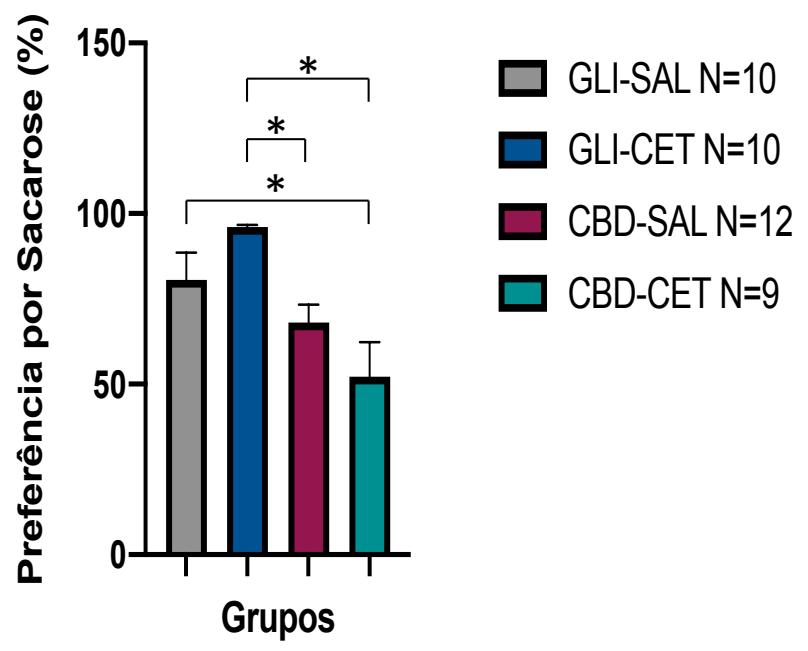

Fonte: Elaborado pelo autor.

\subsubsection{Grupo de ratos machos - NPS/CBD}

Os resultados da ANOVA de uma via realizada no grupo descrito acima evidenciaram que houve diferenças estatisticamente significativas para o fator tratamento $\left(F_{[3,32]}=4,077 ; p<0,014\right)$ (ver figura 25$)$. O teste post hoc de NewmanKeuls $(p<0,05)$ demonstrou que os animais do grupo GLI-SAL apresentaram maiores ingestões de sacarose do que o grupo GLI-CET e do que o grupo NPS/CBD-CET. As demais comparações entre os grupos não apresentaram outras diferenças significativas. 
Figura 25 - Representação gráfica da ANOVA $(F[3,32]=4,077 ; p<0,014)$, e do teste post hoc de Newman-Keuls $(p<0,05)$, realizado entre os grupos de ratos machos após o teste comportamental de preferência por sacarose. As barras coloridas foram reconstruídas pelas médias e erro padrão dos resultados, e representam os respectivos grupos do estudo, em que: GLI-SAL (cinza); GLI-CET (azul); NPS/CBD-SAL (vinho); NPS/CBD-CET (verde). Glicose a 5\% (GLI); Solução Salina (SAL); Nitroprussiato de Sódio (NPS); Canabidiol (CBD); Cetamina (CET). * (Resultado Estatisticamente Significativo)

\section{Teste de Preferência por Sacarose}

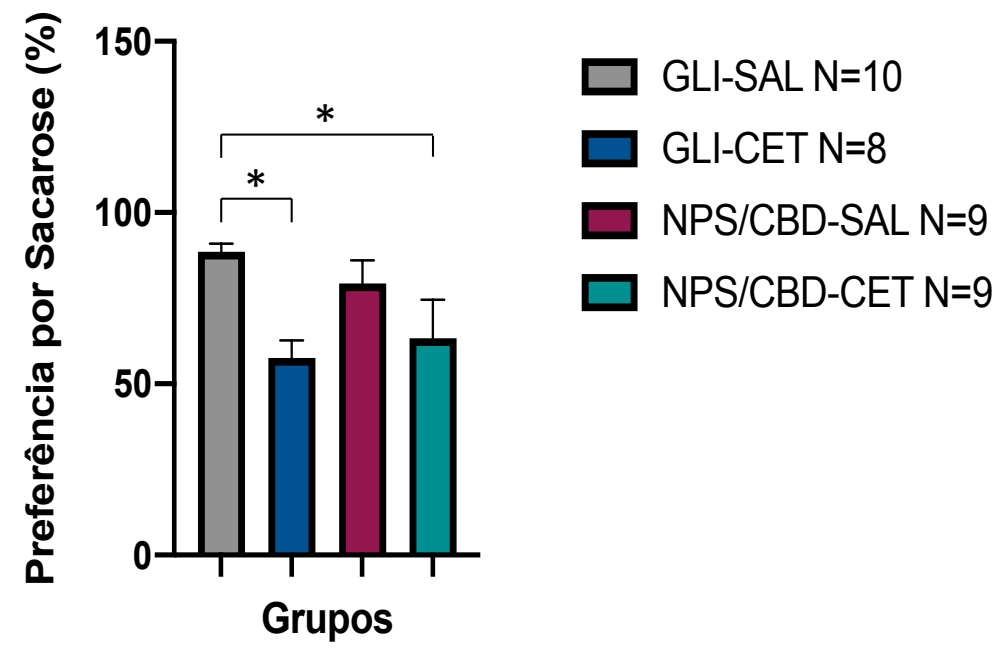

Fonte: Elaborado pelo autor.

\subsubsection{Grupo de ratos fêmeas - NPS/CBD}

Os resultados da ANOVA de uma via realizada no grupo descrito acima evidenciaram que houve diferenças estatisticamente significativas para 0 fator tratamento $\left(F_{[3,30]}=4,371 ; p<0,011\right)$ (ver figura 26$)$. O teste post hoc de NewmanKeuls $(p<0,05)$ demonstrou que os animais do grupo GLI-CET apresentaram maiores ingestões de sacarose do que o grupo NPS/CBD-CET. As demais comparações entre os grupos não apresentaram outras diferenças significativas. 
Figura 26 - Representação gráfica da ANOVA $(F[3,30]=4,371 ; p<0,011)$, e do teste post hoc de Newman-Keuls $(p<0,05)$ realizado entre os grupos de ratos fêmeas, após o teste comportamental de preferência por sacarose. As barras coloridas foram reconstruídas pelas médias e erro padrão dos resultados, e representam os respectivos grupos do estudo, em que: GLI-SAL (cinza); GLI-CET (azul); NPS/CBD-SAL (vinho); NPS/CBD-CET (verde). Glicose a 5\% (GLI); Solução Salina (SAL); Nitroprussiato de Sódio (NPS); Canabidiol (CBD); Cetamina (CET). * (Resultado Estatisticamente Significativo)

\section{Teste de Preferência por Sacarose}

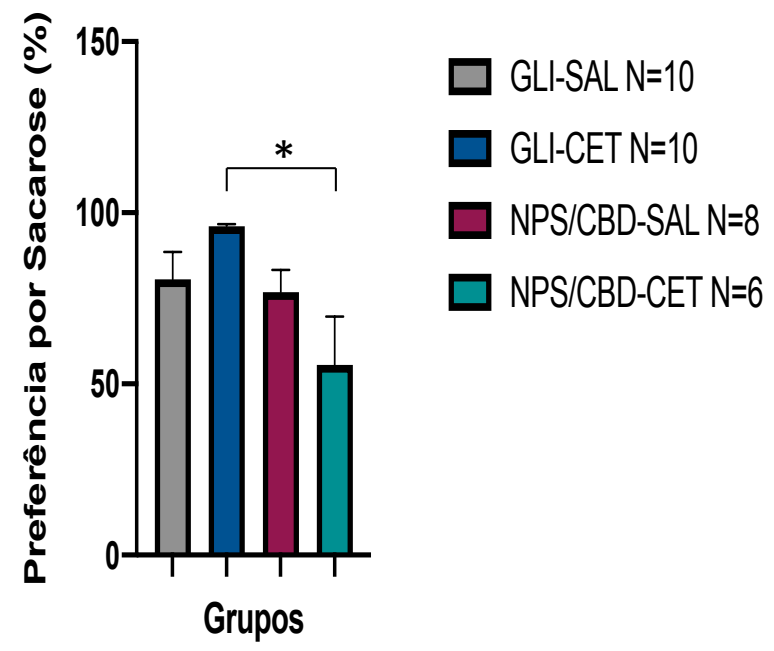

Fonte: Elaborado pelo autor.

\subsection{RESULTADOS DO TESTE DE RECONHECIMENTO DE OBJETOS}

\subsubsection{Grupos de ratos machos - NPS}

Os resultados da ANOVA de uma via realizada no grupo descrito acima evidenciaram que no teste de $30 \min \left(F_{[3,30]}=7,655 ; p=0,001\right)$ houve diferenças estatisticamente significativas para o fator tratamento, mas não no teste de $24 \mathrm{~h}(\mathrm{~F}$ $[3,30]=0,270 ; p=0,845)$ (ver figura 27). $O$ teste post hoc de Newman-Keuls $(p<$ $0,05)$, no teste de $30 \mathrm{~min}$, demonstrou que os animais do grupo GLI-CET apresentaram menores tempos de exploração de um objeto novo do que o grupo GLI-SAL, do que o grupo NPS-SAL e, também, do que o grupo NPS-CET. As demais comparações entre os grupos não apresentaram outras diferenças significativas. 
Figura 27 - Representação gráfica da ANOVA no teste de $30 \min (F[3,30]=7,655 ; p=0,001)$, no teste de $24 \mathrm{~h}(\mathrm{~F}[3,30]=0,270 ; p=0,845)$, e do teste post hoc de Newman-Keuls $(p<0,05)$, realizado entre os grupos de ratos machos após o teste de reconhecimento de objetos. As barras coloridas foram reconstruídas pelas médias e erro padrão dos resultados, e representam os respectivos grupos do estudo, em que: GLI-SAL (cinza); GLI-CET (azul); NPS-SAL (vinho); NPS-CET (verde). Glicose a

$5 \%$ (GLI); Solução Salina (SAL); Nitroprussiato de Sódio (NPS); Cetamina (CET). * (Resultado Estatisticamente Significativo)

\section{Teste de Reconhecimento de Objetos}

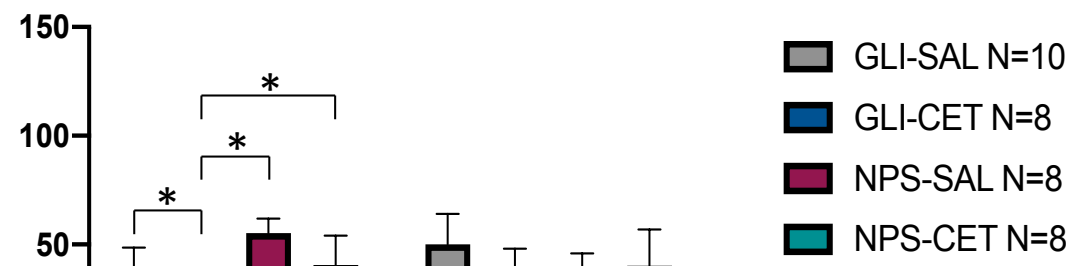

Fonte: Elaborado pelo autor.

\subsubsection{Grupos de ratos fêmeas - NPS}

Os resultados da ANOVA de uma via realizada no grupo descrito acima evidenciaram que no teste de $30 \mathrm{~min}\left(F_{[3,32]}=3,739 ; p=0,020\right)$ e no teste de $24 \mathrm{~h}(\mathrm{~F}$ $[3,32]=7,371 ; p=0,001)$ houve diferenças estatisticamente significativas para $o$ fator tratamento (ver figura 28). O teste post hoc de Newman-Keuls $(p<0,05)$, no teste de $30 \mathrm{~min}$, demonstrou que os animais do grupo GLI-CET apresentaram menores tempos de exploração de um objeto novo do que o grupo GLI-SAL e do que o grupo NPS-SAL. Já o teste de $24 \mathrm{~h}$ evidenciou que os animais do grupo GLI-CET apresentaram menores tempos de exploração de um objeto novo do que o grupo GLI-SAL. As demais comparações entre os grupos não apresentaram outras diferenças significativas. 
Figura 28 - Representação gráfica da ANOVA no teste de $30 \min (F[3,32]=3,739 ; p=0,020)$, no teste de $24 \mathrm{~h}(\mathrm{~F}[3,32]=7,371 ; p=0,001)$, e do teste post hoc de Newman-Keuls $(p<0,05)$, realizado entre os grupos de ratos fêmeas após o teste de reconhecimento de objetos. As barras coloridas foram reconstruídas pelas médias e erro padrão dos resultados, e representam os respectivos grupos do estudo, em que: GLI-SAL (cinza); GLI-CET (azul); NPS-SAL (vinho); NPS-CET (verde). Glicose a

$5 \%$ (GLI); Solução Salina (SAL); Nitroprussiato de Sódio (NPS); Cetamina (CET). * (Resultado Estatisticamente Significativo)

\section{Teste de Reconhecimento de Objetos}

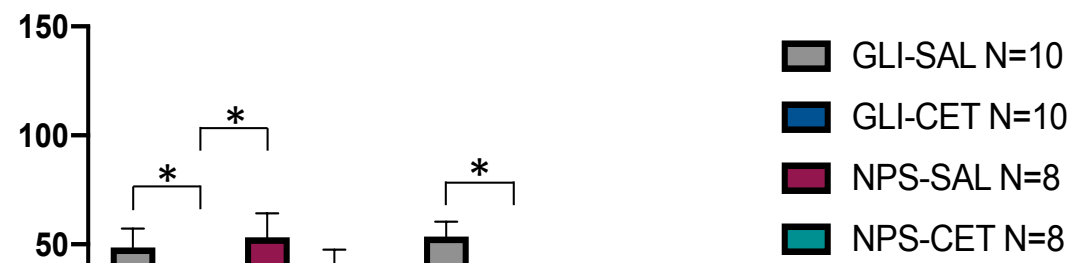

Fonte: Elaborado pelo autor.

\subsubsection{Grupo de ratos machos - CBD}

Os resultados da ANOVA de uma via realizada no grupo descrito acima evidenciaram que no teste de $30 \mathrm{~min}\left(\mathrm{~F}_{[3,36]}=9,992 ; p<0,001\right)$ houve diferenças estatisticamente significativas para o fator tratamento, mas não no teste de $24 \mathrm{~h}(\mathrm{~F}$ $[3,36]=0,720 ; p=0,546)$ (ver figura 29). O teste post hoc de Newman-Keuls $(p<0,05)$ demonstrou que os animais do grupo GLI-CET apresentaram menores tempos de exploração de um objeto novo do que o grupo GLI-SAL, do que o grupo CBD-SAL e, também, do que o grupo CBD-CET. As demais comparações entre os grupos não apresentaram outras diferenças significativas. 
Figura 29 - Representação gráfica da ANOVA no teste de $30 \min (F[3,36]=9,992 ; p<0,001)$, no teste de $24 \mathrm{~h}(\mathrm{~F}[3,36]=0,720 ; p=0,546)$, e do teste post hoc de Newman-Keuls $(p<0,05)$, realizado entre os grupos de ratos machos após o teste de reconhecimento de objetos. As barras coloridas foram reconstruídas pelas médias e erro padrão dos resultados, e representam os respectivos grupos do estudo, em que: GLI-SAL (cinza); GLI-CET (azul); CBD-SAL (vinho); NPS-CET (verde). Glicose a $5 \%$ (GLI); Solução Salina (SAL); Canabidiol (CBD); Cetamina (CET). * (Resultado Estatisticamente Significativo)

\section{Teste de Reconhecimento de Objetos}

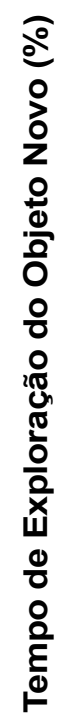

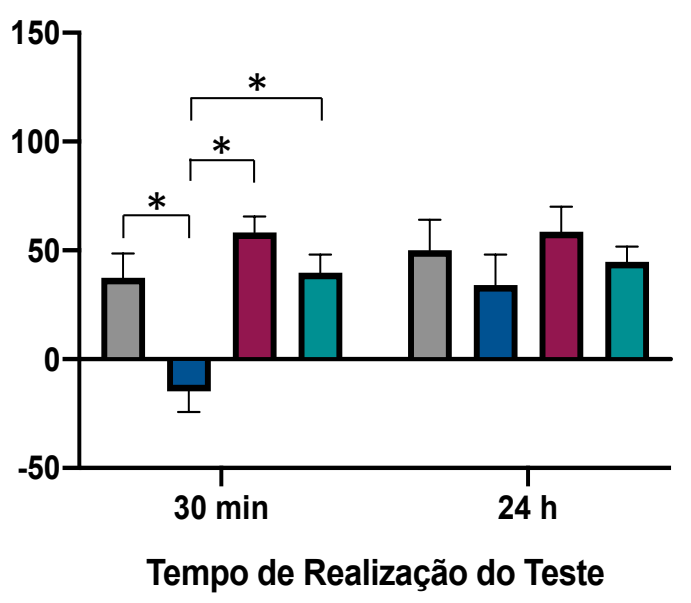

$\square$ GLI-SAL N=10

$\square$ GLI-CET N=8

$\square$ CBD-SAL N=10

$\square$ CBD-CET N=12

Fonte: Elaborado pelo autor.

\subsubsection{Grupo de ratos fêmeas - CBD}

Os resultados da ANOVA de uma via realizada no grupo descrito acima evidenciaram que no teste de $30 \mathrm{~min}\left(F_{[3,36]}=3,461 ; p=0,026\right)$ e no teste de $24 \mathrm{~h}(F$ $[3,36]=8,419 ; p=0,001)$ houve diferenças estatisticamente significativas para o fator tratamento (ver figura 30). O teste post hoc de Newman-Keuls $(p<0,05)$, no teste de $30 \mathrm{~min}$, demonstrou que os animais do grupo GLI-SAL apresentaram maiores tempos de exploração de um objeto novo do que o grupo GLI-CET e do que o grupo CBD-CET. Já o teste de $24 \mathrm{~h}$ evidenciou que os animais do grupo GLI-SAL apresentaram maiores tempos de exploração de um objeto novo do que o grupo GLI-CET, do que o grupo CBD-SAL e do que o grupo CBD-CET. As demais comparações entre os grupos não apresentaram outras diferenças significativas. 
Figura 30 - Representação gráfica da ANOVA no teste de $30 \min (F[3,36]=3,461 ; p=0,026)$, no teste de $24 \mathrm{~h}(\mathrm{~F}[3,36]=8,419 ; p=0,001)$ e do teste post hoc de Newman-Keuls $(p<0,05)$, realizado entre os grupos de ratos fêmeas após o teste de reconhecimento de objetos. As barras coloridas foram reconstruídas pelas médias e erro padrão dos resultados, e representam os respectivos grupos do estudo, em que: GLI-SAL (cinza); GLI-CET (azul); CBD-SAL (vinho); NPS-CET (verde). Glicose a $5 \%$ (GLI); Solução Salina (SAL); Canabidiol (CBD); Cetamina (CET). * (Resultado Estatisticamente Significativo)

\section{Teste de Reconhecimento de Objetos}

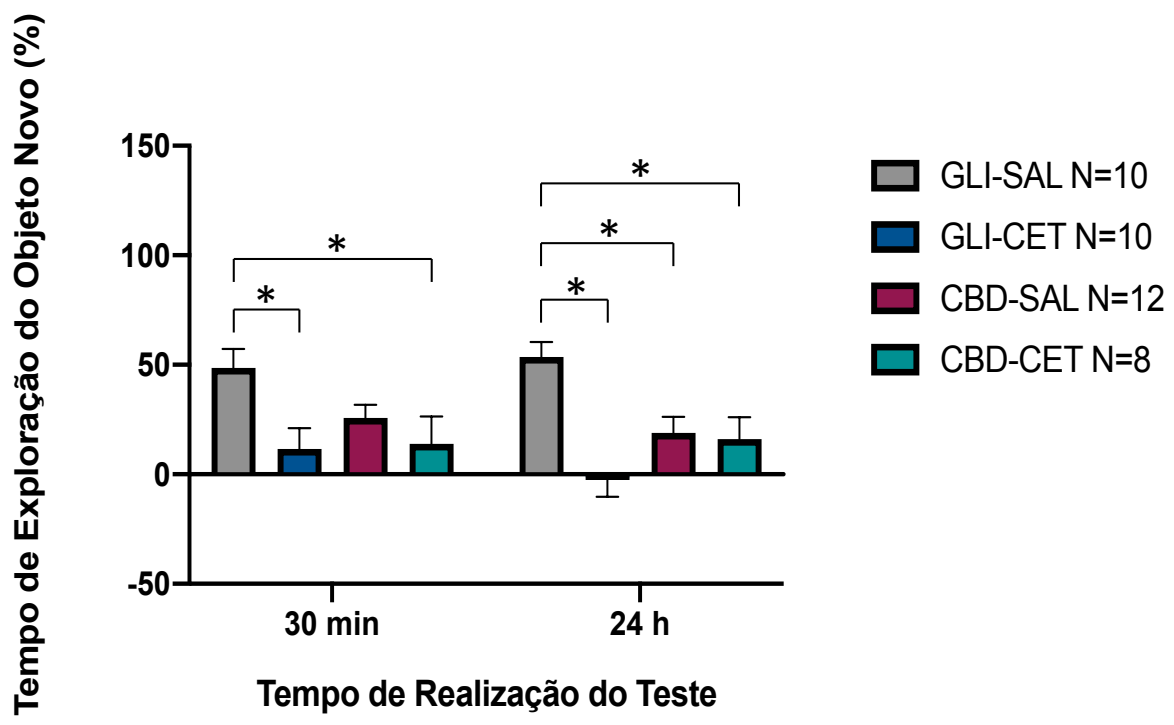

Fonte: Elaborado pelo autor.

\subsubsection{Grupos de ratos machos - NPS/CBD}

Os resultados da ANOVA de uma via realizada no grupo descrito acima evidenciaram que no teste de $30 \mathrm{~min}\left(F_{[3,32]}=5,961 ; p=0,002\right)$ houve diferenças estatisticamente significativas para o fator tratamento, mas não no teste de $24 \mathrm{~h}$ ( $F$ $[3,32]=0,718 ; p=0,548)$ (ver figura 31). $O$ teste post hoc de Newman-Keuls $(p<0,05)$ demonstrou que os animais do grupo GLI-CET apresentaram menores tempos de exploração de um objeto novo do que o grupo GLI-SAL, do que o grupo NPS/CBDSAL e, também, do que o grupo NPS/CBD-CET. As demais comparações entre os grupos não apresentaram outras diferenças significativas. 
Figura 31 - Representação gráfica da ANOVA no teste de $30 \min (F[3,32]=5,961 ; p=0,002)$, no teste de $24 \mathrm{~h}(\mathrm{~F}[3,32]=0,718 ; p=0,548)$, e do teste post hoc de Newman-Keuls $(p<0,05)$, realizado entre os grupos de ratos machos após o teste de reconhecimento de objetos. As barras coloridas foram reconstruídas pelas médias e erro padrão dos resultados, e representam os respectivos grupos do estudo, em que: GLI-SAL (cinza); GLI-CET (azul); NPS/CBD-SAL (vinho); NPS/CBD-CET (verde).

Glicose a 5\% (GLI); Solução Salina (SAL); Nitroprussiato de Sódio (NPS); Canabidiol (CBD);

Cetamina (CET). * (Resultado Estatisticamente Significativo)

Teste de Reconhecimento de Objetos

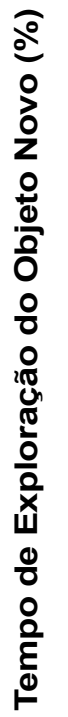

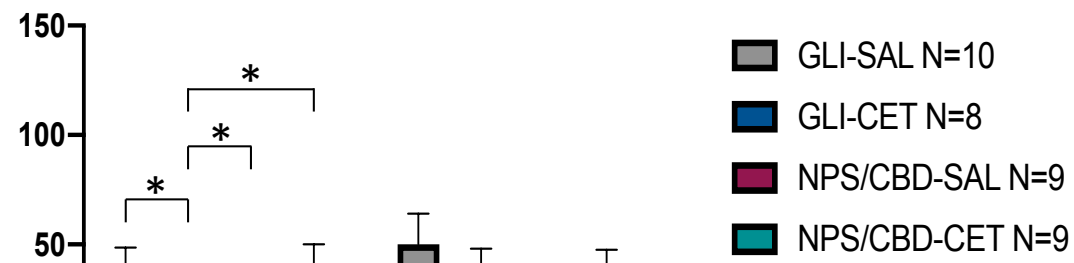

Fonte: Elaborado pelo autor.

\subsubsection{Grupos de ratos fêmeas NPS/CBD}

Os resultados da ANOVA de uma via realizada no grupo descrito acima evidenciaram que no teste de $30 \mathrm{~min}\left(F_{[3,30]}=6,230 ; p=0,002\right)$ e no teste de $24 \mathrm{~h}(F$ $[3,30]=13,280 ; p<0,001)$ houve diferenças estatisticamente significativas para o fator tratamento (ver figura 32). $O$ teste post hoc de Newman-Keuls $(p<0,05)$, no teste de $30 \mathrm{~min}$, demonstrou que os animais do grupo GLI-CET apresentaram menores tempos de exploração de um objeto novo do que o grupo GLI-SAL, do que o grupo NPS/CBD-SAL e do que o grupo NPS/CBD-CET. Já o teste de $24 \mathrm{~h}$ evidenciou que os animais do grupo GLI-CET apresentaram menores tempos de exploração de um objeto novo do que o grupo GLI-SAL, do que o grupo NPS/CBD-SAL e do que o grupo NPS/CBD-CET. As demais comparações entre os grupos não apresentaram outras diferenças significativas. 
Figura 32 - Representação gráfica da ANOVA no teste de $30 \min (F[3,30]=6,230 ; p=0,002)$, no teste de $24 \mathrm{~h}(\mathrm{~F}[3,30]=13,280 ; p<0,001)$, e do teste post hoc de Newman-Keuls $(p<0,05)$, realizado entre os grupos de ratos fêmeas após o teste de reconhecimento de objetos. As barras coloridas foram reconstruídas pelas médias e erro padrão dos resultados, e representam os respectivos grupos do estudo, em que: GLI-SAL (cinza); GLI-CET (azul); NPS/CBD-SAL (vinho); NPS/CBD-CET (verde).

Glicose a 5\% (GLI); Solução Salina (SAL); Nitroprussiato de Sódio (NPS); Canabidiol (CBD);

Cetamina (CET). * (Resultado Estatisticamente Significativo)

Teste de Reconhecimento de Objetos

0
0
0
0
0
0
0
0
0
0
0
0
0
00
0
0
0
0
$x$
$w$
0
0
0
0
$\frac{0}{0}$
0

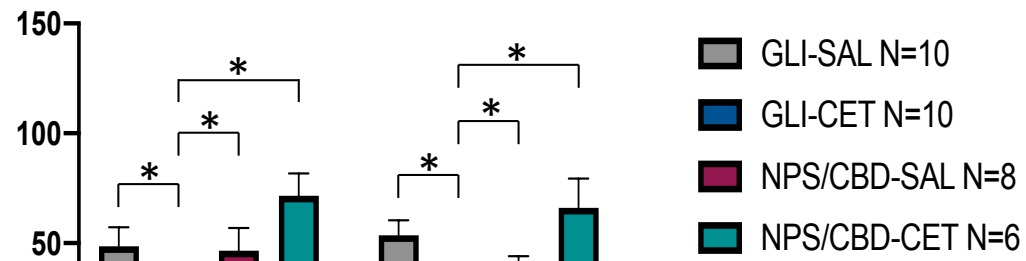

Fonte: Elaborado pelo autor. 


\section{DISCUSSÃO}

\subsection{MODELO DO DESENHO EXPERIMENTAL}

Didaticamente se torna imprescindível argumentar que para uma compreensão mais abrangente sobre a discussão desta tese de doutorado, por parte do leitor, devem ser levadas em consideração as características únicas, pelo menos até o momento, acerca do desenho experimental do estudo neste proposto. De forma inédita, os resultados dos testes comportamentais realizados no trabalho em questão necessitam ser compreendidos, de maneira mais ampla, levando-se em consideração uma explicação mais detalhada sobre um tópico de suma importância para a elaboração deste projeto e arduamente discutido quando da criação do desenho experimental do estudo. Trata-se da cronicidade do uso das injeções IP de CET no modelo animal de esquizofrenia aqui apresentado e de seus respectivos aspectos técnicos, os quais serão discutidos a seguir.

O modelo crônico de uso de CET em roedores, escolhido através do desenho experimental desta tese de doutorado, já foi detalhadamente discutido por Chatterjee e colaboradores, sendo definido como um modelo altamente superior ao modelo agudo de CET, uma vez que ratos, que foram expostos ao modelo crônico, apresentaram um padrão de hiperatividade (correspondente aos sintomas positivos da esquizofrenia) e de aumento de passividade no teste de natação forçada (correspondente aos sintomas negativos da esquizofrenia) persistentes até 10 dias após a retirada da droga (CHATTERJEE et al., 2011). Acredita-se que o mecanismo neurobiológico envolvido neste processo de efeitos comportamentais induzidos pela CET esteja relacionado, pelo menos parcialmente, ao bloqueio dos receptores NMDA localizados em neurônios gabaérgicos de regiões cerebrais límbicas e subcorticais, e que essa ação inibitória esteja associada a um aumento de atividade neuronal com consequente liberação excessiva de dopamina e de glutamato em determinadas regiões estriatais límbicas (DUNCAN et al., 1998; MOGHADDAM et al., 1997; LORRAIN et al., 2003; NAKAO et al., 2003).

Em contrapartida, habitualmente, os testes comportamentais que foram escolhidos neste estudo, no caso o de campo aberto, o de preferência por sacarose e o de reconhecimento de objetos são realizados por meio de dosagens farmacológicas de CET únicas e isoladas. O que significa informar que, na imensa 
maioria das vezes, no que tange ao modelo animal de esquizofrenia induzido por antagonistas NMDA, os estudos científicos atuais são realizados em roedores por meio de aplicações IP na vigência imediata de dose única do princípio farmacológico escolhido para o experimento. Esse fato proporciona para a grande maioria dos experimentos já realizados sobre o tema, a possibilidade de um importante viés metodológico que poderia mascarar os resultados já encontrados sobre o assunto. Noda e colaboradores já em 1995, através de um estudo realizado sob uso de PCP em roedores, descreveram os benefícios do uso crônico dessa substância em detrimento ao uso agudo, nesse caso, em um modelo animal de esquizofrenia com ênfase na dimensão negativa da doença testada por meio do teste de natação forçada (NODA et al., 1995).

Poucos são os estudos que utilizaram antagonistas glutamatérgicos como a CET ou a PCP durante mais de um dia, como no modelo experimental aqui proposto, no qual foram utilizadas injeções IP de 30mg/kg de CET, diariamente por cinco dias consecutivos. Em conformidade ao modelo farmacológico descrito nesta tese de doutorado, Ram e colaboradores desenharam um estudo em modelo animal com o intuito de que fosse compreendido o nível de vulnerabilidade a doenças psiquiátricas como a esquizofrenia, através da tentativa da estimulação de alterações do sistema glutamatérgico de roedores, através do uso de CET e de estresse crônico induzido. Para isso, utilizaram no período pós-natal dos animais injeções IP de $30 \mathrm{mg} / \mathrm{kg}$ de CET, associada ou não ao estresse crônico induzido e descobriram que a atividade locomotora dos animais que foram submetidos a CET e a CET + estresse crônico induzido, estava aumentada em relação aos seus respectivos grupos controle (RAM; RAPHAELI; AVITAL, 2013).

Keilhoff e colaboradores, em um dos seus trabalhos, também utilizaram um modelo animal de esquizofrenia de cinco dias de doses repetidas do mesmo antagonista glutamatérgico. Nesse estudo, os pesquisadores demonstraram através da indução crônica de psicose pela CET, que as injeções repetidas desse anestésico induziram a alterações significativas nos sistemas nitrérgicos e gabaérgicos, os quais remeteram as mesmas alterações encontradas em estudos post morten realizados em cérebros de pacientes portadores de esquizofrenia (KEILHOFF et al., 2004).

De acordo com o conhecimento do autor desta tese, na literatura atual, apenas esses dois artigos descritos no parágrafo acima, mais o estudo de Chatterjee 
et al. (2011) utilizaram modelos animais de esquizofrenia que envolveram dosagens repetidas de CET em seus trabalhos. Desse modo, por motivos óbvios, porém empíricos se pode assumir ou pelo menos levar em consideração que os resultados de tantos dias consecutivos de uso de CET poderiam proporcionar uma tendência de dificultar ainda mais a reversão de qualquer quadro psicótico ora induzido por essa droga, bem como também, eventualmente, até mesmo dificultar a remissão desses sintomas através do uso de drogas como o haloperidol e a clozapina, que sabidamente possuem a condição de reverter esses sintomas nos modelos tradicionais agudos de CET já propostos e evidentemente testados (ENOMOTO; NODA; NABESHIMA, 2007).

Infelizmente, como descrito anteriormente não existem muitos estudos já realizados até o momento sobre este tema, ou seja, que compararam o modelo animal tradicional agudo de esquizofrenia induzido por dosagem única de CET, com o modelo aqui referenciado que utilizou, de forma crônica, cinco dias consecutivos de CET para indução à psicose. Todavia, o único artigo já realizado sobre o tema, já descrito em parágrafos acima foi escrito em 2011 por Chatterjee e colaboradores, os quais compararam sistematicamente os efeitos da administração crônica versus administração aguda de CET em roedores. Nesse artigo, segundo os autores, em função de falta de estudos que apropriadamente avaliem os modelos animais atuais de psicose, a pesquisa em esquizofrenia nesse tema poderia estar sendo feita sob grandes limitações metodológicas (CHATTERJEE et al., 2011).

Desse modo, esses autores elaboraram um estudo que pôde examinar os diferentes tipos de fenótipos gerados pelo uso da CET, através de dosagens diferentes, de tempos de tratamento diversos e de níveis de abstinência gerados. Os resultados evidenciaram que o tratamento agudo de CET na dose de $100 \mathrm{mg} / \mathrm{kg}$ via IP induziu os roedores à hiperlocomoção, sintomas esses classificados como positivos, porém não induziu a sintomas negativos através dos testes comportamentais utilizados na pesquisa. De maneira contrária, a administração crônica por dez dias de CET, além de produzir sintomas positivos de hiperatividade, também promoveu períodos de imobilidade durante o teste de natação forçada, 0 que corresponderia a algum tipo de sintoma psicótico negativo, e ambos os resultados persistiram mesmo após dez dias da interrupção da droga. Concluem que o tratamento crônico de CET, em modelos animais de esquizofrenia, possuiria a capacidade de produzir maiores alterações nos sistemas de neurotransmissores 
envolvidos com a doença, além de uma maior variedade de anormalidades em diversos domínios comportamentais.

\subsection{CAMPO ABERTO}

O século $X X$ ficou conhecido como um período áureo para 0 desenvolvimento de testes comportamentais, os quais contribuíram para o desenvolvimento e inovação na pesquisa animal. Muitos desses testes continuam sendo utilizados, atualmente, em diversas áreas do conhecimento técnico-científico, como por exemplo, na área da biotecnologia, neuropsicofarmacologia, psicobiologia, entre outras mais. Entre esses testes comportamentais, o de campo aberto parece ter se estabelecido como o método de pesquisa animal mais frequentemente utilizado na comunidade científica (SESTAKOVA et al., 2013).

Este método foi publicado, inicialmente, por Hall e Ballachey (1932), porém apenas em 1969, Broadhurst o descreveu sistematicamente com características instrumentais padronizadas e confiáveis que serviram consistentemente para o desenvolvimento dos estudos em animais (BROADHURST, 1969). O teste de campo aberto permite uma avaliação de diversos parâmetros sobre o comportamento motor dos ratos, como por exemplo, locomoção, atividade vertical, exploração, avaliação de risco, tomada de decisão, entre outros (LIEBSCH et al., 1998).

Um cuidado adicional que o autor deste estudo teve na elaboração do padrão das avaliações comportamentais aqui realizadas foi o de encontrar medidas de avaliação de atividade motora que realmente pudessem fornecer dados consistentes a respeito da resposta que os animais do estudo apresentariam, tendo como foco principal a busca por um modelo que mais se aproximasse das alterações motoras encontradas em pacientes portadores de esquizofrenia. Portanto, durante a elaboração do desenho experimental utilizado e descrito neste trabalho de doutorado, a escolha específica dos testes comportamentais motores aqui definidos, no caso a distância total percorrida e a proporção de tempo gasto no centro da arena, se deve ao fato de que esses testes possibilitam, talvez, a melhor forma de análise sobre alguns dos parâmetros mais importantes para a avaliação motora dos modelos animais de esquizofrenia existentes até o momento, sendo esses os testes comportamentais de atividade motora mais utilizados nos artigos sobre psicose e modelos animais de esquizofrenia. 
É sabido na literatura que ratos estimulados por antagonistas glutamatérgicos como a PCP e a própria CET, droga de escolha para a indução do modelo animal de esquizofrenia nesta tese, produzem uma série de alterações comportamentais que mimetizam os sintomas da esquizofrenia em humanos. Essas anormalidades incluem diversas manifestações comportamentais que podem ser subdivididas, basicamente, em cinco dimensões, sendo essas: hiperlocomoção, estereotipias, deficiências no processamento de informações, danos em funções cognitivas (memória de trabalho e atenção) e prejuízos na interação social (LIPSKA; WEINBERGER, 2000).

Desse modo, torna-se natural pensar que a hiperlocomoção em ratos deva ser encarada como um indicativo de uma condição hiperdopaminérgica provocada pelo sistema mesolímbico, bem como que possa estar correlacionada, principalmente, com os sintomas positivos da esquizofrenia (MCCULLOUGH; SALAMONE, 1992). Reiterando essa condição descrita em ratos que cursa com atividade locomotora aumentada, resta complementar que não apenas as drogas antagonistas glutamatérgicas possuiriam a capacidade de induzir a essas manifestações comportamentais. Os agentes farmacológicos classificados como psicoestimulantes como, por exemplo, a anfetamina e a metanfetamina também teriam a condição de exercer hiperestimulação dopaminérgica, sendo também identificados como substâncias eventualmente indutoras de comportamentos schizophrenia like (WEDZONY et al., 2005; ABEKAWAK et al., 2007).

De qualquer maneira, a escolha da droga responsável pela indução aos sintomas psicóticos neste estudo, no caso a CET, foi escolhida pelo fato de diversos estudos atualmente atestarem que os melhores e mais seguros modelos animais de esquizofrenia existentes até o momento são aqueles realizados através do uso de agentes antagonistas glutamatérgicos (TORU; KURUMAJI; ISHIMARU, 1994; STEINPREIS, 1996; THORNBERG; SAKLAD, 1996; MOGHADDAM; ADAMS, 1998).

\subsubsection{Distância total percorrida}

Corroborando as informações citadas acima, os resultados dos testes de distância total percorrida evidenciaram que todos os grupos de animais, que foram expostos a CET, apresentaram maiores índices de hiperlocomoção, quando comparados com os grupos que foram induzidos ao modelo animal de esquizofrenia 
com SAL. Torna-se evidente, de acordo com os resultados destes testes, que o modelo animal de psicose aqui proposto pôde ser considerado efetivo para a indução de esquizofrenia nos animais. Atesta-se essa efetividade, uma vez que a CET se mostrou extremamente eficaz em induzir manifestações comportamentais que cursaram, principalmente, com hiperlocomoção, corroborando vários outros estudos já realizados na literatura, como por exemplo, o de Bujas-Bobanovic e colaboradores, os quais também referiram presença de estereotipias e ataxia nos seus resultados, além do aumento da atividade locomotora (BUJAS-BOBANOVIC et al., 2000; KANDRATAVICIUS et al., 2015; SAMPAIO et al., 2018).

Tendo em mente que o objetivo principal desta tese de doutorado foi o de avaliar os efeitos eventualmente protetores do NPS, do CBD e da associação de ambos no período de maturação cerebral de ratos Wistar se torna importante dizer que o grupo de ratos machos, que foi previamente tratado com injeções intraperitoneais de NPS, não apresentou diferenças estatisticamente significativas na redução das distâncias totais percorridas pelos animais, quando comparado com os roedores que foram previamente tratados com GLI. Em outras palavras, isso significa afirmar que o NPS não pareceu atenuar os efeitos de hiperlocomoção característicos da estimulação desses animais, que foram previamente induzidos por CET nesse grupo. Deve-se lembrar de que a ideia inicial do uso do NPS como um agente, eventualmente protetor, para o desenvolvimento de esquizofrenia partiu de um estudo publicado em 2013, por Hallak et al. (2013).

O estudo de Hallak et al. (2013) provocou o início de um novo paradigma de pesquisa na área da esquizofrenia em que, de maneira geral, o ON teria a capacidade de tratar sintomas provenientes dessa doença, de acordo com sua eventual ação moduladora de receptores NMDA. No entanto, além de se mostrar efetivo para o tratamento da esquizofrenia, esse trabalho evidenciou que uma única aplicação desse potente doador de ON, no caso o NPS, pareceu exercer um efeito protetor ou preventivo no desenvolvimento da doença, pois seus resultados benéficos perduraram por trinta dias após a aplicação da droga, mesmo sendo essa uma substância possuidora de uma meia vida de eliminação bem curta de apenas quatro horas. Alguns outros estudos publicados posteriormente corroboraram os resultados encontrados pela equipe de Hallak et al. (2013), alguns desses, realizados em modelos animais de esquizofrenia, bem como outros realizados em humanos portadores da doença. No que tange aos estudos animais, Issy e 
colaboradores, em 2014, descreveram que o aumento de ON gerado pelo NPS, melhorou consideravelmente os déficits de PPI, normalmente encontrados em ratos expostos aos modelos animais de esquizofrenia (ISSY et al., 2014). Não menos importante, Trevlopoulou e colegas também referiram que o NPS foi capaz, em um modelo animal de psicose realizado em roedores, de atenuar os déficits de reconhecimento de memória e de isolamento social, típicos do resultado do uso de CET nesses animais (TREVLOPOULOU; TOUZLATZI; PITSIKAS, 2016). Outros estudos clínicos, dessa vez realizados em humanos, também confirmaram a hipótese de Hallak et al. (2013), sendo o caso do estudo de Oliveira e colaboradores, os quais avaliaram a eficácia do NPS nos déficits cognitivos da esquizofrenia e encontraram que essa substância pareceu ter sido efetiva em melhorar as funções executivas desses pacientes, que foram testados através dos testes mnemônicos de Stroop e N-back (OLIVEIRA et al., 2015).

Esse mesmo pesquisador, através de outro estudo, refere que o NPS também pareceu ser efetivo, de algum modo ainda a ser investigado, em atuar como agente potencializador de drogas antipsicóticas, no caso do estudo, de clozapina (OLIVEIRA et al., 2014). Em contrapartida, alguns outros estudos clínicos que tentaram corroborar a efetividade do NPS, no tratamento da esquizofrenia, encontraram resultados discrepantes aos de Hallak et al. (2013), atestando formalmente que de acordo com seus resultados, o NPS não foi efetivo em melhorar sintomas da esquizofrenia, bem como não se mostrou competente em atuar como agente potencializador de drogas antipsicóticas (STONE et al., 2016; WANG et al., 2018; WANG et al., 2019). Assim, apenas estudos futuros, mais bem delineados metodologicamente, poderão responder a essa lacuna científica ainda não claramente desvendada.

Entrando mais especificamente no universo da psicofarmacologia básica, a ideia do grupo de Hallak et al. (2013) foi a seguinte: uma vez que a teoria dopaminérgica não consegue explicar adequadamente a fisiopatologia da esquizofrenia, novas evidências tentam encontrar outros mecanismos envolvidos com a gênese desse transtorno. Entre essas se destaca a desregulação do circuito conhecido como NMDA-ON-GMPc (já descrito na introdução desta tese) (MIULLER; SCHWARZ, 2007), que inclusive já possui várias evidências clínicas claras que corroboram essa ideia, na qual indivíduos portadores de esquizofrenia apresentariam alterações em vários níveis desse circuito (LIN; LANE; TSAI, 2012). 
Esse defeito também pode ser identificado em estudos que comprovam que pacientes portadores de esquizofrenia apresentam diminuição nos metabolitos do ON (RAMIREZ et al., 2004; LEE; KIM, 2008; NAKANO et al., 2010) e de GMPc (GATTAZ et al., 1983), quando comparados com sujeitos normais. Na linha dessas evidências, estudos em roedores que foram submetidos a inibição farmacológica e genética da síntese e transmissão do glutamato e do ON, evidenciaram que esses animais passaram a desenvolver comportamento psychosis like após tais intervenções (BIRD et al., 2001; BUJAS-BOBANOVIC et al., 2000; NELSON et al., 1995).

Dando sequência a ideia de Hallak et al. (2013), Bujas-Bobanovic et al. (2000) referem que o NPS foi capaz de abolir completamente os efeitos comportamentais da expressão de c-fos induzida pela PCP. Infelizmente, o mecanismo exato pelo qual o NPS exerce seus efeitos permanece incerto, entretanto, possivelmente, além de aumentar os níveis de ON e de GMPc no cérebro, essa substância deve provocar algum tipo de modulação nos receptores NMDA ainda a ser desvendada (HOYT et al., 1992; MANZONI et al., 1992). Essas observações pré-clínicas levaram o grupo de Hallak et al. (2013) a acreditar que o NPS poderia melhorar sintomas da esquizofrenia, sendo essa a explicação por trás da realização do estudo de 2013. Esse mesmo trabalho, desse modo, demonstrou a eficácia do NPS, bem como de alguma maneira ainda a ser descoberta, a possibilidade da atenuação, ou até mesmo de certo modo, da prevenção do aparecimento da esquizofrenia.

Ainda, sobre os resultados dos testes comportamentais de distância total percorrida, a mesma ausência de resposta pode ser descrita quanto ao uso do CBD nas fases iniciais do período do neurodesenvolvimento de animais, pois nesse grupo de ratos machos não foram encontradas diferenças estatisticamente significativas, quando da comparação realizada com os animais que foram previamente expostos ao uso de GLI. Isso corresponde a dizer que o CBD, aparentemente, não foi capaz de diminuir as distâncias totais percorridas pelos animais no grupo.

A teoria por trás do uso do CBD, no período de maturação cerebral de ratos, destoa da que foi descrita nos parágrafos acima para o NPS. O primeiro estudo a introduzir na literatura o conceito de um eventual efeito protetor ou preventivo do uso do CBD na esquizofrenia foi realizado por Crippa et al. (2015). Esse estudo de revisão marcou uma nova era na compreensão da esquizofrenia como uma doença, 
que poderia ser de algum modo ainda a ser investigado, prevenida através do uso do CBD. Segundo esses autores, pacientes sob Ultra Alto Risco (UHR) para o desenvolvimento de psicose, termo esse criado para denominar indivíduos que apresentariam, em alguns casos, até mais de 50\% de chance de desenvolver esquizofrenia ao longo da vida (MILLER et al., 2002), se beneficiariam sobremaneira de intervenções psicofarmacológicas preventivas realizadas por antipsicóticos, diminuindo o risco de transição para psicose entre 37 a 45\% (MIYAMOTO et al., 2012; MCGORRY et al., 2013).

Antes de tudo, então, seria importante entender através de evidências científicas recentes, se o CBD, o qual possui seu princípio ativo extraído da planta Cannabis sativa poderia, realmente, melhorar sintomas psicóticos característicos de pacientes portadores de esquizofrenia.

Como já mencionado na introdução desta tese de doutorado, é sabido atualmente que o THC, o principal constituinte da Cannabis seria capaz de induzir sintomas psicóticos em indivíduos vulneráveis geneticamente (ZUARDI et al., 2012; HASAN et al., 2019). Sintomas esses que pareceram serem antagonizados através de uma eventual interação farmacológica com o próprio CBD, como demonstra o estudo de Zuardi e colaboradores já na década de 1980 (ZUARDI et al., 1982). Vários outros estudos realizados através do uso do CBD, tanto em animais como em humanos, corroboram esses resultados, evidenciando uma visível atenuação dos sintomas psicóticos induzidos pelo THC, provocando uma série de melhoras clínicas, caracterizadas, por exemplo, através de atenuação do isolamento social típico da esquizofrenia, do embotamento afetivo, da anedonia, entre outros sintomas dimensionais da doença (LEWEKE et al., 2000; MALONE; JONGEJAN; TAYLOR, 2009; LEWEKE et al., 2012).

Diversos outros trabalhos realizados em vários tipos distintos de modelos animais de esquizofrenia, também demonstraram o potencial de eficácia do CBD no controle de sintomas psicóticos (ZUARDI et al., 2012; RENARD et al., 2017; MCGUIRE et al., 2018). Entretanto, muitos outros estudos com resultados divergentes também foram conduzidos e vários desses, aparentemente, não encontraram resultados consistentes a respeito dos efeitos antipsicóticos do CBD (LONG et al., 2010; MIYAMOTO et al., 2012; ALMEIDA et al., 2013). Todavia, através de uma análise metodológica mais detalhada desses trabalhos, é possível 
identificar que o uso crônico da administração do CBD parece ser a chave para a busca de resultados mais consistentes nesses transtornos (CRIPPA et al., 2015).

A própria equipe de Crippa et al. (2015) também elaborou um outro estudo, no qual a administração crônica de CBD pareceu ser eficaz contra as manifestações comportamentais induzidas por diferentes modelos animais de esquizofrenia (PERES et al., 2016). Nesse estudo, o tratamento com CBD de longo prazo, preventivamente, não permitiu que ratos adolescentes desenvolvessem hiperlocomoção, defeitos no teste de PPI, além de déficits no teste de condicionamento ao medo, em uma linhagem de ratos hipertensos espontaneamente (SHR). Esse foi, provavelmente, o primeiro estudo científico capaz de demonstrar que o CBD, aparentemente, apresentou efeitos potencialmente atenuantes e preventivos contra o desenvolvimento da esquizofrenia.

Em humanos, a eficácia clínica do CBD também foi devidamente testada e, pode-se afirmar que o primeiro relato de caso de um paciente tratado com CBD para a esquizofrenia foi o caso de uma paciente feminina que não tolerava o uso de drogas antipsicóticas e que foi tratada com CBD por quatro semanas, apresentando uma diferença significativa na pontuação da escala breve de avaliação psiquiátrica (BPRS) (ZUARDI et al., 1995). Outro estudo importante que atestou a eficácia clínica do CBD foi um ensaio clínico, duplo-cego, controlado, que comparou os efeitos do CBD e da amisulpirida em 42 pacientes com esquizofrenia durante quatro semanas (LEWEKE et al., 2012). Ambos os tratamentos reduziram os sintomas psicóticos sem diferenças significativas entre esses, porém com o grupo CBD apresentando menos efeitos colaterais. Vários outros estudos recentes vêm sendo conduzidos com excelentes resultados, evidenciando, sistematicamente, as propriedades antipsicóticas do CBD, associados a um perfil de efeitos colaterais extremamente inferiores, quando comparado com os antipsicóticos tradicionais (LEWEKE et al., 2016).

O CBD produziria seus efeitos através de um mecanismo que ainda não está claramente evidenciado, mas que provavelmente deva interferir com uma série de sistemas de neurotransmissores, através de diversas vias específicas. Basicamente, a inibição da recaptação e do metabolismo da anandamida devem estar relacionados com as propriedades antipsicóticas do CBD (ZUARDI et al., 2012; ROHLEDER et al., 2016; PACHER; KOGAN; MECHOULAM, 2019). Na verdade, os níveis séricos de anandamida possuiriam uma correlação inversa entre a presença 
de esquizofrenia e a vigência de sintomas psicóticos, em um tipo de mecanismo de feedback ainda a ser investigado (GIUFFRIDA et al., 2004). Por exemplo, pacientes em estados prodrômicos de psicose possuiriam maiores níveis de anandamida no líquor do que pessoas saudáveis, entretanto altos níveis de anandamida estariam associados a um atraso no desenvolvimento de psicose franca (MINICHINO et al., 2019). Não se esquecendo de que a melhora clínica visualizada em pacientes com esquizofrenia, que utilizaram CBD, estaria relacionada a altos níveis de anandamida no líquor (KOETHE; HOYER; LEWEKE, 2009).

O CBD seria sintetizado sob demanda, nos neurônios pós-sinápticos, se comportaria ativando terminais pré-sinápticos e regulando negativamente a liberação de neurotransmissores, no caso GABA e glutamato (MOUSLECH; VALLA, 2009). Outras ações do CBD ainda poderiam estar relacionadas com um aumento da neurogênese em ratos adultos (WOLF et al., 2010; FOGAÇA et al., 2018), com melhora da neuroplasticidade cerebral em humanos (SAGREDO et al., 2018), a eventual interação com receptores 5HT1A e TRPV do tipo 1, e até mesmo a outros efeitos neuroprotetores e anti-inflamatórios (ZUARDI, 2008; CAMPOS; GUIMARÃES, 2008; MULLER; MORALES; REGGIO, 2018). Essas evidências clínicas sobre o uso do CBD tanto como droga antipsicótica, tanto como que um agente possuidor de capacidades preventivas no tratamento da esquizofrenia, descritas e sistematizadas pela equipe de Crippa et al. (2015), também impulsionaram a ideia do desenho experimental do estudo desta tese de doutorado, fornecendo evidências adicionais para que, eventualmente, o uso dessa substância nos períodos iniciais do neurodesenvolvimento humano poderia atenuar ou até mesmo evitar o aparecimento de esquizofrenia.

Outra análise foi realizada no teste de campo aberto com ênfase na distância total percorrida, dessa vez com a aplicação de injeções IP provenientes da associação entre o NPS e o CBD também em um grupo de ratos machos. Diferentemente do esperado, pois de acordo com os resultados do uso prévio do NPS e do CBD isoladamente, que não provocaram resultados significativos nos grupos descritos acima, a associação dessas duas substâncias proporcionou que os ratos expostos a essas apresentassem menores distâncias totais percorridas que os animais do grupo que foram tratados com GLI. Isso implica em informar que de acordo com esses resultados é possível afirmar que o uso associado do NPS e do CBD foi capaz, ineditamente, de atenuar e/ou, até mesmo prevenir, os efeitos 
psicóticos induzidos pela CET. Desse modo, surge a pergunta: por que o uso isolado do CBD e do NPS não apresentou resultados significativos para a diminuição das distâncias totais percorridas, enquanto que o uso associado de ambas as substâncias, apresentou? Para responder a essa pergunta se torna necessário compreender a relação existente, ainda a ser desvendada, entre o sistema glutamatérgico e o sistema dos receptores endocanabinoides.

Como já descrito nesta tese de doutorado, várias regiões cerebrais vêm sendo relacionadas com a gênese da esquizofrenia (PAKKENBERG; SCHEELKRUGER; KRISTIANSEN, 2009). Pode-se citar, por exemplo, a área tegmental ventral (GIORDANO et al., 2018), o nucleus accumbens (PEREZ; LODGE, 2018), o pálido ventral (TARCIJONAS et al., 2019), o núcleo talâmico mediodorsal (BUCHMANN et al., 2014) e o córtex pré-frontal (HOFTMAN; DATTA; LEWIS, 2017). Nessas áreas descritas, mais especificamente naquelas com maior afinidade a receptores dopaminérgicos como, por exemplo, o nucleus accumbens, estudos em modelos animais de roedores e em humanos evidenciam que uma resposta de hipersensibilidade a receptores dopaminérgicos induziria, através de uma espécie de mecanismo de feedback, ainda a ser desvendado, a uma inibição focal de neurônios gabaérgicos, com consequente redução da liberação gabaérgica proveniente de terminais nervosos individualizados no pálido ventral (KOOB; SWEDLOW, 1988; HUBERT; MANVICH; KUHAR, 2010).

O nucleus accumbens é constituído, em sua grande maioria, por mais de 95\% de neurônios gabaérgicos espinhosos médios, os quais são inibidos pela ativação de receptores com alta afinidade para D2 (GELDWERT, et al., 2006; BRADY; O'DONNELL, 2004). Essas estruturas celulares possuem, entre outras propriedades, a função de enviar projeções inibitórias gabaérgicas para o pálido ventral (KOOB; SWEDLOW, 1988; JONES; MOGENSON, 1980). Dessa maneira, a liberação de dopamina no nucleus accumbens, realizada pelas projeções neuronais provenientes da área tegmental ventral, poderia reduzir a inibição de neurônios gabaérgicos do pálido ventral, resultando em um aumento da atividade do tálamo médio dorsal pálido (KALIVAS; CHURCHILL; ROMANIDES, 1999). Esse fenômeno resultaria em uma diminuição do input glutamatérgico dessa região para o córtex pré-frontal, provocando danos na atividade locomotora e na memória de trabalho.

Em teoria, os endocanabinoides poderiam regularizar esse sistema de acordo com o mecanismo já descrito em parágrafos acima, basicamente, regulando 
a liberação de neurotransmissores, como GABA e glutamato (ZUARDI et al., 2012). Nos gânglios da base, os receptores CB1 estariam localizados em maior quantidade nos terminais axonais gabaérgicos, do que nos neurônios glutamatérgicos (MATYAS et al., 2006) e, portanto, um aumento nos níveis séricos de anandamida induzidos pelo CBD poderia atenuar a liberação de receptores GABA nos neurônios do pálido ventral, restaurando o funcionamento normal desse sistema nos pacientes portadores de esquizofrenia (ZUARDI et al., 2012).

Nessa linha de evidências seria plausível pensar que em relação aos resultados encontrados na diminuição das distâncias totais percorridas pelos roedores quando da associação do NPS e do CBD, de algum modo ainda a ser conhecido, o eventual efeito sinérgico observado proveniente da associação dessas substâncias, parece ter sido superior ao uso isolado de ambas as drogas na prevenção do desenvolvimento de sintomas esquizofrenia like.

Em referência quanto às análises dos grupos de ratos fêmeas no quesito distância total percorrida, antes de mais nada, é importante referenciar que da mesma maneira que o grupo dos ratos machos, todos os animais do grupo, que foram expostos a CET, apresentaram maiores distâncias totais percorridas do que os animais que foram induzidos com SAL. Dessa maneira, atesta-se, de acordo com esse padrão de resposta, que a CET foi viavelmente eficaz em produzir aumento de atividade locomotora nos animais do gênero feminino que participaram do estudo. Da mesma forma que os resultados encontrados no grupo dos ratos machos, o estudo de Bujas-Bubanovic et al. (2000) corrobora esses resultados, mais uma vez posicionando a CET como droga efetiva para o modelo animal de esquizofrenia escolhido no estudo aqui apresentado.

De qualquer maneira, é possível observar que mesmo sem análise estatística específica sobre uma eventual influência de gênero nos resultados obtidos se percebe um padrão de resposta significativamente maior dos efeitos psicóticos da CET nos grupos compostos por ratos fêmeas, pois nesses grupos, as distâncias totais percorridas pelos animais foram bem maiores do que as encontradas nos grupos dos ratos machos. Esse padrão de resultado encontrado, empírico, porém nítido, naturalmente implica ao estudo uma importante limitação técnica, uma vez que nenhum estudo estatístico específico foi realizado no que tange a influência do gênero nesses resultados. 
O mesmo padrão idêntico de resultado foi descrito, atualmente, por Pacheco e colaboradores, os quais atestaram em um artigo publicado em 2019, que ratos fêmeas pré-púberes apresentaram um padrão de sintomas psicóticos altamente superiores aos ratos machos, quando testados através de testes comportamentais de interação social, campo aberto e de PPI (PACHECO et al., 2019). Esses pesquisadores concluem que se respeitando a influência de gênero dos efeitos da CET em roedores, ratos Wistar pré-púberes são um excelente modelo animal atual de indução aos comportamentos schizophrenia like.

Essas diferenças descritas acima a respeito dos resultados do uso da CET e de uma eventual influência de gênero nos desfechos encontrados já foram percebidas e devidamente descritas através de alguns trabalhos prévios realizados. Talvez, o primeiro artigo que tenha sido publicado sobre uma possível influência do gênero quanto ao efeito da CET, tenha sido publicado por Winters et al. (1986). Nesse estudo, os pesquisadores envolvidos buscavam melhor elucidação a respeito de eventuais fatores adversos que pudessem influenciar as ações da CET, e corroborando os resultados descritos acima nesta tese encontraram que, aparentemente, o grupo de ratos fêmeas mostrou ser muito mais sensível aos efeitos da CET do que os machos. Para tal, testaram a eficácia da CET para analgesia e catalepsia, observando as suas interações com gênero e clima. Ao término do estudo foi possível afirmar que ratos machos, diferentemente das fêmeas, não manifestaram analgesia em doses menores do que aquelas necessárias para induzir catatonia. Concluíram, relatando que as profundas diferenças de gênero encontradas no estudo a respeito dos efeitos da CET, colocam o gênero como uma variável que necessita ser amplamente estudada em relação ao uso de determinado anestésico.

$\mathrm{Na}$ linha oposta desses resultados, Lecointre e colaboradores estudaram os efeitos da administração pós-natal de CET em ratos de ambos os gêneros, mais especificamente aos 2, 5 e 10 dias de vida, comparando posteriormente os resultados encontrados através de testes comportamentais de atividade locomotora aos 51 e 55 dias de vida dos animais (LECOINTRE et al., 2014). Os resultados observados evidenciaram que a maioria dos animais do gênero masculino apresentou aumento da atividade locomotora horizontal, em detrimento as fêmeas que não apresentaram determinado comportamento. Os autores concluem com observações de que o estrogênio, hormônio mais abundante no gênero feminino, 
poderia ser um fator de proteção ao desenvolvimento de um quadro de esquizofrenia like, mas que determinado resultado ainda precisaria ser amplamente estudado.

Outro artigo, publicado em 2004, por Lees e colaboradores, também corrobora essa possível influência de gênero à eficácia da CET. Os autores discorrem que o impacto da influência de gênero na psicopatologia, no prognóstico, na resposta funcional e clínica, bem como nas intervenções psicofarmacológicas da esquizofrenia, já está muito bem documentado, e concluem inferindo que seria possível, que essa influência de gênero poderia estar, de algum modo ainda a ser investigado, intimamente relacionada aos níveis de estrogênio característicos do organismo feminino (LEES et al., 2004).

Corroborando essas evidências, Borella e colaboradores avaliaram a influência do ciclo do estrógeno e do gênero no comportamento de ratos adultos tratados com CET no período neonatal (BORELLA et al., 2015). Encontraram alterações circunstanciais de déficits no teste de PPI e na memória de trabalho espacial em ratos machos e em fêmeas diestrus (período de baixo nível de estrogênio), mas não em ratos fêmeas proestrus (período de alto nível de estradiol). Desse modo, colocando o estrogênio como um hormônio potencialmente protetor do desenvolvimento de quadros psychosis like.

Assim, como outra limitação importante implicada ao estudo aqui apresentado, dessa vez sobre os resultados encontrados no grupo de ratos fêmeas descritos acima nesta tese de doutorado, não foram feitas avaliações das diferentes fases do ciclo do estrogênio dos animais de gênero feminino que participaram do trabalho. Essa mesma limitação se aplicaria ao estudo de Lecointre et al. (2014) descrito acima, que não encontrou aumento da atividade locomotora horizontal em ratos fêmeas, mas sim nos machos, pois seria possível, por exemplo, que esses ratos fêmeas estivessem em proestrus.

Retornando aos resultados dos testes de distância total percorrida entre os grupos de ratos fêmeas se percebe um nítido padrão diferente de resposta sobre os achados do estudo, em referência quanto aos dados obtidos pelos grupos dos ratos machos. Dando seguimento aos resultados obtidos, o primeiro grupo de comparação composto de ratos fêmeas e que foi exposto ao NPS, em fases precoces do amadurecimento cerebral, apresentaram menores distâncias totais percorridas em comparação ao grupo que foi submetido ao uso da GLI. Dado esse, o qual significa 
dizer que nesse grupo, o NPS pareceu ser efetivo em prevenir o comportamento schizophrenia like induzido pela CET.

Oliveira e colaboradores, em 2015, elaboraram um estudo tentando avaliar a eficácia do uso do NPS em um modelo animal de roedores, que utilizou CET, sem definição de gênero (OLIVEIRA et al., 2015). Os animais foram filmados na arena de campo aberto por $30 \mathrm{~min}$ e, depois, analisados estatisticamente, observando-se a atividade deambulatória e eventuais estereotipias encontradas. Os resultados, que corroboraram os resultados encontrados nesta tese de doutorado, evidenciaram que - NPS preveniu a emergência de hiperatividade induzida pela CET, quando administrado até uma semana antes do uso desse anestésico. Há de se ressaltar que o estudo de Oliveira et al. (2015) não realizou intervenções preventivas com NPS em fases precoces do amadurecimento cerebral como no projeto de doutorado aqui referido.

Vários outros estudos vêm sendo realizados em modelos animais de psicose e em pacientes portadores de esquizofrenia no intuito de se testar a real eficácia do NPS, seja essa droga utilizada sob a forma de tratamento antipsicótico in loco apresentando resultados positivos (TREVLOPOULOU; TOUZLATZI; PITSIKAS, 2016; TITULAER et al., 2019) e também negativos (STONE et al., 2016; HURTUBISE et al., 2017; WANG et al., 2018; WANG et al., 2019), ou utilizada em estudos de caráter preventivo, também com desfechos positivos e promissores (DIANA et al., 2018).

De maneira complementar, o grupo de ratos fêmeas, que utilizou o CBD no período de maturação cerebral, quando comparado com o grupo que recebeu injeções IP de GLI, também apresentou menores distâncias totais percorridas com diferenças estatisticamente significativas, devidamente comprovadas pela análise estatística proposta pelo estudo. Pode-se afirmar, então, que o CBD foi, aparentemente, eficaz em atenuar e/ou prevenir o comportamento de hiperlocomoção induzido pelo uso da CET, provavelmente, através do mesmo mecanismo de ação descrito para os efeitos do CBD no grupo dos ratos machos.

Por fim, outro aspecto analisado no grupo foi o da associação do NPS com o CBD, através de injeções IP desses agentes também no mesmo período inicial do neurodesenvolvimento, quando comparado com o uso da GLI. Os resultados mais uma vez evidenciaram diferenças significativas demonstradas por menores distâncias totais percorridas no grupo que foi exposto a associação do NPS e do 
CBD, demonstrando que a interação dessas duas substâncias também pareceu enfraquecer o quadro psicótico de hiperlocomoção induzido pela CET.

Esse é o primeiro estudo realizado sobre o assunto, de acordo com o conhecimento do grupo de pesquisa responsável pela elaboração deste trabalho, a respeito do uso dessas determinadas substâncias (NPS e CBD) no período de maturação cerebral de roedores. Portanto, não existem outros trabalhos já realizados na literatura que possam corroborar ou discordar dos resultados aqui encontrados. De qualquer maneira, uma breve discussão sobre a influência do gênero na esquizofrenia, de acordo com os resultados encontrados, se faz necessária.

Os resultados obtidos através dos testes de atividade locomotora, no que tange a distância total percorrida, descritos nos parágrafos acima, evidenciaram de maneira geral que os ratos fêmeas apresentaram mais sintomas psicóticos do que os ratos machos quando da estimulação realizada pelas injeções intraperitoneais de CET. Observação essa já descrita nesta tese e que foi corroborada por Winters e colaboradores em 1986, os quais descreveram que ratos fêmeas realmente seriam mais susceptíveis aos efeitos psicóticos da CET (WINTERS et al., 1986).

Nesse caso, naturalmente, uma vez que os ratos fêmeas estimulados por CET estavam mais psicóticos do que os ratos machos, seria esperado, empiricamente, é claro, que esses respondessem de maneira menos eficaz aos tratamentos preventivos realizados com NPS e/ou CBD em detrimento aos ratos machos, se algum tipo de eficácia preventiva dessas substâncias, porventura, fosse constatada. É sabido na literatura que a intensidade do quadro psicótico, a qual o paciente está acometido, sendo inversamente proporcional ao nível do resultado terapêutico encontrado. Por exemplo, quanto mais grave é o quadro psicótico que o paciente está acometido, mais difícil seria sua resposta farmacológica, chegando ao ponto de indivíduos em fases prodrômicas de psicose serem os mais beneficiados pelos tratamentos antipsicóticos atuais (ALBERT; WEIBELL, 2019; CHAN et al., 2019). No entanto, os resultados encontrados nesta tese de doutorado foram opostos aos descritos acima, pois os ratos fêmeas mais gravemente acometidos pela psicose responderam de maneira superior aos ratos machos, menos acometidos de sintomas.

Dessa maneira surge a pergunta: por que esse fenômeno distinto ocorreu? Inadvertidamente, a superioridade de resposta de prevenção à psicose encontrada 
neste trabalho de doutorado e, por conseguinte, atribuída ao NPS e ao CBD no grupo dos ratos fêmeas se apresenta em conformidade com o melhor nível de prognóstico encontrado ao longo da vida em pacientes portadores de esquizofrenia do gênero feminino, quando comparado com homens portadores da doença (SEEMAN, 2012).

Atualmente, em termos de saúde pública, é sabido que de maneira geral as mulheres portadoras de esquizofrenia apresentam melhor prognóstico do que os homens e isso se deve, principalmente, a alguns dados epidemiológicos listados a seguir: principalmente, nos 10-15 anos iniciais da doença, a esquizofrenia em mulheres interrompe a vida com menos frequência do que nos homens, mulheres conseguem voltar ao trabalho, se casar e cuidar de seus filhos muito mais frequentemente que os pacientes do gênero masculino, as mulheres continuam a manter suas amizades e vínculos parentais, além de aderirem melhor aos tratamentos farmacológicos, em muito mais casos do que seus pares do sexo oposto (GALDERISI et al., 2012).

Dando seguimento aos dados atuais sobre a influência do gênero na esquizofrenia, os quais corroboram os resultados comportamentais aqui nesta tese descritos, é importante ressaltar também, que embora as mulheres portadoras de psicose apresentem maiores perfis sistêmicos de efeitos colaterais em referência ao uso de medicamentos antipsicóticos, elas também apresentam maiores índices de resposta terapêutica aos tratamentos antipsicóticos, porventura propostos, com dosagens diárias muito menores do que aquelas necessárias para que os homens respondam ao tratamento (SMITH, 2010).

Concluindo, as evidências científicas contemporâneas a respeito da prevalência da esquizofrenia ao longo da vida, na maior parte do mundo, demonstra que valores quantitativos idênticos são encontrados tanto entre homens quanto em mulheres portadoras do transtorno, entretanto, a incidência é maior em homens em uma proporção de 1.4:1 (MCGRATH et al., 2008), além do que, os homens apresentam uma tendência em terem mais sintomas negativos e cognitivos do que as mulheres, enquanto que mulheres apresentam mais sintomas afetivos. Dentro desse contexto, os episódios psicóticos nas mulheres possuem uma tendência a serem mais breves e com melhor resolução do que em homens (CASTAGNINI; BERRIOS, 2009). 
Mesmo com todos esses dados epidemiológicos obtidos de trabalhos realizados em humanos, os quais corroboram os resultados encontrados nesta tese, a pergunta feita acima, no começo do parágrafo, continua sem resposta. Ainda que a hipótese mais provável para a influência de gênero na esquizofrenia, bem como nos resultados aqui encontrados repouse em uma eventual ação protetora do estrogênio, essa não responde por completo, o que de fato é responsável pela influência de gênero nessa doença e, portanto, ela deve ser vista muito mais como uma teoria possível, do que como um modelo conclusivo de influência e consequente proteção.

\subsubsection{Proporção de tempo gasto no centro da arena}

Os maiores indicadores já estabelecidos de comportamento emocional em roedores durante o teste de campo aberto, para alguns autores, seria a ambulação e a defecação (LISTER, 1990). Esse modelo comportamental vem sendo proposto como referência à resposta ao medo apresentada pelo animal, ou mais especificamente, ao comportamento ansioso do roedor, através da exposição a um ambiente novo e potencialmente perigoso para os animais (GENTSCH et al., 1987). Nesse caso, os principais parâmetros que se alterariam durante a realização do teste seriam o aumento da defecação, concomitante a diminuição da ambulação, especialmente, na zona central do teste (BERNATOVA et al., 2011).

Por esse motivo, a proporção de tempo gasto no centro da arena foi utilizada, neste trabalho de doutorado, com o objetivo principal de avaliação pormenorizada do comportamento ansioso dos animais do estudo (KUNIISHI et al., 2017). Resta a ressalva de que o objetivo principal do autor desta tese, durante o trabalho de campo, foi o de avaliar a possibilidade da atenuação e/ou prevenção do quadro schizophrenia like induzido pela CET, e não propriamente dito sobre a resposta das drogas escolhidas a um transtorno de ansiedade propriamente dito.

Mesmo assim, segundo vários pesquisadores, a avaliação de comportamentos anxiety like gerados por estimulações artificiais realizadas através dos testes comportamentais, como os citados acima, poderiam ser encarados como indícios de sintomas psicóticos, pois sintomas de ansiedade têm sido há muito tempo definidos como uma característica central da esquizofrenia desde a sua 
caracterização (TANDON; NASRALLAH; KESHAVAN, 2009; KARPOV et al., 2016; HOWELLS; KINGDON; BALDWIN, 2017).

Desse modo, apesar de ser considerado um importante teste para a avaliação de indícios de comportamentos psicóticos em roedores (SEGAL-GAVISH et al., 2017), o teste de proporção de tempo gasto, no centro da arena, deve ser encarado muito mais como um teste de avaliação do nível de ansiedade de determinadas espécies de animais (CALISKAN et al., 2019), do que de avaliação específica de um comportamento schizophrenia like propriamente dito.

Dando sequência a interpretação dos resultados encontrados neste tipo de tarefa comportamental, antes de mais nada, como primeiro parâmetro a ser analisado e de suma importância para a validade do modelo animal aqui proposto, os resultados das porcentagens de tempo gasto no centro da arena obtidos pelos animais do estudo, não evidenciaram que os roedores, que foram estimulados por CET, apresentaram menores índices de tempo perdido no centro da arena, quando comparados com os grupos que foram induzidos ao modelo animal de esquizofrenia com SAL. Torna-se notório, então, de acordo com os resultados destes testes, que o modelo animal de psicose aqui proposto não pôde ser considerado efetivo para a indução de sintomas schizophrenia like nos animais.

Essa falta de efetividade para o modelo não corrobora a grande maioria dos trabalhos já realizados na literatura, os quais atestam que a CET seria efetiva para causar diminuição do tempo gasto no centro da arena, quando utilizado em roedores e testadas através da tarefa comportamental de proporção de tempo gasto no centro da arena (LIEBSCH et al., 1998; SESTAKOVA et al., 2013).

Retornando aos objetivos principais desta tese de doutorado, que consistiu na avaliação dos efeitos eventualmente protetores do NPS, do CBD e da associação de ambos no período de maturação cerebral de ratos Wistar, em detrimento a quadros psicóticos ora induzidos por CET, se torna importante dizer que nenhuma comparação estatística realizada durante os testes de proporção de tempo gasto no centro da arena apresentou diferenças estatisticamente significativas no aumento da proporção do tempo gasto no centro da arena, possibilitando um eventual efeito preventivo para psicose, por parte dos agentes utilizados na pesquisa. Em outras palavras, isso significa afirmar que tanto NPS, CBD e a associação de ambas as drogas não pareceu atenuar os efeitos da diminuição da proporção do tempo gasto 
no centro da arena, característicos da estimulação por CET que os animais do estudo foram submetidos.

Voltando ao conceito de que este teste avalia muito mais os comportamentos anxiety like, do que schizophrenia like, resta apresentação da informação de que apenas dois resultados estatisticamente significativos foram encontrados após as comparações realizadas entre os animais durante esse tipo de tarefa comportamental. Trata-se dos resultados provenientes das comparações realizadas entre os grupos de ratos machos e fêmeas, que foram expostos previamente ao CBD no período de maturação cerebral.

Nesses grupos, foi possível verificar que o CBD, aparentemente, foi capaz de diminuir os níveis de ansiedade de alguns animais. Esse dado deve ser interpretado, através da observação da comparação dos ratos, que foram previamente expostos a GLI, no período de maturação cerebral, com os ratos que foram expostos ao CBD durante o mesmo período, e ambos posteriormente induzidos ao comportamento schizophrenia like por SAL, ou seja, por placebo. Nesse grupo foi possível a constatação de que o CBD diminuiu de maneira significativa os níveis basais de ansiedade, naturalmente encontrados em animais durante a realização desses tipos de testes comportamentais, que visam indução de um quadro anxiety like.

De maneira inédita se torna possível acreditar que, desse modo, o CBD teria a capacidade de atenuar ou de até mesmo prevenir o nível basal de ansiedade que existe instintivamente nesses animais. Na literatura atual não existem estudos até o momento realizados sobre essa nova possibilidade de eventuais características preventivas do CBD para quadros de ansiedade, que pudessem corroborar os resultados encontrados neste trabalho.

Nessa linha de evidências, o uso do CBD para o tratamento da ansiedade na literatura científica remete aos dois primeiros estudos que investigaram a possibilidade dos efeitos ansiolíticos do CBD em ratos, os quais evidenciaram resultados distintos. Silveira Filho e Tufik, utilizando o teste de conflito e de supressão de ingestão de comida por medo não encontraram efeitos ansiolíticos do CBD em doses acima de 100 mg/kg (SILVEIRA FILHO; TUFIK, 1981). De maneira contrária, Zuardi e Karniol demonstraram que o CBD $(10 \mathrm{mg} / \mathrm{kg})$ diminuiu a resposta emocional condicionada, previamente induzida por THC (2mg/kg) (ZUARDI; KARNIOL, 1983). 
Posteriormente a esses estudos, durante muitos anos, vários outros deram suporte a hipótese das propriedades ansiolíticas do CBD em diversos modelos animais distintos (CRIPPA; ZUARDI; HALLAK, 2010; ELSAID; KLOIBER; LE FOLL, 2019). Entretanto, alguns desses estudos demonstraram que os resultados encontrados sobre o CBD possuiriam um padrão de curva invertida em "U". O que implica em dizer que doses baixas de CBD, por exemplo, aumentariam a atividade exploratória nos braços abertos do teste de labirinto, ou seja, um efeito típico de drogas ansiolíticas, enquanto que altas doses resultariam em um retorno dos resultados ao padrão inicial do teste, ou seja, sem resposta (GUIMARÃES et al., 1990; MOREIRA; GUIMARÃES, 2005). De qualquer maneira, essas propriedades ansiolíticas do CBD não pareciam estar relacionadas à mediação através de receptores benzodiazepínicos, mas sim a interação desse canabinoide com receptores $5 \mathrm{HT} 1 \mathrm{~A}$, produzindo os efeitos ansiolíticos observados (CRIPPA; ZUARDI; HALLAK, 2010).

Em humanos também foram conduzidos vários estudos sobre os potenciais efeitos ansiolíticos do uso do CBD, e a grande maioria desses evidenciando de maneira clara as propriedades ansiolíticas do uso do CBD (MILLAR et al., 2019). Chama atenção, um estudo publicado recentemente pela equipe de Crippa e colaboradores no qual foi realizada uma investigação sob a forma de ensaio clínico sobre as propriedades ansiolíticas do CBD e suas correlações com os mecanismos neurais envolvidos com esse fenômeno (CRIPPA et al., 2009). Os resultados, surpreendentes, evidenciaram que comparativamente ao placebo, uma única dosagem oral de CBD foi suficiente para diminuir subjetivamente os níveis de ansiedade relatados durante os testes do estudo, sem causar nenhum tipo de sedação nos indivíduos envolvidos com a pesquisa. Esses resultados foram associados com diminuição da atividade do giro parahipocampal, do hipocampo, e do giro temporal esquerdo, bem como com o aumento da atividade do córtex cingulado posterior esquerdo.

Dessa maneira, esses resultados demonstram que as propriedades modulatórias do CBD, na ativação das áreas límbicas e paralímbicas descritas, são consistentes com o mesmo padrão das propriedades encontradas em drogas ansiolíticas utilizadas em pacientes portadores de transtornos psiquiátricos e em voluntários saudáveis, sugerindo que o CBD deva possuir ações ansiolíticas 
similares em quadros de ansiedade patológica (TRZESNIAK; ARAUJO; CRIPPA, 2008; FERRARI et al., 2008).

Como conclusão, resta a descrição que de acordo com os resultados encontrados nesta tese de doutorado se torna viável um novo paradigma de pesquisa, ainda a ser evidentemente comprovado e testado, a respeito da possibilidade de se prevenir, ou de pelo menos atenuar, determinados transtornos ansiosos, através de estimulações preventivas realizadas através do uso do CBD em períodos de maturação cerebral.

\subsection{PREFERENNCIA POR SACAROSE}

O teste de preferência por sacarose descrito, sistematicamente, na seção de materiais e métodos desta tese de doutorado, resumidamente, proporciona a avaliação da porcentagem de preferência da ingestão de solução aquosa adocicada, em detrimento a uma solução aquosa simples (LIU et al., 2018). Acredita-se, de acordo com a literatura atual, que este teste seja útil tanto para a avaliação de um eventual comportamento depressivo, característico de um transtorno de humor, bem como para a avaliação de um comportamento negativo, próprio de um quadro psicótico como a esquizofrenia (PELIZZA; FERRARI, 2009). De qualquer maneira, tanto para a avaliação de depressão, como para a avaliação de um quadro psicótico, o comportamento a ser avaliado pelo teste é a anedonia.

Anedonia é definida pelo Manual Diagnóstico e Estatístico das Doenças Mentais - $5^{a}$ edição (DSM-V) como uma diminuição do interesse ou do prazer em resposta a um estímulo que foi previamente percebido como recompensador (AMERICAN PSYCHIATRIC ASSOCIATION, 2013). Pode também ser compreendida como o resultado de um déficit na motivação de receber uma recompensa e, dessa vez, por esse mecanismo se torna conhecida como anedonia motivacional (TREADWAY; ZALD, 2013; SZCZYPINSKI; GOLA, 2018). Fato que implicaria em dizer em relação ao teste realizado neste projeto que animais saudáveis, os quais experimentam algum tipo de solução açucarada, sentem um grande prazer como recompensa e, consequentemente, passam a dar preferência à ingestão de determinada solução, no intuito de que continuem sentindo cada vez mais prazer pela recompensa, ora produzida pela solução adocicada. 
De acordo com os resultados provenientes dos testes realizados, neste trabalho de doutorado, é importante ressaltar mais uma vez que, primeiramente, para que os testes realizados possuam peso estatístico considerável, uma análise "pura" sobre a eficácia do modelo animal de esquizofrenia com CET no grupo deve, necessariamente, apresentar resultados positivos. No caso, esta análise deve ser realizada de acordo com a avaliação dos resultados provenientes das comparações estatísticas feitas entre grupos GLI-SAL versus GLI-CET, no qual para que o teste seja considerado positivo, o grupo GLI-CET deve, inadvertidamente, apresentar níveis de preferência por sacarose menores do que o grupo GLI-SAL.

Mediante determinada explicação se torna possível a constatação de que nem todos os grupos, que foram estimulados por CET, durante os testes de preferência por sacarose, apresentaram menores porcentagens de ingestão de solução açucarada, quando da comparação com os grupos que foram submetidos ao modelo animal de psicose com SAL. Torna-se claro, desse modo, que a CET não se mostrou perfeitamente eficaz, nesse tipo de teste comportamental, em induzir manifestações comportamentais que evidenciaram diminuição da ingestão de sacarose, diferentemente, por exemplo, do estudo de Kandratavicius e colaboradores, os quais encontraram que a preferência por sacarose diminuiu, consideravelmente, durante as primeiras $48 \mathrm{~h}$, após estimulação de dosagem única de CET na dosagem de $30 \mathrm{mg} / \mathrm{kg}$ (KANDRATAVICIUS et al., 2015).

De maneira inédita, ainda sobre o desfecho da eficácia do modelo animal de esquizofrenia induzido por CET nesta tese de doutorado, o que também pôde ser constatado nesta análise foi uma possível influência de gênero quanto ao efeito da CET nos testes citados acima, pois mesmo sem análise estatística específica a respeito do sexo, sendo facilmente observável que nos grupos dos ratos fêmeas, especificamente, nos testes realizados entre os grupos GLI-SAL versus GLI-CET como explicado acima, nenhuma diferença estatística foi encontrada. Diferentemente dos resultados provenientes dos grupos dos ratos machos, também GLI-SAL versus GLI-CET, em que a CET se mostrou efetiva em induzir a diminuição da ingestão de solução açucarada em praticamente todos os grupos, no caso os expostos ao NPS e a associação de NPS com CBD, mas não ao grupo exposto ao $C B D$ isoladamente. Desse modo, de algum modo ainda a ser estudado, possivelmente, algo não permitiu que efeitos psicóticos plenos provenientes da CET ocorressem nos ratos fêmeas. 
Já foi citado nesta tese de doutorado que as diferenças de gênero encontradas em ratos, que foram expostos a CET, podem estar relacionadas a um eventual efeito protetor do estrogênio. Corroborando essa afirmação, Lecointre e colaboradores afirmam que de acordo com suas análises realizadas através de estimulações por CET, em períodos pós-natais de ratos de ambos os gêneros, os seus resultados indicam uma nítida influência de gênero na resposta desenvolvida por esses animais (LECOINTRE et al., 2014). Esses roedores foram testados antes e após a sua maturidade sexual, ou seja, antes e depois de apresentarem eventuais altas taxas de estrogênio, através de testes comportamentais distintos, e as diferenças encontradas levam, sistematicamente, a uma possível influência de gênero, na qual os ratos machos apresentariam quadros psicóticos mais agressivos do que as fêmeas.

$\mathrm{Na}$ mesma linha de resultados, Borella e colaboradores terminam por informar, através de seus estudos, que tamanha seria a influência de gênero, quando da administração de CET em ratos, que os estudos realizados sobre o tema deveriam especificar em que faixa etária do ciclo do estrogênio, os animais pertencentes ao estudo estariam, ou seja, se as fêmeas estariam em diestrus ou em proestrus, e finalizam por colocar o estrogênio como um hormônio potencialmente protetor do desenvolvimento de quadros schizophrenia like (BORELLA et al., 2015).

Retornando ao conceito de que o objetivo principal desta tese de doutorado foi o de avaliar a possibilidade de uma eventual ação preventiva do NPS, do CBD e da associação de ambos, no período do neurodesenvolvimento de ratos Wistar, torna-se imprescindível referir que o grupo de ratos machos que foi previamente exposto a injeções IP de NPS, não apresentou resultados estatisticamente significativos quanto ao aumento da porcentagem da preferência de sacarose, quando comparado com os animais que foram previamente expostos a GLI. Em outras palavras, isso significa afirmar que o NPS não pareceu atenuar os efeitos da diminuição da ingestão por sacarose, característicos da estimulação por CET que os animais do grupo foram, posteriormente, induzidos.

Segundo o conhecimento do autor desta tese, nenhum artigo científico até o momento tentou entender a possibilidade de efeitos atenuantes ou preventivos do NPS no período de maturação cerebral de ratos, através do teste de preferência por sacarose, apenas um artigo se propôs a tentar entender o efeito imediato do NPS e da CET, em um modelo animal de esquizofrenia, através do referido teste. Trata-se 
de um artigo de Kandratavicius e colaboradores em que pela necessidade urgente de melhores respostas farmacológicas para o tratamento da esquizofrenia, esses pesquisadores tentaram descobrir se o NPS, o trinitrato de glicerina e o azul de metileno poderiam melhorar sintomas da esquizofrenia induzidos pela CET (KANDRATAVICIUS et al., 2015). Para isso, avaliaram o valor terapêutico dessas substâncias através de alguns testes comportamentais, que incluíram o teste de preferência por sacarose, de campo aberto e de reconhecimento de objetos. Concluíram que o NPS seria uma droga promissora para o tratamento da esquizofrenia e que as alterações comportamentais induzidas pela CET dependem de uma janela temporal de administração. Por exemplo, neste trabalho de Kandratavicius et al. (2015), em referência ao teste de sacarose, os pesquisadores puderam afirmar, que o modelo agudo de CET utilizado, não seria o melhor método a ser utilizado em modelos animais de esquizofrenia, pois a CET poderia agir como droga antidepressiva e ansiolítica.

Diversos são os estudos na literatura atual que colocam a CET, quando administrada em doses subanestésicas, como um promissor agente antidepressivo, o qual proporcionaria um início de ação imediato, sendo também muito bem indicado como um excelente agente contra ideação suicida (WILKINSON et al., 2018; ZANOS; GOULD, 2018). Vários estudos pré-clínicos e clínicos vêm demonstrando há muito tempo que os receptores NMDA, classe de receptores glutamatérgicos já evidentemente descritos, nesta tese de doutorado, possuem íntima relação com a fisiopatologia da depressão maior e que o mecanismo de ação de drogas derivadas de antagonistas glutamatérgicos possuiriam propriedades farmacológicas capazes de melhorar sintomas depressivos (SKOLNICK; POPIK; TRULLAS, 2009; DEUTSCHENBAUR et al., 2016; GERHARD; WOHLEB; DUMAN, 2016).

Essas informações citadas acima são imprescindíveis de se levar em consideração, uma vez que essas explicam um dos principais motivos para que o modelo proposto de indução de psicose e, escolhido nesta tese de doutorado, fosse um modelo crônico de indução a CET de cinco dias consecutivos, e não agudo de um dia, assunto esse que já foi amplamente debatido no início da discussão desta tese (KEILHOFF et al., 2004; CHATTERJEE et al., 2011; RAM; RAPHAELI; AVITAL, 2013).

Outro ponto a ser analisado, a respeito dos resultados desse grupo de ratos machos é sobre outro importante dado encontrado quando da exposição ao NPS no 
período de neurodesenvolvimento. Ocorre que diferentemente do esperado pelo autor deste projeto de doutorado, ao invés de um efeito preventivo por parte do NPS, percebe-se através da comparação entre os grupos de GLI-SAL versus NPS-SAL, que o NPS, aparentemente, diminuiu mais ainda a ingestão de solução açucarada após indução com CET. Fato esse, o qual significa dizer que de algum modo ainda a ser compreendido, o NPS, nesse grupo de comparação, proporcionou que os ratos expostos a essa substância, aparentemente, se tornassem mais anedônicos. De modo que surge uma nova questão: por que esse fenômeno inédito aconteceu? Infelizmente, ainda não existe resposta coerente para essa questão e, desse modo, é possível afirmar que apenas estudos futuros poderão investigar e explicar todas as facetas envolvidas sobre 0 uso do NPS em períodos precoces do neurodesenvolvimento.

O único estudo existente na literatura científica atual a abordar aspectos relacionados a este tema, ou seja, que trata dos efeitos do NPS, porém não em sintomas de anedonia propriamente ditos, mas sim no tratamento da depressão de maneira geral foi realizado por Vogt et al. (2015). Nesse estudo, os pesquisadores envolvidos com o projeto referem que a CET seria uma excelente alternativa de droga antidepressiva, a qual possuiria um início de ação extremamente rápido, porém que teria seu uso dificultado pelos possíveis efeitos colaterais psicóticos que essa pode proporcionar (BERMAN et al., 2000). Como já foi exaustivamente explicado nesta tese de doutorado, estudos recentes sugerem que o NPS teria a capacidade de prevenir sintomas psicóticos em roedores, ora induzidos por CET ou por outros agentes antagonistas NMDA (BUJAS-BOBANOVICl et al., 2000; OLIVEIRA, et al., 2015), bem como possuiria a condição de tratar quadros psicóticos em humanos (HALLAK et al., 2013).

Partindo desse pressuposto, Vogt e sua equipe avaliaram os efeitos do uso do NPS em relação às ações antidepressivas da CET, e encontraram que o NPS não alterou os efeitos antidepressivos desse anestésico durante o teste de natação forçada em roedores (VOGT et al., 2015). Dado esse importante, pois durante os testes de preferência por sacarose realizados no grupo de ratos machos descritos acima, o NPS pareceu piorar os efeitos anedônicos dos roedores, o que entre outros aspectos pode ser encarado também como piora de um eventual quadro depressivo. Os mesmos autores ainda referem que durante a pesquisa, o NPS por si só, não causou nenhuma alteração no teste de natação forçada ou no teste de campo 
aberto, e sugerem que deva haver, indiretamente, algum tipo de envolvimento do sistema nitrérgico, ainda a ser investigado, na correlação entre os efeitos antidepressivos e psicotomiméticos da CET.

Dando sequência aos resultados dos testes comportamentais realizados, o mesmo padrão de resultado negativo pode ser descrito quanto ao uso do CBD nas fases iniciais do período do neurodesenvolvimento dos animais, pois ainda nesse mesmo grupo de ratos machos não foram encontradas diferenças significativas no mesmo quesito de preferência por sacarose, quando da comparação realizada com animais que foram previamente expostos ao uso de GLI. Isso corresponde a informar que o CBD, preventivamente, pareceu não ser capaz de aumentar a preferência por sacarose pelos animais no grupo. Nenhum estudo até o momento se propôs a tentar entender os efeitos do CBD em um modelo animal de esquizofrenia agudo, bem como o de exposição crônica de cinco dias à CET como o utilizado nesta tese de doutorado, através do teste comportamental de preferência por sacarose.

O único estudo na literatura que tentou decifrar a questão da preferência por soluções adocicadas do CBD, não o fez em relação à esquizofrenia. Sofia e Knobloch elaboraram um estudo avaliando os efeitos da preferência por sacarose pelo THC, pelo CBD e pelo canabinol, comparando-os com os efeitos anorexígenos da anfetamina (SOFIA; KNOBLOCH, 1976). Descobriram que tanto, canabinol, THC e CBD apresentaram propriedades claras de aumento da preferência por ingestão de solução açucarada.

Por fim, ainda em referência aos grupos de ratos machos estudados, mais uma análise foi realizada no teste de preferência por sacarose, dessa vez com a aplicação de injeções IP provenientes da associação entre o NPS e o CBD. Mais uma vez, em conformidade com os resultados provenientes dos outros grupos de ratos machos, nenhum resultado estatisticamente significativo de real interesse para o trabalho aqui realizado foi encontrado. Desse modo, a associação dessas duas substâncias não proporcionou que os ratos expostos a essas apresentassem maiores ingestões de sacarose que os animais do grupo, que foram tratados com GLI. Isso implica em afirmar que de acordo com esses resultados é possível afirmar que o uso associado do NPS e do CBD não foi capaz, ineditamente, de atenuar e/ou prevenir os efeitos psicóticos induzidos pela CET. 
Quanto aos resultados dos testes de preferência por sacarose entre os grupos de ratos fêmeas se percebe um nítido padrão similar de resposta sobre os achados do estudo, em referência quanto aos dados obtidos pelos grupos dos ratos machos. Dando seguimento aos resultados obtidos, o primeiro grupo de comparação composto de ratos fêmeas e que foram expostas ao NPS em fases precoces do amadurecimento cerebral, não apresentaram maiores taxas de preferência por sacarose, em comparação ao grupo que foi submetido ao uso da GLI. Dado esse, o qual significa que, nesse grupo, o NPS pareceu não ser efetivo em prevenir o comportamento esquizofrenia like induzido pela CET.

Mais especificamente, ainda, e da mesma maneira que no grupo do NPS nos ratos machos se percebe que o NPS, então, além de não aumentar a ingestão de solução açucarada, proporcionou um aparente efeito reverso, pois a preferência por sacarose aparentemente diminuiu mais ainda com o uso dessa substância. Como citado anteriormente, apenas o estudo de Vogt e colaboradores se propuseram a estudar os efeitos do NPS na depressão maior e relataram resultados na linha oposta dos encontrados aqui nesta tese (VOGT et al., 2015).

De maneira complementar, o grupo de ratos fêmeas, que utilizou o CBD no período de maturação cerebral, quando comparado com o grupo de GLI, também não apresentou maiores taxas de preferência por sacarose. Pode-se afirmar que o CBD, aparentemente, não foi eficaz em atenuar e/ou prevenir o comportamento de diminuição de ingestão de solução açucarada induzido pelo uso da CET. Mais uma vez se percebe que o CBD, além de não aumentar a ingestão de solução açucarada, proporcionou um aparente efeito reverso, pois a preferência por sacarose aparentemente diminuiu mais ainda com o uso dessa substância. Isso significa, mais uma vez, uma influência do gênero nos resultados encontrados, pois os ratos fêmeas apresentaram piores respostas ao efeito do CBD após indução com CET, do que os machos. Resta a informação que também não existem estudos já publicados sobre o tema na literatura atual para que eventuais comparações pudessem ser realizadas e discutidas com os resultados aqui obtidos.

Outro aspecto analisado no grupo foi o da associação do NPS com o CBD, por meio de injeções IP desses agentes também no mesmo período inicial do neurodesenvolvimento, quando comparado com o uso da GLI. Os resultados, mais uma vez, evidenciaram diferenças significativas demonstradas por menores taxas de preferência por sacarose no grupo que foi exposto a essa associação de drogas, 
demonstrando que a interação dessas duas substâncias também não pareceu enfraquecer o quadro psicótico de preferência por sacarose induzido pela CET. Reforça o conceito dos dados encontrados, de que além de não aumentar as taxas de ingestão de sacarose, o resultado também foi reverso, colocando essas substâncias como agentes que pioraram o quadro psicótico induzido por CET quando da exposição a associação do NPS e do CBD.

Este é o primeiro estudo realizado sobre o assunto, de acordo com o conhecimento do grupo de pesquisa responsável pela elaboração deste trabalho, a respeito do uso de determinadas substâncias (NPS e CBD) no período de maturação cerebral de roedores. Portanto, não existem outros trabalhos já realizados na literatura que possam corroborar ou discordar dos resultados aqui encontrados.

É possível também de se observar, em conformidade com os resultados dos testes comportamentais de preferência por sacarose, que em todos os grupos de ratos fêmeas, sob o efeito tanto de NPS, quanto de CBD, bem como de NPS e CBD em associação, e apenas no grupo de NPS dos ratos machos, que além dessas substâncias não apresentarem efeitos protetores e/ou preventivos ao desenvolvimento de esquizofrenia, fica mais uma vez clara, de forma empírica, a influência do gênero nestes resultados. De novo, essa visível influência de sexo não apenas quanto ao efeito da resposta da CET no gênero, bem como nos resultados comportamentais encontrados aparece como um fator preponderante de evidências que necessitam ser mais bem compreendidas por estudos futuros, mediante os dados obtidos pela realização deste trabalho. Portanto, mais uma vez se torna necessário que novas linhas de pesquisa, inclusive de caráter preventivo, tenham como foco principal, qual seria o verdadeiro papel do gênero na esquizofrenia.

Além da influência do gênero, outra alternativa que tenta responder por que os resultados aqui encontrados, aparentemente, pioraram o quadro psicótico ora induzido pela CET na maior parte dos grupos, pode estar relacionada com a neurotransmissão dopaminérgica. De acordo com estudos animais, a anedonia motivacional vem sendo associada com danos na transmissão dopaminérgica mesolímbica (SCHEGGI et al., 2018; SCHEGGI et al., 2016; SCHEGGI et al., 2015; TREADWAY; ZALD, 2013), e essa consequente depleção de dopamina levaria a um comportamento seletivo de mínimo, ou até mesmo de ausência completa, de interesse em direção à recompensa, em detrimento aos grandes esforços por 
recompensa característicos de sistemas de neurotransmissão dopaminérgicos saudáveis (SALAMONE et al., 2007).

Scheggi e colaboradores, através de um paradigma de anedonia motivacional induzida por estresse realizado em ratos, demonstraram que essa condição estaria associada a uma resposta dopaminérgica embotada do nucleus accumbens, quando da estimulação através de uma recompensa natural, no caso a sacarose e, também, a um aumento adaptativo nos sítios de ligação dos receptores de dopamina D1 (SCHEGGI et al., 2002). Entretanto, apenas os animais que previamente demonstraram elevação da resposta dopaminérgica após a ingestão de sacarose é que exibiram uma forte motivação em procurar a recompensa de acordo com o protocolo que foi utilizado na pesquisa (MARCHEZE et al., 2013). Essa resposta a dopamina descrita foi avaliada no estudo através dos níveis extraneuronais de dopamina e associadas com a sinalização de receptores dependentes de D1, medidos através da fosforilação dependente de PKA do resíduo de dopamina Th34 e pela fosfoproteina DARPP-32 regulada por AMPc (SCHEGGI et al., 2013).

Essa seria outra limitação importante no trabalho de doutorado aqui apresentado, pois uma vez que o circuito dopaminérgico dos animais induzidos por CET, no teste de preferência de sacarose, não foi devidamente testado através de marcadores neuronais dopaminérgicos, não é possível saber se os animais que participaram da pesquisa apresentaram elevação de resposta a dopamina após a ingestão da solução açucarada. A única maneira de responder corretamente a essa questão seria se previamente ao início do projeto, uma linhagem de animais tivesse seu tônus dopaminérgico, por exemplo, do nucleus accumbens, avaliado por marcadores neuronais dopaminérgicos e, desse modo, avaliado comparativamente a seu grupo controle específico.

\subsection{RECONHECIMENTO DE OBJETOS}

Além de a esquizofrenia proporcionar uma grande gama de sintomas conhecidos como positivos e negativos, como já citado anteriormente, é fato que essa também produz danos extremamente significativos em domínios cognitivos diversos, os quais geram respostas funcionais profundamente negativas (GOLDMAN-RAKIC, 1994; OWENS; JOHNSTONE, 2006). Assim, mesmo com uma 
necessidade emergencial de novos tratamentos para esses domínios cognitivos afetados, atualmente, é possível afirmar que ainda nenhum tratamento específico para os danos cognitivos da esquizofrenia foi aprovado para uso em humanos (LYON; SAKSIDA; BUSSEY, 2012).

No intuito de tentar resolver essa questão, um projeto denominado Measurement and Treatment Research to Improve Cognition in Schizophrenia (MATRICS) (MARDER; FENTON; YOUENS, 2004; NUECHTERLEIN et al., 2008), criado pelo National Institute of Mental Health (NIMH), principal agência norteamericana para a pesquisa de transtornos mentais (PLAKUN, 2017), descobriu e classificou sete domínios cognitivos anormais nos pacientes portadores de esquizofrenia. De acordo com esse projeto, MATRICS, o processo para a descoberta de novas drogas voltadas para o tratamento da dimensão cognitiva na esquizofrenia depende, principalmente, de testes comportamentais realizados em modelos animais de roedores, que apresentem deficiências em domínios cognitivos diversos (LYON; SAKSIDA; BUSSEY, 2012).

Young e colaboradores elaboraram uma revisão sistemática, em 2009, descrevendo os principais testes realizados em modelos animais de esquizofrenia em roedores, voltados para a dimensão cognitiva da doença, e elegeram o teste de reconhecimento de objetos, como um dos mais utilizados nas pesquisas dessa área até o momento (YOUNG et al., 2009). Esse teste, também conhecido como tarefa comportamental de memória declarativa, consiste na tendência natural de que roedores possuem de explorarem um objeto novo, mais intensamente do que a um objeto familiar, e usa esse tipo de comportamento espontâneo como um parâmetro de memória para outro previamente apresentado e, portanto, agora, familiar (RIEDEL; BLOKLAND, 2015). Em conformidade com o teste, é sabido que primatas e roedores apresentam preferência espontânea pela exploração de um objeto novo, em detrimento a um objeto já familiar, e esse tipo de tendência inata pode ser utilizada para testar a memória de um item já encontrado previamente, sem a necessidade de uma recompensa adicional ou de treinamento prolongado da amostra (LYON; SAKSIDA; BUSSEY, 2012).

O primeiro artigo a descrever a tarefa de reconhecimento de objetos foi escrito por Ennaceur e Delacour, em 1988, no qual descreveram como os ratos que previamente foram permitidos a explorar duas cópias idênticas de um mesmo objeto, em uma determinada arena, se comportavam quando esses eram recolocados na 
mesma arena $24 \mathrm{~h}$ depois, e que então passavam a preferir explorar um objeto novo recém inserido no mesmo local, em detrimento a cópia idêntica do objeto antigo (ENNACEUR; DELACOUR, 1988).

Desde então, diversos artigos vêm utilizando a tarefa de reconhecimento de objetos ou de memória declarativa em estudos de modelos de animais específicos de roedores, porém com algumas variações metodológicas específicas e, talvez, por esse motivo, com resultados bem diversificados, e até certo ponto, questionáveis. Para tentar resolver esse tipo eventual de viés metodológico, Leger e colaboradores em 2013 publicaram um artigo na revista Nature Protocols, no qual tentaram criar uma espécie de padronização nos protocolos de realização da tarefa de reconhecimento de objetos (LEGER et al., 2013). Mesmo assim, o teste ainda apresenta várias adaptações metodológicas, sendo realizado por diversas maneiras diferentes, de acordo com o conhecimento de determinado grupo de estudo específico, responsável pela pesquisa em questão. Por esse motivo se torna imprescindível explicar que o teste ora realizado nesta tese de doutorado foi desenhado de acordo com os procedimentos descritos por Wiescholleck e ManahanVaughan (2012).

Não menos importante, é a informação de que o teste de reconhecimento de objetos utilizado nesse projeto, avaliou a memória declarativa dos roedores entre os tempos de $30 \mathrm{~min}$ e de 24 h. No entanto, Sutcliffe e colaboradores, em 2007, postularam que roedores são capazes de fazer a discriminação entre objetos familiares e novos quando o intervalo entre os ensaios ocorre entre 3 min e 1 a 3 hs, mas não quando esse período ultrapassa 24 h (SUTCLIFFE et al., 2007). Por esse motivo, os resultados e suas consequentes discussões aqui realizadas, possuem como foco principal os desfechos dos testes na marcação de $30 \mathrm{~min}$, e não na de 24 h, pelos óbvios motivos descritos acima.

Quanto aos testes comportamentais realizados durante a tarefa de memória declarativa nesta tese de doutorado se torna importante, mais uma vez, uma discussão a respeito dos efeitos psicóticos da CET no modelo animal de esquizofrenia aqui apresentado. O conceito em questão, novamente, seria para a validação plena do modelo animal schizophrenia like utilizado, a CET deveria ser capaz de induzir sintomas psicóticos em todos os grupos que foram expostos a essa, obviamente naqueles sem os eventuais "tratamentos preventivos" ora realizados no período de maturação cerebral dos animais do estudo. 
Didaticamente seria esperado que as comparações estatísticas realizadas entre os grupos GLI-SAL versus GLI-CET apresentassem diferenças estatísticas significativas, confirmadas por seus respectivos testes post hoc. Nesse caso, de acordo com os resultados dos testes de 30 min é possível afirmar, com clareza, que todos os testes de memória declarativa realizados entre esses grupos se mostraram com resultados positivos, posicionando o modelo animal de esquizofrenia aqui proposto como extremamente válido para todas as outras comparações estatísticas realizadas durante os testes aplicados nos outros grupos do estudo.

Estes resultados podem ser corroborados por um número pequeno de estudos que se propuseram a estudar os efeitos da CET na tarefa de reconhecimento de objetos. Por exemplo, Pitsikas e colaboradores, em 2008, demonstraram que a administração aguda de CET $1-3 \mathrm{mg} / \mathrm{kg}$ provocou danos consistentes na performance do teste de reconhecimento de objetos em ratos Wistar (PITSIKAS; BOULTADAKIS; SAKELLARIDIS, 2008). Nesse estudo, a CET foi utilizada antes e logo após o período de aquisição de memória, seguido de um período de intervalo de $1 \mathrm{~h}$. Esses resultados evidenciaram que além dos danos na performance do teste, a CET pareceu influenciar tanto as fases de aquisição e de armazenamento de memória, bem como a fase de evocação mnêmica.

Outro estudo realizado durante a tarefa de memória declarativa, não menos importante, utilizou dosagens bem maiores de CET nos testes, nesse caso, similar às dosagens utilizadas aqui nesta tese de doutorado, ou seja, $30 \mathrm{mg} / \mathrm{kg}$. Trata-se de um estudo realizado por Chan e colegas, no qual os pesquisadores também encontraram danos significativos neste tipo de tarefa comportamental de domínio cognitivo, porém que foram revertidas após o uso intraventricular de um agonista seletivo conhecido por mGluR5 (CHAN et al., 2008).

Outro ponto importante a ser discutido, ainda em referência sobre o uso de CET na tarefa de reconhecimento de objetos realizados aqui neste trabalho, é o da influência do gênero quanto ao uso desse agente anestésico nos animais do estudo. Desse modo, é notório que os animais machos dos testes comportamentais de 30 min apresentaram maiores níveis de dano cognitivo em comparação com as fêmeas, quando da exposição ao modelo animal de esquizofrenia induzido por CET. Interessante, é que quando se observa a tarefa comportamental na marcação de 24 $\mathrm{h}$ todos os grupos dos ratos fêmeas pioraram da função cognitiva, enquanto que os machos foram capazes de reverter por completo o dano cognitivo induzido pela CET. 
Mesmo, sendo essa uma observação empírica, pois infelizmente não foi realizada uma análise estatística específica sobre os efeitos da influência de gênero no modelo, esse dado é facilmente observável através dos resultados dos testes. $\mathrm{Na}$ linha dessas evidências Grayson e Neil, em 2004, demonstraram que a administração aguda de PCP, nas dosagens de $1.5-2 \mathrm{mg} / \mathrm{kg}$ em ratos fêmeas, induziram a danos robustos e seletivos na fase de retenção de memória do paradigma de reconhecimento de objetos, pois após $1 \mathrm{~min}$ de intervalo durante o teste, os ratos foram incapazes de demonstrar preferência por um objeto novo, em detrimento a um familiar (GRAYSON; NEIL, 2004). O interessante desses resultados, e que corrobora o que foi encontrado nesta tese de doutorado durante $\mathrm{O}$ teste de $30 \mathrm{~min}$, foi que esse efeito pôde ser prevenido pela administração de benzoato de estradiol na dose $5-10 \mu \mathrm{g} / \mathrm{kg} \mathrm{em} 24 \mathrm{~h}$, anteriormente a administração aguda da PCP, evidenciando, mais uma vez, que a interação com esteroides gonadais poderia prevenir um quadro schizophrenia like (SUTCLIFFE et al., 2008).

De acordo com a proposta do autor desta tese de doutorado, ou seja, de testar a possibilidade de se prevenir o aparecimento da esquizofrenia, algo parecido como uma espécie rudimentar de algum tipo de vacina que possa ser desenvolvida no futuro, através de injeções IP de NPS, CBD e da associação de ambas nas fases mais precoces do desenvolvimento cerebral de roedores, uma discussão sobre os resultados da ação dessas substâncias no teste de reconhecimento de objetos se torna de suma importância.

Assim, o primeiro paradigma de resultado apresentado, encontrado neste tipo de teste comportamental, foi o dos efeitos do NPS no grupo de ratos Wistar machos durante o teste de $30 \mathrm{~min}$. Esses resultados levam ao entendimento de que essa substância mostrou ser extremamente efetiva em reverter os efeitos de piora cognitiva induzida pela CET, pois quando se comparou o grupo que foi submetido ao NPS nas fases precoces do amadurecimento cerebral, com o grupo que foi submetido a GLI, o NPS pareceu ser efetivo em aumentar a preferência do animal em explorar um objeto novo, em detrimento a um objeto já familiar, o que significa que tanto o armazenamento quanto a evocação de memória de curto prazo, praticamente não apresentaram déficits. Complementando esses resultados neste mesmo grupo, durante o teste de $24 \mathrm{~h}$ se pode afirmar que houve plena recuperação do dano cognitivo previamente gerado pela CET. 
Em conformidade a esses resultados durante o ensaio de $30 \mathrm{~min}$, ou seja, de eventuais efeitos preventivos do NPS quanto ao desenvolvimento de esquizofrenia, já descritos em capítulos acima, Hallak e colegas evidenciaram, em 2015, a partir de um estudo prévio, que apenas uma única infusão de NPS em humanos foi capaz de reverter sintomas de esquizofrenia durante trinta dias (HALLAK et al., 2013). Esse trabalho foi o ponto de partida para um novo paradigma de pesquisa, em que tentaram testar se o NPS também poderia prevenir os sintomas da mesma doença em ratos (OLIVEIRA et al., 2015). Vale ressaltar que esses resultados confirmam exatamente os dados encontrados aqui neste estudo de doutorado em questão, porém no caso do trabalho de Oliveira et al. (2015), apenas testes comportamentais de campo aberto foram realizados, mas não os de memória declarativa como o descrito neste texto.

Outro estudo que encontrou resultados parecidos foi o de Diana e colaboradores, que em 2018 também testou se o NPS possuiria propriedades preventivas quanto ao desenvolvimento de esquizofrenia (DIANA et al., 2018). Nesse caso, esses pesquisadores, utilizando uma linhagem de ratos hipertensos (sabidamente um modelo animal de esquizofrenia já validado cientificamente), encontraram que um tratamento preventivo de longo prazo com NPS, no caso entre 30 e 60 dias posteriormente ao período pós-natal, foi efetivo em evitar hiperlocomoção, diminuição da interação social e prejuízos no condicionamento contextual ao medo. Como pode ser visto também, este estudo de Diana e colaboradores não utilizou testes de memória declarativa, como o descrito aqui nesta tese.

Pitsikas em 2015, também realizou um estudo em modelo animal de esquizofrenia com roedores através de CET, no qual testaram a efetividade do NPS no modelo através de testes comportamentais, inclusive, de memória declarativa. Os resultados também inéditos evidenciaram que o NPS possibilitou a reversão do quadro schizophrenia like ora induzido pela CET, mensurados através da ausência de déficits de armazenamento e evocação nos testes de reconhecimento de memória de curto prazo (PITSIKAS, 2015; TREVLOPOULOU; TOUZLATZI; PITSIKAS, 2016).

Através dessas evidências, os resultados aqui encontrados a respeito do uso preventivo do NPS, no período de neurodesenvolvimento de roedores, posicionam esta tese de doutorado como a primeira a encontrar o resultado de que o NPS 
pareceu ser efetivo em prevenir um quadro psychosis like, através da avaliação do domínio cognitivo desta doença, avaliado pelo teste de reconhecimento de objetos.

Ainda sobre os resultados do teste comportamental de reconhecimento de objetos, o mesmo padrão de resposta positiva pôde ser constatado, porém dessa vez em referência ao uso do CBD em fases precoces do neurodesenvolvimento de roedores, pois nesse mesmo grupo de ratos machos foram encontradas diferenças estatisticamente significavas no padrão de resultado de memória declarativa de 30 min, quando da comparação realizada com animais que foram previamente expostos ao uso de GLI no lugar de CBD. Mais uma vez, durante o teste de $24 \mathrm{~h}$ os animais do grupo se recuperaram totalmente do dano cognitivo ora provocado pelo uso prévio da CET.

Isso significa que o CBD ao ser utilizado preventivamente pareceu ser extremamente capaz em reverter o efeito psicótico da CET durante o teste de 30 min, aumentando o tempo gasto pelo animal em explorar um objeto novo. Corroborando esses resultados, Peres e colaboradores, em 2018, testaram o uso do CBD durante o período pré-adolescente de uma linhagem de ratos hipertensos e encontraram que essa substância foi capaz de prevenir anormalidades comportamentais em um modelo animal de esquizofrenia (PERES et al., 2018). Esses pesquisadores relatam que o uso preventivo do CBD evitou a hiperlocomoção dessa linhagem de ratos (aferida pelo teste de campo aberto), os déficits comumente encontrados nesses animais no teste de PPI, bem como os prejuízos normalmente encontrados sobre a tarefa de condicionamento contextual ao medo. A mesma equipe de Peres e colaboradores, em 2016, já havia descrito os efeitos aparentemente preventivos do CBD, porém daquela vez em um modelo animal de esquizofrenia, que utilizou um tipo específico de ativação imunológica pré-natal baseada no ácido policitidílico em ratas prenhas (PERES et al., 2016). Nesse estudo, apenas a hiperlocomoção, testada através do teste de campo aberto foi avaliada, com resultados preventivos surpreendentes.

De acordo com esses dados, os resultados aqui encontrados colocam esta tese de doutorado como a primeira a descobrir que o CBD possuiria um efeito potencial de prevenir e/ou atenuar os danos de memória declarativa encontrados nos modelos animais de esquizofrenia.

Por fim, a última sequência de testes comportamentais na tarefa de reconhecimento de objetos realizada em ratos machos, utilizou a aplicação de 
injeções IP da associação entre o NPS e o CBD, proporcionando uma análise de resultados compatíveis com desfechos positivos. Desse modo, mais uma vez, em conformidade com os resultados encontrados nos outros grupos de ratos machos, o uso dessas substâncias durante o teste de 30 min se mostrou, aparentemente, efetivo em prevenir o comportamento psychosis like, ora induzido pela CET. No caso, os resultados estatisticamente significativos encontrados dão embasamento científico claro para que esses agentes sejam considerados como capazes de aumentar o tempo gasto pelo animal explorando um objeto novo, ou seja, um comportamento típico que roedores, naturalmente, possuem em condições de saúde normais. Durante a tarefa de $24 \mathrm{~h}$ os resultados evidenciaram, novamente, que todos os animais do grupo reverteram totalmente do dano cognitivo induzido por CET.

A interação entre os sistemas glutamatérgico e endocanabinoide já foi discutida na literatura através de um extenso artigo de revisão escrito por SánchezBlázquez, Rodríguez-Muñhoz e Garzón (2014). Basicamente, a teoria que esses autores acreditam estar por trás da relação entre esses sistemas seria que o sistema endocanabinoide estaria amplamente difundido ao longo do SNC e que seus receptores $\mathrm{CB} 1$ possuiriam um papel crucial na prevenção da neurotoxicidade (PATRICIO-MARTINEZ et al., 2019), causada pela ativação dos receptores NMDA. $\mathrm{Na}$ verdade, seria a própria atividade dos receptores NMDA que forneceria as demandas necessárias dos canabinoides endógenos utilizados para controlar seus canais de cálcio (LIU et al., 2009). Portanto, o grande papel fisiológico desse sistema seria de manter as atividades dos receptores NMDA dentro de limites seguros, protegendo as células neurais da excitotoxidade.

Dessa maneira, os canabinoides poderiam ser capazes de controlar diversas disfunções neurais relacionadas a essa condição como, por exemplo, a superativação de receptores NMDA, entre outras. Nessa revisão, os pesquisadores acreditam que alguns canabinoides poderiam provocar psicose através do mesmo mecanismo comum de neuroproteção citado acima, ou seja, através da redução da atividade de receptores NMDA (SÁNCHEZ-BLÁZQUEZ; RODRÍGUEZ-MUÑHOZ; GARZÓN, 2014). Complementam explicando que os canabinoides produziriam esses efeitos por meio da redução da liberação pré-sináptica de glutamato ou interferindo com os receptores pós-sinápticos em suas vias sinalizadoras de regulação. A eficácia desse sistema requereria que o sistema endocanabinoide aplicasse sua influência negativa de maneira proporcional à força de sinalização dos 
receptores NMDA (MAYA-LÓPEZ et al., 2017). Portanto, esses canabinoides que agiriam no momento errado ou que exerceriam algum tipo de influência inadequada em seus receptores poderiam causar hipofunção de receptores NMDA.

Outro artigo inédito, que estudou a relação entre os dois sistemas, foi escrito por Katona e colaboradores, em 2006, no qual os pesquisadores estudaram a composição molecular do sistema endocanabinoide nas sinapses glutamatérgicas, usando para isso dois tipos de sondas marcadores de RNA, conhecidas por riboprobes (KATONA et al., 2006). Como resultado, afirmaram que a organização espacial do sistema endocanabinoide, que envolveria uma enzima sintética póssináptica conhecida como DGL-a, bem como o receptor pré-sináptico CB1 forneceriam evidências anatômicas diretas para a visão de que o 2-AG seria uma molécula de sinalização retrógrada em sinapses glutamatérgicas no SNC.

A respeito das análises estatísticas do grupo de ratos fêmeas durante o teste de memória declarativa, é válida a informação de que do mesmo modo que os resultados encontrados no grupo dos ratos machos, todos os animais fêmeas, os quais foram submetidos ao uso da CET como droga indutora de psicose, desenvolveram menores índices de preferência por exploração de um objeto novo durante o teste de $30 \mathrm{~min}$, em detrimento a um já habituado, quando comparados com os animais que foram induzidos com placebo, no caso SAL.

Por esse motivo, novamente se confere a esse tipo de padrão de resultado, que a exposição ao antagonista glutamatérgico foi adequadamente eficaz em produzir diminuição do tempo gasto explorando um objeto novo, nesses animais de gênero feminino. Um outro dado não menos importante é que durante o teste de 24 $\mathrm{h}$, diferentemente dos grupos de roedores machos, todos os grupos de animais fêmeas expostas a CET pioraram do dano cognitivo induzido por essa droga anestésica em níveis mais agressivos do que aqueles mensurados pelo teste de 30 $\min$.

Corroborando esses resultados encontrados, Neil e colaboradores, em 2010, elaboraram um estudo de revisão sobre diferentes tipos de modelos animais de esquizofrenia, com ênfase no domínio cognitivo em que drogas antagonistas glutamatérgicas possuiriam a propensão em produzir (NEIL et al., 2010). Descreveram como resultado principal que o uso agudo de CET foi consistente em evidenciar déficits importantes, tanto em memória de curto, quanto de longo prazo, tanto em estudos animais, quanto em estudos realizados em humanos. 
Resta lembrar que esse tipo de resultado, nesta tese de doutorado apresentado, bem como o nítido padrão menos agressivo de efeito psicótico da CET nos ratos fêmeas durante o teste de 30 min e sua consequente influência de gênero, já foi discutido no início da discussão do teste de reconhecimento de objetos no grupo de ratos machos (GRAYSON ; NEIL, 2004; SUTCLIFFE et al., 2008).

Por sua vez, quanto aos desfechos provenientes dos testes de memória declarativa entre os grupos de ratos fêmeas de maneira geral, é notório, um claro e evidente perfil muito parecido de resultados, quando da comparação com os dados obtidos pelos grupos de ratos machos, porém com peculiaridades únicas descritas a seguir. Desse modo, o primeiro grupo de análise comparativa que havia sido composto de ratos fêmeas, os quais foram submetidos ao NPS durante as fases iniciais do neurodesenvolvimento de roedores, apresentaram menores porcentagens de tempo gasto explorando um objeto novo durante ambos testes de 30 min e $24 \mathrm{~h}$, quando comparados com o grupo que havia sido exposto ao uso de GLI. Esse desfecho evidencia que nesse grupo de comparação, o NPS, aparentemente, não foi efetivo em prevenir e/ou atenuar, o comportamento schizophrenia like induzido pela CET.

Sequencialmente, outras análises estatísticas foram realizadas nesse grupo de ratos fêmeas, com o intuito de elucidação dos resultados encontrados durante o teste comportamental de memória declarativa de $30 \mathrm{~min}$ e de $24 \mathrm{~h}$ e, desse modo, os animais que utilizaram o CBD no período de maturação cerebral, quando comparado com os animais que foram expostos a GLI, no mesmo período, apresentaram um padrão de resultados completamente idêntico dos encontrados no grupo de ratos fêmeas que foram expostas ao NPS. Esses animais apresentaram menores índices de tempo gasto explorando um objeto novo, tornando-os um grupo de resultado com porcentagens de preferência por exploração de um objeto novo muito parecidos com um objeto já habituado. Por esse motivo, aparentemente seria possível afirmar que o CBD não foi eficaz em atenuar e/ou prevenir o comportamento psicótico induzido pela CET.

No entanto, o teste de memória declarativa utilizado nesta tese de doutorado e descrito no desenho experimental do estudo aqui proposto como citado anteriormente, reavalia os animais após $24 \mathrm{~h}$ da realização dos testes iniciais, e até então a maior parte dos animais do estudo descritos até aqui, retornaram as suas condições basais prévias de saúde, ou seja, saudáveis após essa avaliação de 24 h. 
De maneira mais clara, por exemplo, a maior parte dos animais machos que apresentaram quadros de psicose franca extremamente agressivos após uso de CET e que foram expostos a GLI, no período de maturação cerebral, ou seja, ao placebo, remitiram completamente a ausência de déficits cognitivos aferidos pelo teste de memória declarativa de $24 \mathrm{~h}$. Vale ressaltar, sendo facilmente observável que desses animais que não remitiram as suas condições basais de saúde, todos eram do gênero feminino, e por esse motivo esses resultados proporcionam mais uma vez dados sobre a teoria, já descrita nesse trabalho, de alguma influência de gênero nos resultados encontrados.

Esses animais descritos no paragrafo acima, os quais não remitiram de seus sintomas psicóticos após o teste de $24 \mathrm{~h}$, ou seja, os roedores dos grupos de ratos fêmeas expostas ao NPS e ao CBD, além de não remitiram após 24 horas de teste, pelo contrário, pioraram ainda mais de seus domínios cognitivos, produzindo menos porcentagem de tempo gasto explorando um objeto novo do que quando realizaram a primeira fase do teste. Por esse motivo, a questão que surge seria: o que pode ter acontecido com esses animais? Além da explicação de gênero descrita acima, uma vez que nenhum outro tipo de grupo de animais machos apresentou um declínio cognitivo progressivo em nível tão crítico, e mais importante, sem remissão até o período de seu sacrifício, uma outra explicação plausível para esse ocorrido seria de que, eventualmente, essas ninhadas de roedores possam ter sofrido algum tipo de acometimento patológico, que infelizmente não havia sido observado antes do início dos testes comportamentais.

Como ilustração, é sabido que algumas drogas utilizadas nesse projeto, por exemplo, NPS e CET podem ser toxicas se usadas em excesso. O NPS possui a possibilidade, se usado em demasia, de causar intoxicação por cianeto, fato que explicaria a piora cognitiva no grupo NPS, mas não no grupo CBD. Na verdade, a explicação por trás desse fenômeno consiste no conhecimento de que o metabolismo do NPS produz como resultado cianeto e tiocianeto e, desse modo, sempre que se usa NPS na pratica clínica é necessário considerar que doses altas e prolongadas dessa substancia poderiam causar um tipo de intoxicação que cursa com cefaleia, ansiedade, agitação, confusão mental, letargia, convulsão e coma (LINAKIS; LACOUTURE; WOOLF, 1991; MOFFETT; PRICE, 2008). Complementase a esse raciocínio a informação de que, tanto NPS quanto CBD, bem como CET são substâncias totalmente seguras para uso, se usadas dentro dos rígidos critérios 
técnicos adotados nesta tese de doutorado (ZUARDI et al., 2012; HAMMER et al., 2015; WAN et al., 2015).

Outro aspecto analisado neste grupo de ratos fêmeas foi o da associação de NPS e de CBD, através de injeções IP dessas drogas, na mesma fase inicial do neurodesenvolvimento de roedores, quando comparado com o uso de GLI no mesmo período. Os resultados novamente aqui atestados vão na linha oposta dos achados descritos acima e dão ênfase ao efeito atenuante e preventivo dessas substâncias em produzir maiores tempos gastos explorando um objeto novo, quando comparado a um objeto já conhecido pelo animal. É possível afirmar que a associação de NPS e CBD no teste de $30 \mathrm{~min}$, aparentemente, foi eficaz em prevenir o comportamento psychosis like induzido pela CET.

Ineditamente, torna-se intrigante a constatação que os ratos fêmeas expostos isoladamente ao NPS e também ao CBD não apresentaram resultados positivos a prevenção de psicose, enquanto que o uso associado de NPS com CBD, evidenciaram efeitos protetivos. Como já descrito anteriormente, a resposta a essa constatação reside em um eventual efeito sinérgico de potencialização entre os sistemas endocanabinóide e glutamatérgico (HALLAK et al., 2011).

Outro resultado importantíssimo foi que durante a avaliação de $24 \mathrm{~h}$, esse grupo de ratos fêmeas, os quais utilizaram a associação de NPS e de CBD também apresentou um efeito preventivo ao desenvolvimento de psicose. Por esse motivo, ou seja, de resultados positivos tanto no teste de 30 min quanto no de $24 \mathrm{~h}$, se pode afirmar que este foi o único grupo do estudo a apresentar efeitos preventivos mais prolongados e duradouros quanto a um quadro schizophrenia like. Fato esse que poderia ser explicado devido a algum tipo de efeito sinérgico de aumento de potência, ainda a ser estudado entre ambas as drogas e caracterizado por maiores níveis de proteção encontrados.

Mais uma vez, de acordo com o conhecimento do grupo de pesquisa responsável pela elaboração desta tese, este é o primeiro estudo realizado sobre o uso preventivo da associação de NPS e de CBD, no período de maturação cerebral de roedores, testados através do teste comportamental de memória declarativa. Portanto, não existem outros trabalhos já realizados na literatura que possam corroborar ou discordar dos resultados aqui encontrados.

O artigo que mais se aproxima do desenho experimental aqui utilizado, realizado por meio da tarefa de memória declarativa, porém que não utilizou essas 
substâncias (NPS e CBD), mas apenas o NPS, e que também não o utilizou em um período de neurodesenvolvimento, foi o de Kandratavicius et al. (2015). Nesse estudo, como já descrito acima, os pesquisadores referem que após um tratamento terapêutico e não preventivo de NPS realizado em roedores, que essa droga foi capaz de recuperar a memória de longo prazo, porém interessantemente o NPS também foi capaz de induzir déficits nos testes de memória de curto prazo nos animais do grupo controle. Eles reiteram que outros estudos realizados com outros tipos de doadores de ON, como por exemplo, o S-nitroso-N-acetilpenicilamina, na memória de trabalho espacial, não evidenciou efeitos similares em controles animais (YAMADA et al., 1996).

Em outro artigo realizado neste mesmo tema, uma substância doadora de ON diferente foi utilizada, dessa vez a molsidomina, além também do próprio NPS, com outro tipo de metodologia de teste de reconhecimento de objetos, porém também sem nenhum tipo de resultado efetivo (GOURGIOTIS et al., 2012). Vale ressaltar que neste estudo foram utilizadas dosagens cinco vezes menores de NPS que no estudo de Kandratavicius et al. (2015). 


\section{CONCLUSÃO}

A premissa básica para que todos os paradigmas experimentais propostos nesta tese de doutorado pudessem ser conduzidos e avaliados, de maneira clara e objetiva, residiu no sucesso do desenho experimental de indução de psicose aqui proposto. Portanto, de acordo com os resultados ora apresentados se pode afirmar com clareza que, de maneira geral, esse modelo experimental utilizado, o qual consistiu no uso crônico de $30 \mathrm{mg} / \mathrm{kg}$ de CET durante cinco dias consecutivos se mostrou extremamente efetivo em produzir sintomas psicóticos característicos das diversas dimensões psicopatológicas da esquizofrenia. Dessa maneira, podendo ser utilizado com segurança e sem riscos de vieses metodológicos oriundos da falta de validação desse modelo, por outros pesquisadores em estudos futuros de modelos animais schizophrenia like.

A CET, durante o teste de campo aberto, foi capaz de produzir hiperlocomoção nos roedores, principalmente, nas fêmeas e em menor monta nos machos, mas não foi nitidamente efetiva em produzir menores tempos permanecidos dentro do centro da arena. Já no teste de preferência por sacarose, o mesmo agente anestésico também foi efetivo em diminuir a ingestão de bebida açucarada, porém esse efeito foi visível apenas nos animais de gênero masculino. Por fim, durante o teste de reconhecimento de objetos, a CET foi capaz de diminuir o tempo de exploração de um objeto novo, porém mais uma vez esse efeito foi muito maior nos roedores do sexo masculino. É possível, então, através destes resultados afirmar que a CET possui a propensão de exercer seus efeitos psicóticos em maior grau em roedores do gênero masculino e que o mecanismo exato, pelo qual esse processo ocorre, precisa ainda ser estudado coerentemente, apesar de possivelmente haver uma influência do estrogênio nesse processo.

Tanto NPS quanto CBD, bem como a associação entre NPS e CBD puderam após o término do estudo ser consideradas, de maneira geral, substâncias com sérios indícios de efetividade na atenuação e/ou até mesmo na prevenção de sintomas característicos da esquizofrenia. Essa afirmação pode ser constatada através dos resultados apresentados após a tarefa comportamental de campo aberto, mais especificamente, durante os testes de hiperlocomoção, nos quais a maior parte dos grupos do estudo, apresentaram resultados apontando que essas substâncias, aparentemente, tiveram a capacidade de atenuar os sintomas 
psicóticos positivos produzidos, através da diminuição das distâncias totais percorridas pelos animais do grupo que foram, previamente ao teste, estimuladas por CET. Chama a atenção, após observação minuciosa dos desfechos do teste de atividade locomotora, que esses resultados foram proeminentemente mais visíveis nos animais de gênero feminino. Surpreendentemente, esses grupos de ratos fêmeas, que também foram os mais gravemente acometidos por sintomas psicóticos positivos oriundos da CET responderam de maneira mais eficaz aos efeitos preventivos, tanto de NPS quanto de CBD, e também da associação de ambos, corroborando estudos atuais, os quais atestam que mulheres portadoras de esquizofrenia apresentam um melhor prognóstico ao longo da vida, por algum tipo de mecanismo que ainda precisa ser investigado e que, provavelmente, esteja relacionado aos níveis de estrogênio presentes nesses organismos.

Outro ponto importante desses resultados é o fato de que a associação do NPS com o CBD pareceu ter gerado alguma espécie de efeito sinérgico de potencialização, visualizada por melhores performances no teste, e por um mecanismo ainda a ser investigado, mas que provavelmente envolva algum tipo de interação entre os sistemas glutamatérgico e dos receptores endocanabinoides.

$\mathrm{Na}$ tarefa comportamental de proporção de tempo no centro da arena, o NPS, o CBD e a associação de ambas as drogas não se mostraram efetivas em aumentar o tempo gasto pelo animal no centro da arena, porém esse tipo de tarefa comportamental deve ser encarado muito mais como um teste de avaliação do nível de ansiedade de determinadas espécies de animais, do que de avaliação específica de um comportamento schizophrenia like propriamente dito. De qualquer maneira, durante a realização deste teste, outro achado inédito ocorreu. Trata-se da possibilidade da prevenção de comportamentos anxiety like através do uso isolado do CBD preventivamente, pois essa substância se mostrou efetiva em aumentar o tempo gasto pelos animais no centro da arena. Desse modo, cria-se um novo paradigma de pesquisa, ainda a ser evidentemente comprovado e testado, a respeito da possibilidade de se prevenir, ou de pelo menos atenuar, determinados transtornos ansiosos, através de estimulações preventivas realizadas por meio do uso do CBD em períodos de maturação cerebral.

Quanto aos resultados do NPS, do CBD e da associação de ambas, no teste comportamental de preferência por sacarose se pode afirmar que essas drogas não se mostraram efetivas em prevenir o comportamento schizophrenia like induzido por 
CET. Entretanto, interessantemente, essas substâncias foram, de maneira geral, responsáveis pela piora da ingestão de sacarose, principalmente, nos animais do gênero feminino, dando mais uma vez a ideia de algum tipo de influência de gênero que precisa ser mais bem investigada futuramente. Essa piora na ingestão de sacarose pode estar relacionada a algum tipo de mecanismo de neurotransmissão cerebral, ainda desconhecido, no qual essas drogas possam estar inter-relacionadas e possuírem a capacidade de exercer tais efeitos acima descritos. Infelizmente, não existem estudos sobre este tema até o momento, porém é sabido, por exemplo, que a CET também é um potente agente antidepressivo, e uma vez que o NPS apresenta propriedades farmacológicas de uma possível espécie de reversão dos efeitos desse agente anestésico, seria perfeitamente viável de interrogar se eventualmente o NPS poderia ter provocado algum tipo de quadro depressivo, que ainda não estaria muito bem elucidado na literatura científica atual.

Finalizando, durante o último teste realizado neste trabalho de doutorado, ou seja, a tarefa comportamental de memória declarativa, tanto NPS quanto CBD, bem como a associação entre ambas pareceram ser extremamente efetivas em prevenir sintomas psicóticos da dimensão cognitiva da esquizofrenia, sendo responsáveis por aumentar o tempo de exploração de um objeto novo em detrimento a um já conhecido, posteriormente aos efeitos de piora cognitiva induzida pela CET no teste. Vale ressaltar também, mais uma vez, uma possível influencia de gênero nos resultados encontrados principalmente nos testes de $24 \mathrm{hs}$, bem como algum tipo ainda a ser estudado de efeito sinérgico de potencialização entre os sistemas endocanabinóide e glutamatérgico. 


\section{REFERÊNCIAS}

ABEKAWA, T.; ITO, K.; NAKAGAWA, S.; KOYAMA, T. Prenatal exposure to an NMDA receptor antagonist, MK-801 reduces density of parvalbumin-immunoreactive GABAergic neurons in the medial prefrontal cortex and enhances phencyclidineinduced hyperlocomotion but not behavioral sensitization to methamphetamine in postpubertal rats. Psychopharmacology, v. 192, n. 3, p. 303-316, Jun. 2007.

AKYOL, O.; ZOROGLU, S. S.; ARMUTCU, F.; SAHIN, S; GUREL, A. Nitric oxide as a physiopathological factor in neuropsychiatric disorders. In Vivo, v. 18, n. 3, p. 377390, May./Jun. 2004.

ALBERT, N.; WEIBELL, M. A. The outcome of early intervention in first episode psychosis. International Review Psychiatry, v. 31, n. 5-6, p. 413-424, Aug./Sep. 2019.

ALMEIDA, V.; LEVIN, R.; PERES, F. F.; NIIGAKI, S. T.; CALZAVARA, M. B.; ZUARDI, A. W.; HALLAK, J. E.; CRIPPA, J. A.; ABÍLIO, V. C. Cannabidiol exhibits anxiolytic but not antipsychotic property evaluated in the social interaction test. Progress in Neuro-Psychopharmacology and Biological Psychiatry, v. 41, p. 3035, Mar. 2013.

ALMEIDA, V.; PERES, F. F.; LEVIN, R.; SUIAMA, M. A.; CALZAVARA, M. B.; ZUARDI, A. W.; HALLAK, J. E.; CRIPPA, J. A.; ABÍLIO, V. C. Effects of cannabinoid and vanilloid drugs on positive and negative-like symptoms on an animal model of schizophrenia: the SHR strain. Schizophrenia Research, v. 153, n. 1-3, p. 150-159, Mar. 2014.

AMERICAN PSYCHIATRIC ASSOCIATION. Diagnostic and Statistical Manual of Mental Disorders. Fourth Edition, Text Revision. Washington, DC: American Psychiatric Publishing, 2000.

AMERICAN PSYCHIATRIC ASSOCIATION. Diagnostic and Statistical Manual of Mental Disorders: DSM-V. Arlignton, VA: American Psychiatric Publishing, 2013.

ANDREASEN, N. C. Understanding the causes of schizophrenia. The New England Journal of Medicine, v. 340, n. 8, p. 645-647, Feb. 1999.

ANDREASEN, N. C.; NOPOULOS, P.; O'LEARY, D. S.; MILLER, D. D.; WASSINK, T.; FLAUM, M. Defining the phenotype of schizophrenia: cognitive dysmetria and its neural mechanisms. Biological Psychiatry, v. 46, n. 7, p. 908-920, 1999.

ANDREWS, G.; SANDERSON, K.; CORRY, J.; ISSAKIDIS, C. Lapsley, H. Costeffectiveness of current and optimal treatment for schizophrenia. The British Journal of Psychiatry, v. 183, n. 5, p. 427-435, Nov. 2003.

AYHAN, Y.; ABAZYAN, B.; NOMURA, J.; KIM, R.; LADENHEIM, B.; KRASNOVA, I. N.; SAWA, A.; MARGOLIS, R. L.; CADET, J. L.; MORI, S.; VOGEL, M. W.; ROSS, C. A.; PLETNIKOV, M. V. Differential effects of prenatal and postnatal expressions of mutant human DISC1 on neurobehavioral phenotypes in transgenic mice: evidence 
for neurodevelopmental origin of major psychiatric disorders. Molecular Psychiatry, v. 16, n. 3, p. 293-306, Mar. 2011.

BATH, K. G.; CHUANG, J.; SPENCER-SEGAL, J. L.; AMSO, D.; ALTEMUS, M.; MCEWEN, B. S.; LEE, F. S. Variant brain-derived neurotrophic factor (Valine66Methionine) polymorphism contributes to developmental and estrous stagespecific expression of anxiety-like behavior in female mice. Biological Psychiatry, v. 72, n. 6, p. 499-504, Sep. 2012.

BERMAN, R. M.; CAPPIELLO, A.; ANAND, A.; OREN, D. A. HENINGER, G. R.; CHARNEY, D. S.; KRYSTAL, J. H. Antidepressant effects of ketamine in depressed patients. Biological Psychiatry, v. 47, n. 4, p. 351-354, Feb. 2000.

BERNATOVA, I.; PUZSEROVA, A.; SESTAKOVA, N.; MACH, M. Horiziontal motor activity of hypertensive rats is associated with level of blood pressure. Acta Physiologica: Official journal of the Federation of European Physiological Societies, v. 685 , n. 202, p. 84, 2011.

BERNSTEIN, H. G.; BOGERTS, B.; KEILHOFF, G. The many faces of nitric oxide in schizophrenia. A review. Schizophrenia Research, v. 78, n. 1, p. 69-86, Oct. 2005.

BIRD, D.; BUJAS-BOBANOVIC, M.; ROBERTSON, H.; DURSUN, S. Lack of phencyclidine-induced effects in mice with reduced neuronal nitric oxide synthase. Psychopharmacology, v. 155, n. 3, p. 299-309, 2001.

BLISS, T. V.; COLLINGRIDGE, G. L. A synaptic model of memory: Long-term potentiation in the hippocampus. Nature, v. 361, n. 6407, p. 31-39, Jan. 1993.

BLOOMFIELD, P. S.; SELVARAJ, S.; VERONESE, M.; RIZZO, G. A. BERTOLDO, A.; OWEN, D. R.; BLOOMFIELD, M. A. P.; BONOLDI, I.; KALK, N.; TURKHEIMER, F.; MCGUIRE, P.; PAOLA, V.; HOWES. O. D. Microglial Activity in People at Ultra High Risk of Psychosis and in Schizophrenia: An [(11)C]PBR28 PET Brain Imaging Study. American Journal Psychiatry, v. 173, n. 1, p. 44-52, Jan. 2016.

BORELLA, V. C. M.; SEEMAN, M. V.; CORDEIRO, R. C.; SANTOS, J. V. S.; SOUZA, M. R. M.; FERNANDES, E. N. S.; MONTE, A. S.; VASCONCELOS, S. M. M.; QUINN, J. P.; LUCENA, D. F.; CARVALHO, A. F.; MACÊDO, D. Gender and estrous cycle influences on behavioral and neurochemical alterations in adult rats neonatally administered ketamine. Developmental Neurobiology, v. 76, n. 5, p. 519-532, May 2015.

BRADY, A. M.; O'DONNELL, P. Dopaminergic modulation of prefrontal cortical input to nucleus accumbens neurons in vivo. Journal of Neuroscience, v. 24, n. 5, p. 1040-1049, Feb. 2004.

BREDT, D. S.; SNYDER, S. H. Nitric oxide, a novel neuronal messenger. Neuron, v. 8, n. 1, p. 3-11, Jan 1992.

BRENMAN, J. E.; BREDT, D. S. Synaptic signaling by nitric oxide. Current Opinion in Neurobiology, v. 7, n. 3, p. 374-378, Jun. 1997. 
BROADHURST, P. L. Psychogenetics of emotionality in the rat. Annals of the New York Academy of Sciences, v. 159, n. 3, p. 806-824, Jul. 1969.

BROWN, A. S.; DERKITS, E. J. Prenatal infection and schizophrenia: a review of epidemiologic and translational studies. American Journal of Psychiatry, v. 167, n. 3, p. 261-280, Mar. 2010.

BUCHANAN, R. W.; JAVITT, D. C.; MARDER, S. R.; SCHOOLER, N. R.; GOLD, J. M.; MCMAHON, R. P.; HERESCO-LEVY, U.; CARPENTER, W. T. The Cognitive and Negative Symptoms in Schizophrenia Trial (CONSIST): the efficacy of glutamatergic agents for negative symptoms and cognitive impairments. American Journal of Psychiatry, v. 164, n. 10, p. 1593-1602, Oct. 2007.

BUCHMANN, A.; DENTICO, D.; PETERSON, M. J.; RIEDNER, B. A.; SARASSO, S.; MASSIMINI, M.; TONONI, G.; FERRARELLI, F. Reduced mediodorsal thalamic volume and prefrontal cortical spindle activity in schizophrenia. Neuroimage, v. 102 Pt 2, p. 540-547, Nov. 2014.

BUJAS-BOBANOVIC, M.; BIRD, D. C.; ROBERTSON, H. A.; DURSUN, S. M. Blockade of phencyclidine-induced effects by a nitric oxide donor. British journal of pharmacology, v. 130, n. 5, p. 1005-1012, Jul. 2000.

CALISKAN, H.; AKAT, F.; TATAR, Y.; ZALOGLU, N.; DURSUN, A. D.; BASTUG, M.; FICICILAR, $\mathrm{H}$. Effects of exercise training on anxiety in diabetic rats. Behavioural Brain Research, v. 376, p. 112084, Dec. 2019.

CAMPOS, A. C.; GUIMARÃES, F. S. Involvement of 5HT1A receptors in the anxiolytic-like effects of cannabidiol injected into the dorsolateral periaqueductal gray of rats. Psychopharmacology, v. 199, n. 2, p. 223-230, Aug. 2008.

CARDNO, A. G.; GOTTESMAN, II. Twin studies of schizophrenia: from bow-andarrow concordances to star wars $\mathrm{Mx}$ and functional genomics. American journal of Medical Genetics, v. 97, n. 1, p. 12-17, 2000.

CARDNO, A. G.; MARSHALL, E. J.; COID, B.; MACDONALD, A. M.; RIBCHESTER, T. R.; DAVIES, N. J.; VENTURI, P.; JONES, L. A.; LEWIS, S. W.; SHAM, P. C.; GOTTESMAN, I. I.; FARMER, A. E.; MCGUFFIN, P.; REVELEY, A. M.; MURRAY, R. M. Heritability estimates for psychotic disorders: the Maudsley twin psychosis series. Archives of General Psychiatry, v. 56, n. 2, p. 162-168, Feb. 1999.

CARLSSON, A.; LINDQVIST, M. Effect of chlorpromazine or haloperidol on formation of 3methoxytyramine and normetanephrine in mouse brain. Acta Pharmacologica et Toxicologica, v. 20, n. 2, p. 140-144, Sep. 1963.

CARLSSON, A.; LINDQVIST, M.; MAGNUSSON, T. 3,4-Dihydroxyphenylalanine and 5-hydroxytryptophan as reserpine antagonists. Nature, v. 180 , n. 4596, p. 1200, Nov. 301957.

CASTAGNINI, A.; BERRIOS, G. E. Acute and transient psychotic disorders (ICD-10 F23): a review from a European perspective. European Archives of Psychiatry and Clinical Neuroscience, v. 259, n. 8, p. 433-443, Dec. 2009. 
CHAN, M. H.; CHIU, P. H.; SOU, J. H.; CHEN, H. H. Attenuation of ketamine-evoked behavioral responses by mGluR5 positive modulators in mice. Psychopharmacology, v. 198, n. 1, p. 141-148, May 2008.

CHAN, S. K. W.; CHAN, H. Y. V.; DEVLIN, J.; BASTIAMPILLAI, T.; MOHAN, T.; HUI, C. L. M.; CHANG, C. C.; LEE, E. H. M.; CHEN, E. Y. H. A systematic review of longterm outcomes of patients with psychosis who received early intervention services. Internatioal Review of Psychiatry, v. 31, n. 5-6, p. 425-440, Aug./Sep. 2019.

CHATTERJEE, M.; GANGULY, S.; SRIVASTAVA, M.; PALIT, G. Effect of 'chronic' versus 'acute' ketamine administration and its 'withdrawal' effect on behavioural alterations in mice: implications for experimental psychosis. Behavioural Brain Research, v. 216, n. 1, p. 247-254, Jan. 2011.

CHESSELL, I. P.; PROCTER, A. W.; FRANCIS, P. T.; BOWEN, D. M. D-cycloserine, a putative cognitive enhancer, facilitates activation of the $\mathrm{N}$-methyl-D-aspartate receptor-ionophore complex in Alzheimer brain. Brain Research, v. 565, n. 2, p. 345348, Nov. 1991.

CRIPPA, J. A.; DERENUSSON, G.; ZUARDI, A. W.; WICHERT-ANA, L. DURAN, F.; FERRARI, T. B.; MARTIN-SANTOS, R.; MCGUIRE, P. K.; BUSATTO, G. F.; HALLAK, J. E. The effect of cannabidiol (CBD), a cannabis sativa constituent, on neural correlates of anxiety: a regional cerebral blood flow study. Schizophrenia Bulletin, v. 35, p. 197-198, 2009.

CRIPPA, J. A.; HALLAK, J. E.; ABILIO, V. C.; LACERDA, A. L.; ZUARDI, A. W. Cannabidiol and Sodium Nitroprusside: Two Novel Neuromodulatory Pharmacological Interventions to Treat and Prevent Psychosis. CNS \& Neurological Disorders-Drug Targets, v. 14, n. 8, p. 970-978, 2015.

CRIPPA, J. A.; ZUARDI, A. W.; HALLAK, J. E. Therapeutical use of the cannabinoids in psychiatry]. Brazilian Journal of Psychiatry, v. 32, supl. 1, p. S56-S66, May 2010.

CROW, T. J. Is schizophrenia the price that Homo sapiens pays for language? Schizophrenia Researche, v. 28, n. 2-3, p. 127-41, Dec. 1997.

CROW, T. J. Molecular pathology of schizophrenia: more than one disease process? British Medical Journal, v. 280, n. 6207, p. 66-68, Jan. 1980.

DAILYMED. Nitropress. 2016.2 Disponível em: https://dailymed.nlm.nih.gov/dailymed/fda/fdaDrugXsl.cfm?setid=123c61ec-d930499e-a27a-0cd82d2bd8ce\&type=display. Acesso em: 08 jan. 2020.

DALTIO, C. S.; MARI, J. J.; FERRAZ, M. B. Direct medical costs associated with schizophrenia relapses in health care services in the city of Sao Paulo. Revista de Saúde Pública, v. 45, n. 1, p. 14-23, Feb. 2011.

DAVIS, K. L.; KAHN, R. S.; KO, G.; DAVIDSON, M. Dopamine in schizophrenia: A review and reconceptualization. American Journal of Psychiatry, v. 148, n. 11, p. 1474-1486, Nov. 1991. 
DEAKIN, J. F.; SIMPSON, M. D. A two-process theory of schizophrenia: evidence from studies in post-mortem brain. Journal of Psychiatric Research, v. 31, n. 2, p. 277-295, Mar./Apr. 1997.

DEAN, B.; SUNDRAM, S.; BRADBURY, R.; SCARR, E.; COPOLOV, D. Studies on $[3 \mathrm{H}] \mathrm{CP}-55940$ binding in the human central nervous system: regional specific changes in density of cannabinoid-1 receptors associated with schizophrenia and cannabis use. Neuroscience, v. 103, n. 1, p. 9-15, 2001.

DEUTSCHENBAUR, L.; BECK, J.; KIYHANKHADIV, A.; MUHLHAUSER, M.; BORGWARDT, S.; WALTER, M.; HASLER, G.; SOLLBERGER, D.; UNDINE, E.; LANG, E. Role of calcium, glutamate and NMDA in major depression and therapeutic application. Progress Neuro-Psychopharmacology and Biological Psychiatry, v. 64, p. 325-333, Jan. 2016.

DEVANE, W. A.; AXELROD, J. Enzymatic synthesis of anandamide, an endogenous ligand for the cannabinoid receptor, by brain membranes. Proceedings of the National Academy of Sciences, v. 91, n. 14, p. 6698-6701, Jul. 1994.

DIANA, M. C.; PERES, F. F.; JUSTI, V.; BRESSAN, R. A.; ACIOLY, L. T. L; CRIPPA, J. A.; HALLAK, J. E. C.; ABILIO, V. C. Sodium nitroprusside is effective in preventing and/or reversing the development of schizophrenia-related behaviors in an animal model: The SHR strain. CNS Neuroscience \& Therapeutics, v. 24, n. 7, p. 624-632, Jul. 2018.

DONOGHUE, K.; DOODY, G. A.; MURRAY, R. M.; JONES, P. B.; MORGAN, C.; DAZZAN, P.; HART, J.; MAZZONCINI, R.; MACCABE, J. H. Cannabis use, gender and age of onset of schizophrenia: data from the AESOP study. Psychiatry Research, v. 215, n. 3, p. 528-532, Mar. 2014.

D'SOUZA, D. C.; FRIDBERG, D. J.; SKOSNIK, P. D.; WILLIAMS, A.; ROACH, B.; SINGH, N.; CARBUTO, M.; ELANDER, J.; SCHNAKENBERG, A.; PITTMAN, B.; SEWELL, R. A.; RANGANATHAN, M.; MATHALON, D. Dose-related modulation of event-related potentials to novel and target stimuli by intravenous $\delta 9-\mathrm{THC}$ in humans. Neuropsychopharmacology, v. 37, n. 7, p. 1632, 2012.

D'SOUZA, D. C.; PERRY, E.; MACDOUGALL, L.; AMMERMAN, Y.; COOPER, T.; WU, Y.; BRALEY, G.; GUEORGUIEVA, R.; KRYSTAL, J. H. The psychotomimetic effects of intravenous delta-9-tetrahydrocannabinol in healthy individuals: Implications for psychosis. Neuropsychopharmacology, v. 29, n. 8, p. 1558-1572, Aug. 2004.

DUNCAN, G. E.; MOY, S. S.; KNAPP, D. J.; MUELLER, R. A.; BREESE, G. R. Metabolic mapping of the rat brain after subanesthetic doses of ketamine: potential relevance to schizophrenia. Brain Research, v. 787, n. 2, p. 181-190, Mar. 1998.

EAGLE, A. L.; GAJEWSKI, P. A.; YANG, M.; KECHNER, M. E.; AL MASRAF, B. S.; KENNEDY, P. J.; WANG, H.; MAZEI-ROBISON, M. S.; ROBISON, A. J. ExperienceDependent Induction of Hippocampal DeltaFosB Controls Learning. Journal of Neuroscience, v. 35, n. 40, p. 13773-13783, Oct. 2015. 
ELSAID, S.; KLOIBER, S.; LE FOLL, B. Effects of cannabidiol (CBD) in neuropsychiatric disorders: A review of pre-clinical and clinical findings. Progress in Molecular Biology and Translational Science, v. 167, p. 25-75, 2019.

ENNACEUR, A.; DELACOUR, J. A new one-trial test for neurobiological studies of memory in rats. 1: Behavioral data. Behavioral Brain Research, v. 31, n. 1, p. 4759, Nov. 1988.

ENOMOTO, T.; NODA, Y.; NABESHIMA, T. Phencyclidine and genetic animal models of schizophrenia developed in relation to the glutamate hypothesis. Methods and Findings in Experimental and Clinical Pharmacology, v. 29, n. 4, p. 291-301, May 2007.

FADDA, E.; DANYSZ, W.; WROBLEWSKI, J. T.; COSTA, E. Glycine and D-serine increase the affinity of $\mathrm{N}$-methyl-D-aspartate sensitive glutamate binding sites in rat brain synaptic membranes. Neuropharmacology, v. 27, n. 11, p. 1183-1185, Nov. 1988.

FEINBERG, I. Schizophrenia: Caused by a fault in programmed synaptic elimination during adolescence? Journal of Psychiatric Research, v. 17, n. 4, p. 319-334, 1982.

FERRARI, M. C.; BUSATTO, G. F.; MCGUIRE, P. K.; CRIPPA, J. A. Structural magnetic resonance imaging in anxiety disorders: an update of research findings. Brazilin Journal of Psychiatry, v. 30, n. 3, p. 251-264, Sep. 2008.

FERRIS, R. M.; TANG, F. L.; MAXWELL, R. A. A comparison of the capacities of isomers of amphetamine, deoxypipradrol and methylphenidate to inhibit the uptake of tritiated catecholamines into rat cerebral cortex slices, synaptosomal preparations of rat cerebral cortex, hypothalamus and striatum and into adrenergic nerves of rabbit aorta. Journal of Pharmacology and Experimental Therapeutics, v. 181, n. 3, p. 407-416, Jun. 1972.

FOGACA, M. V.; CAMPOS, A. C.; COELHO, L. D.; DUMAN, R. S.; GUIMARÃES, F. $S$. The anxiolytic effects of cannabidiol in chronically stressed mice are mediated by the endocannabinoid system: Role of neurogenesis and dendritic remodeling. Neuropharmacology, v. 135, p. 22-33, Jun. 2018.

FOWLER, C. J. The cannabinoid system and its pharmacological manipulation--a review, with emphasis upon the uptake and hydrolysis of anandamide. Fundamental \& Clinical Pharmacology, v. 20, n. 6, p. 549-562, Dec. 2006.

FROHLICH, J.; VAN HORN, J. D. Reviewing the ketamine model for schizophrenia. Journal of Psychopharmacology, v. 28, n. 4, p. 287-302, Apr. 2014.

FUSAR-POLI, P.; DESTE, G.; SMIESKOVA, R.; BARLATI, S. YUNG, A. R.; HOWES, O.; STIEGLITZ, R. D.; VITA, A.; MCGUIRE, P.; BORGWARDT, S. Cognitive functioning in prodromal psychosis: a meta-analysis. Archives of General Psychiatry, v. 69, n. 6, p. 562-571, Jun. 2012. 
GALDERISI, S.; BUCCI, P.; UÇOK, A.; PEUSKENS, J. No gender differences in social outcome in patients suffering from schizophrenia. European Psychiatry, v. 27, n. 6, p. 406-408, Aug. 2012.

GAO, Y.; VASILYEV, D. V.; GONÇALVES, M. B.; HOWELL, F. V. HOBBS, C., REISENBERG, M., SHEN, R.; Mei-Yi ZHANG, Brian W. STRASSLE, Peimin LU, MARK, L.; PIESLA, M. J.; DENG, K.; KOURANOVA, E. V.; RING, R. H.; WHITESIDE, G. T.; BATES, B.; WALSH, F. S.; WILLIAMS, G.; PANGALOS, M. N.; SAMAD, T. A.; DOHERTY, P. Loss of retrograde endocannabinoid signaling and reduced adult neurogenesis in diacylglycerol lipase knock-out mice. Journal of Neuroscience, v. 30, n. 6, p. 2017-2024, Feb. 2010.

GAONI, Y.; MECHOULAM, R. Isolation, structure and partial synthesis of an active constituent of hashish. Journal of the American Chemical Society, v. 86, p. 16461647, 1964.

GATTAZ, W. F.; CRAMER, H.; BECKMANN, H. Low CSF concentrations of cyclic GMP in schizophrenia. Brazilian Jounal of Psychiatry, v. 142, p. 288-291, Mar. 1983.

GELDWERT, D.; NORRIS, J. M.; FELDMAN, I. G.; SCHULMAN, J. J.; JOYCE, M. P.; RAYPORT, S. Dopamine presynaptically and heterogeneously modulates nucleus accumbens medium-spiny neuron GABA synapses in vitro. BMC Neuroscience, v. 7, n. 1, p. 53, Jun. 2006.

GENTSCH, C.; LICHTSTEINER, M.; FEER, H. Open field and elevated plus-maze: a behavioural comparison between spontaneously hypertensive (SHR) and WistarKyoto (WKY) rats and the effects of chlordiazepoxide. Behavioural Brain Research, v. 25, n. 2, p. 101-107, Aug. 1987.

GERHARD, D. M.; WOHLEB, E. S.; DUMAN, R. S. Emerging treatment mechanisms for depression: focus on glutamate and synaptic plasticity. Drug Discovery Today, v. 21, n. 3, p. 454-464, Mar. 2016.

GIORDANO, G. M.; STANZIANO, M.; PAPA, M.; MUCCI, A.; PRINSTER, A.; SORICELLI, A.; GALDERISI, S. Functional connectivity of the ventral tegmental area and avolition in subjects with schizophrenia: a resting state functional MRI study. European Neuro-Psychopharmacology, v. 28, n. 5, p. 589-602, May 2018.

GIUFFRIDA, A.; LEWEKE, F. M.; GERTH, C. W.; SCHREIBER, D.; KOETHE, D.; FAULHABER, J.; KLOSTERKÖTTER, J.; PIOMELLI, D. Cerebrospinal anandamide levels are elevated in acute schizophrenia and are inversely correlated with psychotic symptoms. Neuro-Psychopharmacology, v. 29, n. 11, p. 2108-2114, Nov. 2004.

GOLDMAN-RAKIC, P. S. Working memory dysfunction in schizophrenia. Journal of Neuropsychiatry Clinical Neuroscience, v. 6, n. 4, p. 348-357, 1994.

GONSIOREK, W.; LUNN, C.; FAN, X.; NARULA, S.; LUNDELL, D.; HIPKIN, R. W. Endocannabinoid 2-arachidonyl glycerol is a full agonist through human type 2 cannabinoid receptor: antagonism by anandamide. Molecular Pharmacology, v. 57, n. 5, p. 1045-1050, May 2000. 
GOURGIOTIS, I.; KAMPOURI, N. G.; KOULOURI, V.; LEMPESIS, I. G.; PRASINOU, M. D.; GEORGIADOU, G.; PITSIKAS, N. Nitric oxide modulates apomorphineinduced recognition memory deficits in rats. Pharmacology Biochemistry and Behavior, v. 102, n. 4, p. 507-514, Oct. 2012.

GRAYSON, B.; NEILL, J. C. The effect of PCP on novel object recognition in the rat. Journal of Psychopharmacology, v. 3, n. 18, p. A72, 2004.

GROVES, P. M.; REBEC, G. V. Biochemistry and behavior: some central actions of amphetamine and antipsychotic drugs. Annual Review Psychology, v. 27, p. 91127, 1976.

GUIMARÃES, F. S.; CHIARETTI, T. M.; GRAEFF, F. G.; ZUARDI, A. W. Antianxiety effect of cannabidiol in the elevated plus-maze. Psychopharmacology, v. 100, n. 4, p. 558-559, 1990.

GUPTA, S.; CAHILL, J. D.; RANGANATHAN, M.; CORRELL, C. U. The endocannabinoid system and schizophrenia: links to the underlying pathophysiology and to novel treatment approaches. Journal of Clinical Psychiatry, v. 75, n. 3, p. 285-287, Mar. 2014.

HAIJMA, S. V.; VAN HAREN, N.; CAHN, W.; KOOLSCHIJN, P. C. M.; HULSHOFF POL, H. E.; KAHN, R. S. Brain volumes in schizophrenia: a meta-analysis in over 18 000 subjects. Schizophrenia Bulletin, v. 39, n. 5, p. 1129-1138, Sep. 2013.

HALL, C.; BALLACHEY, E. L. A study of the rat's behavior in a field: A contribution to methods in comparative psychology University of California Publications in Psychology, v. 6, p. 1-12, 1932.

HALLAK, J. E. C.; OLIVEIRA, J. P. M.; ABRAÃO, J.; EVORA, P. R.; ZUARDI, A. W.; CRIPPA, J. A. S.; ABREU, P. B.; BAKER, G. B.; DURSUN, S. M. Rapid improvement of acute schizophrenia symptoms after intravenous sodium nitroprusside: a randomized, double-blind, placebo-controlled trial. JAMA Psychiatry, v. 70, n. 7, p. 668-676, Jul. 2013.

HALLAK, J. E.; DURSUN, S. M.; BOSI, D. C.; DE MACEDO, L. R.; SOUSA, J. P. M.; ABRÃO, J.; CRIPPA, J. A. S.; MCGUIRECE, P.; KRYSTAL, J. H.; BAKER, G. B.; ZUARDI, A. W. Show more The interplay of cannabinoid and NMDA glutamate receptor systems in humans: preliminary evidence of interactive effects of cannabidiol and ketamine in healthy human subjects. Progress in NeuroPsychopharmacology and Biological Psychiatry, v. 35, n. 1, p. 198-202, Jan. 2011.

HAMMER, G. B.; LEWANDOWSKI, A.; DROVER, D. R.; ROSEN, D. A.; COHANE, C.; ANAND, R.; MITCHELL, J.; REECE, T.; SCHULMAN, S. R. Safety and efficacy of sodium nitroprusside during prolonged infusion in pediatric patients. Pediatric Critical Care Medicine, v. 16, n. 5, p. 397-403, Jun. 2015.

HASAN, A.; KELLER, R. V.; FRIEMEL, C. M.; HALL, W.; SCHNEIDER, M.; KOETHE, D.; LEWEKE, F. M.; STRUBE, W.; HOCH, E. Cannabis use and 
psychosis: A review of reviews. European Archives of Psychiatry and Clinical Neuroscience, p. 1-10, Sep. 2019.

HILKER, R.; HELENIUS, D.; FAGERLUND, B.; SKYTTHE, A.; CHRISTENSEN, K.; WERGE, T. M.; NORDENTOFT, M.; GLENTHOJ, B. Heritability of Schizophrenia and Schizophrenia Spectrum Based on the Nationwide Danish Twin Register. Biological Psychiatry, v. 83, n. 6, p. 492-498, Mar. 2018.

HOBBS, A. J.; IGNARRO, L. J. [13] Nitric oxide-cyclic GMP signal transduction system. Methods in Enzymology, v. 269, p. 134-148, 1996.

HOFTMAN, G. D.; DATTA, D.; LEWIS, D. A. Layer 3 Excitatory and Inhibitory Circuitry in the Prefrontal Cortex: Developmental Trajectories and Alterations in Schizophrenia. Biological Psychiatry, v. 81, n. 10, p. 862-873, May 2017.

HOWELLS, F. M.; KINGDON, D. G.; BALDWIN, D. S. Current and potential pharmacological and psychosocial interventions for anxiety symptoms and disorders in patients with schizophrenia: structured review. Human Psychopharmacology: Clinical and Exprermental, v. 32, n. 5, p. e2628, Sep. 2017.

HOWES, O. D.; KAMBEITZ, J.; KIM, E.; STAHL, D.; SLIFSTEIN, M.; ABIDARGHAM, A.; KAPUR, S. The nature of dopamine dysfunction in schizophrenia and what this means for treatment. Archives of General Psychiatry, v. 69, n. 8, p. 776786, Aug. 2012.

HOWES, O.; MCCUTCHEON, R.; STONE, J. Glutamate and dopamine in schizophrenia: an update for the 21st century. Journal of Psychopharmacology, v. 29, n. 2, p. 97-115, 2015.

HOWLETT, A. C.; BARTH, F.; BONNER, T. I.; CABRAL, G.; CASELLAS, P.; DEVANE, W. A.; FELDER, C. C.; HERKENHAM, M.; MACKIE, K.; MARTIN, B. R.; MECHOULAM, R.; PERTWEE, R. G.. International Union of Pharmacology. XXVII. Classification of cannabinoid receptors. Pharmacological Reviews, v. 54, n. 2, p. 161-202, Jun. 2002.

HOYT, K. R.; TANG, L. H.; AIZENMAN, E.; REYNOLDS, I. J. Nitric oxide modulates NMDA-induced increases in intracellular $\mathrm{Ca2}+$ in cultured rat forebrain neurons. Brain Research, v. 592, n. 1-2, p. 310-316, Oct. 1992.

HUBERT, G. W.; MANVICH, D. F.; KUHAR, M. J. Cocaine and amphetamineregulated transcript-containing neurons in the nucleus accumbens project to the ventral pallidum in the rat and may inhibit cocaine-induced locomotion. Neuroscience, v. 165, n. 1, p. 179-187, 2010.

HURTUBISE, J. L.; MARKS, W. N.; DAVIES, D. A.; CATTON, J. K.; BAKER, G. B.; HOWLAND, J. G. MK-801-induced impairments on the trial-unique, delayed nonmatching-to-location task in rats: effects of acute sodium nitroprusside. Psychopharmacology, v. 234, n. 2, p. 211-222, Jan. 2017.

INSEL, T. R. Rethinking schizophrenia. Nature, v. 468, n. 7321, p. 187-193, Nov. 2010. 
ISSY, A. C.; PEDRAZZI, J. F.; YONEYAMA, B. H.; DEL-BEL, E. A. Critical role of nitric oxide in the modulation of prepulse inhibition in Swiss mice. Psychopharmacology, v. 231, n. 4, p. 663-672, Feb. 2014.

JAVITT, D. C. Glycine transport inhibitors and the treatment of schizophrenia. Biological Psychiatry, v. 63, n. 1, p. 6-8, Jan. 2008.

JAVITT, D. C.; BALLA, A.; SERSHEN, H.; LAJTHA, A. A. E. Bennett Research Award. Reversal of phencyclidine-induced effects by glycine and glycine transport inhibitors. Biological Psychiatry, v. 45, n. 6, p. 668-679, Mar. 1999.

JAVITT, D. C.; SILIPO, G.; CIENFUEGOS, A.; SHELLEY, A. M.; BARK, N.; PARK, M.; LINDENMAYER, J. P.; SUCKOW, R.; ZUKIN, S. R. Adjunctive high-dose glycine in the treatment of schizophrenia. International Journal of Neuropsychopharmacology, v. 4, n. 4, p. 385-391, Dec. 2001.

JIANG, B.; HUANG, S.; DE PASQUALE, R.; MILLMAN, D.; SONG, L.; LEE, H. K.; TSUMOTO, T.; KIRKWOOD, A. The maturation of GABAergic transmission in visual cortex requires endocannabinoid-mediated LTD of inhibitory inputs during a critical period. Neuron, v. 66, n. 2, p. 248-259, Apr. 2010.

JOHNSON, C. C. The actions and toxicity of sodium nitroprusside. Archives Internationales de Pharmacodynamie et de Therapie, v. 35, p. 489-496, 1929.

JOHNSON, J. W.; ASCHER, P. Glycine potentiates the NMDA response in cultured mouse brain neurons. Nature, v. 325, n. 6104, p. 529-531, Feb. 1987.

JONES, D. L.; MOGENSON, G. J. Nucleus accumbens to globus pallidus GABA projection: electrophysiological and iontophoretic investigations. Brain Research, v. 188, n. 1, p. 93-105, Apr. 1980.

KAHN, R. S.; SOMMER, I. E. The neurobiology and treatment of first-episode schizophrenia. Molecular Psychiatry, v. 20, n. 1, p. 84-97, Feb. 2015.

KALIA, L. V.; KALIA, S. K.; SALTER, M. W. NMDA receptors in clinical neurology: excitatory times ahead. The Lancet Neurology, v. 7, n. 8, p. 742-755, Aug. 2008.

KALIVAS, P. W.; CHURCHILL, L.; ROMANIDES, A. Involvement of the pallidalthalamocortical circuit in adaptive behavior. Annals of the New York Academy of Sciences, v. 877, n. 1, p. 64-70, Jun. 1999.

KANDRATAVICIUS, L.; BALISTA, P. A.; WOLF, D. C.; ABRAO, J.; EVORA, P. R.; RODRIGUES, A. J.; CHAVES, C.; MAIA-DE-OLIVEIRA, J. P.; LEITE, J. P.; DURSUN, S. M.; BAKER, G. B.; GUIMARAES; F. S.; HALLAK, J. E. C. Effects of nitric oxide-related compounds in the acute ketamine animal model of schizophrenia. BMC Neuroscience, v. 16, n. 1, p. 9, 2015.

KAPUR, S.; ZIPURSKY, R. B.; JONES, C.; REMINGTON, G. J.; WILSON, A. A.; SILVA, J.; HOULE, S. The D2 receptor occupancy profile of loxapine determined using PET. Neuropsychopharmacology, v. 15, n. 6, p. 562-566, Dec. 1996. 
KARLSGODT, K. H.; NIENDAM, T. A.; BEARDEN, C. E.; CANNON, T. D. White matter integrity and prediction of social and role functioning in subjects at ultra-high risk for psychosis. Biological Psychiatry, v. 66, n. 6, p. 562-569, Sep. 2009.

KARPOV, B.; JOFFE, G.; AALTONEN, K.; SUVISAARI, J.; BARYSHNIKOV, I.; Näätänen, P.; KOIVISTO, M.; MELARTIND, T.; OKSANEN, J.; SUOMINEN, K.; HEIKKINEN, M.; PAUNIO, T.; ISOMETSÄ, E. Anxiety symptoms in a major mood and schizophrenia spectrum disorders. European Psychiatry, v. 37, p. 1-7, Sep. 2016.

KATONA, I.; URBAN, G. M.; WALLACE, M.; LEDENT, C.; JUNG, K. M.; PIOMELLI, D.; MACKIE, K.; FREUND, T. F. Molecular composition of the endocannabinoid system at glutamatergic synapses. Journal of Neuroscience, v. 26, n. 21, p. 56285637, May. 2006.

KEILHOFF, G.; BECKER, A.; GRECKSCH, G.; WOLF, G.; BERNSTEIN, H. G. Repeated application of ketamine to rats induces changes in the hippocampal expression of parvalbumin, neuronal nitric oxide synthase and cFOS similar to those found in human schizophrenia. Neuroscience, v. 126, n. 3, p. 591-598, 2004.

KETY, S. S. Biochemical theories of schizophrenia. International Journal of Psychiatry, v. 1, p. 409-446, Jul. 1965.

KIM, E.; HOWES, O. D.; KAPUR, S. Molecular imaging as a guide for the treatment of central nervous system disorders. Dialogues Clinical Neuroscience, v. 15, n. 3, p. 315-328, Sep. 2013.

KIM, J. S.; KORNHUBER, H. H.; SCHMID-BURGK, W.; HOLZMULLER, B. Low cerebrospinal fluid glutamate in schizophrenic patients and a new hypothesis on schizophrenia. Neuroscience Letters, v. 20, n. 3, p. 379-382, Dec. 1980.

KOETHE, D.; GIUFFRIDA, A.; SCHREIBER, D.; HELLMICH, M.; SCHULTZELUTTER, F.; RUHRMANN, S.; KLOSTERKÖTTER, J.; PIOMELLI, D.; LEWEKE, F. $M$. Anandamide elevation in cerebrospinal fluid in initial prodromal states of psychosis. The British Journal of Psychiatry, v. 194, n. 4, p. 371-372, Apr. 2009.

KOETHE, D.; HOYER, C.; LEWEKE, F. M. The endocannabinoid system as a target for modelling psychosis. Psychopharmacology, v. 206, n. 4, p. 551-561, Nov. 2009.

KOHRS, R.; DURIEUX, M. E. Ketamine: Teaching an old drug new tricks. Anesthesia \& Analgesia, v. 87, n. 5, p. 1186-1193, Nov. 1998.

KOOB, G. F.; SWERDLOW, N. R. The functional output of the mesolimbic dopamine system. Annals of the New York Academy of Sciences, v. 537, n. 1, p. 216-227, 1988.

KUNIISHI, H.; ICHISAKA, S.; YAMAMOTO, M.; IKUBO, N.; MATSUDA, S.; FUTORA, E.; HARADA, R.; ISHIHARA, K.; HATA, Y. Early deprivation increases high-leaning behavior, a novel anxiety-like behavior, in the open field test in rats. Neuroscience Research, v. 123, p. 27-35, Oct. 2017. 
LABRIE, V.; RODER, J. C. The involvement of the NMDA receptor D-serine/glycine site in the pathophysiology and treatment of schizophrenia. Neuroscience \& Biobehavioral Reviews, v. 34, n. 3, p. 351-372, Mar. 2010.

LAURIE, D. J.; SEEBURG, P. H. Ligand affinities at recombinant N-methyl-Daspartate receptors depend on subunit composition. Europan Journal of Pharmacology, v. 268, n. 3, p. 335-345, Aug. 1994.

LECOINTRE, M.; VÉZIER, C.; BÉNARD, M.; RAMDANI, Y.; DUPRÉ, N.; BRASSELAGNEL, C.; HENRY, V. J.; ROY, V.; MARRET, S.; GONZALEZ, B. J.; JÉGOU, S.; LEROUX-NICOLLET, I. Age-dependent alterations of the NMDA receptor developmental profile and adult behavior in postnatally ketamine-treated mice. Developmental Neurobiology, v. 75, n. 3, p. 315-333, Sep. 2014.

LEE, B. H.; KIM, Y. K. Reduced plasma nitric oxide metabolites before and after antipsychotic treatment in patients with schizophrenia compared to controls. Schizophrenia Research, v. 104, n. 1-3, p. 36-43, Sep. 2008.

LEES, J.; HALLAK, J. E.; DEAKIN, J. F.; DURSUN, S. M. Gender differences and the effects of ketamine in healthy volunteers. Journal of Psychopharmacology, v. 18, n. 3, p. 337-339, Sep. 2004.

LEGER, M.; QUIEDEVILLE, A.; BOUET, V.; HAELEWYN, B.; BOULOUARD, M.; SCHUMANN-BARD, P.; FRERET, T. Object recognition test in mice. Nature Protocols, v. 8, n. 12, p. 2531-2537, Dec. 2013.

LEITÃO, R. J.; FERRAZ, M. B.; CHAVES, A. C.; MARI, J. J. Custos da esquizofrenia: Custos diretos e utilização de recursos no Estado de São Paulo. Revista de Saúde Pública, v. 40, n. 2, p. 304-309, Abr. 2006.

LEUCHT, S.; LEUCHT, C.; HUHN, M.; CHAIMANI, A.; MAVRIDIS, D.; HELFER, B.; SAMARA, M.; RABAIOLI, M.; BÄCHER, S.; CIPRIANI, A.; GEDDES, J. R.; SALANTI, G.; DAVIS, J. M. Sixty Years of Placebo-Controlled Antipsychotic Drug Trials in Acute Schizophrenia: Systematic Review, Bayesian Meta-Analysis, and Meta-Regression of Efficacy Predictors. American Journal of Psychiatry, v. 174, n. 10, p. 927-942, Oct. 2017.

LEVIN, R.; PERES, F. F.; ALMEIDA, V.; CALZAVARA, M. B.; ZUARDI, A. W.; HALLAK, J. E. C.; CRIPPA, J. A. S.; ABÍLIO, V. C. Effects of cannabinoid drugs on the deficit of prepulse inhibition of startle in an animal model of schizophrenia: the SHR strain. Frontiers in Pharmacology, v. 5, p. 1-10, Feb. 2014.

LEWEKE, F. M.; MUELLER, J. K.; LANGE, B.; ROHLEDER, C. Therapeutic Potential of Cannabinoids in Psychosis. Biological Psychiatry, v. 79, n. 7, p. 604-612, Apr. 2016.

LEWEKE, F. M.; PIOMELLI, D.; PAHLISCH, F.; MUHL, D.; GERTH, C. W.; HOYER, C.; KLOSTERKOTTER, M. H.; KOETHE, D. Cannabidiol enhances anandamide signaling and alleviates psychotic symptoms of schizophrenia. Translational Psychiatry, v. 2, n. 3, p. e94, Mar. 2012. 
LEWEKE, F. M.; SCHNEIDER, U.; RADWAN, M.; SCHMIDT, E.; EMRICH, H. M. Different effects of nabilone and cannabidiol on binocular depth inversion in Man. Pharmacology Biochemistry and Behavior, v. 66, n. 1, p. 175-181, May 2000.

LEWIS, D. A.; LEVITT, P. Schizophrenia as a disorder of neurodevelopment. Annual Review of Neuroscience, v. 25, n. 1, p. 409-432, 2002.

LIDDLE, P. F. The symptoms of chronic schizophrenia. A re-examination of the positive-negative dichotomy. The British Journal of Psychiatry, v. 151, n. 2, p. 145151, Aug. 1987.

LIEBERMAN, J. A.; KANE, J. M.; ALVIR, J. Provocative tests with psychostimulant drugs in schizophrenia. Psychopharmacology, v. 91, n. 4, p. 415-433, 1987.

LIEBSCH, G.; MONTKOWSKI, A.; HOLSBOER, F.; LANDGRAF, R. Behavioural profiles of two Wistar rat lines selectively bred for high or low anxiety-related behaviour. Behavioural Brain Research, v. 94, n. 2, p. 301-310, Aug. 1998.

LIN, C. H.; LANE, H. Y.; TSAI, G. E. Glutamate signaling in the pathophysiology and therapy of schizophrenia. Pharmacology Biochemistry and Behavior, v. 100, n. 4, p. 665-677, Feb. 2012.

LINAKIS, J. G.; LACOUTURE, P. G.; WOOLF, A. Monitoring cyanide and thiocyanate concentrations during infusion of sodium nitroprusside in children. Pediatric Cardiology, v. 12, n. 4, p. 214-218, Oct. 1991.

LINDENMAYER, J. P.; BERNSTEIN-HYMAN, R.; GROCHOWSKI, S. A new five factor model of schizophrenia. Psychiatric Quarterly, v. 65, n. 4, p. 299-322, 1994.

LIPSKA, B. K.; WEINBERGER, D. R. To model a psychiatric disorder in animals: schizophrenia as a reality test. Neuropsychopharmacology, v. 23, n. 3, p. 223-239, Sep. 2000.

LISTER, R. G. Ethologically-based animal models of anxiety disorders. Pharmacology \& Therapeutics, v. 46, n. 3, p. 321-340, 1990.

LIU, M. Y.; YIN, C. Y.; ZHU, L. J.; ZHU, X. H. XU, C.; LUO, C. X.; CHEN, H.; ZHU, D. $\mathrm{Y}$;; ZHOU, Q. G. Sucrose preference test for measurement of stress-induced anhedonia in mice. Natureprotocols, v. 13, n. 7, p. 1686-1698, Jul. 2018.

LIU, Q.; BHAT, M.; BOWEN, W. D.; CHENG, J. Signaling pathways from cannabinoid receptor-1 activation to inhibition of $\mathrm{N}$-methyl-D-aspartic acid mediated calcium influx and neurotoxicity in dorsal root ganglion neurons. Journal of Pharmacology and Experimental Therapeutics, v. 331, n. 3, p. 1062-1070, Dec. 2009.

LOCKWOOD, A.; PATKA, J.; RABINOVICH, M.; WYATT, K.; ABRAHAM, P. Sodium nitroprusside-associated cyanide toxicity in adult patients-fact or fiction? A critical review of the evidence and clinical relevance. Open Access Journal of Clinical Trials, v. 2, p. 133-148, Sep. 2010. 
LODGE, D. The history of the pharmacology and cloning of ionotropic glutamate receptors and the development of idiosyncratic nomenclature. Neuropharmacology, v. 56, n. 1, p. 6-21, Jan. 2009.

LONG, L. E.; CHESWORTH, R.; HUANG, X. F.; MCGREGOR, I. S. ARNOLD, J. C.; KARL, T. A behavioural comparison of acute and chronic Delta9tetrahydrocannabinol and cannabidiol in C57BL/6JArc mice. International Journal of Neuropsychopharmacology, v. 13, n. 7, p. 861-876, Aug. 2010.

LORRAIN, D. S.; BACCEI, C. S.; BRISTOW, L. J.; ANDERSON, J. J.; VARNEY, M. A. Effects of ketamine and $\mathrm{N}$-methyl-D-aspartate on glutamate and dopamine release in the rat prefrontal cortex: Modulation by a group II selective metabotropic glutamate receptor agonist LY379268. Neuroscience, v. 117, n. 3, p. 697-706, Mar. 2003.

LU, H. C.; MACKIE, K. An Introduction to the Endogenous Cannabinoid System. Biological Psychiatry, v. 79, n. 7, p. 516-525, Apr. 2016.

LUBY, E. D.; GOTTLIEB, J. S.; COHEN, B. D.; ROSENBAUM, G.; DOMINO, E. F. Model psychoses and schizophrenia. American Journal of Psychiatry, v. 119, n. 1, p. 61-67, Jul. 1962.

LUK, T.; JIN, W.; ZVONOK, A.; LU, D.; LIN, X. Z.; CHAVKIN, C.; MAKRIYANNIS, A.; MACKIE, K. Identification of a potent and highly efficacious, yet slowly desensitizing CB1 cannabinoid receptor agonist. Britsh Journal of Pharmacology, v. 142, n. 3, p. 495-500, Jun. 2004.

LYON, L.; SAKSIDA, L. M.; BUSSEY, T. J. Spontaneous object recognition and its relevance to schizophrenia: a review of findings from pharmacological, genetic, lesion and developmental rodent models. Psychopharmacology, v. 220, n. 4, p. 647-672, Apr. 2012.

MACKAY, A. V.; IVERSEN, L. L.; ROSSOR, M.; SPOKES, E.; BIRD, E.; ARREGUI, A.; CREESE, I.; SNYDER, S. H. Increased brain dopamine and dopamine receptors in schizophrenia. Archives of General Psychiatry, v. 39, n. 9, p. 991-997, Sep. 1982.

MACKIE, K.; DEVANE, W. A.; HILLE, B. Anandamide, an endogenous cannabinoid, inhibits calcium currents as a partial agonist in N18 neuroblastoma cells. Molecular Pharmacology, v. 44, n. 3, p. 498-503, Sep. 1993.

MALONE, D. T.; JONGEJAN, D.; TAYLOR, D. A. Cannabidiol reverses the reduction in social interaction produced by low dose Delta(9)-tetrahydrocannabinol in rats. Pharmacology Biochemistry and Behavior, v. 93, n. 2, p. 91-96, Aug. 2009.

MANZONI, O.; PREZEAU, L.; DESAGHER, S.; SAHUQUET, A.; SLADECZEK, F.; BOCKAERT, J.; FAGNI, L. Sodium nitroprusside blocks NMDA receptors via formation of ferrocyanide ions. Neuroreport, v. 3, n. 1, p. 77-80, Jan. 1992.

MARCHESE, G.; SCHEGGI, S.; SECCI, M. E.; DE MONTIS, M. G.; GAMBARANA, C. Anti-anhedonic activity of long-term lithium treatment in rats exposed to repeated 
unavoidable stress. International Journal of Neuropsychopharmacology, v. 16, n. 7, p. 1611-1621, Aug. 2013.

MARDER, S. R.; FENTON, W.; YOUENS, K. Schizophrenia, IX: Cognition in schizophrenia-the MATRICS initiative. American Journal of Psychiatry, v. 161, n. 1, p. 25, Jan. 2004.

MARDER, S.; FLEISCHHACKER, W. W.; EARLEY, W.; LU, K.; YAN, Z.; NÉMETH, G.; LASZLOVSZKY, I.; SZALAI, E.; DURGAM, S. Efficacy of cariprazine across symptom domains in patients with acute exacerbation of schizophrenia: Pooled analyses from 3 phase II/III studies. European Neuropsychopharmacology, v. 29, n. 1, p. 127-136, Jan. 2019.

MARIK, P. E.; VARON, J. Hypertensive crises: Challenges and management. Chest, v. 131, n. 6, p. 1949-1962, Jun. 2007.

MATYAS, F.; YANOVSKY, Y.; MACKIE, K.; KELSCH, W.; MISGELD, U.; FREUND, T. F. Subcellular localization of type 1 cannabinoid receptors in the rat basal ganglia. Neuroscience, v. 137, n. 1, p. 337-361, 2006.

MAYA-LÓPEZ, M.; COLIN-GONZALEZ, A. L.; AGUILERA, G.; LIMA, M. E.; CEOLIN, A. C.; RANGEL-LÓPEZ, E.; VILLEDA-HERNÁNDEZ, J.; REMBAO-BOJÓRQUEZ, D.; TÚNEZ, I.; LUNA-LÓPEZ, A.; LAZZARINI-LECHUGA, R.; GONZÁLEZPUERTOS, V. I.; POSADAS-RODRÍGUEZ. P.; SILVA-PALACIOS, A.; KÖNIGSBERG, M.; SANTAMARÍA, A. Neuroprotective effect of WIN55,212-2 against 3-nitropropionic acid-induced toxicity in the rat brain: involvement of CB1 and NMDA receptors. American Journal of Translational Research, v. 9, n. 2, p. 261-274, Feb. 2017.

MAYER, B.; HEMMENS, B. Biosynthesis and action of nitric oxide in mammalian cells. Trends in Biochemical Sciences, v. 22, n. 12, p. 477-481, Dec. 1997.

MAZARATI, A.; SHIN, D.; AUVIN, S.; CAPLAN, R. SANKAR, R. Kindling epileptogenesis in immature rats leads to persistent depressive behavior. Epilepsy \& Behavior, v. 10, n. 3, p. 377-383, May 2007.

MCCULLOUGH, L. D.; SALAMONE, J. D. Increases in extracellular dopamine levels and locomotor activity after direct infusion of phencyclidine into the nucleus accumbens. Brain Research, v. 577, n. 1, p. 1-9, Apr. 1992.

MCGORRY, P. D.; NELSON, B.; PHILLIPS, L. J.; YUEN, H. P.; FRANCEY, S. M.; THAMPI, A.; BERGER, G. E.; AMMINGER, G. P.; SIMMONS, M. B.; KELLY, D.; DIP G.; THOMPSON, A. D.; YUNG, A. R. Randomized controlled trial of interventions for young people at ultra-high risk of psychosis: twelve-month outcome. Journal of Clinical Psychiatry, v. 74, n. 4, p. 349-356, Apr. 2013.

MCGRATH, J.; SAHA, S.; CHANT, D.; WELHAM, J. Schizophrenia: A concise overview of incidence, prevalence, and mortality. Epidemiologic Reviews, v. 30, n. 1, p. 67-76, 2008. 
MCGUIRE, P.; ROBSON, P.; CUBALA, W. J.; VASILE, D.; MORRISON, P. D.; BARRON, R.; TAYLOR, A.; WRIGHT, S. Cannabidiol (CBD) as an Adjunctive Therapy in Schizophrenia: A Multicenter Randomized Controlled Trial. American Journal of Psychiatry, v. 175, n. 3, p. 225-231, Mar. 2018.

MECHOULAM, R.; BEN-SHABAT, S.; HANUS, L.; LIGUMSKY, M.; Norbert E. KAMINSKI.; SCHATZ, A. R.; GOPHER, A.; ALMOG, S.; MARTIN, B. R.; COMPTON, D. R.; PERTWEE. R. G.; GRIFFIN, G.; BAYEWITCH. M.; BARG, J.; VOGEL, Z. Identification of an endogenous 2-monoglyceride, present in canine gut, that binds to cannabinoid receptors. Biochemical Pharmacology, v. 50, n. 1, p. 83-90, Jun. 1995.

MILLAR, S. A.; STONE, N. L.; BELLMAN, Z. D.; YATES, A. S.; ENGLAND, T. J.; O'SULLIVAN, S. E. A systematic review of cannabidiol dosing in clinical populations. British Journal of Clinical Pharmacology, v. 85, n. 9, p. 1888-1900, Sep. 2019.

MILLER, T. J.; MCGLASHAN, T. H.; ROSEN, J. L.; SOMJEE, L.; MARKOVICH, P. J.; STEIN, K.; WOODS, S. W. Prospective diagnosis of the initial prodrome for schizophrenia based on the Structured Interview for Prodromal Syndromes: preliminary evidence of interrater reliability and predictive validity. American Journal of Psychiatry, v. 159, n. 5, p. 863-865, May 2002.

MINICHINO, A.; SENIOR, M.; BRONDINO, N.; ZHANG, S. H.; GODWLEWSKA, B. R.; BURNET, P. W. J.; CIPRIANI, A.; LENNOX, B. R. Measuring Disturbance of the Endocannabinoid System in Psychosis: A Systematic Review and Meta-analysis. JAMA Psychiatry, v. 76, n. 9, p. 914-923, Jun. 2019.

MION, G. History of anaesthesia: The ketamine story - past, present and future. European Journal of Anaesthesiology, v. 34, n. 9, p. 571-575, Sep. 2017.

MIULLER, N.; SCHWARZ, M. J. The immunological basis of glutamatergic disturbance in schizophrenia: Towards an integrated view. Neuropsychiatric Disorders An Integrative Approach, v. 72, p. 269-280, 2007.

MIYAMOTO, S.; MIYAKE, N.; JARSKOG, L. F.; FLEISCHHACKER, W. W.; LIEBERMAN, J. A. Pharmacological treatment of schizophrenia: a critical review of the pharmacology and clinical effects of current and future therapeutic agents. Molecular Psychiatry, v. 17, n. 12, p. 1206-1227, Dec. 2012.

MOFFETT, B. S.; PRICE, J. F. Evaluation of sodium nitroprusside toxicity in pediatric cardiac surgical patients. Annals of Pharmacotherapy, v. 42, n. 11, p. 1600-1604, Nov. 2008.

MOGHADDAM, B.; ADAMS, B. W. Reversal of phencyclidine effects by a group II metabotropic glutamate receptor agonist in rats. Science, v. 281, n. 5381, p. 13491352, Aug. 1998.

MOGHADDAM, B.; ADAMS, B.; VERMA, A.; DALY, D. Activation of glutamatergic neurotransmission by ketamine: a novel step in the pathway from NMDA receptor blockade to dopaminergic and cognitive disruptions associated with the prefrontal cortex. Journal of Neuroscience, v. 17, n. 8, p. 2921-2927, Apr. 1997. 
MOORE, K. E. The actions of amphetamine on neurotransmitters: a brief review. Biological Psychiatry, v. 12, n. 3, p. 451-462, Jun. 1977.

MOREIRA, F. A.; GUIMARÃES, F. S. Cannabidiol inhibits the hyperlocomotion induced by psychotomimetic drugs in mice. European Journal of Pharmacology, v. 512, n. 2-3, p. 199-205, 2005.

MORRIS, B. J.; COCHRAN, S. M.; PRATT, J. A. PCP: from pharmacology to modelling schizophrenia. Current Opinion in Pharmacology, v. 5, n. 1, p. 101-106, Feb. 2005.

MOUSLECH, Z.; VALLA, V. Endocannabinoid system: An overview of its potential in current medical practice. Neuroendocrinology Letters, v. 30, n. 2, p. 153-179, 2009.

MUESER, K. T.; MCGURK, S. R. Schizophrenia. Lancet, v. 363, n. 9426, p. 20632072, Jun. 2004.

MULLER, C.; MORALES, P.; REGGIO, P. H. Cannabinoid Ligands Targeting TRP Channels. Frontiers in Molecular Neuroscience, v. 11, p. 487, 2018.

MULLICA, D. F.; TIPPIN, D. B.; SAPPENFIELD, E. L. The crystal structure analysis of iron nitroprusside, $\mathrm{Fe}[\mathrm{Fe}(\mathrm{CN}) 5 \mathrm{NO}] \cdot 3 \mathrm{H} 2 \mathrm{O}$. Journal of Crystallographic and Spectroscopic Research, v. 21, p. 81, 1991.

MURRAY, R. M.; BHAVSAR, V.; TRIPOLI, G.; HOWES, O. 30 Years on: How the Neurodevelopmental Hypothesis of Schizophrenia Morphed Into the Developmental Risk Factor Model of Psychosis. Schizophrenia Bulletin, v. 43, n. 6, p. 1190-1196, Oct. 2017.

MURRAY, R. M.; JONES, P.; O'CALLAGHAN, E.; BOCK, G. R.; WHELAN, J.; Fetal brain development and later schizophrenia. Ciba Found Symp, v. 156, p. 155-170, 1991.

NAKANO, Y.; YOSHIMURA, R.; NAKANO, H.; IKENOUCHI-SUGITA, A.; Hikaru HORI, H.; NAKANO, W. U.; UEDA, N.; NAKAMURA, J. Association between plasma nitric oxide metabolites levels and negative symptoms of schizophrenia: a pilot study. Human Psychopharmacology: Clinical and Experimental, v. 25, n. 2, p. 139-144, Mar. 2010.

NAKAO, S.; NAGATA, A.; MIYAMOTO, E.; MASUZAWA, M.; MURAYAMA, T.; SHINGU, K. Inhibitory effect of propofol on ketamine-induced c-Fos expression in the rat posterior cingulate and retrosplenial cortices is mediated by GABAA receptor activation. Acta Anaesthesiologica Scandinavica, v. 47, n. 3, p. 284-290, Mar. 2003.

NEILL, J. C.; BARNES, S.; COOK, S.; GRAYSON, B.; IDRIS, N. F.; MCLEAN, S. L.; SNIGDHA, S.; RAJAGOPAL, L.; HARTE, M. K. Animal models of cognitive dysfunction and negative symptoms of schizophrenia: focus on NMDA receptor antagonism. Pharmacology \& Therapeutics, v. 128, n. 3, p. 419-432, Dec. 2010. 
NELSON, R. J.; DEMAS, G. E.; HUANG, P. L.; FISHMAN, M. C.; DAWSON, V. L.; DAWSON, T. M.; SNYDER, S. H. Behavioural abnormalities in male mice lacking neuronal nitric oxide synthase. Nature, v. 378, n. 6555, p. 383, 1995.

NEURAL CIRCUITS AND BEHAVIOR CORE. Object recognition. NCBC, 2019. Disponível em: https://ncbc.medicine.uiowa.edu/equipmentfees/equipment/behavior/object-recognition. Acesso em: 08 jan. 2020.

NODA, Y.; YAMADA, K.; FURUKAWA, H.; NABESHIMA, T. Enhancement of immobility in a forced swimming test by subacute or repeated treatment with phencyclidine: a new model of schizophrenia. Britsh Journal of Pharmacology, v. 116, n. 5, p. 2531-2537, Nov. 1995.

NONG, Y.; HUANG, Y. Q.; JU, W.; KALIA, L. V.; AHMADIAN, G.; WANG, Y. T.; SALTER, M. W. Glycine binding primes NMDA receptor internalization. Nature, v. 422, n. 6929, p. 302-307, Mar. 2003.

NUECHTERLEIN, K. H.; GREEN, M. F.; KERN, R. S.; BAADE, L. E.; BARCH, D. M.; COHEN, J. D.; ESSOCK, S.; FENTON, W. S.; FRESE III, F. J.; GOLD, J. M.; GOLDBERG, T.; HEATON, R. K.; KEEFE, R. S. E.; KRAEMER, H.; MESHOLAMGATELY, R.; SEIDMAN, L. J.; STOVER, E.; WEINBERGER, D. R.; YOUNG, A. S.; ZALCMAN, M. S. H. S. S.; MARDER, S. R. The MATRICS Consensus Cognitive Battery, part 1: test selection, reliability, and validity. American Journal of Psychiatry, v. 165, n. 2, p. 203-213, Feb. 2008.

NUNES, E. A.; CANEVER, L.; OLIVEIRA, L.; LUCA, R. D.; QUEVEDO, J.; ZUGNOII, A.; PEREGRINO, A.; CRIPPA. J. A. S.; DURSUN, S. M.; BAKER, G. B.; HALLAK, J. E. C. Effects of pregabalin on behavioral alterations induced by ketamine in rats. Brazilian Journal of Psychiatry, v. 34, n. 3, p. 329-333, Oct. 2012.

OLIVEIRA, C. M.; SAKATA, R. K.; ISSY, A. M.; GARCIA, J. B. [Ketamine and preemptive analgesia.]. Revista Brasileira de Anestesiologia, v. 54, n. 5, p. 739752, Oct. 2004.

OLIVEIRA, J. P. M.; ABRAO, J.; EVORA, P. R.; ZUARDI, A. W.; CRIPPA, J. A. S.; ABREU, P. B.; BAKER, G. B.; DURSUN, S. M.; HALLAK, J. E. C. The effects of sodium nitroprusside treatment on cognitive deficits in schizophrenia: a pilot study. Journal of Clinical Psychopharmacology, v. 35, n. 1, p. 83-85, Feb. 2015.

OLIVEIRA, J. P. M.; ABREU, P. B.; BRESSAN, R. A.; CACHOEIRA, C.; BAKER, G. B.; DURSUN, S. M.; HALLAK, J. E. Sodium nitroprusside treatment of clozapinerefractory schizophrenia. Journal of Clinical Psychopharmacology, v. 34, n. 6, p. 761-763, Dec. 2014.

OLIVEIRA, J. P. M.; SOARES, B. L.; RAMALHO, T.; GAVIOLI, E. C.; SOARES, V. P.; TEIXEIRA, L.; BAKER, G. B.; DURSON, S. M.; HALLAK, J. E. C. Nitroprusside single-dose prevents the psychosis-like behavior induced by ketamine in rats for up to one week. Schizophrenia Research, v. 162, n. 1-3, p. 211-215, Mar. 2015.

OLNEY, J. W.; FARBER, N. B. Glutamate receptor dysfunction and schizophrenia. Archives of General Psychiatry, v. 52, n. 12, p. 998-1007, Dec. 1995. 
OLNEY, J. W.; NEWCOMER, J. W.; FARBER, N. B. NMDA receptor hypofunction model of schizophrenia. Journal of Psychiatric Research, v. 33, n. 6, p. 523-533, Nov./Dec. 1999.

O'SULLIVAN, S. E. Cannabinoids go nuclear: evidence for activation of peroxisome proliferator-activated receptors. Britsh Journal of Pharmacology, v. 152, n. 5, p. 576-582, Nov. 2007.

OWEN, F.; CROSS, A. J.; CROW, T. J.; LONGDEN, A.; RILEY, G. J. Increased dopamine-receptor sensitivity in schizophrenia. Lancet, v. 2, n. 8083, p. 223-226, Jul. 1978.

OWENS, D. G.; JOHNSTONE, E. C. Precursors and prodromata of schizophrenia: findings from the Edinburgh High Risk Study and their literature context. Psychological Medicine, v. 36, n. 11, p. 1501-1514, Nov. 2006.

PACHECO, F. D.; CANEVER, L.; MASTELLA, G. A.; WESSLER, P. G.; GODOI, A. K.; HUBBE, I.; AFONSO, A. C.; CELSO, D.; QUEVEDO, J.; ZUGNO, A. L. Effects of ketamine on prepubertal Wistar rats: Implications on behavioral parameters for Childhood-Onset Schizophrenia. International Journal of Developmental Neuroscience, v. 79, p. 49-53, Dec. 2019.

PACHER, P.; KOGAN, N. M.; MECHOULAM, R. Beyond THC and Endocannabinoids. Annual Reviews Pharmacology and Toxicology, v. 60, Oct. 2019.

PAKKENBERG, B.; SCHEEL-KRUGER, J.; KRISTIANSEN, L. V. Schizophrenia; from structure to function with special focus on the mediodorsal thalamic prefrontal loop. Acta Psychiatrica Scandinavica, v. 120, n. 5, p. 345-354, Nov. 2009.

PAPANASTASIOU, E.; STONE, J. M.; SHERGILL, S. When the drugs don't work: the potential of glutamatergic antipsychotics in schizophrenia. Britsh Journal of Pharmacology, v. 202, p. 91-93, Feb. 2013.

PATRICIO-MARTINEZ, A.; SANCHEZ-ZAVALETA, R.; ANGULO-CRUZ, I.; GUTIERREZ-PRAXEDIS, L.; RAMÍREZ, E.; MARTÍNEZ-GARCÍA, I.; LIMÓN, I. D. The Acute Activation of the CB1 Receptor in the Hippocampus Decreases Neurotoxicity and Prevents Spatial Memory Impairment in Rats Lesioned with betaAmyloid 25-35. Neuroscience, v. 416, p. 239-254, Sep. 2019.

PEARCE, R. K.; SEEMAN, P.; JELLINGER, K.; TOURTELLOTTE, W. W. Dopamine uptake sites and dopamine receptors in Parkinson's disease and schizophrenia. European Neurology, v. 30, Suppl. 1, p. 9-14, 1990.

PELIZZA, L.; FERRARI, A. Anhedonia in schizophrenia and major depression: State or trait? Annals of General Psychiatry, v. 8, n. 1, p. 22, Oct. 2009.

PERES, F. F.; DIANA, M. C.; LEVIN, R.; SUIAMA, M. A.; ALMEIDA, V.; VENDRAMINI, A. M.; SANTOS, C. M.; ZUARDI, A. W.; HALLAK, J. E. C.; CRIPPA, J. A.; ABÍLIO, V. C. Cannabidiol Administered During Peri-Adolescence Prevents 
Behavioral Abnormalities in an Animal Model of Schizophrenia. Frontiers in Pharmacology, v. 9, p. 901, Aug. 2018.

PERES, F. F.; DIANA, M. C.; SUIAMA, M. A.; JUSTI, V.; ALMEIDA, V.; BRESSAN, R. A.; ZUARDI, A. W.; HALLAK, J. E.; CRIPPA, J. A.; ABILIO, V. C. Peripubertal treatment with cannabidiol prevents the emergence of psychosis in an animal model of schizophrenia. Schizophrenia Research, v. 172, n. 1-3, p. 220-221, Apr. 2016.

PERES, F. F.; LEVIN, R.; ALMEIDA, V.; ZUARDI, A. W.; HALLAK, J. E.; CRIPPA, J. A.; ABILIO, V. C. Cannabidiol, among Other Cannabinoid Drugs, Modulates Prepulse Inhibition of Startle in the SHR Animal Model: Implications for Schizophrenia Pharmacotherapy. Frontiers in Pharmacology, v. 7, p. 303, Set. 2016.

PEREZ, S. M.; LODGE, D. J. Convergent Inputs from the Hippocampus and Thalamus to the Nucleus Accumbens Regulate Dopamine Neuron Activity. Journal Neuroscience, v. 38, n. 50, p. 10607-10618, Dec. 2018.

PERTWEE, R. G. The diverse CB1 and CB2 receptor pharmacology of three plant cannabinoids: $\Delta 9$-tetrahydrocannabinol, cannabidiol and $\Delta 9$-tetrahydrocannabivarin. British Journal of Pharmacology, v. 153, n. 2, p. 199-215, 2008.

PFENNINGER, E. G.; DURIEUX, M. E.; HIMMELSEHER, S. Cognitive impairment after small-dose ketamine isomers in comparison to equianalgesic racemic ketamine in human volunteers. Anesthesiology, v. 96, n. 2, p. 357-366, Feb. 2002.

PILOWSKY, L. S.; KERWIN, R. W.; MURRAY, R. M. Schizophrenia: A neurodevelopmental perspective. Neuropsychopharmacology, v. 9, n. 1, p. 83-91, Aug. 1993.

PITSIKAS, N. The role of nitric oxide in the object recognition memory. Behavioural Brain Research, v. 285, p. 200-207, May 2015.

PITSIKAS, N.; BOULTADAKIS, A.; SAKELLARIDIS, N. Effects of sub-anesthetic doses of ketamine on rats' spatial and non-spatial recognition memory. Neuroscience, v. 154, n. 2, p. 454-460, Jun. 2008.

PLAKUN, E. M. Psychotherapy Research and the NIMH: An Either/Or or Both/And Research Agenda? Journal of Psychiatric Practice, v. 23, n. 2, p. 130-133, Mar. 2017.

RAM, E.; RAPHAELI, S.; AVITAL, A. Prepubertal chronic stress and ketamine administration to rats as a neurodevelopmental model of schizophrenia symptomatology. International Journal of Neuropsychopharmacology, v. 16, n. 10, p. 2307-2314, Nov. 2013.

RAMIREZ, J.; GARNICA, R.; BOLL, M. C.; MONTES, S.; RIOS, C. Low concentration of nitrite and nitrate in the cerebrospinal fluid from schizophrenic patients: a pilot study. Schizophrenia Research, v. 68, n. 2-3, p. 357-361, Jun. 2004. 
RANDALL, P. L. Schizophrenia, abnormal connection, and brain evolution. Medical Hypotheses, v. 10, n. 3, p. 247-280, Mar. 1983.

REICHENBERG, A.; CASPI, A.; HARRINGTON, H.; HOUTS, R.; KEEFE, R. S. E.; MURRAY, R. M.; POULTON, R.; MOFFITT, T. E. Static and dynamic cognitive deficits in childhood preceding adult schizophrenia: a 30-year study. American Journal of Psychiatry, v. 167, n. 2, p. 160-169, Feb. 2010.

RENARD, J.; NORRIS, C.; RUSHLOW, W.; LAVIOLETTE, S. R. Neuronal and molecular effects of cannabidiol on the mesolimbic dopamine system: Implications for novel schizophrenia treatments. Neuroscience Biobehavioral Reviews, v. 75, p. 157-165, Apr. 2017.

RIEDEL, W. J.; BLOKLAND, A. Declarative memory. Handbook of Experimental Pharmacology, v. 228, p. 215-236, 2015.

ROHLEDER, C.; MULLER, J. K.; LANGE, B.; LEWEKE, F. M. Cannabidiol as a Potential New Type of an Antipsychotic. A Critical Review of the Evidence. Frontiers Pharmacology, v. 7, p. 422, 2016.

ROSER, P.; VOLLENWEIDER, F. X.; KAWOHL, W. Potential antipsychotic properties of central cannabinoid (CB1) receptor antagonists. World Journal of Biological Psychiatry, v. 11, n. 2-2, p. 208-219, Mar. 2010.

RUSSWURM, M.; KOESLING, D. Guanylyl cyclase: NO hits its target. Biochemical Society Symposia, v. 71, p. 51-63, 2004.

SAGREDO, O.; PALAZUELOS, J.; GUTIERREZ-RODRIGUEZ, A.; SATTA, V.; GALVE-ROPERH, I.; MARTÍNEZ-ORGADO, J. Cannabinoid signalling in the immature brain: Encephalopathies and neurodevelopmental disorders. Biochemical Pharmacology, v. 157, p. 85-96, Nov. 2018.

SALAMONE, J. D.; CORREA, M.; FARRAR, A.; MINGOTE, S. M. Effort-related functions of nucleus accumbens dopamine and associated forebrain circuits. Psychopharmacology, v. 191, n. 3, p. 461-482, Apr. 2007.

SAMPAIO, L. R. L.; CYSNE FILHO, F. M. S.; DE ALMEIDA, J. C.; DINIZ, D. D. S.; Advantages of the Alpha-lipoic Acid Association with Chlorpromazine in a Model of Schizophrenia Induced by Ketamine in Rats: Behavioral and Oxidative Stress evidences. Neuroscience, v. 373, p. 72-81, Mar. 2018.

SÁNCHEZ-BLÁZQUEZ, P.; RODRÍGUEZ-MUÑOZ, M.; GARZÓN, J. The cannabinoid receptor 1 associates with NMDA receptors to produce glutamatergic hypofunction: implications in psychosis and schizophrenia. Frontiers Pharmacology, v. 4, p. 169, Jan. 2014.

SCHEGGI, S.; LEGGIO, B.; MASI, F.; GRAPPI, S.; GAMBARANA, C.; NANNI, G.; RAUGGI, R.; MONTIS, M. G. Selective modifications in the nucleus accumbens of dopamine synaptic transmission in rats exposed to chronic stress. Journal of Neurochemistry, v. 83, n. 4, p. 895-903, Nov. 2002. 
SCHEGGI, S.; MELIS, M.; FELICE, M.; ARONI, S.; MUNTONI, A. L.; PELLICCIA, T.; GAMBARANA, C.; MONTIS, M. G.; PISTIS, M. PPARalpha modulation of mesolimbic dopamine transmission rescues depression-related behaviors. Neuropharmacology, v. 110, part. A, p. 251-259, Nov. 2016.

SCHEGGI, S.; PELLICCIA, T.; FERRARI, A.; MONTIS, M. G.; GAMBARANA, C. Impramine, fluoxetine and clozapine differently affected reactivity to positive and negative stimuli in a model of motivational anhedonia in rats. Neuroscience, v. 291, p. 189-202, Apr. 2015.

SCHEGGI, S.; PELLICCIA, T.; GAMBARANA, C.; MONTIS, M. G. Aripiprazole relieves motivational anhedonia in rats. Journal of Affective Disorders, v. 227, p. 192-197, Feb. 2018.

SCHEGGI, S.; SECCI, M. E.; MARCHESE, G.; MONTIS, M. G.; GAMBARANA, C. Influence of palatability on motivation to operate for caloric and non-caloric food in non food-deprived and food-deprived rats. Neuroscience, v. 236, p. 320-331, Apr. 2013.

SCHIORRING, E. An open field study of stereotyped locomotor activity in amphetamine-treated rats. Psychopharmacology, v. 66, n. 3, p. 281-287, 1979.

SEEMAN, M. V. Women and psychosis. Women's Health, v. 8, n. 2, p. 215-224, Mar. 2012.

SEGAL-GAVISH, H.; GAZIT, N.; BARHUM, Y.; BEN-ZUR, T. TALER, M.; HORNFELD, S. H.; GIL-AD, I.; WEIZMAN, A.; SLUTSKY, I.; NIWA, M.; KAMIYA, A.; SAWA, A.; OFFEN, D.; BARZILAY, R. BDNF overexpression prevents cognitive deficit elicited by adolescent cannabis exposure and host susceptibility interaction. Human Molecular Genetics, v. 26, n. 13, p. 2462-2471, Jul. 2017.

SESTAKOVA, N.; PUZSEROVA, A.; KLUKNAVSKY, M.; BERNATOVA, I. Determination of motor activity and anxiety-related behaviour in rodents: methodological aspects and role of nitric oxide. Interdisciplinary Toxicology, v. 6 , n. 3, p. 126-135, Sep. 2013.

SHAO, Z.; NOH, H.; KIM, W. B.; NI, P.; NGUYEN, C.; COTE, S. E.; NOYES, E.; ZHAO, J.; PARSONS, T.; PARK, J. M.; ZHENG, K.; PARK, J. J.; COYLE, J. T.; WEINBERGER, D. R.; STRAUB, R. E.; BERMAN, K. F.; APUD, J.; ONGUR, D.; COHEN, B. M.; MCPHIE, D. L.; RAPOPORT, J. L.; PERLIS, R. H.; LANZ, T. A.; XI, H. S.; YIN, C.; HUANG, W.; HIRAYAMA, T.; FUKUDA, E.; YAGI, T.; GHOSH, S.; EGGAN, K. C.; KIM, H. Y.; EISENBERG, L. M.; MOGHADAM, A. A.; STANTON, P. K.; CHO, J. H.; CHUNG, S. Dysregulated protocadherin-pathway activity as an intrinsic defect in induced pluripotent stem cell-derived cortical interneurons from subjects with schizophrenia. Nature Neuroscience, v. 22, n. 2, p. 229-242, Feb. 2019.

SIGURDSSON, T. Neural circuit dysfunction in schizophrenia: Insights from animal models. Neuroscience, v. 321, p. 42-65, May 2016. 
SILVEIRA FILHO, N. G.; TUFIK, S. Comparative effects between cannabidiol and diazepam on neophobia, food intake and conflict behavior. Research Communications in Psychology, Psychiatry \& Behavior, v. 3, n. 6, p. 251-256, 1981.

SKOLNICK, P.; POPIK, P.; TRULLAS, R. Glutamate-based antidepressants: 20 years on. Trends in Pharmacological Sciences, v. 30, n. 11, p. 563-569, Nov. 2009.

SMIT, F.; BOLIER, L.; CUIJPERS, P. Cannabis use and the risk of later schizophrenia: a review. Addiction, v. 99, n. 4, p. 425-430, Apr. 2004.

SMITH, S. Gender differences in antipsychotic prescribing. International Review Psychiatry, v. 22, n. 5, p. 472-484, 2010.

SNYDER, S. H. Amphetamine psychosis: a "model" schizophrenia mediated by catecholamines. American Journal of Psychiatry, v. 130, n. 1, p. 61-67, Jan. 1973.

SNYDER, S. H. Catecholamines in the brain as mediators of amphetamine psychosis. Archives of General Psychiatry, v. 27, n. 2, p. 169-179, Aug. 1972.

SOFIA, R. D.; KNOBLOCH, L. C. Comparative effects of various naturally occurring cannabinoids on food, sucrose and water consumption by rats. Pharmacology Biochemistry and Behavior, v. 4, n. 5, p. 591-599, May 1976.

SORENSEN, H. J.; MORTENSEN, E. L.; SCHIFFMAN, J.; REINISCH, J. M.; MAEDA, J.; MEDNICK, S. A. Early developmental milestones and risk of schizophrenia: a 45-year follow-up of the Copenhagen Perinatal Cohort. Schizophrenia Research, v. 118, n. 1-3, p. 41-47, May 2010.

STEINPREIS, R. E. The behavioral and neurochemical effects of phencyclidine in humans and animals: some implications for modeling psychosis. Behavioural Brain Research, v. 74, n. 1-2, p. 45-55, Jan. 1996.

STONE, J. M.; MORRISON, P. D.; KOYCHEV, I.; GAO, F.; REILLY, T. J.; KOLANKO, M.; MOHAMMADINASAB, A.; KAPUR, S.; MCGUIRE. P. K. The effect of sodium nitroprusside on psychotic symptoms and spatial working memory in patients with schizophrenia: a randomized, double-blind, placebo-controlled trial. Psychological Medicine, v. 46, n. 16, p. 3443-3450, Dec. 2016.

SUTCLIFFE, J. S.; MARSHALL, K. M.; NEILL, J. C. Influence of gender on working and spatial memory in the novel object recognition task in the rat. Behavioural Brain Research, v. 177, n. 1, p. 117-125, Feb. 2007.

SUTCLIFFE, J. S.; RHAMAN, F.; MARSHALL, K. M.; NEILL, J. C. Oestradiol attenuates the cognitive deficit induced by acute phencyclidine treatment in mature female hooded-Lister rats. Journal of Psychopharmacology, v. 22, n. 8, p. 918922, Nov. 2008. 
SZCZYPINSKI, J. J.; GOLA, M. Dopamine dysregulation hypothesis: the common basis for motivational anhedonia in major depressive disorder and schizophrenia? Reviews in the Neurosciences, v. 29, n. 7, p. 727-744, Sep. 2018.

TANDON, R.; NASRALLAH, H. A.; KESHAVAN, M. S. Schizophrenia, "just the facts" 4. Clinical features and conceptualization. Schizophrenia Research, v. 110, n. 1-3, p. 1-23, May 2009.

TARCIJONAS, G.; FORAN, W.; HAAS, G. L.; LUNA, B.; SARPAL, D. K. Intrinsic Connectivity of the Globus Pallidus: An Uncharted Marker of Functional Prognosis in People With First-Episode Schizophrenia. Schizophrenia Bulletin, v. 46, n. 1, p. 184-192, May 2019.

THOMPSON, B. L.; LEVITT, P. Now you see it, now you don't-closing in on allostasis and developmental basis of psychiatric disorders. Neuron, v. 65, n. 4, p. 437-439, Feb. 2010.

THORNBERG, S. A.; SAKLAD, S. R. A review of NMDA receptors and the phencyclidine model of schizophrenia. Pharmacotherapy, v. 16, n. 1, p. 82-93, Jan./Feb. 1996.

TITULAER, J.; MALMERFELT, A.; MARCUS, M. M.; SVENSSON, T. H. Enhancement of the antipsychotic effect of risperidone by sodium nitroprusside in rats. European Neuropsychopharmacology, v. 29, n. 11, p. 1282-1287, Nov. 2019.

TORU, M.; KURUMAJI, A.; ISHIMARU, M. Excitatory amino acids: implications for psychiatric disorders research. Life Sciences, v. 55, n. 22, p. 1683-1699, 1994.

TREADWAY, M. T.; ZALD, D. H. Parsing Anhedonia: Translational Models of Reward-Processing Deficits in Psychopathology. Current Directions in Psychological Science, v. 22, n. 3, p. 244-249, Jun. 2013.

TREVLOPOULOU, A.; TOUZLATZI, N.; PITSIKAS, N. The nitric oxide donor sodium nitroprusside attenuates recognition memory deficits and social withdrawal produced by the NMDA receptor antagonist ketamine and induces anxiolytic-like behaviour in rats. Psychopharmacology, v. 233, n. 6, p. 1045-1054, Mar. 2016.

TRZESNIAK, C.; ARAUJO, D.; CRIPPA, J. A. Magnetic resonance spectroscopy in anxiety disorders. Acta Neuropsychiatrica, v. 20, n. 2, p. 56-71, Apr. 2008.

TRZESNIAK, C.; OLIVEIRA, I. R.; KEMPTON, M. J.; ALMEIDA, A. G.;. CHAGAS, M. H. N.; FERRARI, M. C.; FILHO, A. S.; ZUARDI, A. W.; PRADO, D. A.; BUSATTO. G. F.; MCGUIREB, P. K.; HALLAKA, J. E. C.; CRIPPA, J. A. S. Are cavum septum pellucidum abnormalities more common in schizophrenia spectrum disorders? A systematic review and meta-analysis. Schizophrenia Research, v. 125, n. 1, p. 112, Jan. 2011.

TUOMINEN, H. J.; TIIHONEN, J.; WAHLBECK, K. Glutamatergic drugs for schizophrenia: a systematic review and meta-analysis. Schizophrenia Research, v. 72, n. 2-3, p. 225-234, Jan. 2005. 
TZAVARA, E. T.; LI, D. L.; MOUTSIMILLI, L.; BISOGNO, T.; DI MARZO, V.; PHEBUS, L. A.; NOMIKOS, G. G.; GIROSA, B. Endocannabinoids activate transient receptor potential vanilloid 1 receptors to reduce hyperdopaminergia-related hyperactivity: therapeutic implications. Biological Psychiatry, v. 59, n. 6, p. 508-515, Mar. 2006.

VAN OS, J.; KAPUR, S. Schizophrenia. Lancet, v. 374, n. 9690, p. 635-645, Aug. 2009.

VOGT, M. A.; VOGEL, A. S.; PFEIFFER, N.; GASS, P.; INTA, D. Role of the nitric oxide donor sodium nitroprusside in the antidepressant effect of ketamine in mice. European Neuropsychopharmacology, v. 25, n. 10, p. 1848-1852, Oct. 2015.

WADDINGTON, J. L. Schizophrenia: Developmental neuroscience and pathobiology. Lancet, v. 341, n. 8844, p. 531-536, Feb. 1993.

WAN, L. B.; LEVITCH, C. F.; PEREZ, A. M.; BRALLIER, J. W.; LOSIFESCU, D. V.; CHANG, L. C.; FOULKES, A.; MATHEW, S. J.; CHARNEY, D. S.; MURROUGH, J. W. Ketamine safety and tolerability in clinical trials for treatment-resistant depression. Journal of Clinical Psychiatry, v. 76, n. 3, p. 247-252, Mar. 2015.

WANG, X.; DING, S.; LU, Y.; JIAO, Z.; ZHANG, L.; ZHANG, Y.; YANG, Y.; ZHANG, Y.; LI, W.; LV, L. Effects of sodium nitroprusside in the acute dizocilpine (MK-801) animal model of schizophrenia. Brain Research Bulletin, v. 147, p. 140-147, Apr. 2019.

WANG, X.; ZHAO, J.; HU, Y.; JIAO, Z.; LU, Y.; DING, M.; KOU, Y.; LI, B.; MENG, F.; ZHAO, H.; LI, H.; LI, W.; YANG, Y.; LV, L. Sodium nitroprusside treatment for psychotic symptoms and cognitive deficits of schizophrenia: A randomized, doubleblind, placebo-controlled trial. Psychiatry Research, v. 269, p. 271-277, Nov. 2018.

WEDZONY, K.; FIJAL, K.; CHOCYK, A. Blockade of NMDA receptors in postnatal period decreased density of tyrosine hydroxylase immunoreactive axonal arbors in the medial prefrontal cortex of adult rats. Journal of Physiology Pharmacology, v. 56, n. 2, p. 205-221, Jun. 2005.

WEINBERGER, D. R. Future of Days Past: Neurodevelopment and Schizophrenia. Schizophrenia Bulletin, v. 43, n. 6, p. 1164-1168, Oct. 2017.

WEINBERGER, D. R. Implications of normal brain development for the pathogenesis of schizophrenia. Archives of General Psychiatry, v. 44, n. 7, p. 660-669, Jul. 1987.

WIESCHOLLECK, V.; MANAHAN-VAUGHAN, D. PDE4 inhibition enhances hippocampal synaptic plasticity in vivo and rescues MK801-induced impairment of long-term potentiation and object recognition memory in an animal model of psychosis. Translational Psychiatry, v. 2, p. e89, Mar. 2012.

WILKINSON, S. T.; BALLARD, E. D.; BLOCH, M. H.; MATHEW, S. J.; MURROUGH, J. W.; FEDER, A.; SOS, P.; WANG, G.; ZARATE JR., C. A.; SANACORA, G. The Effect of a Single Dose of Intravenous Ketamine on Suicidal Ideation: A Systematic 
Review and Individual Participant Data Meta-Analysis. American Journal of Psychiatry, v. 175, n. 2, p. 150-158, Feb. 2018.

WINTERS, W. D.; HANCE, A. J.; CADD, G. C.; LAKIN, M. L. Seasonal and sex influences on ketamine-induced analgesia and catalepsy in the rat; a possible role for melatonin. Neuropharmacology, v. 25, n. 10, p. 1095-1101, Oct. 1986.

WOLF, S. A.; BICK-SANDER, A.; FABEL, K.; LEAL-GALICIA, P.; TAUBER, S.; RAMIREZ-RODRIGUEZ, G.; MÜLLER, A.; MELNIK, A.; WALTINGER, T. P.; ULLRICH, O.; KEMPERMANN, G. Cannabinoid receptor CB1 mediates baseline and activity-induced survival of new neurons in adult hippocampal neurogenesis. Cell Communication and Signaling, v. 8, n. 12, p. 1-14, Jun. 2010.

WONG, D. F.; KUWABARA, H.; HORTI, A. G.; RAYMONT, V.; BRASIC, J.; GUEVARA, M.; YE, A.; DANNALS, R. F.; RAVERT, H. T.; NANDI, A.; RAHMIM, A.; MINGE, J. E.; GRACHEV, I.; ROY. C.; CASCELLAB, N. Quantification of cerebral cannabinoid receptors subtype 1 (CB1) in healthy subjects and schizophrenia by the novel PET radioligand [11C]OMAR. Neuroimage, v. 52, n. 4, p. 1505-1513, Oct. 2010.

WOOD, S. J.; RENIERS, R. L.; HEINZE, K. Neuroimaging findings in the at-risk mental state: a review of recent literature. The Canadian Journal of Psychiatry, v. 58, n. 1, p. 13-18, Jan. 2013.

WOODBERRY, K. A.; GIULIANO, A. J.; SEIDMAN, L. J. Premorbid IQ in schizophrenia: a meta-analytic review. American Journal of Psychiatry, v. 165, n. 5, p. 579-587, May 2008.

WU, E. Q.; BIRNBAUM, H. G.; SHI, L.; BALL, D. E.; KESSLER, R. C.; MOULIS, M.; AGGARWAL, J. The economic burden of schizophrenia in the United States in 2002. Journal of Clinical Psychiatry, v. 66, n. 9, p. 1122-1129, Sep. 2005.

YAMADA, K.; NODA, Y.; HASEGAWA, T.; KOMORI, Y.; NIKAI, T.; SUGIHARA, H.; NABESHIMA, T. The role of nitric oxide in dizocilpine-induced impairment of spontaneous alternation behavior in mice. Journal of Pharmacology and Experimental Therapeutics, v. 276, n. 2, p. 460-466, Feb. 1996.

YANG, A. C.; TSAI, S. J. New Targets for Schizophrenia Treatment beyond the Dopamine Hypothesis. International Journal of Molecular Sciences, v. 18, n. 8, Aug. 2017.

YOUNG, J. W.; POWELL, S. B.; RISBROUGH, V.; MARSTON, H. M.; GEYER, M. A. Using the MATRICS to guide development of a preclinical cognitive test battery for research in schizophrenia. Pharmacology \& Therapeutics, v. 122, n. 2, p. 150-202, May 2009.

ZANOS, P.; GOULD, T. D. Mechanisms of ketamine action as an antidepressant. Molecular Psychiatry, v. 23, n. 4, p. 801-811, Apr. 2018. 
ZUARDI, A. W. Cannabidiol: From an inactive cannabinoid to a drug with wide spectrum of action. Brazilian Journal of Psychiatry, v. 30, n. 3, p. 271-280, Sep. 2008.

ZUARDI, A. W. History of cannabis as a medicine: a review. Brazilian Journal of Psychiatry, v. 28, n. 2, p. 153-157, Jun. 2006.

ZUARDI, A. W.; CRIPPA, J. A.; HALLAK, J. E.; BHATTACHARYYA, S.; ATAKAN, Z.; MARTÍN-SANTOS, R.; MCGUIRE, P. K.; GUIMARÃES, F. S. A critical review of the antipsychotic effects of cannabidiol: 30 years of a translational investigation. Current Pharmaceutical Design, v. 18, n. 32, p. 5131-5140, 2012.

ZUARDI, A. W.; GUIMARÃES, F. S.; HALLAK, J. E.; CRIPPA, J. A. S. Is the highest density of CB1 receptors in paranoid schizophrenia a correlate of endocannabinoid system functioning? Expert Review of Neurotherapeutics, v. 11, n. 8, p. 11111114, Aug. 2011.

ZUARDI, A. W.; GUIMARÃES, F. S.; MOREIRA, A. C. Effect of cannabidiol on plasma prolactin, growth hormone and cortisol in human volunteers. Brazilian Jounal of Medical and Biological Research, v. 26, n. 2, p. 213-217, Feb. 1993.

ZUARDI, A. W.; HALLAK, J. E.; DURSUN, S. M.; MORAIS, S. L.; SANCHES, R. F.; MUSTY, R. E.; CRIPPA, J. A. S. Cannabidiol monotherapy for treatment-resistant schizophrenia. Journal of Psychopharmacology, v. 20, n. 5, p. 683-686, Sep. 2006.

ZUARDI, A. W.; KARNIOL, I. G. Changes in the conditioned emotional response of rats induced by $\triangle 9-T H C, C B D$ and mixture of the two cannabinoids. Arquivos de Biologia e Tecnologia, v. 26, p. 391-397, 1983.

ZUARDI, A. W.; MORAIS, S. L.; GUIMARÃES, F. S.; MECHOULAM, R. Antipsychotic effect of cannabidiol. The Journal of Clinical Psychiatry, v. 56, n. 10, p. 485-486, Oct. 1995.

ZUARDI, A. W.; SHIRAKAWA, I.; FINKELFARB, E.; KARNIOL, I. G. Action of cannabidiol on the anxiety and other effects produced by delta 9-THC in normal subjects. Psychopharmacology, v. 76, n. 3, p. 245-250, 1982. 


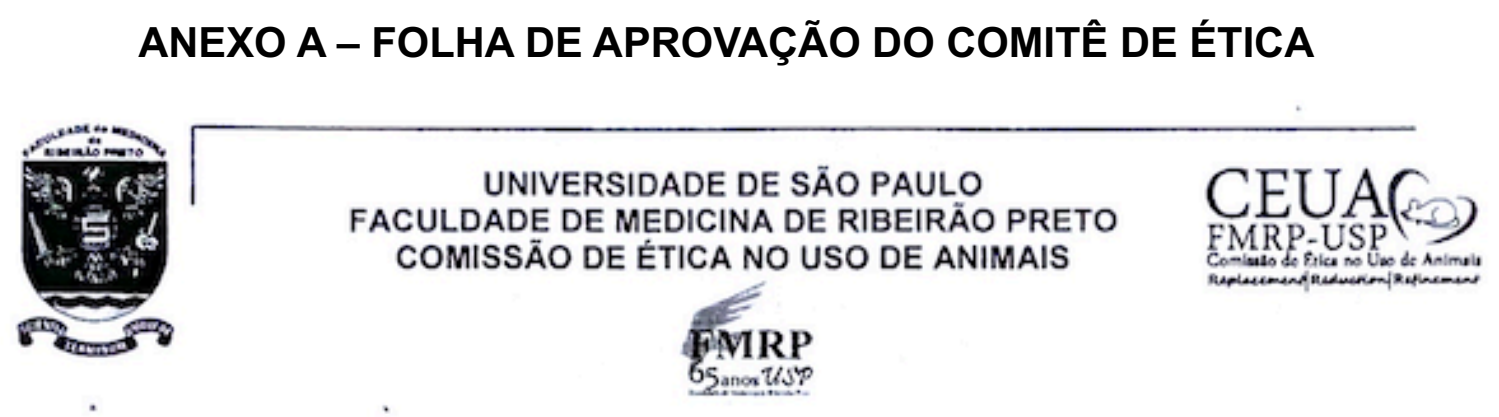

CER TIFICADO

Certificamos que o Protocolo intitulado "Efeitos de doses repetidas do nitroprussiato de sódio ou do canabidiol no periodo de maturação cerebral em um modelo animal de esquizofrenia", registrado com o número 62/2016, sob a responsabilidade do Prof. Dr. Jaime Eduardo Cecilio Hallak, envolvendo a produção, manutenção ou utilização de animais pertencentes ao filo Chordata, subfilo Vertebrata (exceto humanos) para fins de pesquisa cientifica, encontra-se de acordo com os preceitos da Lei $n^{\circ} 11.794$ de 8 de outubro de 2008, do Decreto $n^{\circ} 6.899$ de 15 de julho de 2009 e com as normas editadas pelo Conselho Nacional de Controle de Experimentação Animal (CONCEA), e foi APROVADO pela Comissão de Ética no Uso de Animais da Faculdade de Medicina de Ribeirão Preto da Universidade de São Paulo em reunião de 30 de outubro de 2017.

Este Protocolo prevê a utilização de 82 ratos Wistar-OLD machos pesando $125 \mathrm{~g}, 82$ ratos Wistar-OLD fềmeas pesando $125 \mathrm{~g}$ e 21 ratos Wistar-OLD fềmeas pesando $300 \mathrm{~g}$, oriundos do Serviço de Biotério da Prefeitura do Campus de Ribeirão Preto da Universidade de São Paulo. Vigência da autorização: 30/10/2017 a 01/10/2019.

We certify that the Protocol $n^{\circ} 62 / 2016$, entitled "Effects of repeated doses of sodium nitroprusside or cannabidiol in brain maturation in an animal model of schizophrenia", is in accordance with the Ethical Principles in Animal Research adopted by the National Council for the Control of Animal Experimentation (CONCEA) and was approved by the Local Animal Ethical Committee from Ribeiråo Preto Medical School of the University of Såo Paulo in 10/30/2017. This protocol involves the production, maintenance or use of animals from phylum Chordata, subphylum Vertebrata (except humans) for research purposes, and includes the use of 82 Wistar-OLD male rats weighing 125g; 82 Wistar-OLD female rats weighing $125 \mathrm{~g}$ and 21 Wistar-OLD female rats weighing $300 \mathrm{~g}$ from the Central Animal House of Ribeirao Preto Medical School, University of São Paulo. This certificate is valid until 10/01/2019.

Ribeirão Preto, 30 de outubro de 2017

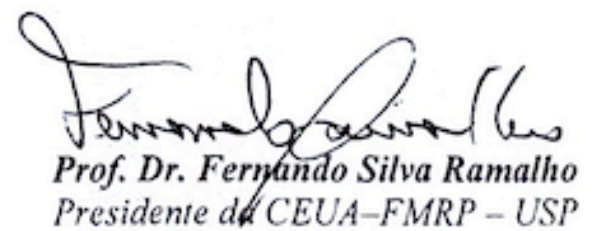

